\title{
(1)
}

UNIVERSIDAD PERUANA DE CIENCIAS APLICADAS

FACULTAD DE INGENIERIA

PROGRAMA ACADÉMICO DE INGENIERÍA INDUSTRIAL

\section{PROPUESTA DE MEJORA EN LOS PROCESOS DE PRODUCCIÓN PARA REDUCIR LOS DESPERDICIOS EN UN LABORATORIO COSMÉTICO}

\section{TESIS}

Para optar por el título profesional de Ingeniero Industrial

\author{
AUTOR \\ Vela García , Friggens (0000-0002-9919-2991) \\ ASESOR \\ Viacava Campos, Gino Evangelista (0000-0002-0126-4126)
}

Lima, Octubre del 2018 


\section{AGRADECIMIENTO}

A la Universidad de Ciencia Aplicadas UPC en especial a todos los docentes que participaron en mi formación, en especial y mi asesor de tesis, al Gerente General de la Empresa Mediscience, por el incondicional apoyo para la ejecución del presente estudio de investigación 
DEDICATORIA

A mi familia, por el apoyo incondicional que recibo día a día, para el logro de mis objetivos. 


\section{Índice}

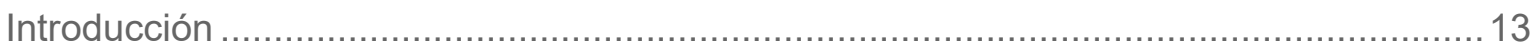

1 Capítulo I - Marco Teórico/Estado del Arte …...................................................... 14

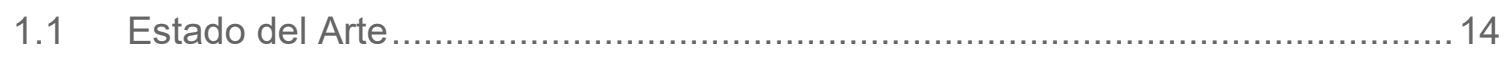

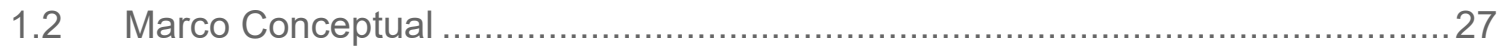

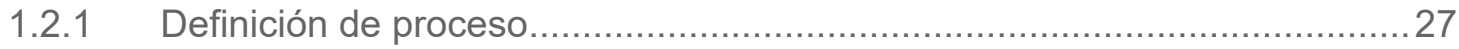

1.2.2 Cadena de valor en la industria cosmética ........................................... 27

1.2.3 Principales operaciones en la industria cosmética .................................2 27

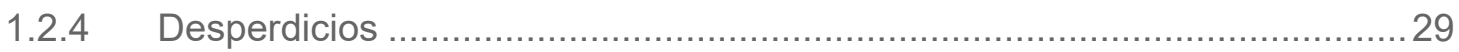

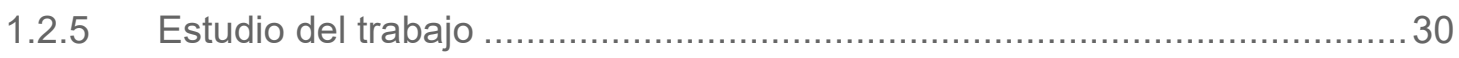

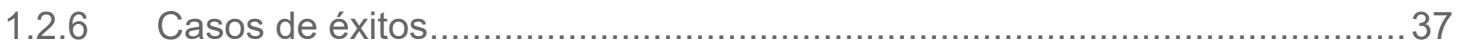

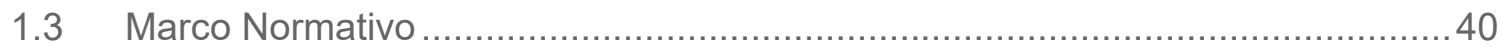

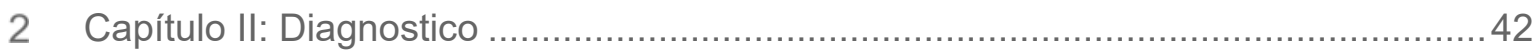

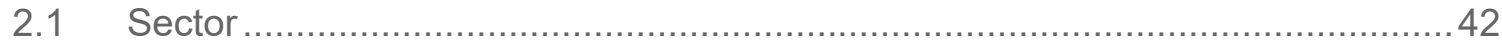

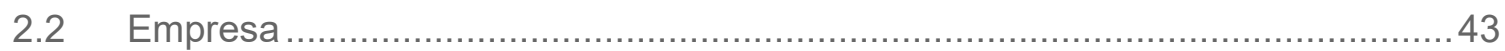

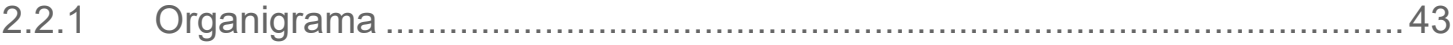

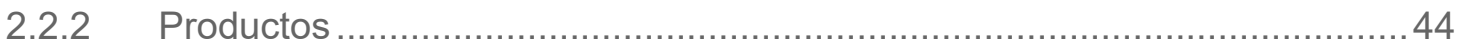

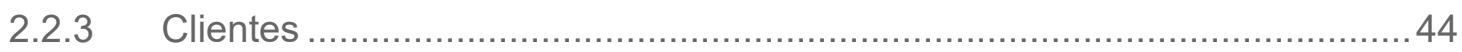

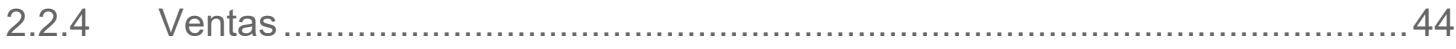

2.2.5 Participación clientes por ventas.............................................................. 45

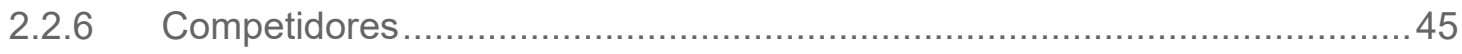

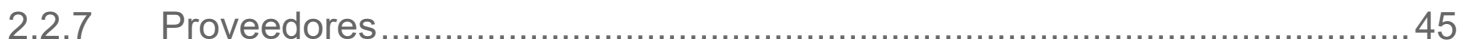

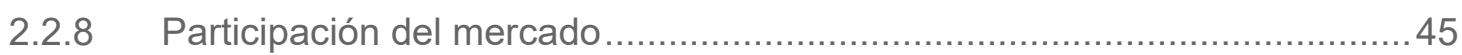

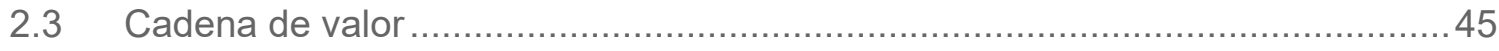

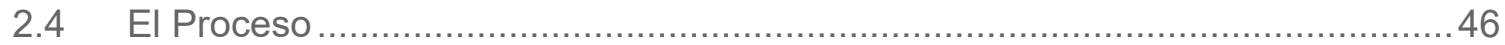

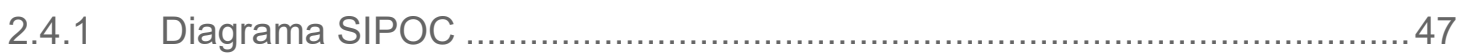

2.4.2 Diagrama de Operaciones (DOP) ……................................................. 49

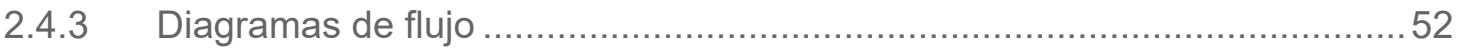

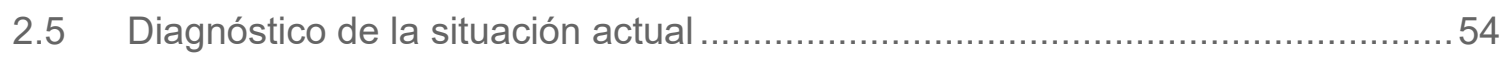

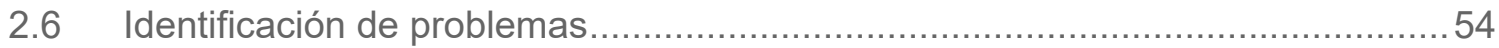

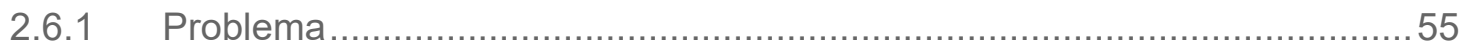


2.6.2 Análisis de causas del problema: Diagrama de Ishikawa ...........................56

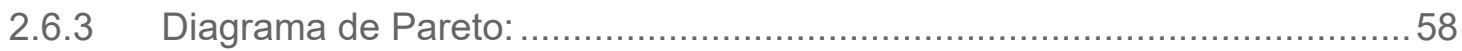

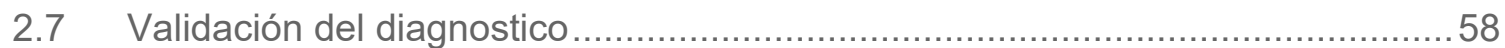

2.7.1 D1: Actividades de limpieza ineficiente ............................................... 59

2.7.2 D2: Actividades de trasvase ineficiente ..................................................60

2.7.3 D3: Ineficiencia en las actividades de arranque y dosificación en el

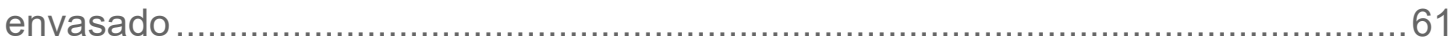

2.7.4 D4: Caída de presión del aire comprimido ...................................................... 63

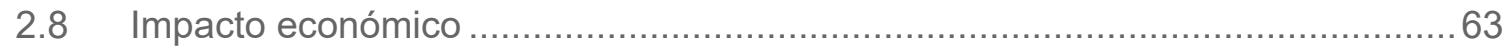

2.8.1 Análisis de horas extras no planificadas ................................................ 64

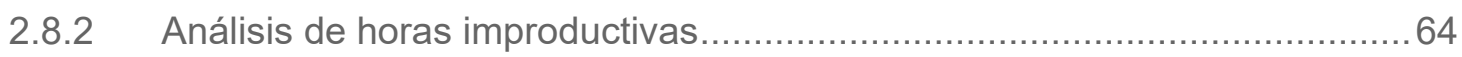

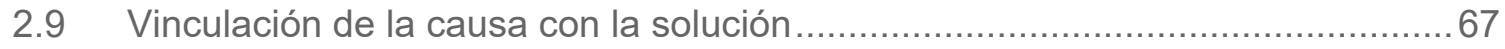

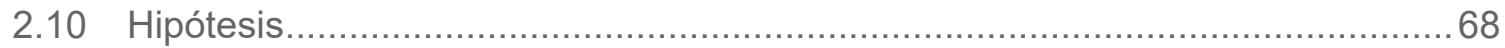

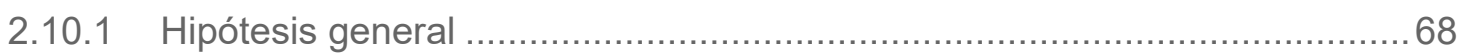

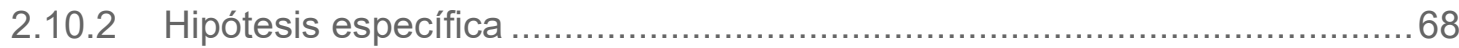

3 Capitulo III: Propuesta de Mejora ............................................................................ 70

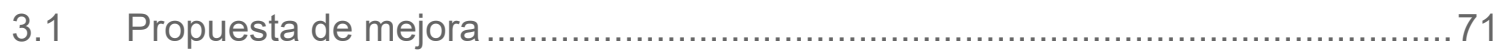

3.1.1 Propuesta en las actividades de limpieza .............................................. 72

3.1.2 Propuesta en la actividades de trasvase en fabricación .............................77

3.1.3 Propuesta en las actividades de arranque en el envasado .........................81

3.1.4 Propuesta de balance de líneas de envasado .......................................... 83

3.2 Recursos para el desarrollo de la implementación .......................................... 83

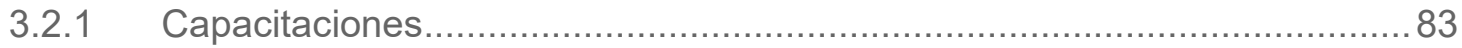

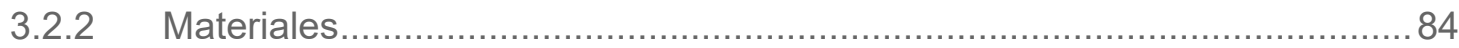

3.3 Indicadores de medición de la investigación (Ref. Optimización de tiempos de

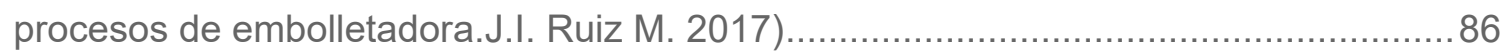

3.4 Cronograma de actividades de la investigación............................................ 87

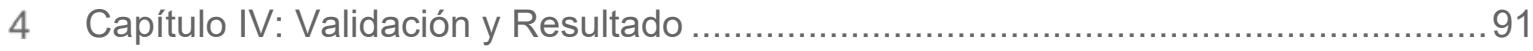

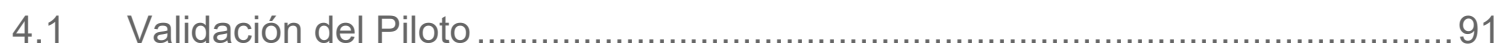

4.1.1 Análisis comparativo de la situación inicial y posterior al piloto ....................91

4.1.2 Implementación de materiales y recursos .................................................93 


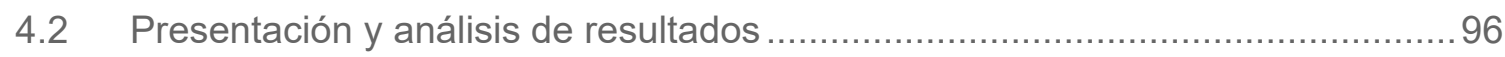

4.2.1 Actividades de limpieza: Se hizo el análisis del DAP ..................................96

4.2.2 Actividades de trasvase en la fabricación ...................................................98

4.2.3 Actividades de arranque en el envasado ............................................... 101

4.2.4 Resumen de resultados de la mejora de procesos .................................. 103

4.2.5 Resumen de resultados del balance de líneas de envasado y UPH (Ver

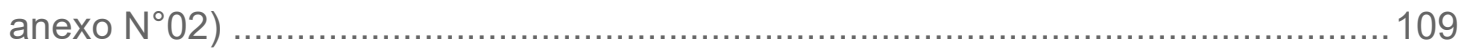

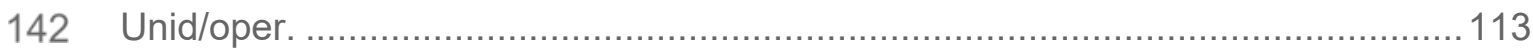

4.2.6 Evaluación económica....................................................................... 113

4.2.7 Impacto de las partes interesadas ...................................................... 117

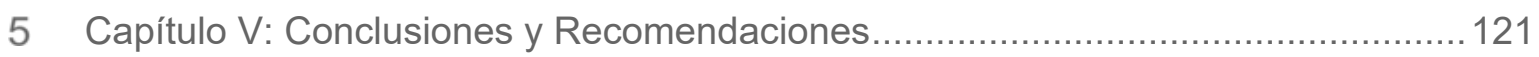

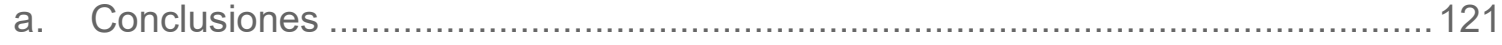

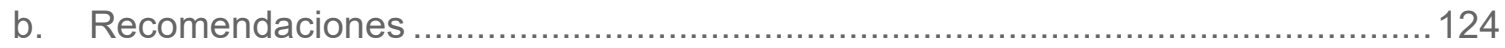

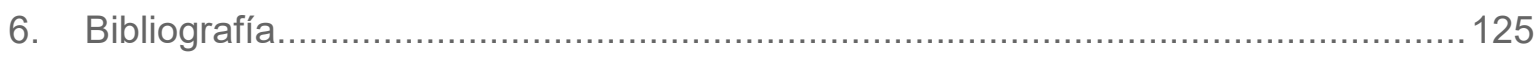

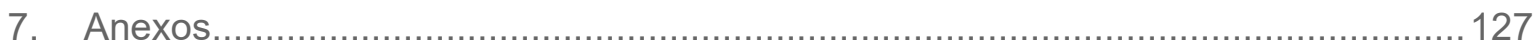




\section{INDICE DE FIGURAS}

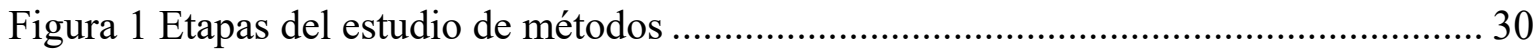

Figura 2 Guía de implementación del estudio de métodos............................................... 31

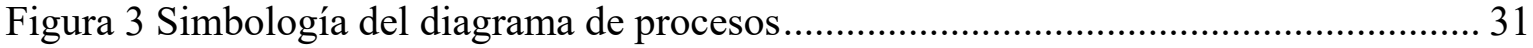

Figura 4 Simbología del diagrama de procesos analíticos ................................................ 32

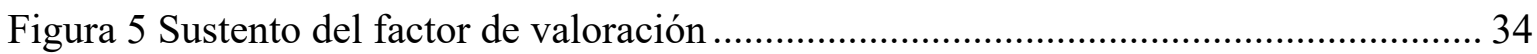

Figura 6 Ejemplo de sistema de suplementos por descanso............................................. 35

Figura 7 Organigrama del área de producción del laboratorio cosmético........................... 43

Figura 8 Cadena de Valor del Laboratorio Cosmético ...................................................... 45

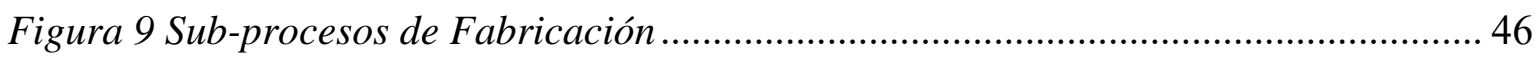

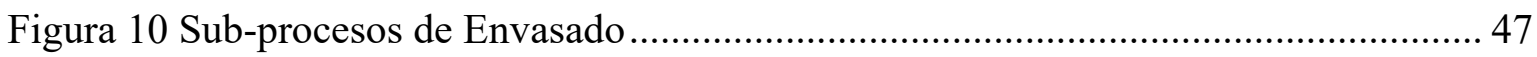

Figura 11 Diagrama SIPOC del proceso de fabricación .................................................... 47

Figura 12 Diagrama SIPOC del proceso de Envasado ....................................................... 48

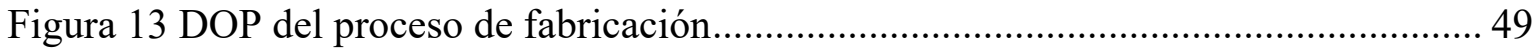

Figura 14 Diagrama DOP del proceso de producción de la línea de Envasado ................... 50

Figura 15 Diagrama de flujo del proceso de fabricación actual ......................................... 52

Figura 16 Diagrama de flujo del proceso de envasado actual .......................................... 53

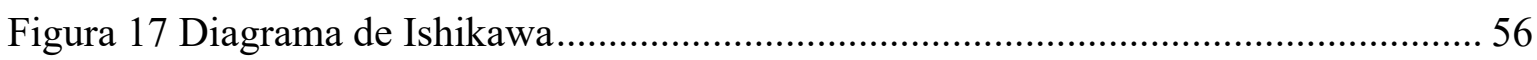

Figura 18 Value Stream Mapping (VSM) actual ......................................................... 57

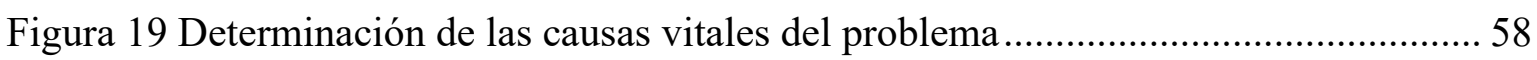

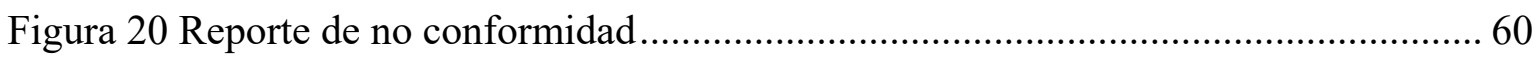

Figura 21 Registros de merma de granel en el proceso de fabricación ............................... 60

Figura 22 Registros de merma de granel en el proceso arranque ....................................... 61

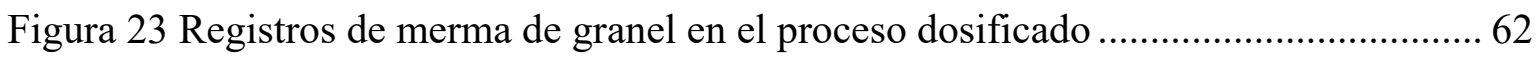

Figura 24 Registro de horas extras no planificadas mensual reportada por contabilidad ... 64

Figura 25 Registro de horas improductivas reportadas por contabilidad ........................... 65

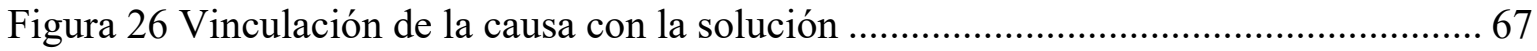

Figura 27 Diseño de la propuesta de mejora ................................................................. 71

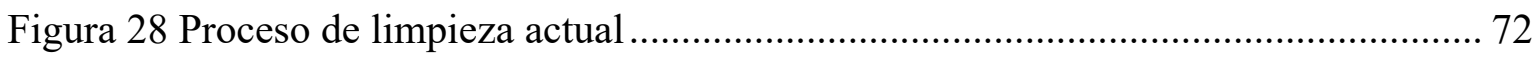

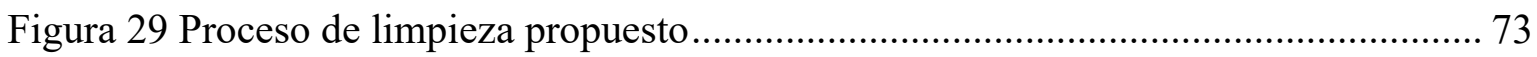

Figura 30 Layout de la empresa con el recorrido actual de la actividad de limpieza.......... 74

Figura 31 Diagrama de recorrido de la actividad de limpieza propuesto ............................ 75

Figura 31.b Ampliación del Diagrama de recorrido de la actividad de limpieza propuesto

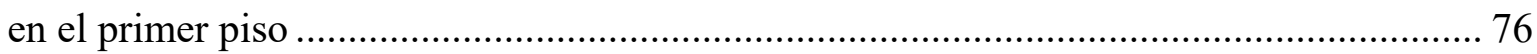

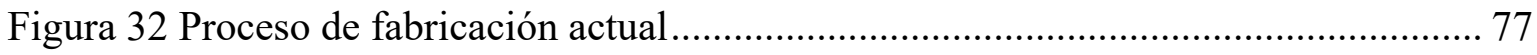


Figura 33 Proceso de fabricación propuesto.................................................................... 78

Figura 34 Layout de la empresa con el recorrido del proceso de fabricación actual .......... 79

Figura 35 Diagrama de recorrido del proceso de fabricación propuesto............................. 80

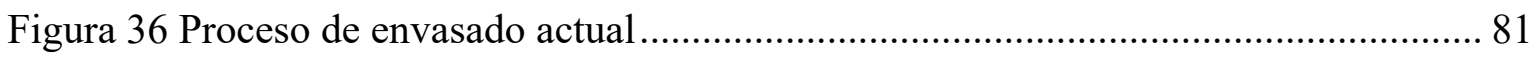

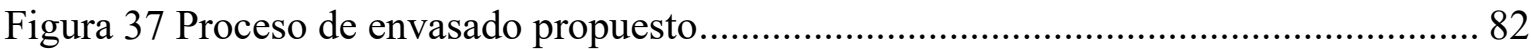

Figura 38 Cronograma de actividades de implementación ............................................... 87

Figura 39 Análisis comparativo de indicadores del proyecto.......................................... 92

Figura 40 Resumen de resultado del comparativo de indicadores .................................... 93

Figura 41 Resultados de la mejora del tiempo en el proceso de limpieza del área de fabricación y envasado

Figura 42 Resultados de la mejora del recorrido en el proceso de limpieza del área de fabricación y envasado

Figura 43 Resultados de la mejora de tiempos en el proceso de trasvase del área de fabricación

Figura 44 Resultados de la mejora del recorrido en el proceso de trasvase del área de fabricación 105

Figura 45 Resultados de la optimización de granel en la actividad de trasvase 106

Figura 46 Resultados de la mejora de tiempos en el proceso de arranque en el envasado 107 Figura 47 Resultados de la mejora de recorridos en el proceso de arranque en el envasado 107

Figura 48 Resultados de la optimización de granel en la actividad de purga. 108 Figura 49 Resultado del estudio de tiempos del producto Shampoo en la línea de envasado 110

Figura 50 Balance de línea del producto Shampoo en la línea de envasado 111 


\section{INDICE DE TABLAS}

Tabla 1 Cálculo de suplementos por descanso en la empresa seleccionada........................ 36

Tabla 2 Calculo de tiempos frecuentes por actividades ..................................................... 36

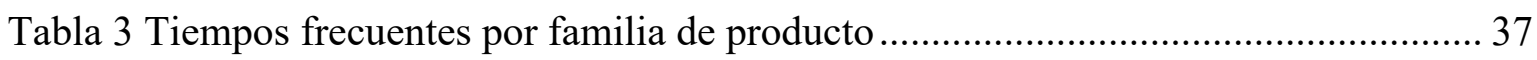

Tabla 4 Registro de ineficiencia en las actividades de limpieza ...................................... 59

Tabla 5 Registro de data de presión de aire comprimido en la envasadora.........................63 63

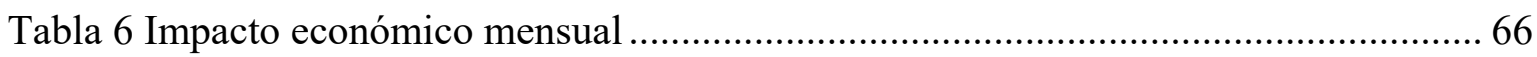

Tabla 7 Programa de capacitación para la implementación ............................................... 83

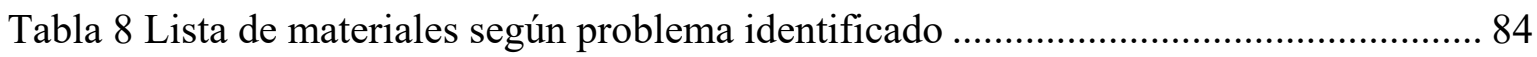

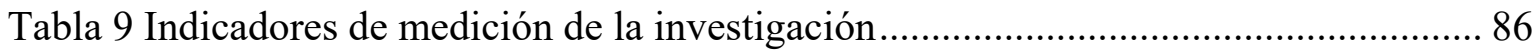

Tabla 10 Desarrollo de la implementación del método de limpieza en el primer piso

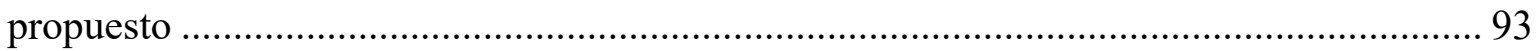

Tabla 11 Desarrollo de la implementación del método de trasvase propuesto ................... 95

Tabla 12 Desarrollo de la implementación del método de arranque propuesto .................. 95

Tabla 13 Resultados del diagrama del proceso de limpieza de marmitas y tanques ........... 97

Tabla 14 Diagrama del proceso de limpieza de marmitas y tanques propuesto.................. 97

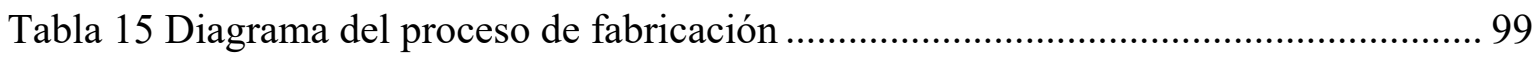

Tabla 16 Diagrama del proceso de fabricación ................................................................ 100

Tabla 17 Diagrama del proceso de Envasado-Acondicionado........................................... 101

Tabla 18 Diagrama del proceso de Envasado - Acondicionado propuesto ........................ 102

Tabla 19 Ejecución del balance de línea en las líneas de Envasado y UPH utilizando el

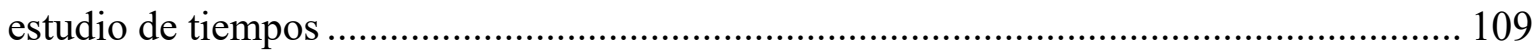

Tabla 20 Variación porcentual de la programación de UPH........................................... 110 


\section{ANEXOS}

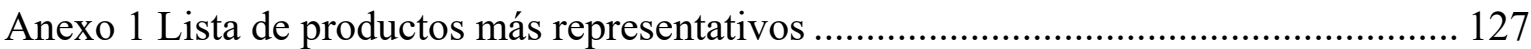

Anexo 2 Estándares de UPH para la programación de la producción............................... 127

Anexo 3 Diagrama de Actividades del proceso de limpieza de equipos-maquias y

tanques

Anexo 4 Diagrama de Actividad del proceso limpieza propuesta.................................. 129

Anexo 5 Diagrama de actividades del proceso de fabricación actual ............................... 130

Anexo 6 Diagrama de actividades del proceso de fabricación propuesto .......................... 131

Anexo 7 Diagrama de actividades del proceso de envasado actual ................................. 132

Anexo 8 Diagrama de Actividades del proceso de envasado propuesto ........................... 133

Anexo 9 Estudio de tiempo por cronometro del Shampoo Ammens Original x 675 ........ 134

Anexo 10 Estudio de tiempo por cronometro del Sh. Natural Guarana ........................... 135

Anexo 11 Estudio de tiempo por cronometro del Sh. Ammens Origina x $112 \mathrm{~mL}$.......... 136

Anexo 12 Costo del proyecto de investigación ................................................................ 137

Anexo 13 Balance de línea de la línea de shampoo ......................................................... 138 


\section{RESUMEN}

En la presente investigación se planteó como problema general: ¿De qué manera la implementación de propuestas de mejora utilizando herramientas de ingeniería industrial pueden disminuir los desperdicios en las áreas de producción en un laboratorio cosmético? Para lo cual se utilizaron el estudio de métodos y tiempos en las estaciones y fabricación y envasado y el análisis de balance de línea mediante estudio de tiempo por cronometro en la estación de envasado.

La investigación se desarrolló con un diseño propuesto que se analizó experimentalmente en un lote industrial de prueba, de tipo pre experimental de pre-test y post-test con unos dos grupos de productos shampoo y cremas y se definieron los indicadores de control comparando la información de las condiciones iniciales sin la propuesta y las condiciones finales después de la propuesta.

Los estudios de métodos y tiempos en la aplicación de los lotes pilotos permitieron validar los resultados de mejora en la línea de producción logrando mejorar recorridos, tiempos de recorridos, y eliminación de actividades que no generaban valor o incrementaban los desperdicios en las líneas.

Los resultados fueron $33 \%$ de mejora de los tiempos de actividades de trasvase $37 \%$ de mejora en los tiempos en las actividades de limpieza, y $42 \%$ de mejora en los tiempos de arranque de envasado, bajo a 50\% las horas extras no planificadas, $45 \%$ las horas improductivas y se logró un $25 \%$ de los productos con estándares de tiempos de UPH lo que mejoría la programación de la producción. Estos resultados obtenidos contribuyen al incremento los desperdicios de producción que es el objetivo principal de esta implementación.

Palabras clave: Desperdicios, sistema de producción, Cosmetica 


\begin{abstract}
In this research, it was posed the next general problem: How can the implementation of improvement proposals using industrial engineering tools reduce the waste in the production's areas in a cosmetic laboratory? For which, the study of methods and times in the stations and manufacturing and packaging and the analysis of line balance by time study by chronometer in the packing station were used.

The research was developed with a proposed design that was experimentally analyzed in an pilot industrial batch, of pre-experimental type of pre-test and post-test with two groups of shampoo and cream products, and control indicators were defined by comparing the information of the initial conditions without the proposal and the final conditions after the proposal.

The studies of methods and times in the application of the pilot batchs allowed to validate the results of improvement in the production line, achieving to improve routes, times of routes, and elimination of activities that did not generate value or that increased the waste in the lines.

The results were $33 \%$ of improvement in the times of transfer's activities, $37 \%$ of improvement in the cleaning activities times, and $42 \%$ of improvement in packing start times, low to $50 \%$ the unplanned overtime, $45 \%$ unproductive hours and were achieved $25 \%$ of the products with UPH times standards, which would improve production programming. These obtained results contribute to the decrese of production waste, which is the main objective of this implementation.
\end{abstract}

Keywords: Waste, production's system, Cosmetics 
Introducción

El presente trabajo de investigación se enmarca dentro del sector cosmético y la empresa en estudio tiene una antigüedad de 5 años manufacturando productos dermocosméticos y cosméticos, este rubro en el país tuvo un crecimiento promedio de $7 \%$ anual en los últimos 10 años, lo cual hace necesario que sean competitivas.

Se inicia con el estudio del arte y el marco conceptual elementos que permitirán conocer el sector, la problemática y las herramientas de solución que existen referente a los problemas de producción en la industria cosmética hoy en día. El diagnóstico del estudio nos permitió determinar las causas principales que determinan los desperdicios en los procesos de producción, la aplicación del VSM nos permite diagramar los principales problemas y junto con las herramientas Ishikawa y Pareto se determinaron las causas raíces que finalmente se vinculó en una matriz con la solución haciendo uso de la herramienta de ingeniería industrial para resolver los problemas y se validó el diagnostico con muestreos de campo.

La aplicación de la metodología planteada por algunas referencias revisadas para el estudio planteando el estudio de métodos y el estudio de tiempo por cronometro en las operaciones de producción nos permitieron plantear oportunidades de mejoras con la finalidad de disminuir los desperdicios de tiempo de actividad, recorrido de actividad, trasporte, tiempo de ciclo, validación de UPH y finalmente la disminución de merma de granel.

De la aplicación de la metodología en el piloto de prueba nos permitió registrar data que nos permitió comparar con el estado inicial, el análisis de la data y referenciando los casos de éxitos nos permitió lograr el objetivo de reducir los desperdicios en las operaciones de producción del laboratorio cosmético.

Finalmente se concluye el presente trabajo que aporta como modelo de resolución a casos similares en el sector y se recomienda las acciones que surgieron a partir del trabajo de investigación y que servirán para continuar profundizando en el tema en referencia. 


\section{Capítulo I - Marco Teórico/Estado del Arte}

\subsection{Estado del Arte}

Según J. Acero (2014) hoy en día, las empresas se ven obligadas a mirarse a sí misma para modificar y mejorar sus procesos para poder ser más competitivos. La particularidad de ser flexible y dar a sus clientes productos con calidad y mejores tiempos de entrega, al menor costo y con altos estándares de calidad en sus productos las ubica dentro de las tallas mundiales entre las ligas mayores de las organizaciones.

Así mismo J. Acero (2014) no refiere que el sector cosmético latinoamericano es uno de los de mayor crecimiento a nivel mundial, con ingresos anuales alrededor de los 80.000 millones de dólares y con perspectivas de convertirse en el segundo mercado más importante después de Asia. La industria cosmética Latinoamericana hoy es más grande que el mercado norteamericano, es casi el $80 \%$ del europeo, y el $65 \%$ del asiático. Este sector tiene un mercado de casi 1,2 millones de empleos directos e indirectos y de 4 a 5 millones de personas que generan ingresos a partir de la misma.

A. Salvador (2015) nos habla del sector a nivel internacional y nos dice que el principal mercado fuera de latioanamerica es el mercado de los Estados Unidos (EE.UU) la Unión Europea y el Japón con un valor de 34.3, 25.7 y 11.9 millones de euros respectivamente, lo cual nos dimensiona lo interesante de este mercado y que tienen un valor muy significado en la economía mundial.

Para Ilo (2014), el sector cosmético en Perú tiene un impacto económico de aproximadamente 5 millones de dólares americano. El sector cosmético tiene una importancia en el desarrollo de la industrialización del país y a nivel mundial, se observa que hay esfuerzos denodados que en un mediano plazo será uno de los sectores más representativos en el país, por sobretodo proporciona una gran empleabilidad e integra a muchos otros sectores por sobre todo la industria petroquímica. No obstante el impacto económico que representa en Perú es necesario seguir en la búsqueda de nuevas oportunidades de mejorar para el sector. 
Se concluye que el sector cosmético a nivel mundial representa un valor muy significativo, por que integra otros rubros de manufacturas que aportan gran empleabilidad, por ejemplo la industrias petroquímica, de donde se hace transformaciones para obtener ceras y parafinas y otros que son muy utilizado en cosmética; la industria de los envases, tanto de plásticos, como de materiales colapsibles muy bien desarrollada en Colombia, quien es el principal exportador de envases a Perú actualmente, la industria del servicio y básicamente el transporte ligado a cosmética aporta ingresos muy rentables al sector. Pese a que el mayor porcentaje de productos cosméticos son importados al Perú, la industria peruana ha empezado a enrumbarse a un crecimiento escalonado y ascendente que los próximos 10 años darán mucho que decir. En mi opinión en comparación a la década pasada el sector cosmético seguirá creciendo y diversificándose cada día más y más, con el desarrollo de la dermocosmetica en Perú, ha permitido la aparición de un nicho mucho más especializado de los cosméticos y que es prescrito por los médicos dermatólogos, pediatras dermatólogos y hasta ginecólogos, dando la aparición de empresas interesadas en este rubro como es laboratorios Mediscience, el cual es una de las empresas objeto de estudio.

Según Amarjit Sahota(2014), uno de los principales problemas que tiene el sector es el abastecimiento de la cadena productiva, dado que los diferentes proveedores no se encuentran calificados sobre todo la industria china, los principales proveedores a nivel mundial no consideran que es un sector estrictamente regulado, otro de los problemas que presenta el sector son la alta especialización que deben tener las operaciones para poder entregar al usuario productos de alta calidad y muy especializados sobre todo aquellos que se encuentran dentro de la dermocosmetica que tienen que demostrar actividad terapéutica en el uso de los cosméticos.

Respecto a la problemática J. Acero (2014) al recibir los insumos, como resinas, colorantes, alcoholes, ceras y pigmentos, se almacenan y clasifican, para que cuando llegue una orden puedan tomar las cantidades adecuadas de ingredientes y comenzar a producir. Para asegurar la calidad e inocuidad del producto final, la materia prima debe ser rigurosamente analizada en laboratorio y hasta un mínimo de cinco días en cuarentena a espera de resultados microbiológico. Una vez que pasan la cuarentena, el conteo y el pesado y se recibe una orden, desde el almacén se trasladan todos los insumos a la fábrica, si no se garantiza un buen análisis del granel existirá interacción entre los insumos y puede llevar a perder grandes toneladas de granel o producto fabricado, teniendo ya un problema antes 
de ingresar a la línea de envasado. Cabe mencionar que la elaboración de lápices labiales es muy singular, debido a que parte de ella es realizada artesanalmente y la otra de manera automatizada. Mientras que la zona donde se elaboran perfumes y fragancias, es de alta seguridad debido al manejo de productos altamente inflamables y porque la exigencia es tan alta, que necesitan su propia área de trabajo. Una vez que los productos están listos y envasados, se etiqueta y empacado en el almacén por lotes, donde el área de control de calidad aprueba su salida para ser entregados a los puntos de venta, toda esta secuencia de operaciones si no tienen controles adecuados y procesos estandarizados, existirán desviaciones de procesos y desperdicios que pueden afectar la rentabilidad de las empresas.

Ilo (2014) nos menciona que los problemas de no calidad en las líneas de producción están referidos a procesos manuales, donde la buenas prácticas de las diferentes operaciones están en función de la habilidad del operario, y su nivel de capacitación es así que existen problemas de diversos tipos que se manifiestan como aspectos de no calidad del proceso, es decir que no van a cumplir ciertas características intrínsecas de los productos y sus atributos para mantener la satisfacción de los usuarios. Además indica, que los procesos en la industria cosmética tienen un flujo unidireccional pero siguiendo la normativa sanitaria, cumpliendo los procedimientos en cada estación de trabajo, uno de los procesos muy importante y donde empiezan a producirse mermas es el proceso de dispensación de materias primas, si no tenemos una balanza bien calibrada o si no tenemos los implementos necesarios para arrastrar toda la materia prima de los envases, se pueden perder dinero por que los activos cosméticos tienen altos costos, y un gramo de activo puede tener un valor monetario muy significativo.

La fecha de prescripción, vida útil o vencimiento es una etapa que se realiza analizando el producto mediante exámenes de estabilidad física, química y microbiológica. Estos ensayos, garantizan la efectividad del mismo, además de conocer la vida útil del producto cosmético, que se comprueba evaluando la concentración de activos y conservantes en el tiempo de ensayo, como así también la compatibilidad producto-envase, muchas materias primas se pierden por vencimiento de vida útil.

Se puede concluir que en la industria de los cosméticos se tiene diversos problemas desde inicio de la cadena productiva que empiezan los proveedores que no encuentran validados $\mathrm{u}$ homologados en su calidad lo cual ya despachan envases, etiquetas, tapas, precintos fallados que finalmente van a repercutir en la conciliación de materiales de las diferentes 
órdenes de producción y estos problemas continúan en cada estación siempre y cuando estos no están estandarizados, definitivamente son operaciones altamente especializadas que se requiere procesos tecnológicos seguros, los procesos manuales siempre estarán a expensas de producir mermas y desperdicios porque se depende de la especialización del operador.

H Saranga and RD Banker (2016) estudiaron las desviaciones de procesos de envasado en la industria farmacéutica y el cambio en la productividad y los factores que impulsan los cambios, en el estudio utilizaron la metodología basado en el desarrollo de datos no paramétricos aplicando la metodología de lean manufacturing para estudiar el cambio de productividad y como los desperdicios influyen en esta. La aplicación de esta técnica para disminuir los desperdicios en la operación de acondicionado fue secuencial empezando por los procesos simples hacia los procesos más complejos.

Fengzhu LI, Shunan Bao (2014) aplicaron lean manufacturing a los procesos de producción en industria cosmética y al proceso de logística con el núcleo de la logística Lean es eliminar todas las actividades (desperdicio) sin valor agregado dentro de las producciones, movimientos y almacenamientos. Se reduce el tiempo de entrega, reduce el costo y mejora la calidad. Para ser competitivos, las empresas en los países occidentales utilizan ampliamente los principios de la fabricación y logística lean en las industrias farmacéuticas y cosméticas, especialmente para el sistema de fabricación de capsulas y comprimidos debido a su alto contenido de trabajo de ensamblaje. Ellos analizan el estado actual de la Lean Logísticas en la fabricación de capsulas y comprimidos en China, resume los principios de Lean Logistics, presenta la aplicación de principios de Lean Logistics basados en un estudio de caso real de una nueva planificación de sistemas de fabricación. En detalle, se introducen los orígenes de la logística lean, se describen las características de la logística de fabricación de los comprimidos y capsulas, se proponen los requisitos del sistema de logística Lean, se utiliza la metodología PFEP (Plan para cada parte) y se analizan las especificaciones de fabricación, envase y empaque. En este artículo también se describe y analiza la logística de la cadena de suministro, el almacenamiento en almacén, el sistema de información y la logística de la línea de producción. Los conceptos Milk Run y Super Market se aplican en la planificación logística del sistema de fabricación. 
Mohamed E. M. E.Sayed (2014), implementaron los principios y herramientas lean en envasados de enlatados de conservas para resolver los problemas de desperdicios en una industria pesquera. Este éxito ha llevado a diferentes implementaciones de estos principios en otras actividades de la organización, como el diseño y la gestión. Si bien estas implementaciones pueden producir algunas mejoras, la segmentación de los procesos de desarrollo de productos en la mayoría de las empresas limita el potencial para lograr los objetivos deseados y, en algunos casos, el éxito del proceso de implementación en sí. En otras palabras, no se puede lograr el pleno éxito de la implementación de los principios de Lean cuando se aplica a segmentos aislados del proceso de desarrollo del producto. Abordan el diseño del lean en el envasado, en el contexto de un proceso de realización de producto completamente integrado. El documento analiza la naturaleza integrada de cualquier proceso de realización del producto y su flujo desde el concepto hasta la producción. También aborda el efecto de esta naturaleza integrada del proceso en la implementación de los diferentes principios Lean tales como valor, flujo de valores, flujo, extracción y perfeccionamiento para el proceso de envasado en línea.

M.F. Suárez y J.A.M Dávila en su libro Innovar(2013) nos describen de la implementación de Kayzen en una empresa mexicana para mejorar la productividad de una industria alimentos en la cual usan esta técnica para el mejoramiento de sus líneas de fabricación y envasado, la técnica principal se inicia con estandarización de los procesos, se aplica herramientas de control estadístico de procesos, y los círculos de calidad primarias y secundarias aspecto novedoso hoy en día, para disuadir a cero errores en los trabajadores.

R. Gracia C. (2014) en su libro Estudio del trabajo nos indica que tomar riesgos es la esencia de la actividad económica de la empresa, a la cual consideramos inútil tratar de eliminarla pero si muy discutible tratar de mitigarla. Para aplicar exitosamente esta actividad es esencial que los riesgos que se tomen sean los correctos. Sin embargo, para lograr este objetivo debemos saber y entender qué riesgos debemos tomar.

En la actualidad, conjugar adecuadamente los recursos económicos, materiales y el factor humano origina incrementos de productividad. Con base en la premisa de que en todo proceso siempre se encuentran mejores posibilidades de solución, puede efectuarse un análisis a fin de determinar en qué medida se ajusta cada alternativa a los criterios elegidos 
y a las especificaciones originales, lo cual se logra a través de los lineamientos del estudio de métodos.

G.Kanawaty en su libro, introducción al estudio del trabajo, nos indica que es necesario investigar y perfeccionar las operaciones en el lugar del trabajo y no es nada nuevo, los buenos gerentes lo están haciendo constantemente. Es muy útil hacer el estudio del trabajo, pues aplicando sus procedimientos sistemáticos se puede lograr resultados equiparables e incluso superiores a otros estudios en relación con mejorar la productividad y disminuir costos.

Es un instrumento poco costoso y de fácil aplicación, y es uno de los métodos más exactos para establecer medidas de tiempo, normas, procedimientos y normas de rendimiento, de las que dependen la planificación y el control eficaces de la producción. Los principales artículos revisados en esta investigación se detallan sus motivaciones y aportes:

Paper: Herramienta didáctica para la explicación de conceptos de balanceo de Línea en cursos de producción de los programas de ingeniería industrial.

\section{Motivación de los Autores:}

Los diferentes problemas en las líneas de producción son variados pero el balanceo de las líneas cumple un papel preponderante, uno de los elementos más importantes en cualquier empresa manufacturera es lograr el adecuado balanceo de sus líneas de producción. De manera específica el balanceo de línea busca distribuir la carga de trabajo entre los recursos de un proceso, de tal manera que se logre equilibrar las capacidades productivas con las necesidades de operación.

\section{Aporte:}

En el presente documento el autor busco proponer una herramienta didáctica para la explicación de conceptos alrededor del balanceo de línea. El montaje logra discutir también un segundo escenario donde se explica una metodología para el balanceo de línea denominada Bucket Brigades. Este es un método eficiente que tiene pocas aplicaciones prácticas en Colombia debido a que es bastante nuevo y poco conocido por la comunidad Académica; razón por la que el presente documento también busca difundir el método como alternativa a la consecución de los objetivos de balanceo de línea. 
Paper: Hierarchical approach for paced mixed-model assembly line balancing and sequencing with jolly operators

\section{Motivación de los autores}

Los diferentes problemas de producción en la industria manufactura motivan a los autores a disminuir desperdicios que afectan en los costos productivos y por ende se traslada a los clientes finales en este sentido para aumentar la flexibilidad y reducir los costos, varias compañías adoptan líneas de montaje de modelos mixtos cuya producción suele ser más eficiente, este estudio plantea las alternativas de producción considerando el ensamblaje para poder hacer una secuencia de operaciones más eficientes.

Los productos son variaciones del mismo modelo básico con atributos específicos y distintivos. Desafortunadamente, tales atributos normalmente conducen a variaciones en los tiempos de proceso de la tarea. En el caso de líneas de ensamblaje amortiguadas sin ritmo, estas variaciones afectan la productividad y es necesaria estudiar los tiempos en cada estación para definir entandares.

\section{Aporte:}

Muestra las herramientas para hacer una estudio de trabajo y tiempos con la finalidad de determinar los estándares para lograr disminuir las ineficiencias de las líneas, siempre se observan desperdicios, y para tales debilidades, algunas compañías adoptan líneas de ensamblaje sin amortiguación y ritmo donde el tiempo del ciclo es controlado por el movimiento continuo / síncrono de los productos desde la primera estación de ensamblaje hasta la última. Tal como se observa en la figura donde claramente se plantea la forma de distribución de los tiempos de ciclo por cada estación de trabajo esa secuencia ensamblada resulta ser más productiva en forma lineal.

Paper: Marco de Referencia de la Aplicación de Manufactura Esbelta en la industria

\section{Motivación de los Autores:}

Actualmente las empresas que aplican las herramientas de Manufactura Esbelta cometen el error de implementarlas de manera aislada para cubrir las necesidades de mejora a un corto plazo, por lo que obtienen beneficios limitados. Este es uno de los aspectos que llevo a los autores a realizar esta investigación para cubrir esos errores que normalmente suceden. 


\section{Aporte:}

Nos presenta primero una revisión de literatura relacionada con la implementación de herramientas de Manufactura Esbelta en la Industria, tales como Takt Time, 5's, Ocho desperdicios “mudas”, Control Visual, Células de Manufactura, a Prueba de errores (PokaYoke), Nivelación de la producción (Heijunka), Automatización inteligente (Jidoka), Mejora continua (Kaizen), Kanban, Cambios rápidos de modelo (SMED), Mantenimiento total de la producción (TPM), Justo a tiempo (JIT) y Mapeo del flujo de valor (VSM), analizando su aplicación tanto individual como en conjunto, se visualiza que las 5'S, el VSM, Kaizen, Kanban y TPM son las más utilizadas en el ramo Manufacturero con un 9,46\%, 8.1\%, 6,75\%, $5,4 \%$ y $4,05 \%$ respectivamente, y SMED con un $4,05 \%$ y JIT con un $6,76 \%$ en el sector Automotriz; caso contrario, las Células de Manufactura, Heijunka es la menos utilizadas (en $1,35 \%$ ) y que la combinación de herramientas es muy utilizadas por que da mejores resultados a las diferentes industrias.

Paper: Production lot-sizing decision making considering bottleneck drift in multi-stage manufacturing system

\section{Motivación de los autores}

La motivación en esta investigación de los autores se basa en hoy en día muchas empresas de manufactura producen en lotes dado que tienen una cartera multiproducto de capacidad limitada y ante este esquema es necesario tener herramientas para encontrar el lote más productivo de acuerdo a la capacidad instalada de la empresa, muchas empresas no tienen en cuenta el factor lote económico y este trabajo está orientado a dar las herramientas para lograr ese objetivo.

\section{Aporte:}

Dar las herramientas estratégicas de gran tamaño con un mínimo de tiempo de procedimiento en un entorno operativo de pedido a entrega (OTD). Mientras el plan de dimensionamiento de lotes puede formarse estudiando los parámetros de fabricación del procedimiento establecido de cuello de botella, para una fabricación en varias etapas del sistema, el cuello de botella no es fijo y fluctúa con la tasa de producción o tamaño del lote. Este artículo propone una estrategia de gran tamaño para determinar el tamaño óptimo de lote para cada clase de producto tomando en consideración el cuello de botella. Se emplea un método de 
análisis de redes de colas (QNA) para tratar el modelo de programación de enteros mixtos no lineales en un enfoca en el tiempo de flujo total y minimización del sistema. Se resuelve utilizando el método propuesto, y los resultados se validan con Flexsim, un modelo de simulación.

Paper: Objetives and operational strategic decisions as support for lean manufacturing

\section{Motivación del autor}

Los autores motivaron a la investigación porque hay una necesidad de esquematizar las herramientas de lean para disminuir desperdicios que merman el rendimiento de la productividad y el objetivo de la presente investigación consistió en identificar los mecanismos de coordinación entre las herramientas de lean manufacturing y la estrategia de operaciones, en siete compañías del sector textil ubicadas en el Valle de Aburrá, Colombia.

\section{Aporte:}

Fue utilizar una metodología de estudio de caso, con base en un enfoque cuantitativo y un alcance descriptivo -correlacionar. Entre los principales resultados se encontró que el objetivo de entrega y la decisión estratégica de capacidad son los principales motores para el incremento de la utilidad operacional a partir de la incorporación de la filosofía lean en las actividades diarias de la organización. De manera particular en aquellas organizaciones donde su implementación aun es limitada, son estos dos elementos los que deben fortalecerse desde la estrategia corporativa, como es el caso de las compañías del sector textil.

Paper: Mejoras de procesos productivos mediante Lean Manufacturing

\section{Motivación de los autores:}

La demanda excesiva de las empresas por mejorar sus procesos es una muestra de que las líneas de producción siempre tienen desviaciones que deben ser controladas, y para eso es necesario tener una metodología para identificar los problemas y luego para solucionarlos en ese sentido lean manufacturing presenta herramientas desde muy básicas para la estandarización como las 5S hasta sistemas más avanzados como Six-Sixma.

\section{Aporte:}


La presente investigación realizada a Compañías CDC, contribuyeron a cómo identificar y entregar una propuesta de mejora a las ineficiencias en la producción de colchones. La filosofía Lean Manufacturing fue la base técnica de este estudio, siendo el Diagrama de Flujo de Valor (VSM) y los Diagramas de Ishikawa, las herramientas determinantes para la identificación y descripción de mudas en el proceso productivo, mediante los cuales se pudo poner en evidencia los principales desperdicios del proceso, pudiendo ofrecer una mejora que dé cuenta de un nuevo proceso más limpio y eficiente.

Paper: Tiempos en la recolección manual tradicional del café en Colombia Motivación de los Autores:

El café una de las principales actividades de Colombia y en una zona de Colombia existen varia empresas y en ellas se da operaciones productivas que no estaban controladas y generaban muchos desperdicios de tiempos y recorridos que eran necesarios estudiarlos para poder estandarizar con los operadores los tiempos de trabajo. El estudio se desarrolló en dos fincas cafeteras, localizadas en Chinchiná, Caldas- Colombia y Cajibío, Cauca- Colombia; en lotes sembrados con variedades Castillo y Caturra de 1 hectárea, con densidades de siembra entre 5.000 y 10.000 plantas por hectárea. Previamente, se definieron los protocolos de seguimiento y medición en campo, en pruebas piloto.

La unidad de análisis fue el recolector, para su selección se consideró el nivel de experiencia mayor a un año en la recolección de café con el sistema tradicional, comúnmente empleado en Colombia.

\section{Aporte:}

Para la estandarización de los tiempos en el proceso de recolección de manual de café se presentaron técnicas de ingeniería de métodos que permitieron identificar los elementos que conforman el proceso; valorar el ritmo; estimar los suplementos fijos y variables influyentes y definir el tiempo estándar. Este estudio consideró además un análisis de los micros movimientos o therblighs del proceso indispensable en la evaluación de desempeño del recolector y la definición del tiempo del ciclo de recolección. La técnica videográfica fue empleada para la captura de información en campo durante la recolección de café con el sistema tradicional. Los tiempos estándar y los factores de desempeño en términos de 
indicadores de rendimiento y calidad brindan información para el monitoreo, control y toma de decisiones en las fincas cafeteras. Los elementos anteriores contribuyen al establecimiento de planes de entrenamiento y formación de recolectores de café.

Paper: Utilización de curvas de aprendizaje e intervalos de confianza en un estudio de tiempos para el cálculo de tiempos estándar

\section{Motivación de los autores}

El presente artículo es motivado por la poca claridad que existe en los estadísticos para la toma de tiempo en los procesos de manufactura y explora el uso de curvas de aprendizaje e intervalos de confianza en un estudio de tiempos llevado a cabo en una línea de ensamble a escala durante una práctica de laboratorio en la Universidad de la Salle con la finalidad de determinar parámetros que ayuden a determinar tiempos de ciclos en líneas productivas.

Aporte:

Los autores nos aportan una metodología totalmente diferente a los estudios de tiempos que suelen hacer, en este caso nos muestras los autores una metodología empleada que consta de dos fases, así, en la primera fase para el análisis del estudio de tiempos, se hace el cálculo del número de ciclos, la depuración de datos atípicos y el uso de las curvas para determinar los procesos aptos para la estandarización; y en la segunda fase, es decir, el establecimiento de tiempos estándar, se realiza el cálculo de los tiempos estándar.

Paper: Identificación de costos ocultos a partir de un estudio de organización del trabajo en una empresa del sector farmacéutico en cuba

\section{Motivación de los autores:}

La organización del trabajo juega un papel fundamental en la eficiencia de los procesos, los autores se ven motivada por la necesidad de evaluar el impacto del estudio del trabajo en los resultados de la empresa a través de indicadores de gestión. Por otra parte, la Organización Internacional de Trabajo ha definido los tiempos que pueden generar en derroches para la producción. Además, estudios franceses han mostrado que la incorrecta gestión del tiempo puede generar disfuncionamientos y estos incidir en costos ocultos.

\section{Aporte:}


Nos aporta elementos que muestran como el análisis siempre es desde una visión estratégica y no con una fundamentación técnica desde la organización del trabajo. Es por ello que los autores no explican o muestran procedimientos o metodologías de cómo identificar los disfuncionamientos y examinarlos, por lo cual esta investigación nos ayuda a como cuantificar los costos ocultos asociados a las disfuncionalidades existentes en el proceso de organización del trabajo para evitar que estos afecten a la productividad y como objetivo: identificar los costos ocultos a partir de un estudio de organización del trabajo en una empresa del sector farmacéutico en Cuba. Las técnicas fundamentales utilizadas son la entrevista, la encuesta y la lista de chequeo. En la indagación se detectó como principales disfuncionamientos: la inexistencia de instrumentos y herramientas necesarias y los tiempos improductivos por indisciplina laboral, este último genera altos costos, para ello se proponen indicadores que permiten monitorear su comportamiento. El procedimiento aplicado aporta una herramienta para controlar los disfuncionamientos existentes en la organización del trabajo y sus costos a través de indicadores.

En conclusión se muestras varios autores que realizaron investigación y participaron en los diferentes estudios, esto fue obtenido de la revisión de base de datos on line, 15 artículos ESBCO HOST seleccionados y leídos con alguna relación con el tema de estudio , solamente 7 de ellos fueron seleccionados como modelo en la metodología para la solución de problemas similares al estudio, en PROQUETS encontramos 2 artículos relacionados con el tema, en SAFARI se seleccionó 3 artículos, tanto en PROQUETS y SAFARI se encontraron libros en líneas de ediciones actualizadas los cuales nos sirvieron para estructurar el marco teórico y estado del arte.

La metodología fue seleccionar por tipología de investigación sendos artículos el cual se mencionan en los siguientes cuadros y se presentaron las motivaciones y aportes de los más importantes:

Tipología de Paper revisados en la investigación

\begin{tabular}{|l|c|c|c|c|c|c|}
\hline Tipología & $\mathrm{N}^{\circ}$ Paper & Titulo & Autor & País & Año & Fuente \\
\hline$\frac{0}{0}$ & 01 & $\begin{array}{c}\text { Marco de Referencia de la } \\
\text { Aplicación de } \\
\text { Manufactura Esbelta en la } \\
\text { industria }\end{array}$ & $\begin{array}{c}\text { J.Tapia C., } \\
\text { Escobedo P. }\end{array}$ & México & 2016 & $\begin{array}{c}\text { Revista de } \\
\text { ciencia y } \\
\text { trabajo }\end{array}$ \\
\hline
\end{tabular}




\begin{tabular}{|c|c|c|c|c|c|c|}
\hline & 02 & $\begin{array}{l}\text { Objetives and operational } \\
\text { strategic decisions as } \\
\text { support for lean } \\
\text { manufacturing }\end{array}$ & $\begin{array}{l}\text { M. Grisales, } \\
\text { N.; G. } \\
\text { Gaitán P. }\end{array}$ & Colombia & 2017 & $\begin{array}{c}\text { Revista de } \\
\text { investigación } \\
\text { del trabajo }\end{array}$ \\
\hline & 03 & $\begin{array}{l}\text { Mejoras de procesos } \\
\text { productivos mediante } \\
\text { Lean Manufacturing }\end{array}$ & I.Escaida V. & Argentina & 2016 & $\begin{array}{l}\text { Revista de } \\
\text { Ingeniería }\end{array}$ \\
\hline \multirow{3}{*}{ 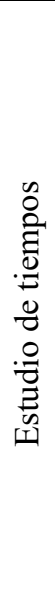 } & 04 & $\begin{array}{c}\text { Tiempos en la recolección } \\
\text { manual tradicional del } \\
\text { café }\end{array}$ & $\begin{array}{l}\text { K. Salazar } \\
\text { V.; A. } \\
\text { Arroyavel } \\
\text { T. }\end{array}$ & Colombia & 2017 & $\begin{array}{l}\text { Organización } \\
\text { del trabajo y } \\
\text { la producción }\end{array}$ \\
\hline & 05 & $\begin{array}{l}\text { Utilización de curvas de } \\
\text { aprendizaje e intervalos de } \\
\text { confianza en un estudio de } \\
\text { tiempos para el cálculo de } \\
\text { tiempos estándar }\end{array}$ & N.Mitzy R. & Argentina & 2017 & INGE CUC \\
\hline & 06 & $\begin{array}{lr}\text { Optimización de } & \text { tiempos } \\
\text { de procesos } & \text { en } \\
\text { desistabodoras } & y \\
\text { embotelladora } & \end{array}$ & $\begin{array}{l}\text { J.I. Ruiz, R. } \\
\text { J.Leyva T. }\end{array}$ & $\begin{array}{c}\text { Costa } \\
\text { Rica }\end{array}$ & 2017 & $\begin{array}{c}\text { Revista } \\
\text { Científica } \\
\text { Himjay }\end{array}$ \\
\hline \multirow{3}{*}{ 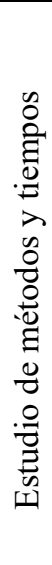 } & 07 & $\begin{array}{l}\text { Caracterización, control y } \\
\text { mejoramiento de un } \\
\text { proceso de fabricación de } \\
\text { Balatas }\end{array}$ & $\begin{array}{l}\text { H. Bautista } \\
\text { R, M. } \\
\text { Shaker T. }\end{array}$ & México & 2018 & $\begin{array}{c}\text { Culcyt } \\
\text { Manufactura } \\
\text { revista }\end{array}$ \\
\hline & 08 & $\begin{array}{l}\text { Estudio de movimientos en } \\
\text { la recolección manual de } \\
\text { naranjas en Caldas, }\end{array}$ & $\begin{array}{l}\text { A. } \quad \text { M. } \\
\text { Ovalle C. } \\
\text { O.L. } \\
\text { Ocampo L. }\end{array}$ & Colombia & 2018 & $\begin{array}{l}\text { Revista de } \\
\text { Ingeniería }\end{array}$ \\
\hline & 09 & $\begin{array}{l}\text { Identificación de costos } \\
\text { ocultos a partir de un } \\
\text { estudio de organización del } \\
\text { trabajo en una empresa del } \\
\text { sector farmacéutico en } \\
\text { cuba }\end{array}$ & $\begin{array}{l}\text { A.M } \\
\text { Negrón G., } \\
\text { M.S. Fleitas } \\
\text { T. }\end{array}$ & Cuba & 2018 & $\begin{array}{l}\text { Revista } \\
\text { Chilena de } \\
\text { Ingeniería }\end{array}$ \\
\hline \multirow{3}{*}{ 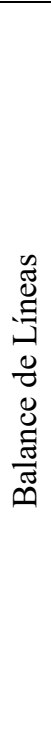 } & 10 & $\begin{array}{l}\text { Herramienta didáctica para } \\
\text { la explicación de } \\
\text { conceptos de balanceo de } \\
\text { líneas en cursos de } \\
\text { producción de los } \\
\text { programas de ingeniería } \\
\text { industrial }\end{array}$ & $\begin{array}{l}\text { K. A. } \\
\text { Peláez M. } \\
\text { J.L. Payán } \\
\text { Q. }\end{array}$ & Colombia & 2015 & $\begin{array}{l}\text { Revista } \\
\text { Educación en } \\
\text { Ingeniería }\end{array}$ \\
\hline & 11 & $\begin{array}{l}\text { Hierarchical approach for } \\
\text { paced mixed-model } \\
\text { assembly line balancing } \\
\text { and sequencing with jolly } \\
\text { operators }\end{array}$ & $\begin{array}{l}\text { M. Faccioa } \\
\text { P.; M. } \\
\text { Gamberia } \\
\text { T. }\end{array}$ & Italia & 2015 & $\begin{array}{l}\text { International } \\
\text { Jornal of } \\
\text { Production } \\
\text { Research }\end{array}$ \\
\hline & 12 & $\begin{array}{lr}\text { Production } & \text { lot-sizing } \\
\text { decision } & \text { making } \\
\text { considering } & \text { bottleneck } \\
\text { drift in } & \text { multi-stage } \\
\text { manufacturing } & \text { system }\end{array}$ & $\begin{array}{l}\text { Zhou, F.L.a, } \\
\text { L.Wang T. }\end{array}$ & China & 2017 & $\begin{array}{l}\text { Journal of } \\
\text { Production }\end{array}$ \\
\hline
\end{tabular}

Fuente: Elaboración Propia 


\subsection{Marco Conceptual}

\subsubsection{Definición de proceso}

A. Cuatrecasas (2015) manifiesta que un proceso es una secuencia de pasos dispuesta con algún tipo de lógica que se enfoca en lograr algún resultado específico. Los procesos son dispositivos de procedimiento diseñados para mejorar la productividad, para implantar un orden o descartar problemas. Este proceso puede emplearse en una gran variedad de ámbitos, como el jurídico, informático o el empresarial. Cabe resaltar que los procesos son ante todo procedimientos proyectados para el servicio del ser humano como una manera definida de accionar.

Es muy claro lo que plantea Cuatrecasas, pero adicionalmente el aporte de la ingeniería industrial a la definición de procesos como el flujo direccional de entradas, que por una secuencia de operaciones y actividades se transforman estas entradas agregándose valor para dar como resultados a salidas o productos, en cada etapa de este flujo se determinan controles y se miden mediante indicadores de eficiencia y eficacia.

\subsubsection{Cadena de valor en la industria cosmética}

Arévalo, A. y Escobar, B. (2014), el concepto de cadena de valor se mencionan como una dirección estratégica de una empresa, a nivel de unidad de negocio, determinará formas alternas de articulación de las actividades entre los distintos eslabones y seleccionará las que mejor contribuyan a diferenciar sus productos o a reducir sus costos.

De acuerdo a lo que dicen los autores la cadena de valor es una herramienta metodológica para el análisis de todas aquellas estaciones y eslabones que se interrelacionan unos con otros y cada una de ellas contribuye o aporta al cumplimiento de los objetivos estratégicos, todos los grupos de interés o stakeholder están íntimamente relacionados.

\subsubsection{Principales operaciones en la industria cosmética}

Salvador, A. y Chisvert, A. (2015) en su libro “Análisis of cosmetic products define las principales operaciones que se dan en los procesos de fabricación de los productos cosméticos son los siguientes: 


\section{- EMULSIONACIÓN}

Consiste en agitar una mezcla agua/aceite/surfactante o emulsificante, con un artefacto mecánico que provoque turbulencia, el resultado de la operación depende de la naturaleza y las proporciones de las fases.

\section{- HOMOGENIZACIÓN}

Es una operación unitaria común en los procesos de cosméticas con lo cual se logran adicionar varios insumos y con agitación se pueden obtener sistemas monofásicos, es muy importante considerar la velocidad de disolución de los insumos.

\section{- FILTRACIÓN}

La filtración consiste en la remoción de partículas suspendidas y coloidales presentes en una suspensión acuosas que escurre a través de un medio poroso.

\section{- DOSIFICACIÓN}

Puedo definir que esta operación consiste en el llenado del granel en su envase primario, la cantidad de masa o volumen a ser llenado puede ser regulado por un sistema electro-neumático, el cual las válvulas bajo el principio de desplazamiento de las levas logran ocupar un espacio que representa el volumen o la masa a llenar.

\section{- TAPADO}

Defino esta operación en una actividad que consiste en colocar de modo automático o manual el accesorio que logrará hermetizar el envase primario.

- ETIQUETADO

Se define esta operación en una actividad que consiste en adicionar al envase primario la etiqueta, donde se encuentra la información del rotulado del producto.

- ESTUCHADO

Consiste en colocar el envase primario en su envase secundario, este proceso puede realizarse de modo automático o de modo manual.

- LOTIZADO-IMPRESIÓN 
Se define esta operación unitaria como aquella actividad que consiste en colocar mediante una impresión injeck el lote y vencimiento tanto al envase primario, como al envase secundario.

- EMBALADO: Operación que consiste en colocar los productos terminados en cajas muy bien estilizadas a medida de cada producto terminado.

\subsubsection{Desperdicios}

G. Kanawaty (2014) en su libro Introducción al estudio del trabajo nos define desperdicio es cualquier elemento dentro del proceso de producción (incluyendo áreas de servicio y administrativas) que añade costo sin valor al producto. Estas surgen de la clasificación desarrollada por Ohno (mentor y artífice del just in time), y comprende los siguientes:

- Muda de sobreproducción: Producir más de lo demandado o producir algo antes de que sea necesario.

- Muda de espera: La espera a que las maquinas hagan el proceso debe ser eliminada. En vez de maximizar la utilización de las máquinas, lo que se tiene que promover es maximizar la eficiencia del trabajador. Espera sin generar valor, en cualquier circunstancia en la producción es un aspecto en contra para la productividad.

- Muda de inventario: Es la existencia de material entre diferentes operaciones debido a lotes de producción muy grandes o de procesos con un tiempo de ciclo muy grande.

- Muda de procesos innecesarios: Tienen que ser eliminados haciéndose la pregunta, por qué un proceso es necesario y por qué un producto es producido. Todos los procesos innecesarios tienen que ser eliminados.

- Muda de transporte: No añade ningún valor al producto. En vez de mejorar el transporte, éste debe ser minimizado o eliminado cuando sea necesario, por medio de celdas de trabajo.

- Muda de movimiento: Movimiento de los trabajadores, de las maquinas o del producto. 
- Muda de productos defectuosos, prevenir los defectos, en vez de buscarlos y eliminarlos.

- Desaprovechar trabajadores No aprovechar las habilidades de la gente, por diferentes motivos.

\subsubsection{Estudio del trabajo}

Según la OIT el estudio del trabajo, es una evaluación sistemática de los métodos utilizados para la realización de actividades con el objetivo de optimizar la utilización eficaz de los recursos y de establecer estándares de rendimiento respecto a las actividades que se realizan.

Comprende las técnicas del estudio de métodos y la medida del trabajo, mediante las cuales se asegura el mejor aprovechamiento de los recursos materiales y humanos para llevar adelante una tarea determinada.

Según la OIT la forma para optimizar un proceso de producción y disminuir desperdicios debe seguir el siguiente diseño:

\subsubsection{Estudio de métodos}

De acuerdo a R. Garcia C. (2014), el estudio de métodos de una tarea es la investigación sistemática de las operaciones que la componen, su tipología, materiales y herramientas utilizadas. El estudio de métodos divide y desglosa la tarea en una parte razonable de operaciones. De esta manera se entiende mejor cómo se ejecuta la tarea y permitiendo unificar un método operativo para todos los implicados en su ejecución. Además, es el punto de partida para su mejora. No obstante, se hace notar que el hecho de describir un método operativo ya es una mejora que probablemente sea la más importante. Por lo tanto, el autor define primero que el estudio de métodos se secuencia tal como se observa en la Figura $\mathrm{N}^{\circ} 1$

Figura 1 Etapas del estudio de métodos 


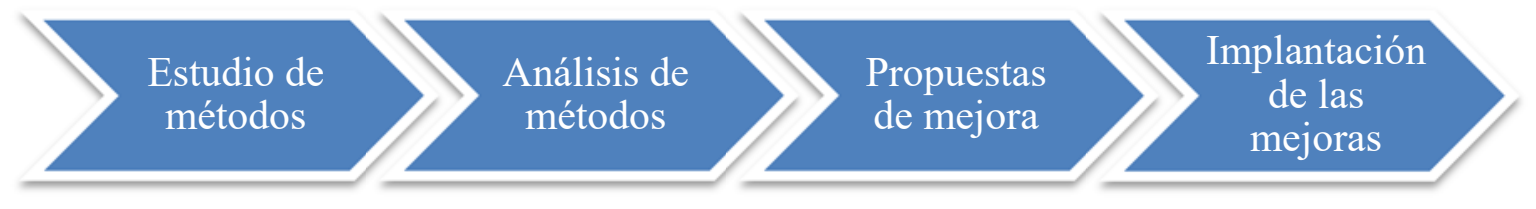

Fuente: Elaboracion propia, adaptada del autor.

Asimismo, el paso de "Estudio de métodos", el cual es la etapa fundamental según el autor para la investigación, debe seguir la guía mostrada en la Figura $\mathrm{N}^{\circ} 2$

Figura 2 Guía de implementación del estudio de métodos
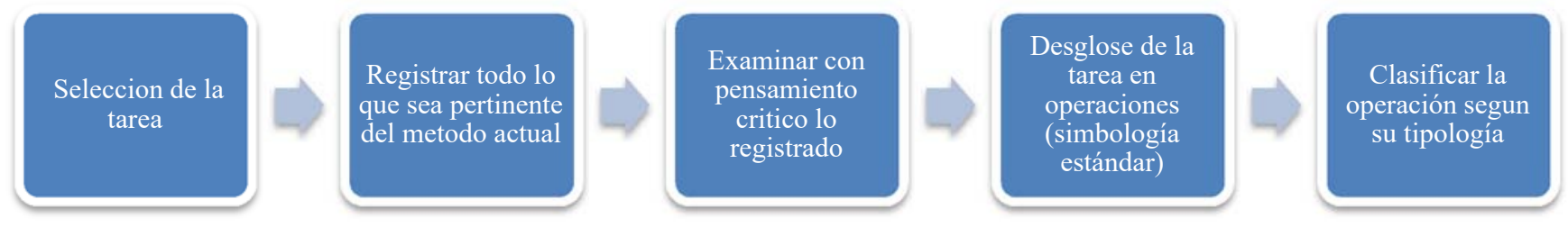

Registrar el

metodo operativo

en un diagrama de

metodo de tareas.
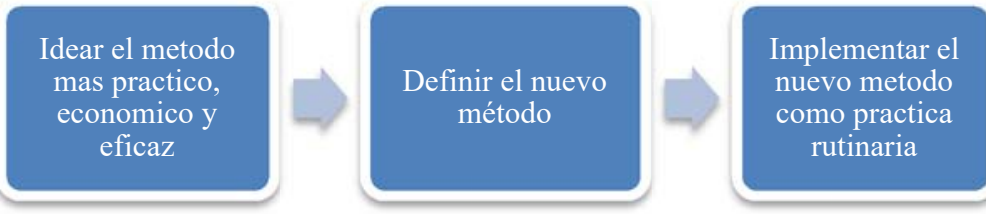

Fuente: Elaboracion propia, adaptada del autor

\subsubsection{Análisis de métodos}

Según G.Kanawaty, se utilizan diferentes herramientas para poder hacer el estudio analítico y estos son los diferentes gráficas que ayudan a encontrar y proponer mejoras de solución.

1. Gráfico o diagrama de proceso (cursograma)

Es un diagrama que presenta un cuadro general de cómo se suceden las principales operaciones e inspecciones. Los símbolos se observan en la Fig. 3

Figura 3 Simbología del diagrama de procesos

$$
\text { OPERACIÓN INSPECCION }
$$




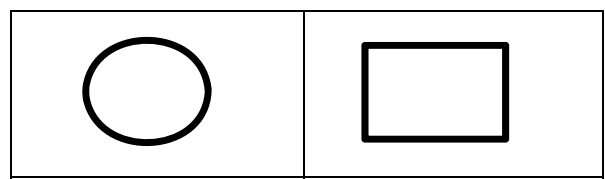

Fuente: Elaboración propia

\section{El cursograma analítico}

Es un diagrama que muestra la trayectoria de un producto señalando todos los hechos sujetos a examen mediante el símbolo correspondiente. Se aplica a:

- El operario: Diagrama de lo que hace la persona.

- El material: Diagrama de lo que ocurre al material.

- El equipo o maquinaria: Diagrama de uso.

La simbología utilizada se muestra en la Fig. 4

Figura 4 Simbología del diagrama de procesos analíticos

\begin{tabular}{|l|l|l|l|l|}
\hline OPERACIÓN & INSPECCIÓN & TRANSPORTE & ALMECENAMIENTO & ESPERA \\
\hline$(2$ & & & \\
\hline
\end{tabular}

Fuente: Elaboración propia

3. Diagrama bimanual

Es un cursograma en que se consigna la actividad de las manos del operario indicando la relación entre ellas

4. Diagrama de actividad o DAP o cursograma de actividades

Es un gráfica en donde se detalla todas las actividades o tareas que tienen un proceso con la finalidad de analizar y buscar los elementos que tienen o no tienen valor y nos puede servir para proponer mejoras agrupando actividades, también se detalla el uso de recursos para cada tarea

5. Diagrama de recorrido 
El diagrama de recorrido consiste en un plano (preferentemente a escala) de la planta o área de trabajo, que cuenta con la correcta ubicación de las máquinas. Esto permite trazar y analizar los movimientos de los productos y/o componentes.

\subsubsection{Estudio de tiempos}

Según Methodology of study of time and movement, Intoduction to the GSD desarrollado por Noris Leonor Tejada, el estudio de tiempo y movimiento es una técnica de gran ayuda para las empresas, el cual no es valorado actualmente. Esta supone un valor importante para conseguir un trabajo de manera eficiente y eficaz. El estudio de tiempo y movimiento va dirigido a la mejora de la productividad y fue utilizada desde los siglos XIX. El GSD proporciona un enfoque al área de manufactura en donde se establecen tiempos de fabricación consistentes los cuales reducen los costes de la misma. El estudio de tiempo y movimiento tiene como objetivo lo siguiente:

- Minimizar el tiempo requerido para la ejecución de trabajos.

- Conservar los recursos y minimizar los costes.

- Proporcionar un producto que sea cada vez más confiable y de alta calidad.

- Eliminar o reducir los movimientos ineficientes y acelerar los eficientes.

\subsection{Metodología para la técnica de medición de tiempo con cronometro}

Se debe seguir los siguientes pasos:

- Identificación de las Operaciones: Se hará un reconocimiento a las operaciones y actividades, en el proceso de envasado y acabado.

- Seleccionar al trabajador representativo del grupo de trabajo: Es importante antes de aplicar las técnicas de medición elegir al trabajador que cumpla con casi o todos los atributos requeridos en el área de trabajo.

- Medición (cronometro vuelta a cero): Para la toma de tiempos se dará inicio a la actividad a la par que el cronómetro está marcando cero $(0)$, dejándose que éste avance a medida que se desarrolla la actividad. 


\subsection{Descripción del formato de mejora}

- ID de la Operación: Numeración y secuencia de la operación.

- Procesos: Actividades que agregan valor al producto terminado.

- \# de operarios observados: Cantidad de trabajadores en la línea de trabajo a analizar.

- $\quad \mathrm{N}^{\mathrm{o}} \mathrm{X}$ de operaciones: La cantidad de unidades realizadas, en un mismo lapso de tiempo.

- Tiempos Observados: Muestra necesaria, para una probabilidad de éxito al $90 \%$ y 1.64 de nivel de confianza (distribución Normal).

- TM seg: Tiempo promedio del tiempo observado, dentro de una variación no mayor, ni menor del $20 \%$.

- \# Observaciones: Cantidad de muestras tomadas con el cronometro vuelta a cero.

- TM seg. x unid.: Tiempo promedio observado por unidad.

- Factor de Valorización (FV): Valoración, esto significa calificar el rendimiento de la actividad observada y su dificultad.

Figura 5 Sustento del factor de valoración 


\begin{tabular}{|c|c|c|c|c|c|}
\hline \multicolumn{4}{|c|}{ Escalas } & \multirow[b]{2}{*}{ Descripción del desempeño } & \multirow{2}{*}{$\begin{array}{c}\text { Velocidad de } \\
\text { marcha } \\
\text { comparable } \\
\text { (km/h) }\end{array}$} \\
\hline $60-80$ & $75-100$ & $100-133$ & $\begin{array}{l}0-100 \\
\text { Norma } \\
\text { Británica }\end{array}$ & & \\
\hline 0 & 0 & 0 & 0 & Actividad nula & \\
\hline 40 & 50 & 67 & 50 & $\begin{array}{l}\text { Muy lento, movimientos torpes, inseguros; el operario } \\
\text { parece medio dormido y sin interés en el trabajo. }\end{array}$ & 3.2 \\
\hline 60 & 75 & 100 & 75 & $\begin{array}{c}\text { Constante, resuelto, sin prisa, como de obrero no pagado } \\
\text { a destaje, pero bien dirigido y vigilado, parece lento, pero } \\
\text { no pierde tiempo adrede mientras lo observan }\end{array}$ & 4.8 \\
\hline 80 & 100 & 133 & $\begin{array}{c}100 \\
\text { Ritmo Tipo }\end{array}$ & $\begin{array}{c}\text { Activo, capaz, como de obrero calificado medio pagado a } \\
\text { destajo; logra con tranquilidad el nivel de calidad y } \\
\text { precisión fijado. }\end{array}$ & 6.4 \\
\hline 100 & 125 & 167 & 125 & $\begin{array}{l}\text { Muy rápido; el operario actúa con gran seguridad, } \\
\text { destreza y coordinación de movimientos muy por encima } \\
\text { del obrero calificado medio. }\end{array}$ & 8.0 \\
\hline 120 & 150 & 200 & 150 & $\begin{array}{l}\text { Excepcionalmente rápido; concentración y esfuerzo } \\
\text { intenso sin probabilidad de durar por largos períodos; } \\
\text { actuación de "virtuoso", sólo alcanzada por unos pocos } \\
\text { trabajadores sobresalientes. }\end{array}$ & 9.6 \\
\hline
\end{tabular}

Fuente: OIT (Escala Británica)

- Tiempo Normal:

Tiempo valorizado, por unidad de tiempo

- Suplementos o Tolerancia:

Tiempos asignados y permitidos al personal bajo ciertas condiciones laborales

Figura 6 Ejemplo de sistema de suplementos por descanso

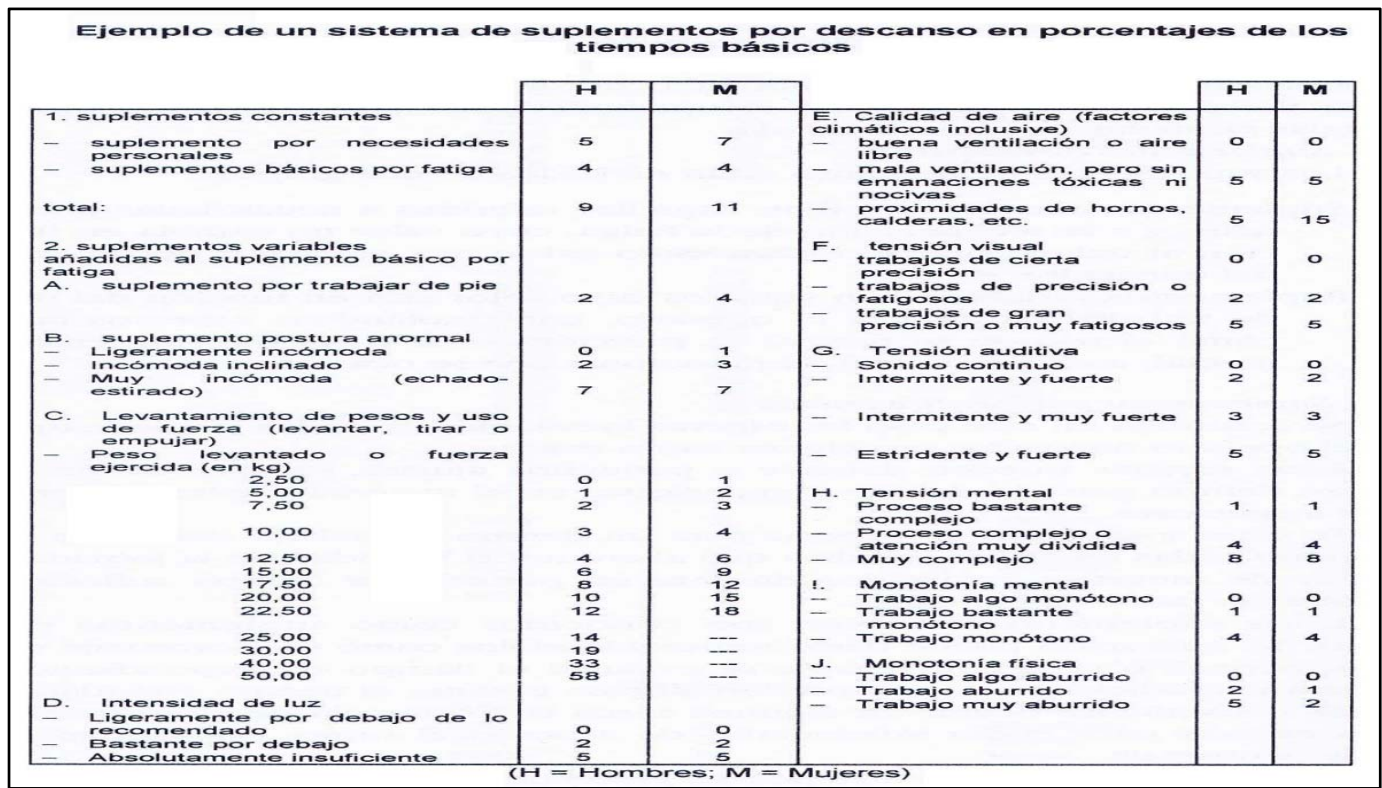

Fuente: OIT (Escala Británica) 
Tabla 1 Cálculo de suplementos por descanso en la empresa seleccionada

\begin{tabular}{|l|r|r|r|r|}
\hline \multicolumn{4}{|c|}{ ENVASADO } & \multicolumn{3}{c|}{ ACABADO } \\
\hline & HOMBRES & MUJERES & HOMBRES & MUJERES \\
\hline Suplementos básicos por fatiga & 4 & 4 & 4 & 4 \\
\hline Suplementos por trabajar de pie & 2 & 0 & 2 & 0 \\
\hline Suplemento postura anormal & 0 & 3 & 0 & 3 \\
\hline Suplemento de levantamiento de pesa & 2 & 0 & 2 & 0 \\
\hline Calidad de aire (mala Ventilación) & 5 & 5 & 5 & 5 \\
\hline Trabajo de precisión & 0 & 2 & 0 & 2 \\
\hline Trabajo monótono & 5 & 2 & 5 & 2 \\
\hline \multicolumn{1}{|c|}{} & 18 & 16 & 18 & 16 \\
\hline
\end{tabular}

Fuente: Elaboración propia

- Ts x unid: Tiempo estándar por unidad.

- UPH operación: Cantidad realizada, en una hora, por cada operación

- Nro. personal: Personal disponible, para un adecuado balanceo.

- Tiempos Frecuentes: Son tiempos adicionales, que se les agrega a la máquina de envasado, en busca de obtener UPH reales.

Tabla 2 Calculo de tiempos frecuentes por actividades

\begin{tabular}{|c|c|c|c|c|c|c|c|c|c|c|c|c|c|}
\hline \multirow{3}{*}{$\begin{array}{c}\text { Actividades } \\
\text { Calibrar } \\
\text { peso } \\
\end{array}$} & \multicolumn{10}{|c|}{ Tiempos Frecuentes } & \multicolumn{3}{|c|}{ Promedios } \\
\hline & & & & & & & & & & & Seg./Lote & Seg./Orden & Min.Orden \\
\hline & 191 & 257 & 120 & 199 & 200 & 150 & 210 & 240 & 181 & 160 & 191 & 191 & 3.2 \\
\hline \multirow[t]{3}{*}{ Calibrar lote } & 156 & 155 & 186 & 168 & 300 & 272 & 273 & 253 & 240 & 240 & \multirow[t]{3}{*}{211} & \multirow[t]{3}{*}{1900} & \multirow[t]{3}{*}{31.7} \\
\hline & 258 & 158 & 216 & 157 & 282 & 175 & 207 & 215 & 220 & 244 & & & \\
\hline & 259 & 356 & 170 & 162 & 113 & 90 & 135 & 244 & 255 & 174 & & & \\
\hline $\begin{array}{c}\text { Calibrar } \\
\text { rollo } \\
\end{array}$ & 69 & 61 & 54 & 49 & 59 & 86 & 62 & 50 & 59 & 71 & 62.5 & 558 & 9.3 \\
\hline $\begin{array}{c}\text { Cambio } \\
\text { bidón } \\
\end{array}$ & 177 & 215 & 234 & 360 & 163 & 304 & 59 & 93 & 78 & 92 & 177.5 & 1598 & 26.6 \\
\hline $\begin{array}{c}\text { Ajuste en la } \\
\text { calibración }\end{array}$ & 37 & 33 & 37 & 33 & 83 & 66 & 45 & 68 & 99 & 65 & 56.6 & 1019 & 17 \\
\hline \multicolumn{11}{|c|}{ Total } & 698 & 5265 & 87.8 \\
\hline & & & & & & & & & & & $\begin{array}{c}\text { Promedio } \\
\text { Lote } \\
\end{array}$ & $\begin{array}{c}\text { Promedio } \\
\text { Orden } \\
\end{array}$ & Suplemento \\
\hline
\end{tabular}




\begin{tabular}{|c|c|c|c|c|c|c|c|c|c|c|c|c|c|}
\hline $\begin{array}{c}\text { Tiempo de } \\
\text { demora de } \\
\text { un lote }\end{array}$ & 36 & 26 & 27 & 26 & 27 & 35 & 31 & 35 & 24 & 24 & 29.7 & 267 & $33 \%$ \\
\hline
\end{tabular}

Fuente: Elaboración propia

- Tiempo Frecuente por producto

Tabla 3 Tiempos frecuentes por familia de producto

\begin{tabular}{|c|c|c|c|c|}
\hline \multicolumn{5}{|c|}{$\%$ DE TIEMPO FRECUENTE } \\
\hline $\begin{array}{c}\text { Familia Shampoo y } \\
\text { Acondicionador }\end{array}$ & Familia cremas & $\begin{array}{c}\text { Familia Colonias } \\
\text { y Lociones }\end{array}$ & $\begin{array}{c}\text { Familia } \\
\text { Desodorantes }\end{array}$ & Familia Talcos \\
\hline $27 \%$ & $27 \%$ & $17 \%$ & $0 \%$ & $17 \%$ \\
\hline
\end{tabular}

Fuente: Elaboración propia

\subsubsection{Casos de éxitos}

\subsubsection{Caso de estudio 1: Estudio de tiempos y movimientos de producción en planta, para mejorar el proceso de fabricación de Escudos en Kaia Bordados, por Diego Alejandro Cajamarca Guerra, Universidad Militar Nueva Granada. 2015. España.}

Según el autor de esta tesis, el crecimiento empresarial que necesita la empresa Kaia Bordados estará basada en mejorar la productividad y eficiencia de la organización a través de estudios de tiempos de producción en planta para así poder ser capaces de mejorar los procesos, tiempos de producción, así como el bienestar del factor humano. Con el estudio de tiempo y movimientos realizados el autor espera economizar el esfuerzo humano para reducir fatiga, crear mejores condiciones de trabajo y ser capaz de ahorrar el uso de materiales, máquinas y recursos humanos. Esta tesis se relaciona con este artículo ya que se basa, de manera práctica, al estudio de las condiciones de trabajo que posee una empresa de manufactura, en este caso de bordados, en la cual la base principal es el estudio de métodos y tiempos, la cual sirve de apoyo para mejorar el rendimiento que posee un operador y poder este ser más productivo. 


\subsubsection{Caso de estudio 2: Medición de tiempos y Métodos (MTM) por Mac por Marc Couto Carrasco y Paul Hoyos Suarez, IES Escola del Treball, Barcelona, 2014.}

Los autores de este artículo describen como el MTM es de gran importancia para las industrias ya que analiza toda operación manual o método, así como los movimientos requeridos para realizar un trabajo y así poder asignar a cada movimiento un tiempo específico expresado en TMU. Expresa también la dificultad que se tiene al realizar el estudio para identificar claramente los movimientos básicos realizados por los operadores. El artículo se relaciona con el que desarrollaremos en que describe bien los fundamentos básicos del MTM, así como las unidades de tiempo utilizadas. Se diferencia en que describe, de manera resumida lo que es el tiempo estándar por visualización, así como la simulación que se podría realizar para visualizar el rendimiento del entorno estudiado.

\subsubsection{Caso de estudio 3: Estudio de Tiempos y movimientos en el proceso de producción de una industria manufacturera de ropa. Por Oscar A. Castillo Rivas, Universidad de San Carlos, Guatemala, 2015}

El autor de esta tesis describe detalladamente el estudio de tiempo y movimiento, así como sus características principales y su aplicabilidad a las industrias hoy en día. El estudio al ser enfocado en una empresa textil, se describen todas sus funciones, actividades, maquinarias a utilizar, etc., para así tener un mejor panorama de la manera en cómo se realizará el estudio y poder obtener los mejores resultados posibles con las técnicas del estudio de tiempo y movimiento. Se describe detalladamente aspectos también de lo que es ergonomía y prevención de riesgos, así como de calidad por igual. Tras el estudio realizado algunas de las recomendaciones a realizar por parte de la empresa fueron: reubicar las líneas de producción, eliminar la bodega de máquinas, y fomentar hábitos de orden y limpieza por parte del personal. Se relaciona esta tesis con el artículo presentado en que ambos muestran la importancia del estudio de tiempo y movimiento y de lo que este puede representar para las empresas. Por igual ambos muestran los movimientos denominados Therblig, que es una de las bases fundamentales para esta metodología. 


\subsubsection{Caso de estudio 4: Determinación de tiempos estándares para la industria de la confección a través del sistema de tiempos predeterminados GSD (General Sewing Data) datos generales de costura, por Christian Jonathan Rivera Rodríguez, Universidad de San Carlos de Guatemala, 2016.}

El trabajo de investigación referida explica la importancia que es medir el tiempo de trabajo, así como la manera en como una persona realiza una actividad en su área de trabajo y como este puede ser mejorado para ser más eficiente en lo que hace, al analizar los métodos que utiliza. El autor describe los códigos de GSD y de cómo este sistema puede ser utilizado en operaciones de corte, costura, planchado, inspección y empaque, todo con el objetivo de mejoras los procesos de trabajos. El objetivo deseado por GSD era de conseguir un sistema simple, fácil de entender, pero que equilibrara los requisitos y la productividad del mismo. Tiene relación con el artículo a describir ya que es una forma de guía para las personas y las empresas de cómo utilizar el sistema de tiempos predeterminados y los datos generales de costuras, principalmente a las empresas manufactureras.

\subsubsection{Caso de estudio 5: Implementación del Kaizen para mejorar la productividad y desperdicios en una empresa en México: Un estudio exploratorio-cualitativo de una aproximación gerencial japonesa en el contexto latinoamericano.}

Manuel Francisco Suarez y Jose Ángel Dávila(2013), implementaron el pensamiento kayzen en una empresa de alimentos mexicano dicho estudio se ha centrado en la búsqueda por reducir los costos operativos logrando mejorar en un $12 \%$ la productividad en una primera fase y un $18 \%$ en una segunda fase, dejando en pie al proceso de mejora en el tiempo, principalmente se trabajó armado los círculos de calidad, el cual se capacito a todo el personal tanto estratégicos como operativos, se midió los indicadores de producción antes de la aplicación y después de la aplicación.

En el artículo se muestra la investigación de un corte cualitativo y que ha cobrado una gran importancia en la gestión operacional y estratégica de las organizaciones de este nuevo siglo, referente a las aplicaciones de esta herramienta de mejora continua. 


\subsubsection{Caso de estudio 6: En Empresa Automotriz (India) Aplicación de Estudio de método y Tiempos}

Los Señores A. Ramachandran y el Dr. R. Kesavan realizaron un trabajo de investigación en una empresa de ensamblaje automotriz en la India con la finalidad de mejorar el sistema productivo que tenían hasta entonces. La técnica que se aplico fue el Estudio de tiempo y estudio de Método. La metodología en referencia plantea el análisis de actividad delos tiempos para proponer estándares de tiempo en las líneas de producción.

\subsection{Marco Normativo}

Salvador, A y Chisvert, A en el capítulo de regulación cosmética manifiestan que el sector cosmético a nivel internacional está enmarcado dentro de las normas de calidad en el caso de estados unidos supervisadas y reguladas por la FDA a través de la norma AST-235 el cual regula toda la manufactura de los productos cosméticos amparado por la Good Manufacturing Practica, el cual son normas que se basan en la evitar la No contaminación y No Confusión.

En el ámbito Europeo, el sector se regula a través de COLIPA que es la unidad reguladora europea, el cual regula todos los insumos y sustancias químicas permitidas para la fabricación de los productos cosméticos, existen algunos filtros y persevantes prohibidos que están permitidos en el Perú pero no en Europa.

En el ámbito Sudamericano el sector está regulado por la Decisión 516 que es un conjunto de normas homologadas en los países del pacto andino: Perú, Bolivia, Ecuador, Colombia y Venezuela, 123 normas que actúan sobre el desempeño y obligaciones que deben tener todas las empresas de este rubro, aquí por ejemplo se regula que el porcentaje máximo de merma permitida es del 5\%.

En el ámbito peruano el sector está regulado por la Ley 29459 que regula sobre los productos farmacéuticos, dispositivos médicos y productos sanitarios, los cosméticos pertenecen al grupo de los productos sanitarios, la DIGEMID es el órgano regulador, de control y de fiscalización, los procedimientos normativos están basados en la norma de Buenas Prácticas de Manufactura y lo referente a los requisitos de calidad están referidos 
en la DS-016- 2011 y las características y requerimientos de los establecimientos como los laboratorios están regulados en la DS-014-2011

Los aspectos regulativos y normativos se expresan de forma consecutivas en el siguiente marco:

- Ley No 29459, Ley de los Productos Farmacéuticos, Dispositivos Médicos y Productos Sanitarios, del 26/11/09. Artículo $8^{\circ}$ y $13^{\circ}$.

- Decisión 516 que aprueba la Armonización de Legislaciones en materia de Productos Cosméticos, de 08/03/02. Artículo $7^{\circ}$ y $8^{\circ}$.

- Resolución 797 que aprueba el Reglamento de la decisión 516 sobre control y vigilancia sanitaria de productos cosméticos, de 03/02/04.

- Resolución 1333, que aprueba Adiciones a la Resolución 797- Criterios de homologación de la codificación en materia de cosméticos. Formatos para la Notificación Sanitaria Obligatoria de productos cosméticos, su renovación, reconocimiento y cambios; del 02/06/10. Artículo $23^{\circ}$.

- Decreto Supremo $\mathrm{N}^{\circ}$ 010-2010-MINCETUR, Reglamento Operativo del Componente de Mercancías Restringidas de la VUCE, del 09/07/2010, Artículo $2^{\circ}$, $4^{\circ}$ y $5^{\circ}$.

- Ley $N^{\circ}$ 27444, Ley del Procedimiento Administrativo General del 11/04/01. Artículo $31^{\circ}$ y $44^{\circ}$. 


\section{Capítulo II: Diagnostico}

En el capítulo anterior tratamos el estado de arte y el marco teórico como elementos principales para poder tratar el capítulo 2, y nos servirá de guía para plantear alternativas de solución frente a la problemática que vamos a desarrollar, aplicaremos metodologías que sirvieron para resolver problemas similares ocurridos en otros contextos y en otros sectores.

Previamente empezaremos revisando el sector, y presentaremos el diagnóstico de la situación actual de la empresa de cosmético, el planteamiento del problema con cada una de sus variables X y el impacto económico que generan dichas variables y estás serán cuantificadas y fundamentadas.

Utilizaremos herramientas de diagnóstico como el VSM para representar los problemas, el Diagrama de Ishikawa para determinar las causas, el diagrama de Pareto para determinar causas reales y causas triviales y la priorización de la causa raíz.

Se presentan herramientas de la ingeniería industrial para solución de los problemas en la matriz de consistencia que relaciona, problema-causa-solución.

Finalmente terminaremos el capítulo 2, postulando la hipótesis general y especifica del trabajo de investigación.

\subsection{Sector}

El sector donde se desarrollará el presente trabajo de investigación pertenece al sector cosmético, y según la cámara de comercio de lima entre los años 2018 y 2019 crecerá en un $6 \%$ y $8 \%$ y un mercado de 8422.477 millones de soles, es cerrado con pocos competidores y regulado por la autoridad sanitaria DIGEMID. Según Euro monitor de la Cámara de comercio de Lima, el mercado internacional se muestra en crecimiento en los últimos 17 años llegando a 160,000 millones de dólares. 


\subsection{Empresa}

La empresa en estudio luego de más de 20 años de experiencia en la región, inicia sus actividades comerciales en Perú en Junio del 2013, lanzando sus primeros productos dermocosméticos.

La empresa está orientada, al igual que en los países de Ecuador y Chile, a brindar al médico dermatólogo excelentes alternativas terapéuticas en el tratamiento a sus pacientes y productos para la belleza y limpieza.

\section{- Misión}

Generar vínculos de proximidad con nuestros clientes, ofreciéndoles productos dermatológicos de alta calidad, involucrando en el alto desempeño de la empresa el desarrollo profesional y personal de nuestros colaboradores.

\section{- Visión}

Ser el laboratorio dermatológico referente para médicos, consumidores y empresas a nivel regional.

\subsubsection{Organigrama}

Se presenta el organigrama donde se realizará el trabajo de investigación: Area de producción del laboratorio cosmético.

Figura 7 Organigrama del área de producción del laboratorio cosmético 


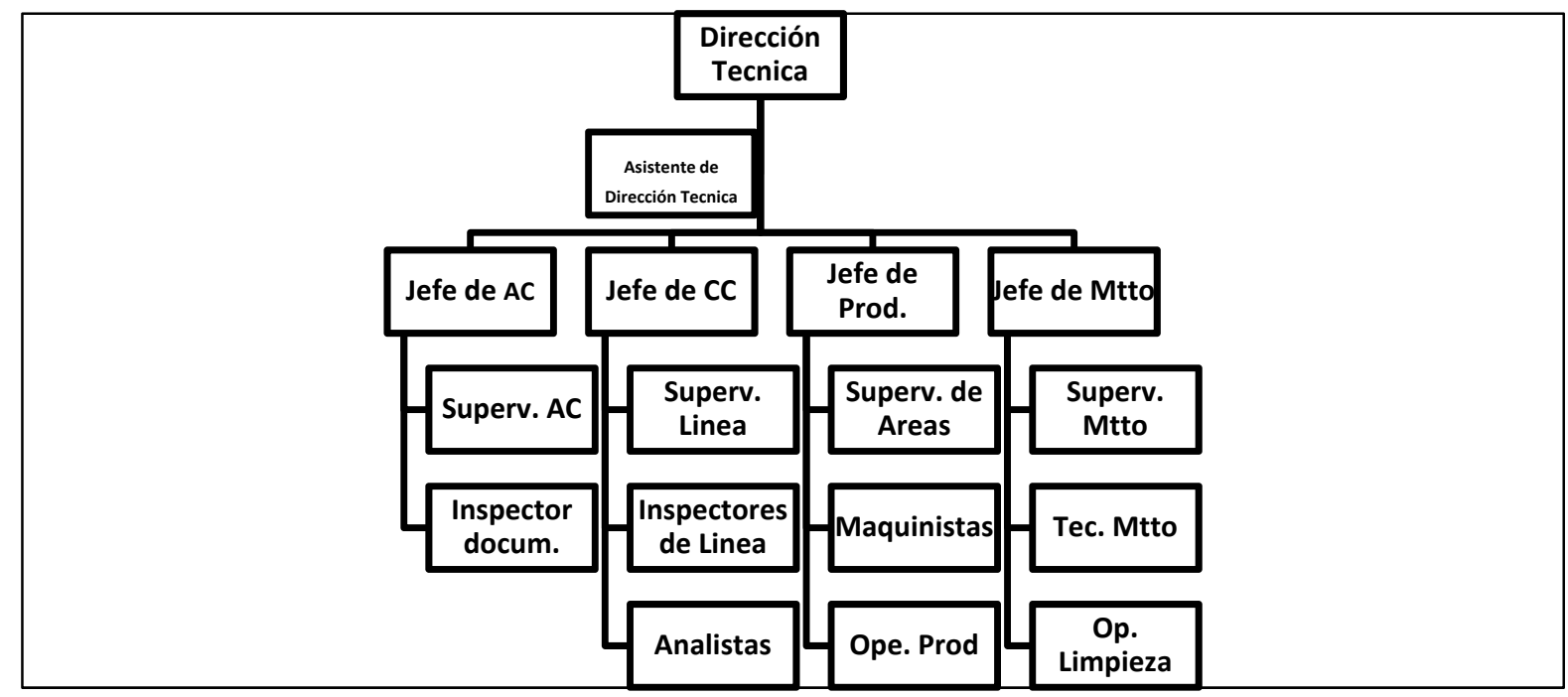

Fuente: Elaboración propia.

En la Fig. 7, se observa el organigrama específico del área de producción, el cual la máxima autoridad es la Dirección Técnica, que a su vez le reporta 4 jefaturas de planta.

\subsubsection{Productos}

Los productos de la empresa Cosmética tiene sub líneas que son: limpieza e hidratación, Solares, cicatrización, acné y pediatría que forman parte de las líneas de Shampoo, cremaslociones y colonias y además la línea de inyectables.

\subsubsection{Clientes}

La empresa en referencia vende sus productos a través de la promoción médica y venta retail, para lo cual los visitadores médicos promocionan todos los productos a los médicos dermatólogos, pediatrías y cirujanos plásticos y la venta directa se hace a través de las farmacias, boticas, dermashop, dermocentros especializados y Clínicas privadas,

\subsubsection{Ventas}

Las ventas mayoritariamente en unidades los tiene la cadena de boticas INKAFARMA, seguida por la cadena MI FARMA, pero en ingresos por ventas el mayor porcentaje tiene MIFARMA, esto debido a que la comisión por venta mayor proporcionado es del $60 \%$ para la cadena Inkafarma, en el siguiente cuadro se muestra la representación por ingresos de 
ventas por cada cliente, los Retail y las cadenas menores tienen ventas por comisión que fluctúan entre 15-20\%. Las ventas de los últimos años se muestran en la siguiente tabla.

\subsubsection{Participación clientes por ventas}

Las ventas netas en el 2017 ascendieron a S/ 8'123,234 de los cuales la cadena Mifarma representa un mayor ingreso con un $41 \%$ de valor relativo registrando S/. 3'330,525; la cadena Inkafarma es el segundo mayor ingreso con un valor relativo de $36 \%$ que representa S/. 2'924,364; la cadena de Farmacia Universal en un $3^{\circ}$ lugar con valor nominal S/. 1'299,717; con un porcentaje relativo de 16\%, el establecimiento de especialidad Quimder aporto un total de ingresos netos por ventas de $\mathrm{S} / .406,161$ que represento un valor relativo de $6 \%$ y otros contribuyeron con un ingreso de S/. 162,464 que representa el 2\% entre las que están las clínicas especializadas y los dermashop.

\subsubsection{Competidores}

Entre los principales competidores están las empresas de origen trasnacional dado que es un mercado con hábitos de consumos de los sectores $\mathrm{A}, \mathrm{B}$ entre los que destacan son Bioderma, Isdin, La Roche Posay, Unique y Ebel.

\subsubsection{Proveedores}

Los principales proveedores del laboratorio cosmético son aquellos que proveen de materias primas, material de envase y material de empaque, así mismo proveedores que se encargan de hacer los diferentes merchandise para el área comercial.

\subsubsection{Participación del mercado}

El mercado cosmético en el que participa el laboratorio cosmético es cerrado y restringido, regulado por la DIGEMID con valor de S/. 156'161,723; el porcentaje de participación hasta el año 2017 es todavía relativamente bajo, registrando un 2\% frente al mayor competidor que tiene un $18 \%$ del mercado, y entre ellos es una repartición homogénea.

\subsection{Cadena de valor}

Figura 8 Cadena de Valor del Laboratorio Cosmético 


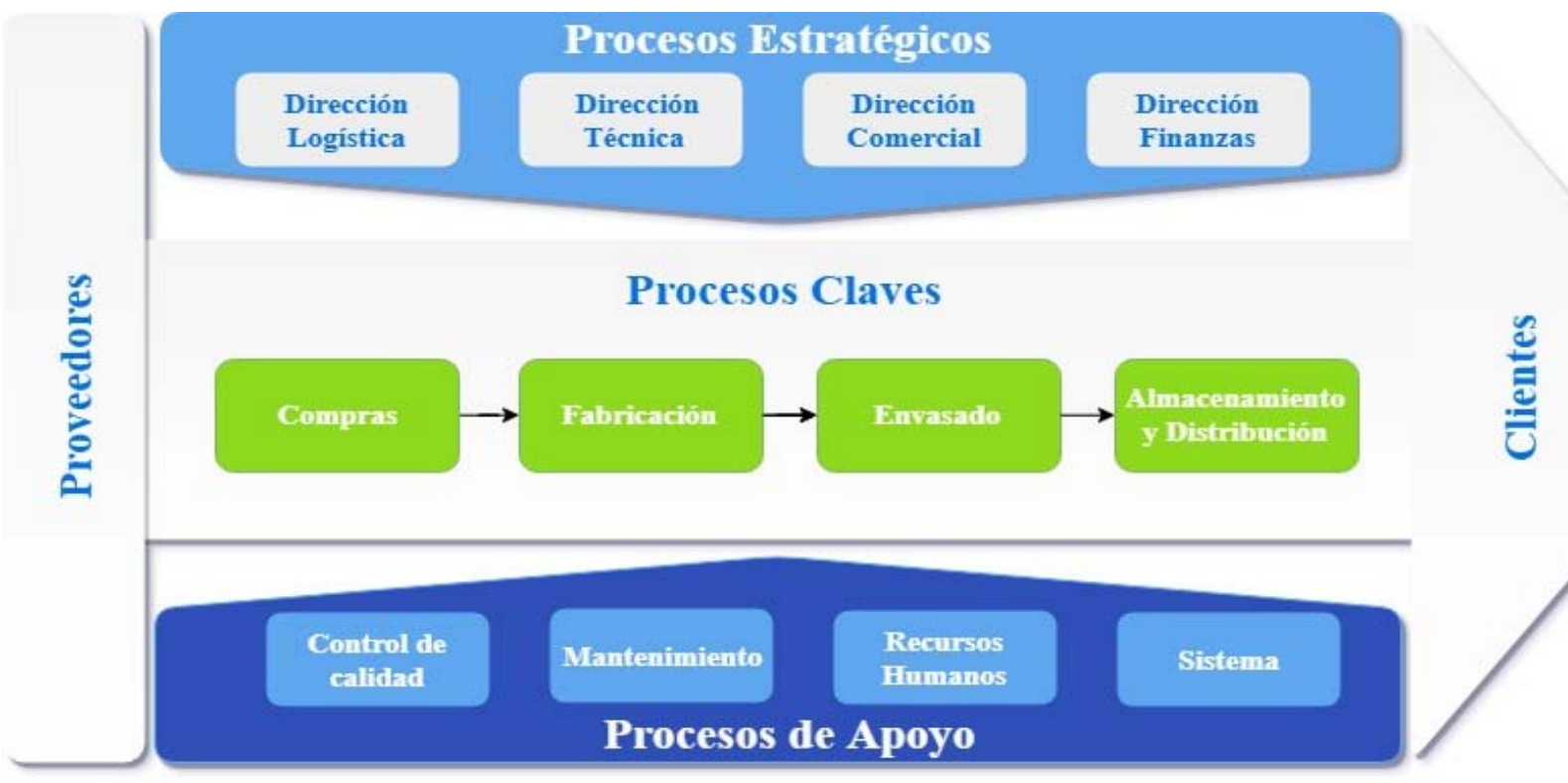

Fuente: Elaboración propia

En la Fig. 8 se presenta la cadena de valor de los procesos claves en el laboratorio cosmético, se inicia en el proceso de compras de materias primas, materiales de envases y materiales de empaque de diferentes proveedores, éstos son fabricantes nacionales.

Las materias primas se transforman en el granel, el cual pasa a la operación de envasado (dosificado, tapado, precintado o sellado, etiquetado, impresión, estuchado y embalado), el producto terminado pasa a los almacenes para ser distribuido a los clientes. Estos procesos claves están bajo la dirección de los procesos estratégicos (D. Técnica, D. Comercial, D. Finanzas y D. Logística) y soportados por los procesos de apoyo (RRHH, Mantenimiento, Control de Calidad y Sistemas)

\subsection{El Proceso}

Los procesos involucrados en el presente estudio son:

Procesos de Fabricación: Es el conjunto de operaciones y actividades que transformaran las materias primas en granel haciendo uso de operaciones unitarias como, mezclar, emulsionar, homogenizar y trasvasar. Se divide los sub-procesos de la Fig. 9.

Figura 9 Sub-procesos de Fabricación 
Operación de

Arranque(actividades de limpieza)

\section{Operación de trasvase}

Fuente: Elaboración propia

Proceso de Envasado: Es el conjunto de operaciones y actividades donde el granel es puesto en envases, cerrado y acondicionado. Los subprocesos se muestran en la Fig. 10

Figura 10 Sub-procesos de Envasado

Operacion de

Arranque(Actividades de limpieza)

\section{Operación de Dosificado}

Fuente: Elaboración propia

En las operaciones de dosificado se dan las actividades de dosificado propiamente dicho y el tapado. Las operaciones de acondicionado corresponden al sello por inducción, el etiquetado, el lotizado, el estuchado y el embalado.

\subsubsection{Diagrama SIPOC}

Se presenta los siguiente diagramas (Fig.11 y Fig. 12) en cual se expresa la secuencia que sigue el material desde el proveedor hasta la llegada a los clientes pasando por todos los procesos que agregan valor (Procesos de producción: Fabricación y envasado)

Figura 11 Diagrama SIPOC del proceso de fabricación

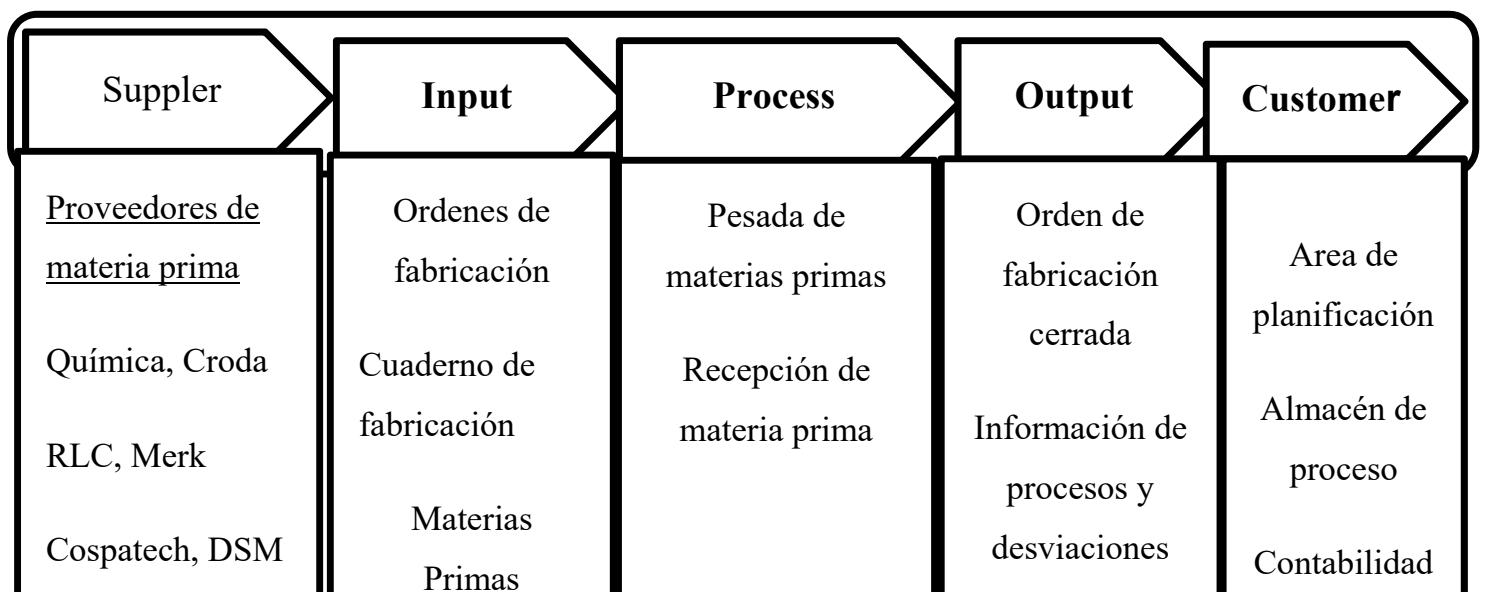


Fuente: Elaboración propia.

Figura 12 Diagrama SIPOC del proceso de Envasado

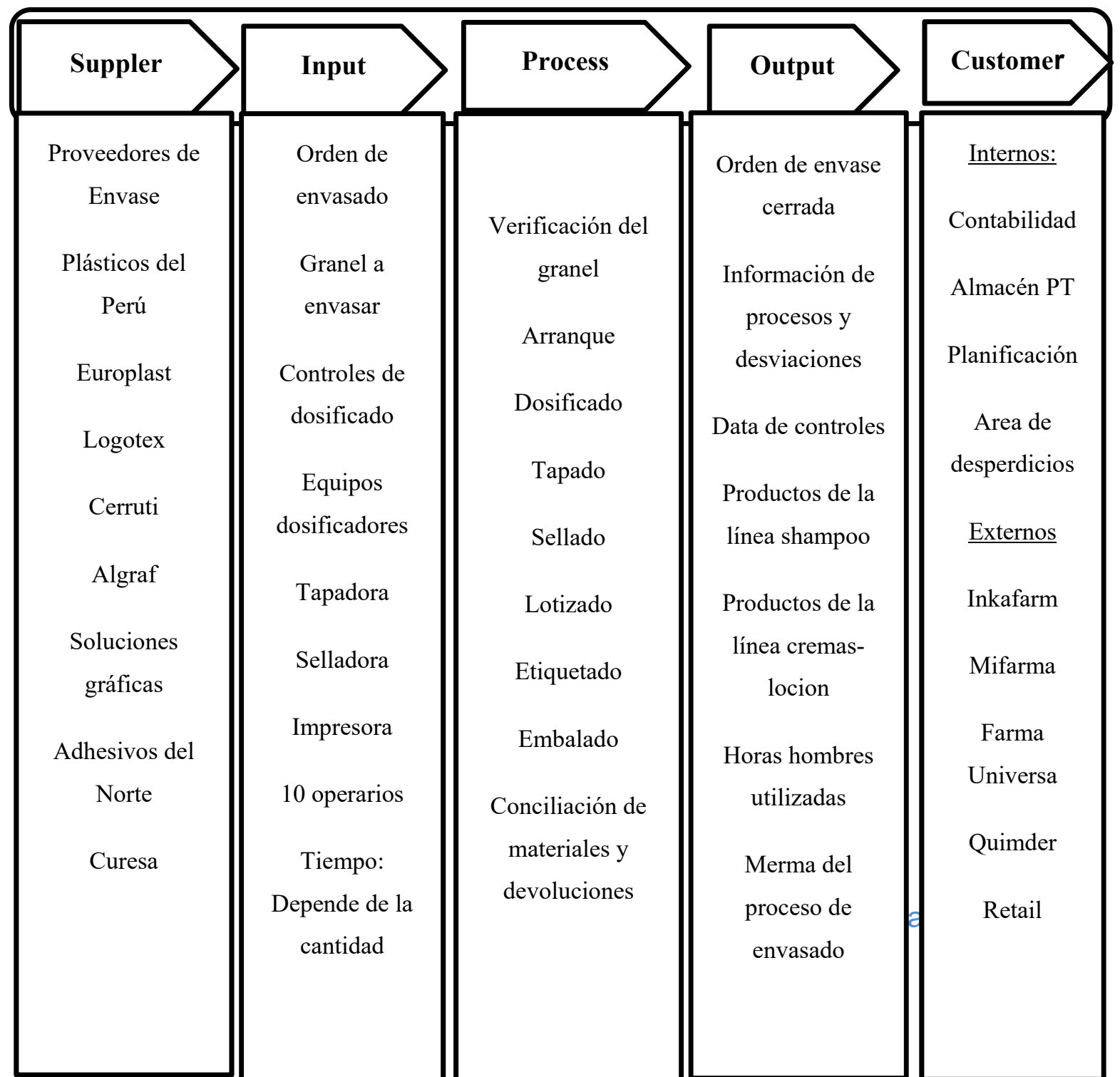


Fuente: Elaboración propia.

\subsubsection{Diagrama de Operaciones (DOP)}

Se presenta los siguientes diagramas (Fig. 13 y Fig. 14) para delimitar las operaciones en las cuales se presentará el objeto de estudio, en éste se distingue claramente dos operaciones bien definidas: Fabricación (hasta la elaboración del granel) y Envasado (hasta el embalado)

Figura 13 DOP del proceso de fabricación

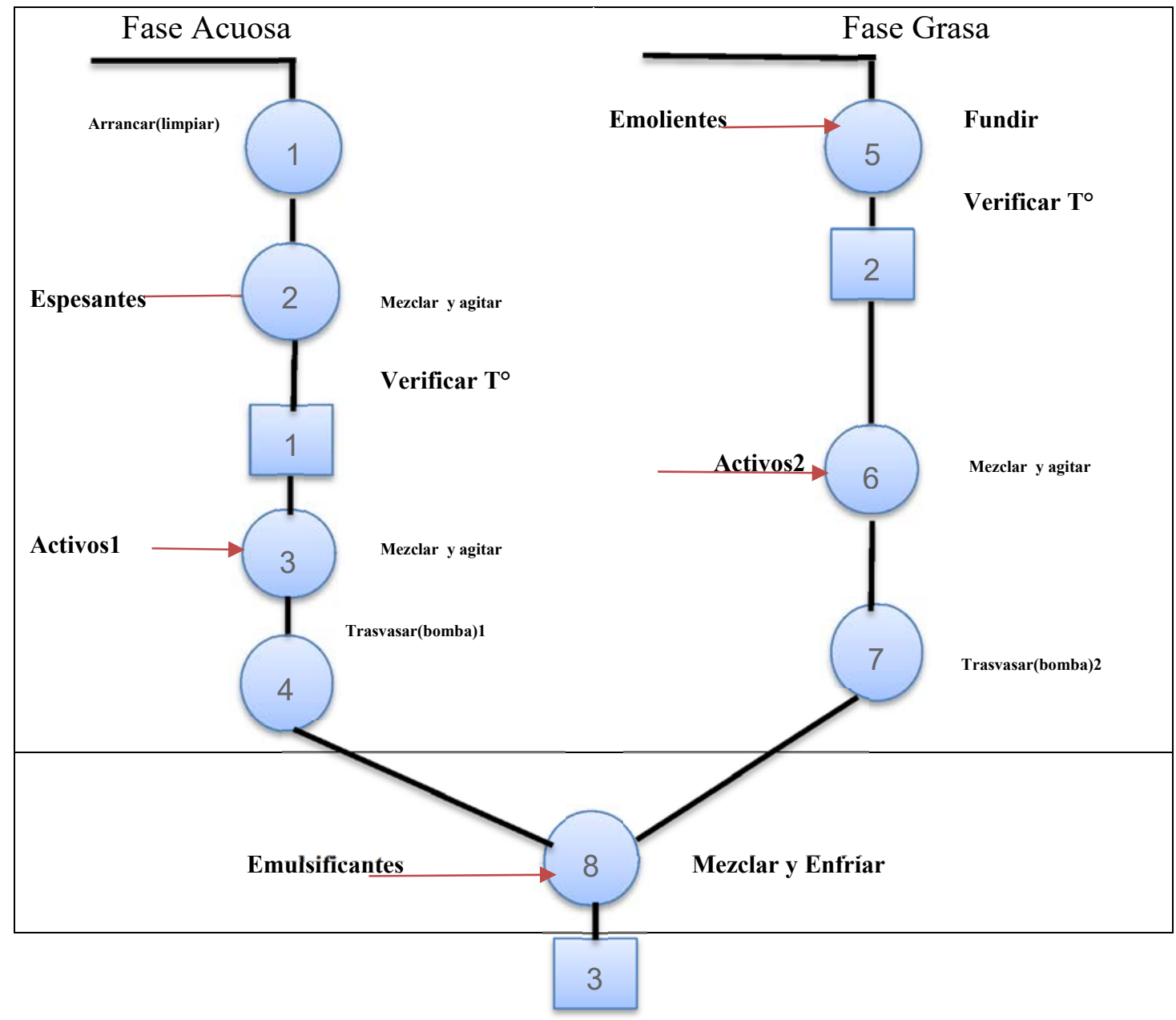




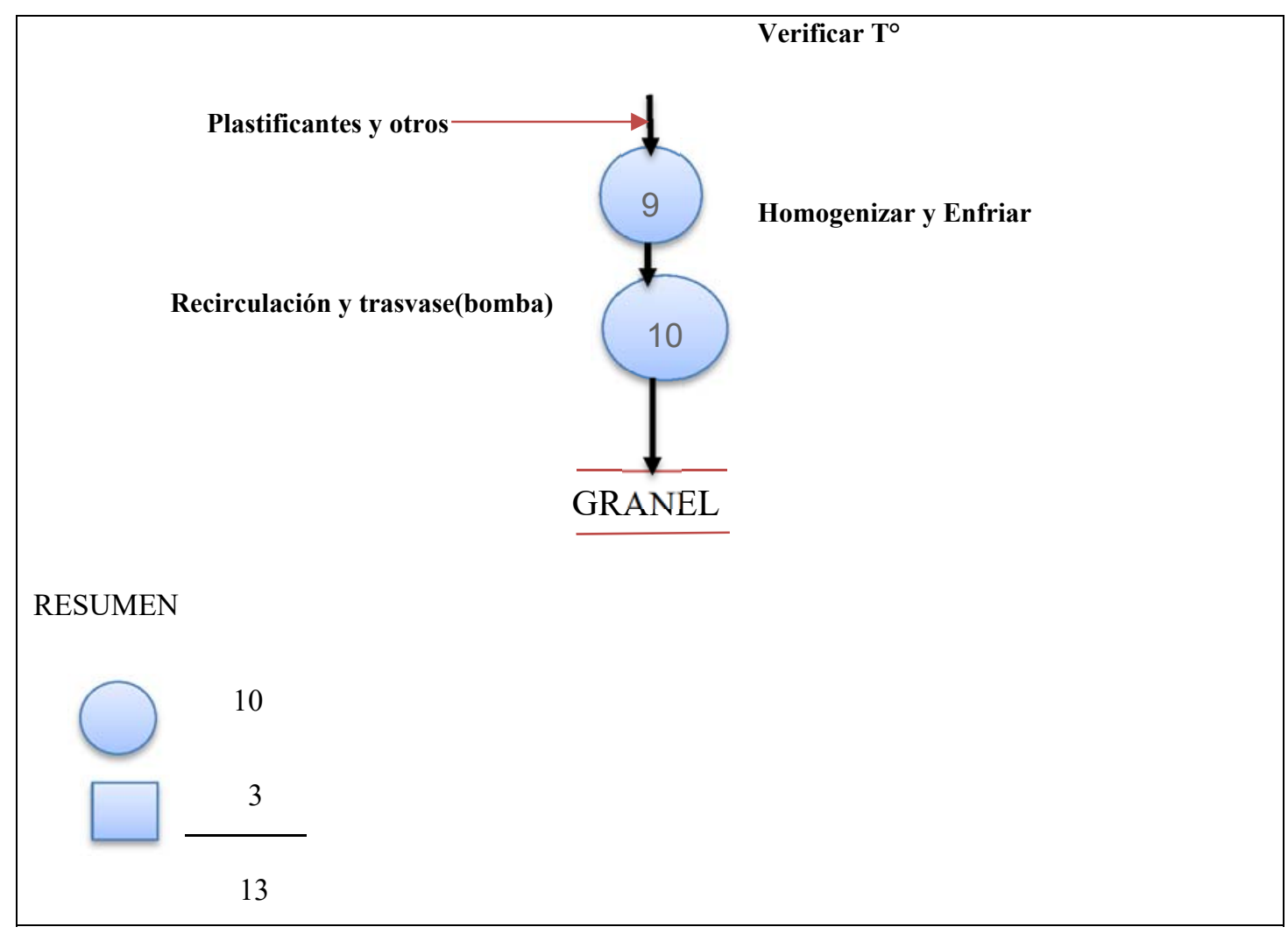

Fuente: Elaboración propia

Figura 14 Diagrama DOP del proceso de producción de la línea de Envasado

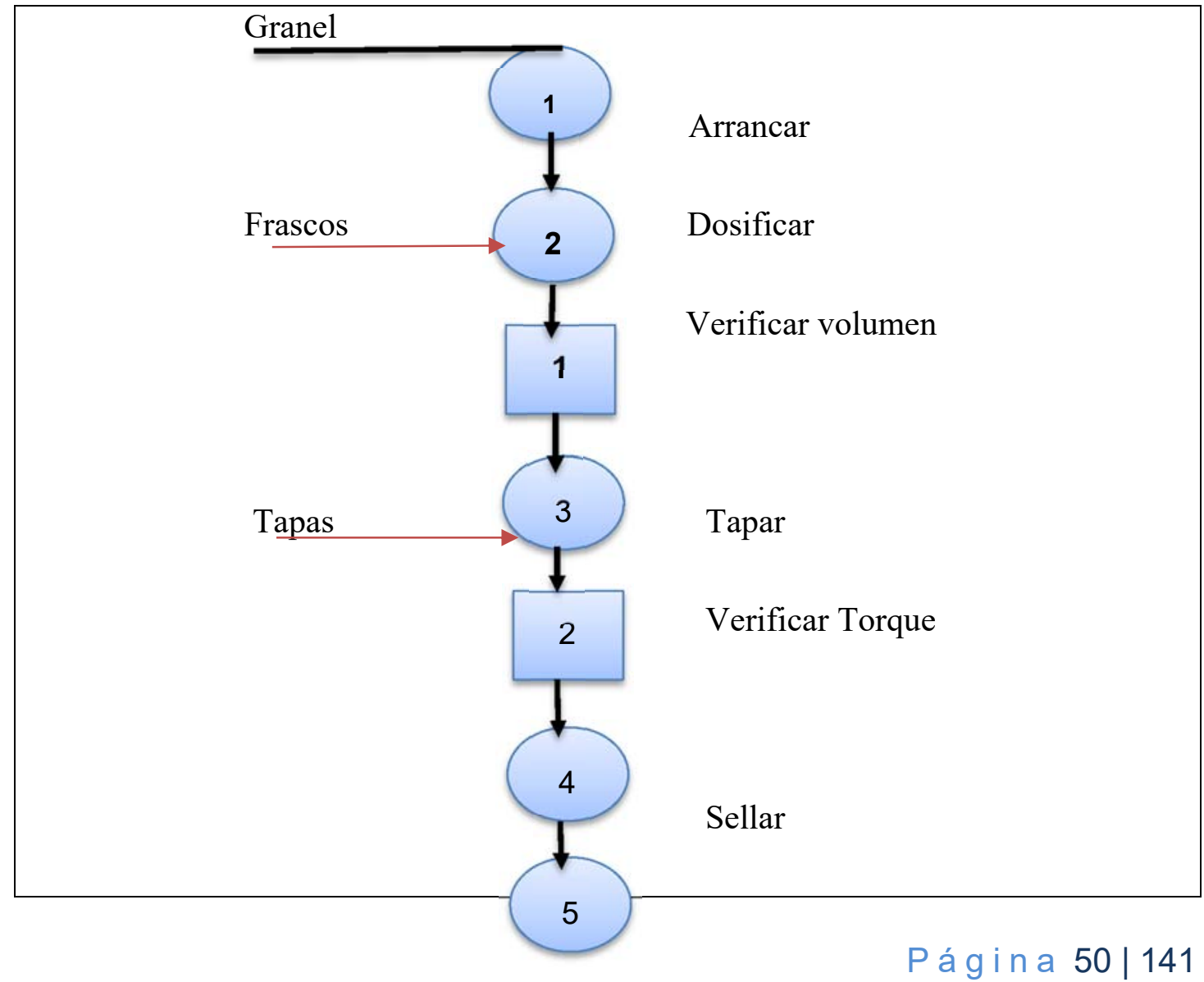




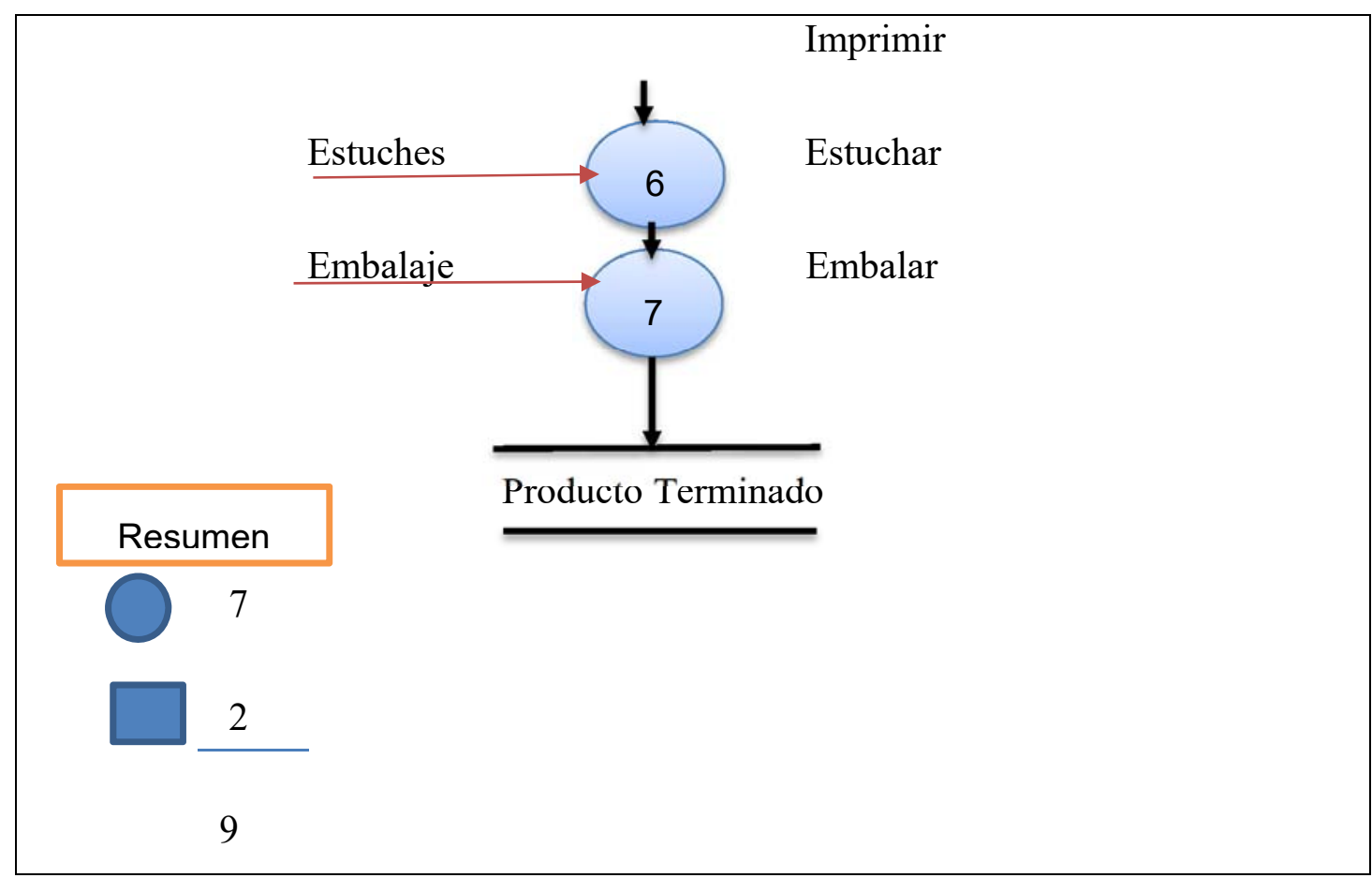

Fuente: Elaboración Propia 


\subsubsection{Diagramas de flujo}

- Se detallas las actividades del proceso de fabricación

Figura 15 Diagrama de flujo del proceso de fabricación actual

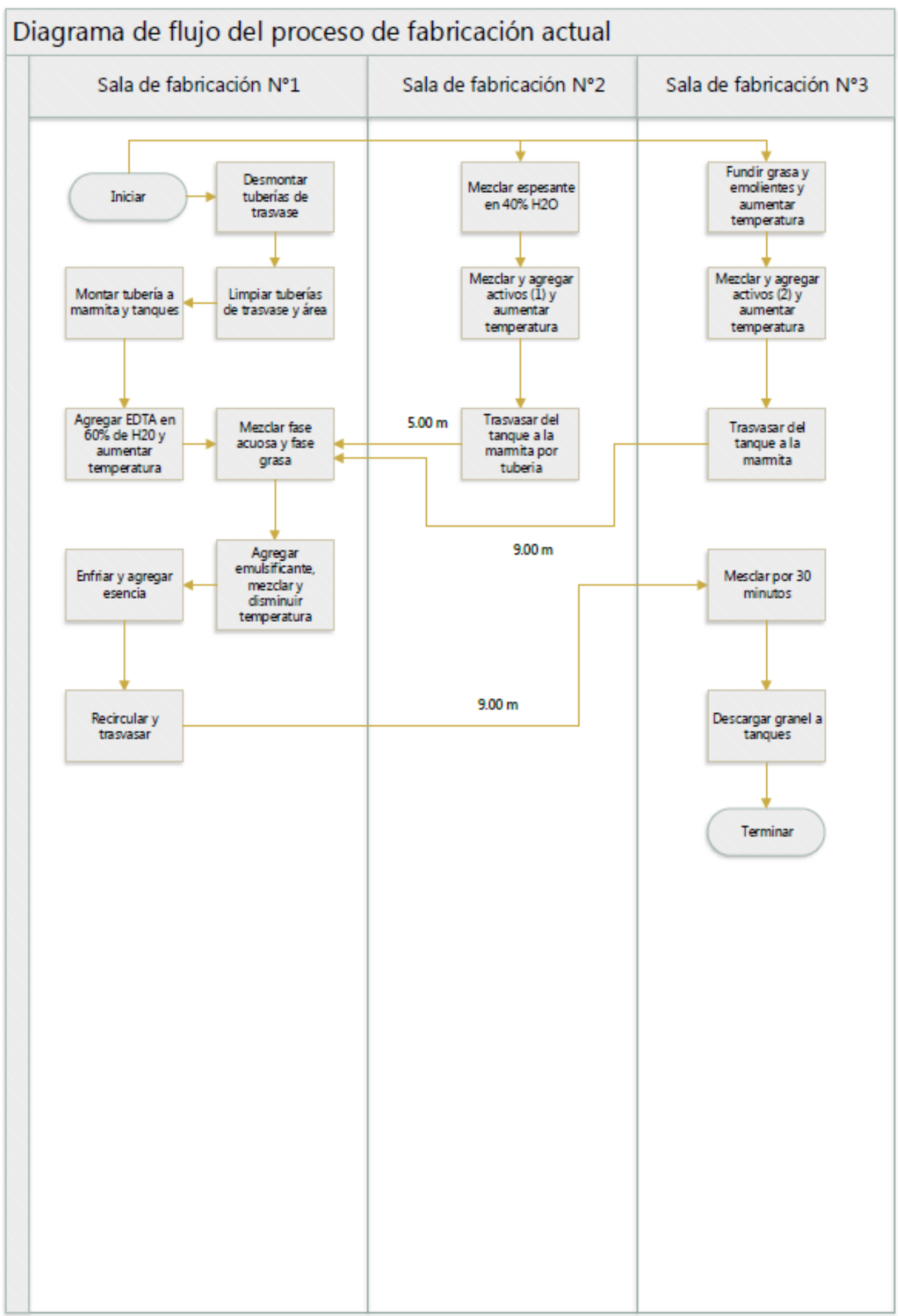

Fuente: Elaboración propia 
- A continuación se detallan las actividades del proceso de envasado

Figura 16 Diagrama de flujo del proceso de envasado actual

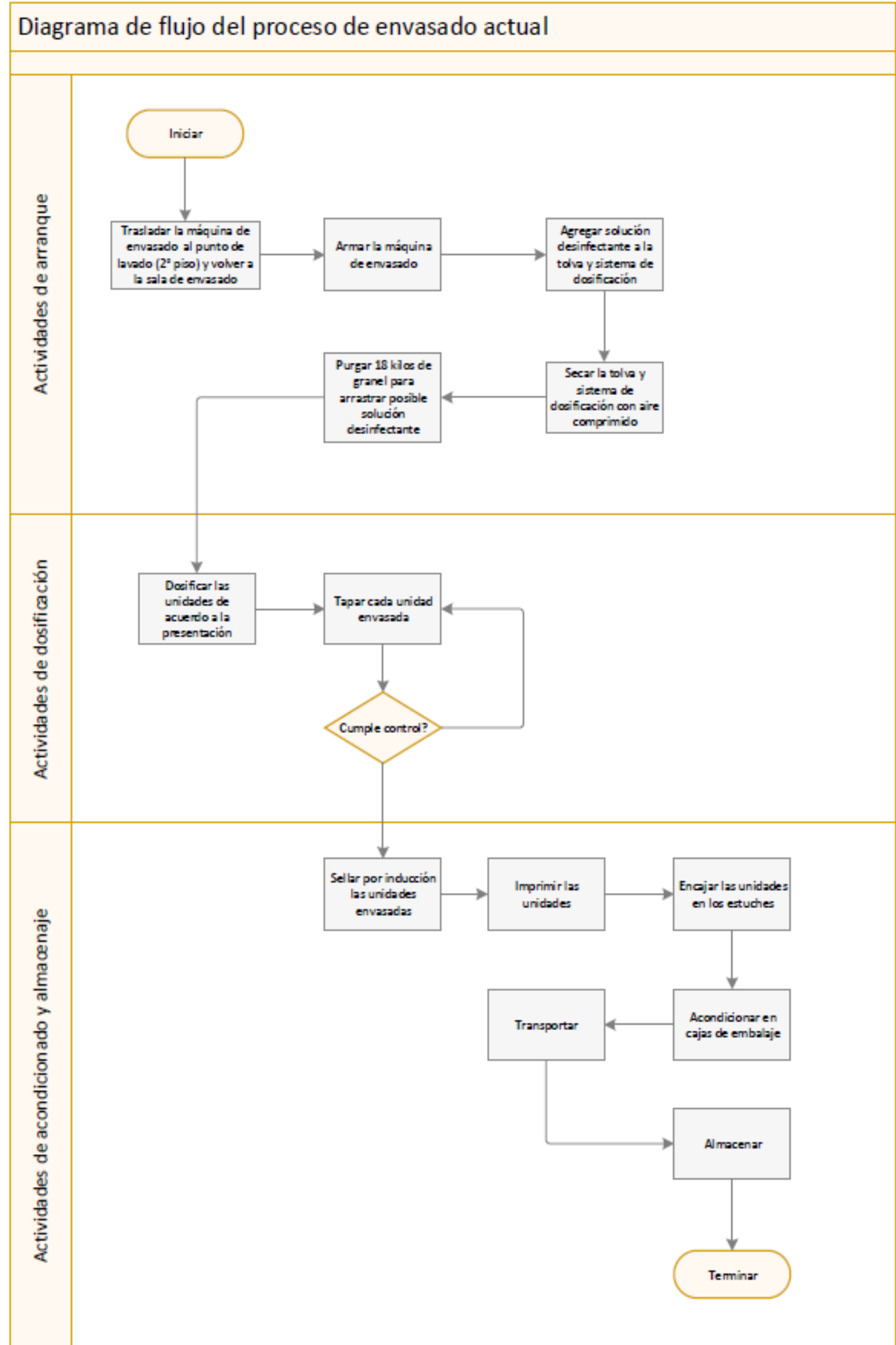

Fuente: Elaboración propia 


\subsection{Diagnóstico de la situación actual}

Actualmente la fabricación como se vio en el diagrama de flujo, se realiza en tres salas de fabricación $(1,2$ y 3 ) con lo cual hay movimiento de material y del operario que debe ser observada, el personal, dentro del proceso de fabricación y envasado hace un desplazamiento para la limpiezas desde el primer piso hasta el segundo piso, con lo cual se generan tiempos improductivos, al realizar las actividades de trasvase se observa gran pérdida de granel que la bomba ya no puede retirarla. En el proceso de envase la actividad de purga genera perdida de granel que debe ser evaluada.

Existen estándares teóricos de UPH (unidades por hora) en el envasado que no se cumplen en la práctica (ver anexo 2), se programa entregar 1000 unidades en un tiempo determinado de dos horas, en la práctica, es mayor, como consecuencia se genera horas extras no planificadas o caso contrario el tiempo es menor y se destinan a los operadores a actividades de limpieza innecesarias, generándose horas improductivas.

\subsection{Identificación de problemas}

Los desperdicios de granel en fabricación y en envasado son aquellos que afectan a las órdenes producción entregando una cantidad de producto terminado por debajo de lo estipulado en el sector y el objetivo, merma menor al 5\%.

Así mismo existen desperdicios de tiempo que ocasionan horas extras no planificadas mayores al objetivo (por debajo del 5\% del total de horas trabajadas de todo el personal operativo) que representa un máximo de 288 horas extras mensuales

Este desperdicio de tiempo improductivo se incrementa porque en las operaciones de limpieza hay actividades que generan desplazamientos y recorrido que pueden ser mejorados. Lo mismo se puede identificar en las actividades de fabricación que el recorrido del trasvase y el personal puede mejorar no solo para disminuir distancia si no también merma de granel, que se ve incrementada por que las tuberías de trasvase resultan no favorables para retirar el granel. 


\subsubsection{Problema}

Desperdicios en la línea de producción que afectan la cantidad de unidades a entregar (No se cumple con la cantidad a entregar), existe un conjunto de horas extras no planificadas y horas improductivas fuera del objetivo. 
2.6.2 Análisis de causas del problema: Diagrama de Ishikawa

Figura 17 Diagrama de Ishikawa

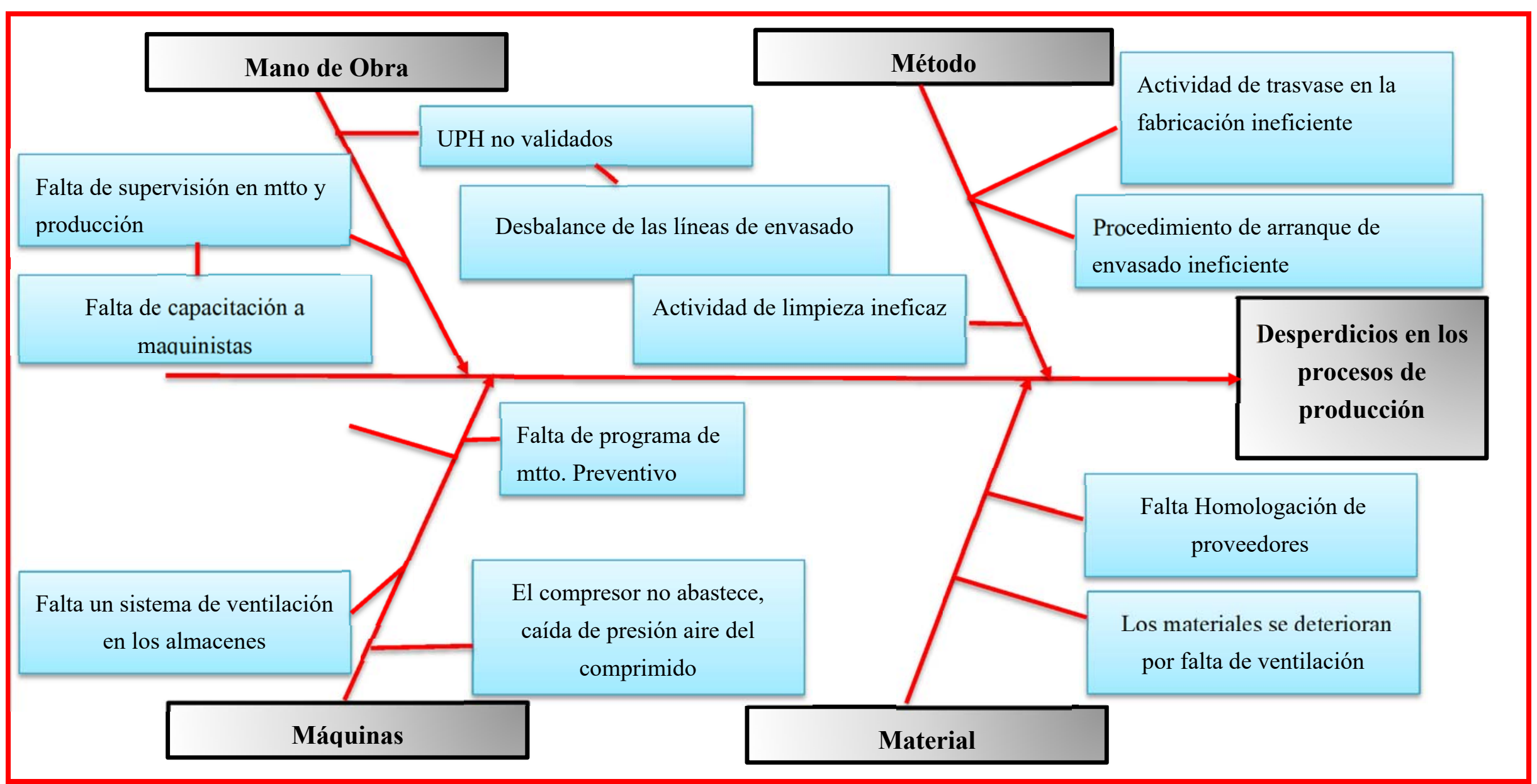

Fuente: Elaboración propia 
Figura 18 Value Stream Mapping (VSM) actual

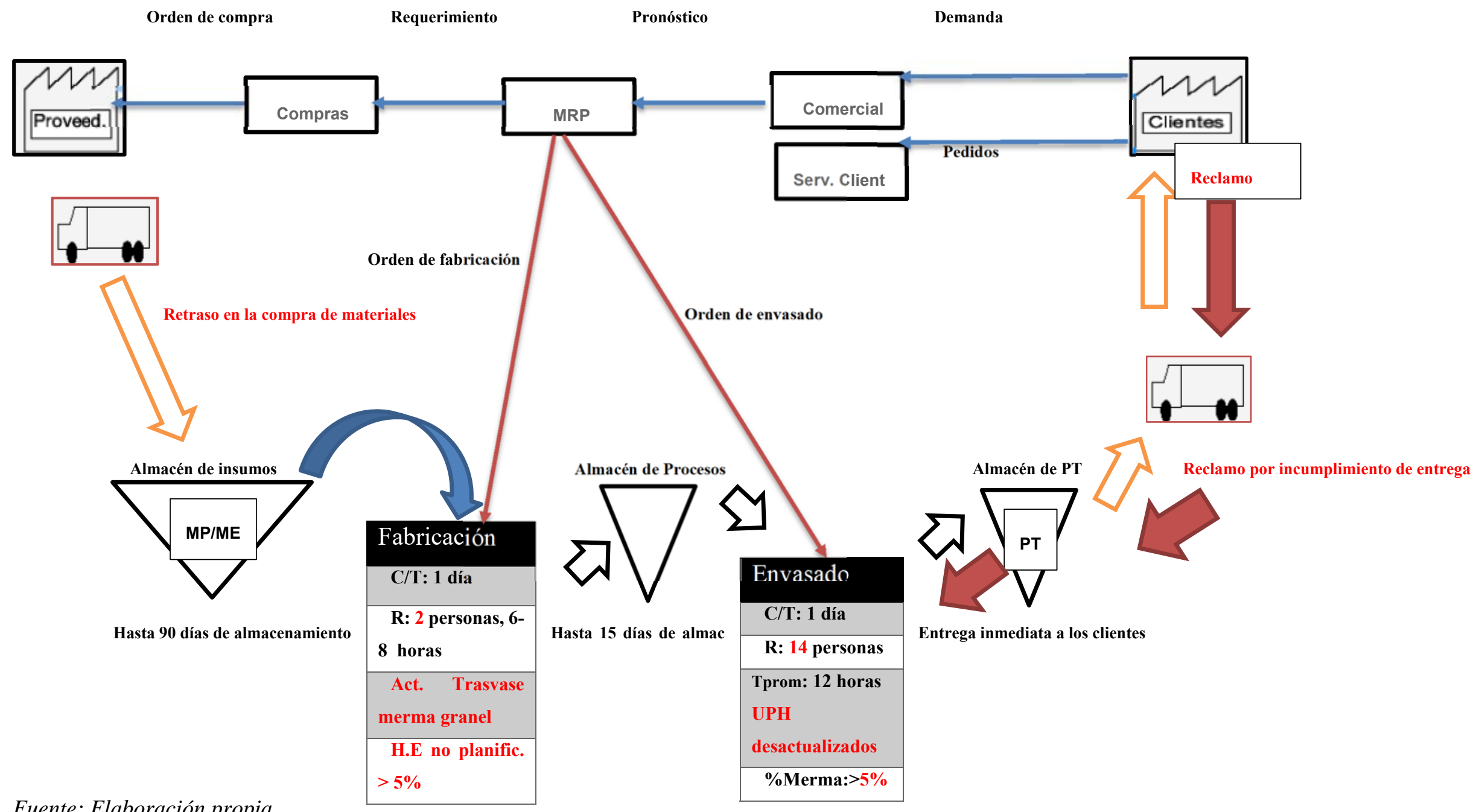

Fuente: Elaboración propia 


\subsubsection{Diagrama de Pareto:}

Se ponderan las causas principales y secundarias del diagrama de Ishikawa de acuerdo a la incidencia que son reportados en las órdenes de producción revisadas (318 órdenes) (ver ejemplo en anexo 15), en cada orden se detalla en observaciones todas las variables anotadas por el operador que afectan la productividad (mermas, horas de exceso, horas improductivas, incumplimiento de las cantidades de entregad). De esa revisión y validación se obtiene la ponderación de incidencia relativa y acumulada (ver anexo 14), del cual se construye el diagrama de Pareto.

Figura 19 Determinación de las causas vitales del problema

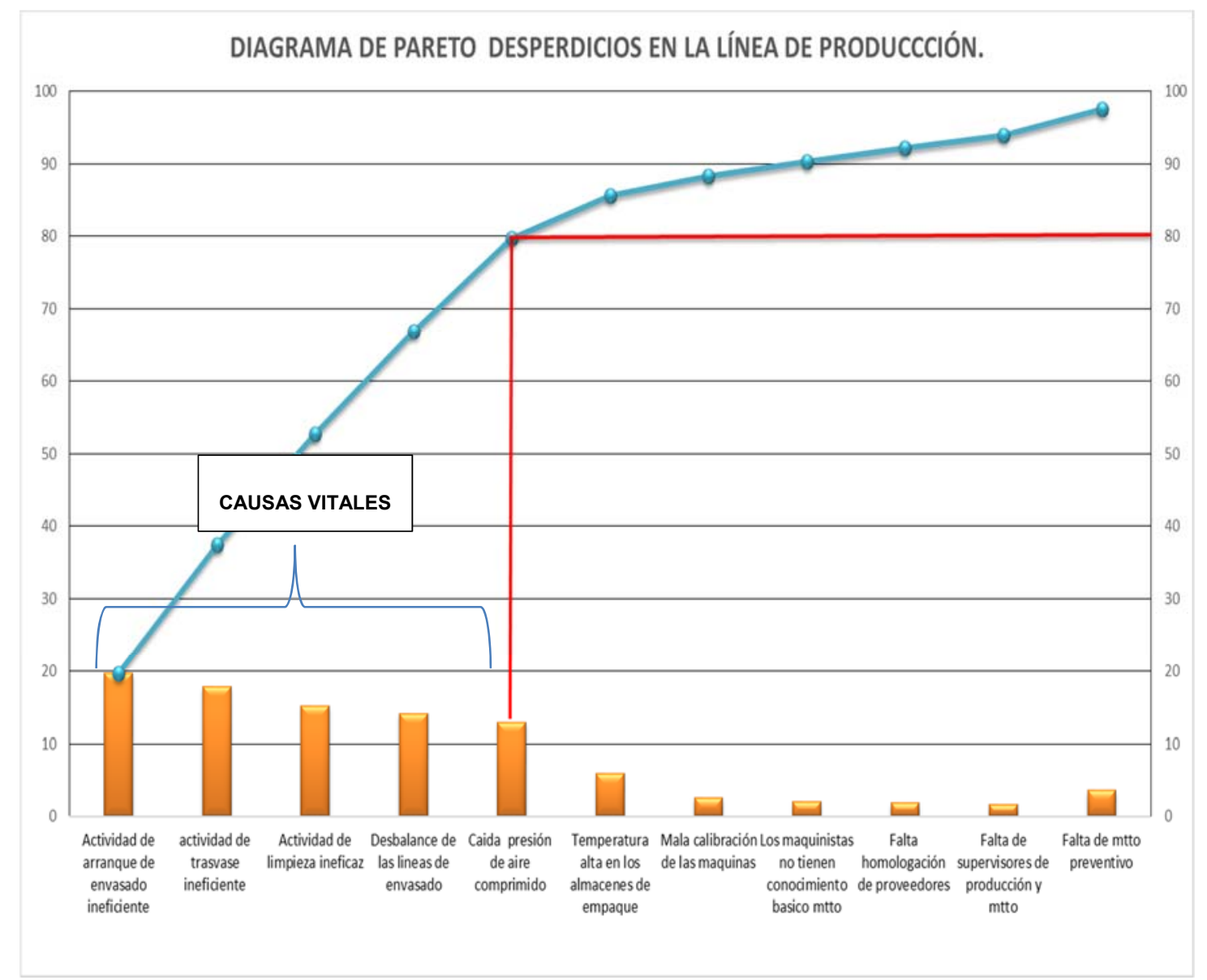

Fuente: Elaboración propia

En la Fig. 19 del análisis de Pareto se determinan que las causas vitales que generan el 80\% de nuestros problemas se deben a: actividades de limpieza ineficiente, actividades de trasvase en el proceso de fabricación ineficiente, actividades de arranque en el proceso de envasado ineficiente, desbalance de líneas de envasado y la caída de presión del aire comprimido.

\subsection{Validación del diagnostico}




\subsubsection{D1: Actividades de limpieza ineficiente}

Se implementa el formato LF-APC-005 para el registro de ineficiencias en las actividades de limpiezas y se hicieron el seguimiento a las siguientes ordenes de producción 53332, 56233, $7238,8232,9343$ y 9247 y se detallan registros de desperdicios de recorridos, de perdida de granel y variabilidad en el tiempo utilizado.

\begin{tabular}{|l|c|c|c|}
\hline LF-AC-005 & \multicolumn{3}{|c|}{$\begin{array}{r}\text { Formato de Registro de ineficiencia en las } \\
\text { actividades de limpieza }\end{array}$} \\
\cline { 1 - 2 } Necorridos & $\begin{array}{c}\text { Recorridos } \\
\text { inncesarios } \\
\text { No de OP }\end{array}$ & $\begin{array}{c}\text { Inncesarios de } \\
\text { limpieza de } \\
\text { labricación(mts) }\end{array}$ & $\begin{array}{c}\text { Tiempo de } \\
\text { Envasados(mts) } \\
\text { proceso (Horas) }\end{array}$ \\
\hline $\mathbf{1 0 0 0 5 3 3 2}$ & 112 & 84 & 2.810 \\
\hline $\mathbf{1 0 0 0 5 6 2 3 3}$ & 119 & 92 & 3.720 \\
\hline $\mathbf{1 0 0 0 7 2 3 8}$ & 125 & 116 & 2.530 \\
\hline $\mathbf{1 0 0 0 8 2 3 2}$ & 101 & 96 & 4.170 \\
\hline $\mathbf{1 0 0 0 9 2 4 3}$ & 108 & 92 & 3.160 \\
\hline $\mathbf{1 0 0 0 9 2 4 7}$ & 117 & 119 & 2.570 \\
\hline
\end{tabular}

Tabla 4 Registro de ineficiencia en las actividades de limpieza Fuente: Elaboración propia

La Tabla 4, muestra el formato implementado para validar la ineficiencia del proceso de limpieza, se tomó al azar las ordenes mencionadas y se hicieron seguimiento mediante observación directa a las actividades de limpieza de los tanques y el reactor que se utilizaron en dichas ordenes, se observa recorridos (desperdicios) por que se traslada las marmitas y tanques desde el primer piso hasta el segundo piso tanto en la fabricación como en el envasado y se registran la distancia recorrida para cada estación. Así mismo se observó que los tiempos empleados no son uniforme presentando variaciones desde 2.530 hasta 2.810 horas demostrando ineficiencia en la actividad.

Se presenta en la siguiente figura un tanque contaminado con un colorante, en el reporte de no conformidad se determinó que fue una mala limpieza al tanque con lo cual se logró contaminar el granel, esta es una evidencia para revisar las actividades y asegurar su eficacia, en esta no conformidad se mermo $317 \mathrm{Kg}$. de granel. 
Figura 20 Reporte de no conformidad

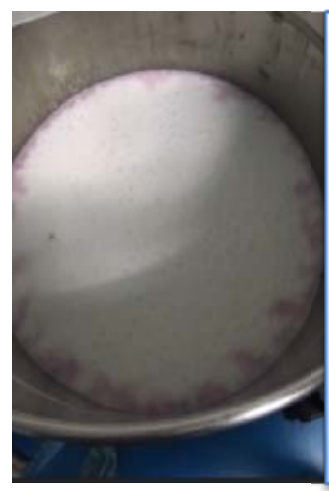

Reporte de No conformidad N GAC-0023:

Contaminación del colorante rojo:

Orden de Producción: 1000234

Lote: $\mathrm{N}^{\circ} 100056233$

(Granel mermado)

Fuente: Elaboración propia

\subsubsection{D2: Actividades de trasvase ineficiente}

La generación de mermas es una de las principales manifestaciones de ineficiencia en esta actividad, para esto se hace el balance de materiales.

- En el proceso de fabricación

Se hace el análisis en la fabricación mediante la siguiente formula:

Kilogramos de Entradas = Kilogramos de Salida + Merma granel

Figura 21 Registros de merma de granel en el proceso de fabricación

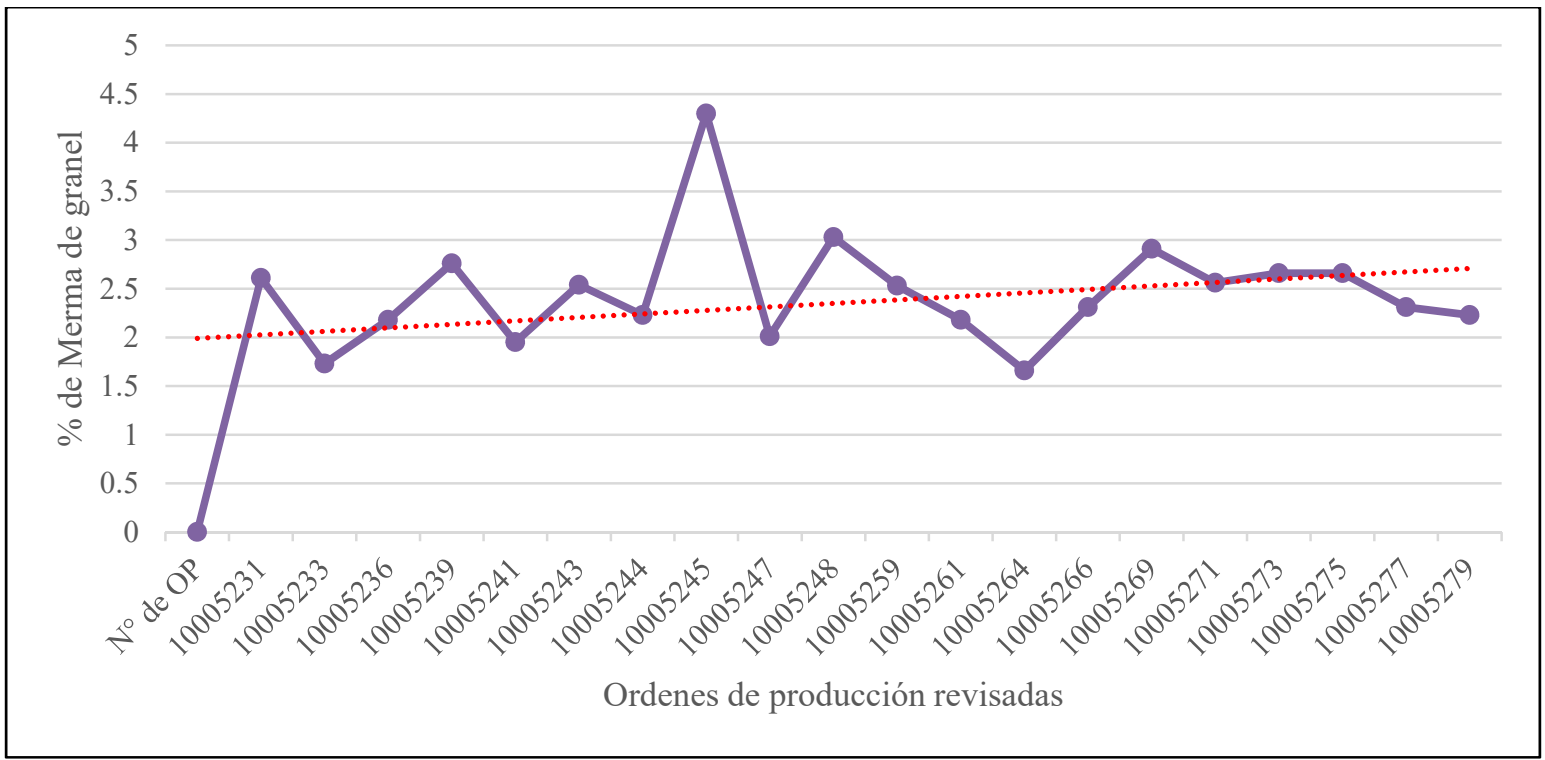

Fuente: Laboratorios Cosmético 
La merma en el proceso de fabricación tienen una tendencia a incrementarse en el tiempo, según la información revisada de las órdenes de producción que se encuentran en físico en el área de aseguramiento de la calidad, de los 20 lotes revisados se obtuvo una merma promedio de $2.50 \%$ en la fase de fabricación del granel y el objetivo en esta fase es $1.0 \%$.

\subsubsection{D3: Ineficiencia en las actividades de arranque y dosificación en el envasado}

- En la actividad de arranque del envasado (Setup)

La operación de arranque consiste en la etapa de sanitización y montaje (regulación), una vez que la máquina de envasado está limpia se procede a sanitizar con solución de alcohol al $70 \%$ todas las partes de acero que entran en contacto con el producto y se termina esta actividad haciendo la purga con granel del producto a envasar. Para demostrar la ineficiencia por perdida de granel durante el arranque se plantea la siguiente ecuación:

Kilogramo Entrada = Kilogramos Salidas + Purga de granel

Figura 22 Registros de merma de granel en el proceso arranque

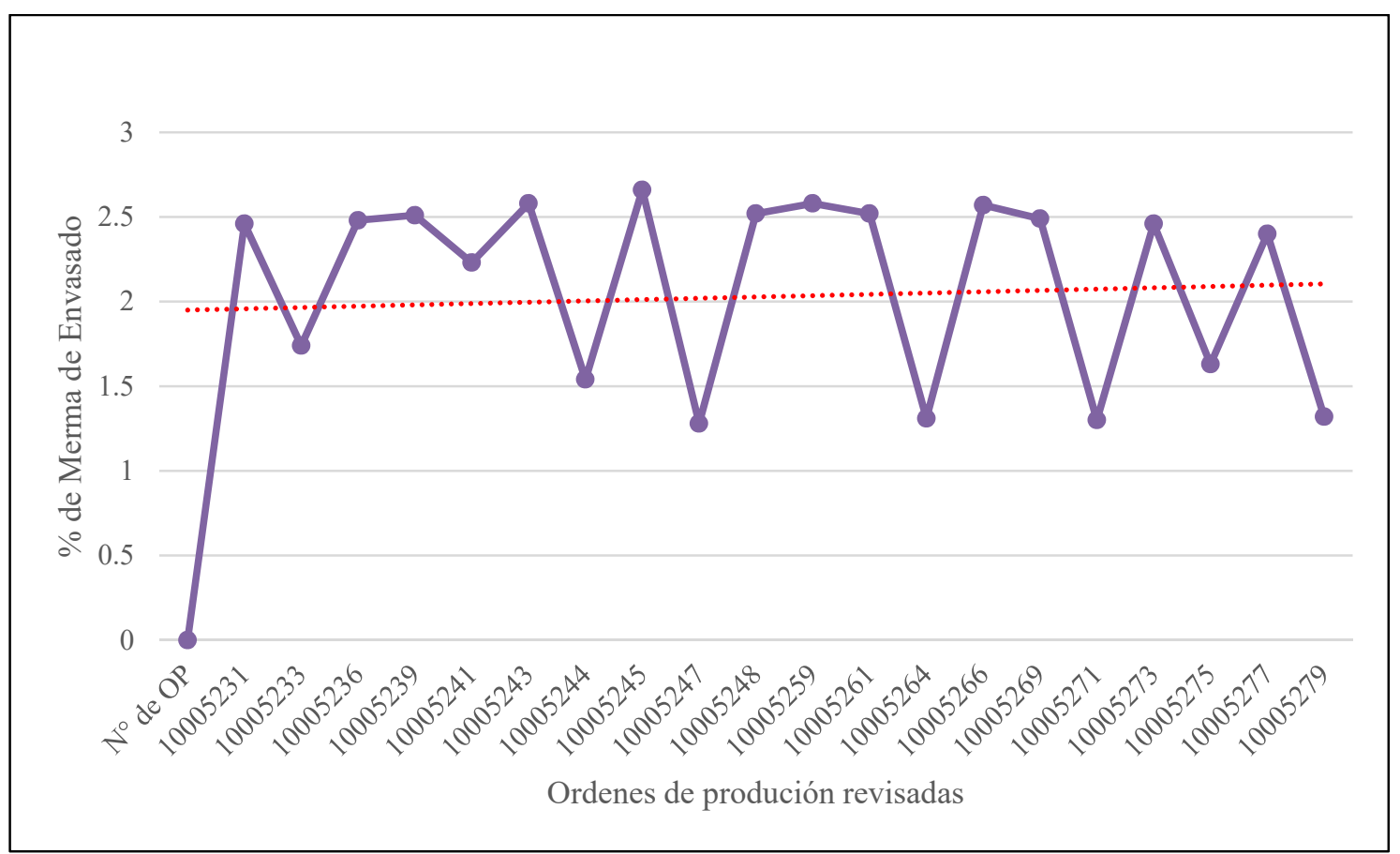

Fuente: Laboratorio Cosmético 
Como se observa en la Fig. 22 hay una tendencia a mantenerse en esos rangos, la perdida de granel en la actividad de arranque, hay una variabilidad muy notoria, en esta etapa no hay un objetivo propio, pero por la experiencia del sector esta etapa debería ser $0 \%$.

- En la actividad del dosificado en el envasado

El análisis de merma en el proceso de envasado se va a considerar a partir del granel de entrada que es lo entregado por el almacén de producto en proceso menos la purga, y se tiene la siguiente formula:

$$
\text { Kilogramos Entradas }=\mathrm{N}^{\circ} \text { de Unidades envasadas } \mathrm{x} \text { Peso promedio }+ \text { Merma }
$$

Figura 23 Registros de merma de granel en el proceso dosificado

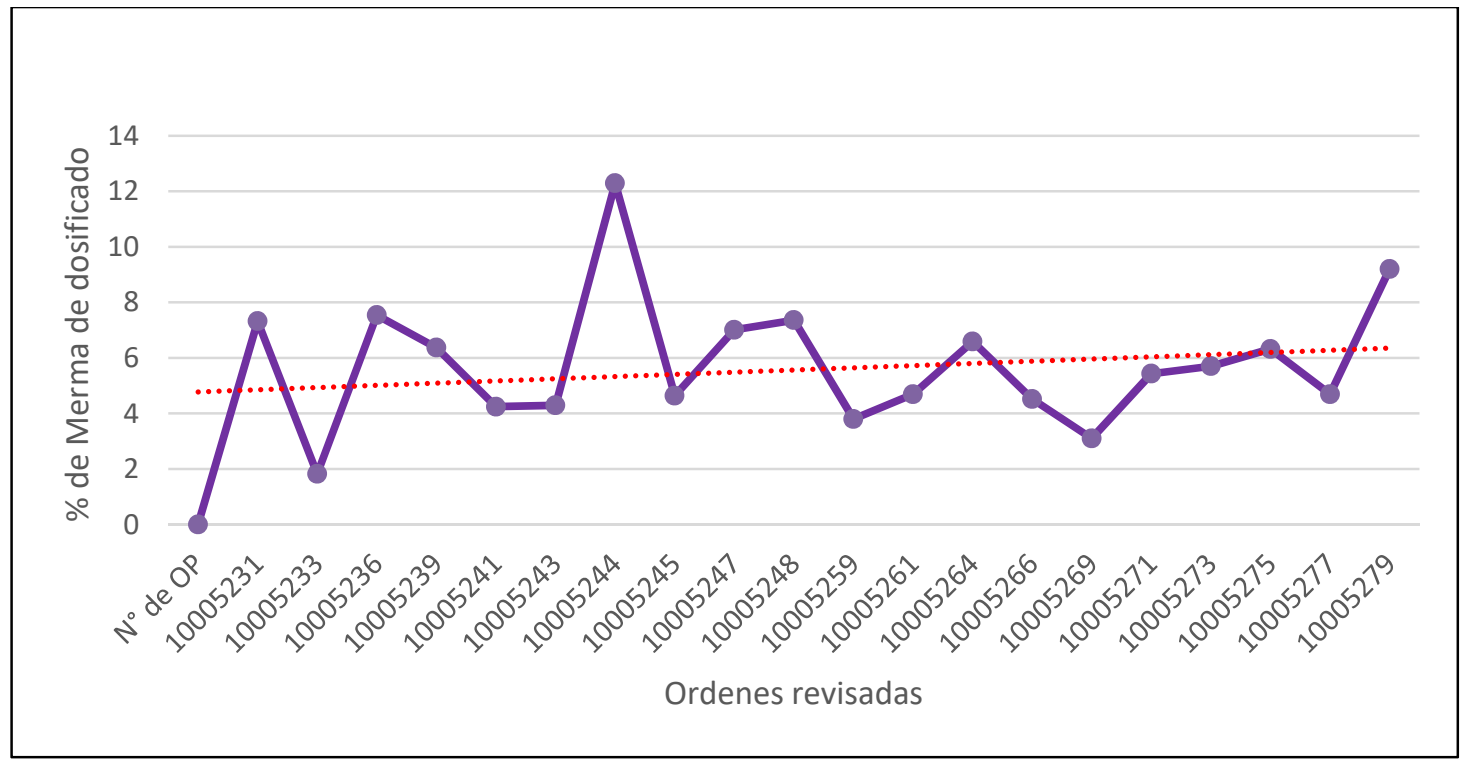

Fuente: Laboratorio cosmético

Se identifica en la Fig. 23 una tendencia al crecimiento de la merma en el dosificado, se evidencia que el dosificado se refleja por el peso promedio supera el peso teórico, en las presentaciones de $30 \mathrm{~g}$, en promedio se dosifica a $32 \mathrm{~g}$ y en la presentación de 50 , en promedio se envasa a $54 \mathrm{~g}$, esta variación en el dosificado se le denomina merma de sobredosificado en esta fase según el sector el objetivo es $4 \%$. Y se observan órdenes que están por encima de este objetivo, esta variación del dosificado se debe a la falta de capacidad del compresor. 


\subsubsection{D4: Caída de presión del aire comprimido}

La presión de aire comprimido debe ser continuo y constante, caída por debajo de 300 psi afecta el dosificado, porque el desplazamiento de la leva para dosificar debe estar entre 290 y 320 psi, variaciones en estas genera más llenado o menos llenado de producto en el frasco envasado, generando merma por sobrellenado.

Se implementa el formato F-APC-005 para el registro de la presión de aire comprimido a la entrada de la maquina envasadora

Tabla 5 Registro de data de presión de aire comprimido en la envasadora

\begin{tabular}{|c|c|c|c|c|c|}
\hline \multirow{3}{*}{\begin{tabular}{|l|} 
F-PAC-005 \\
\\
\end{tabular}} & \multicolumn{2}{|c|}{ Valvula de Presión } & \multirow{2}{*}{\multicolumn{3}{|c|}{$\begin{array}{c}\text { Laboratorio Cosmetico: Registro de presion } \\
\text { de aire comprimido }(290-310 \mathrm{psi})\end{array}$}} \\
\hline & \multirow{2}{*}{\begin{tabular}{|l}
$\mathrm{N}^{\circ}:$ \\
Serie: \\
\end{tabular}} & \multirow{2}{*}{\begin{tabular}{|c|} 
Máquina \\
Envasadora \\
\end{tabular}} & & & \\
\hline & & & & & \\
\hline Hora & Dia & Presión (psi) & Hora & Dia & Presión (psi) \\
\hline 7:12:00 a. $\mathbf{m}$. & $7 / 08 / 2018$ & 310 & 7:00:00 a. m. & 8/08/2018 & 310 \\
\hline 8:12:00 a. m. & $7 / 08 / 2018$ & 285 & 8:00:00 a. $\mathrm{m}$. & 8/08/2018 & 270 \\
\hline 9:12:00 a. $\mathrm{m}$. & $7 / 08 / 2018$ & 270 & 9:00:00 a. m. & 8/08/2018 & 255 \\
\hline 10:12:00 a. m. & 7/08/2018 & 293 & 10:00:00 a. m. & 8/08/2018 & 265 \\
\hline 11:12:00 a. m. & $7 / 08 / 2018$ & 270 & 11:00:00 a. m. & 8/08/2018 & 256 \\
\hline 12:12:00 p. m. & $7 / 08 / 2018$ & 285 & 12:00:00 p. m. & 8/08/2018 & 280 \\
\hline 1:12:00 p. m. & $7 / 08 / 2018$ & 300 & 1:00:00 p. m. & 8/08/2018 & 245 \\
\hline 2:12:00 p. m. & 7/08/2018 & 255 & 2:00:00 p. m. & 8/08/2018 & 292 \\
\hline 3:12:00 p. m. & $7 / 08 / 2018$ & 267 & 3:00:00 p. m. & 8/08/2018 & 289 \\
\hline 4:12:00 p. m. & $7 / 08 / 2018$ & 278 & 4:00:00 p. m. & 8/08/2018 & 278 \\
\hline 5:12:00 p. m. & $7 / 08 / 2018$ & 267 & 5:00:00 p. m. & 8/08/2018 & 285 \\
\hline 6:12:00 p. m. & $7 / 08 / 2018$ & 260 & 6:00:00 p. m. & 8/08/2018 & 287 \\
\hline
\end{tabular}

\section{Fuente: Elaboración propia}

En la Tabla 5, se presenta la data de la toma de presión de aire comprimido a la entrada de la máquina envasadora donde se evidencia caídas por mementos de la presión diferencial, de acuerdo al manual de máquina, la regulación de la presión de aire comprimido debe ser entre 290-300 psi.

\subsection{Impacto económico}

Los efectos presentados en el ítem anterior se manifiestan en un impacto económico que son generados por los desperdicios el costo relativo mensual ocasionado por los las mermas del granel, el costo de horas extras, el costo de horas improductivas, para efectos del análisis se reportan de modo mensual, el costo de oportunidad por el valor que representa dejar de vender una unidad de producto terminado que se deja de entregar por la merma de granel. 


\subsubsection{Análisis de horas extras no planificadas}

El promedio de horas extras en el laboratorio cosmético no planificadas representa el $90 \%$ del total de horas registradas, estas horas son registradas en el formato de registro de horas extras (Fig. 24) y son aprobadas por el jefe de producción.

Figura 24 Registro de horas extras no planificadas mensual reportada por contabilidad

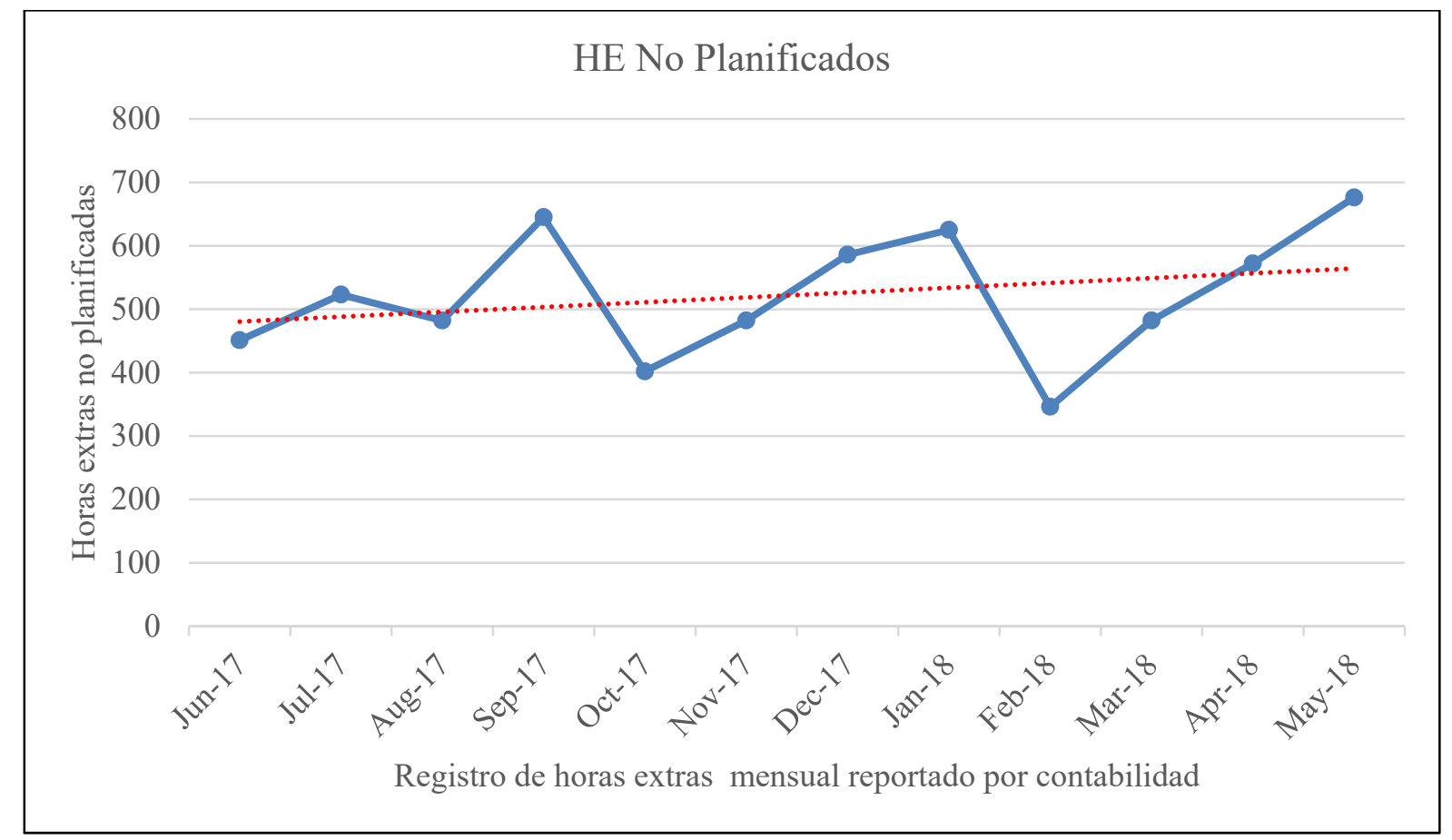

Fuente: Área de contabilidad

Se presenta el promedio mensual de horas extras no planificadas y reportada por el área de contabilidad, información consolidada a partir de los registros de horas que realiza el personal de modo diario. Hay una tendencia hacia arriba de las horas extras frente al objetivo del 5\% del total de horas, máximo 288 horas. (El total de horas totales de producción se calcula el total de operarios por las horas a trabajar mensual: 48 horas/semana $\mathrm{x} 30$ operarios $\mathrm{x} 4$ semanas, dan un total de 5760 horas disponibles, el 5\% máximo permitido es 288 horas que es dado como política de la empresa).

\subsubsection{Análisis de horas improductivas}

Las horas improductivas detalladas en la Fig. 25 se han definido por la gerencia general como aquellas horas que el personal de producción no está trabajando en una orden de producción y se considera actividades de limpieza y actividades de documentación. Estas horas son 
registradas en el formato de registro de horas y son entregadas al asistente de contabilidad para el registro y control.

Figura 25 Registro de horas improductivas reportadas por contabilidad

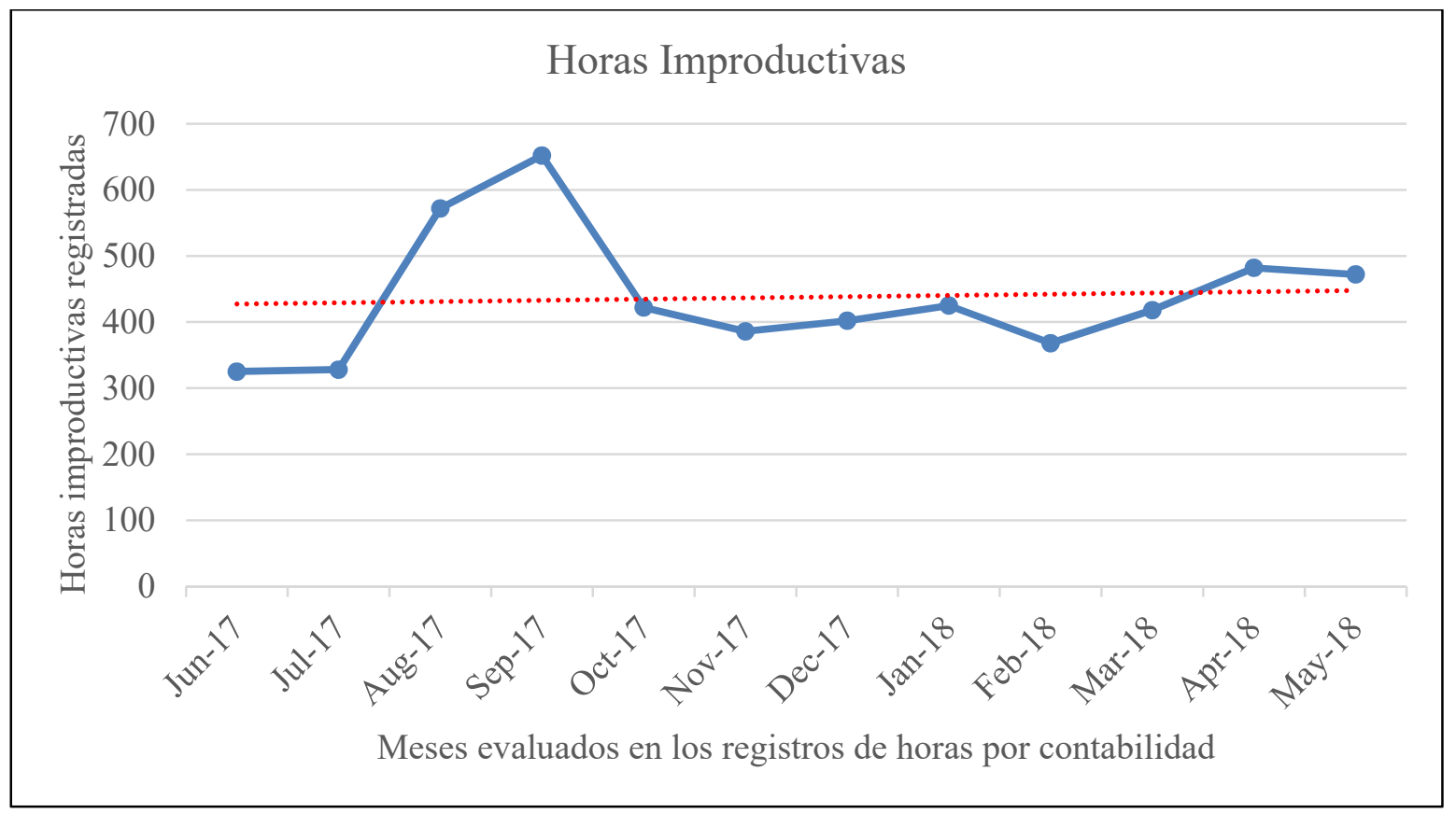

Fuente: Área de contabilidad

Hay una tendencia al crecimiento de las horas improductivas reportadas en el último año y un promedio de 400 horas, estas horas no generan valor y se encuentra por encima del objetivo $5 \%$ del total de horas trabajadas en un mes que representa 288 horas. (El total de horas totales de producción se calcula el total de operarios por las horas a trabajar mensual: 48 horas/semana x 30 operarios x 4 semanas, dan un total de 5760 horas disponibles, el 5\% máximo permitido en horas improductivas). 
Tabla 6 Impacto económico mensual

\begin{tabular}{|l|c|c|}
\hline \multicolumn{2}{|c|}{ COSTO RELATIVO MENSUAL OCASIONADOS POR LOS DESPERDICIOS } \\
\hline \multicolumn{1}{|c|}{ CLIENTE } & $\begin{array}{c}\text { COSTO } \\
\text { PROMEDIO (S/.) }\end{array}$ & $\begin{array}{c}\text { COSTO RELATIVO } \\
(\mathbf{\%})\end{array}$ \\
\hline Costo de granel mermado & 11,960 & 6.38 \\
\hline Costo de oportunidad por dejar de vender & 10,235 & 5.47 \\
\hline Costo de horas extras no planificadas & 5,687 & 3.04 \\
\hline Costo por horas improductivas & 4,235 & 2.26 \\
\hline $\begin{array}{l}\text { COSTO PROMEDIO TOTAL DE } \\
\text { PRODUCCIÓN MENSUAL }\end{array}$ & $\mathbf{1 8 7 , 1 7 2}$ & $\mathbf{1 7 . 1 5}$ \\
\hline
\end{tabular}

Fuente: Contabilidad laboratorio cosmético (ver anexo 16-17)

En la Tabla 6, Se observa que actualmente se tienen un costo relativo mensual promedio por desperdicios del $17.15 \%$ del total promedio del costo de producción. El impacto económico total anual reporta $\mathrm{S} / 385,404$ frente a $\mathrm{S} / 2^{\prime} 246,064$ total costo de producción. Se muestra en la siguiente tabla el impacto económico anual.

Tabla 7 Impacto económico Anual

\begin{tabular}{|l|c|c|}
\hline \multicolumn{2}{|c|}{ COSTO RELATIVO MENSUAL OCASIONADOS POR LOS DESPERDICIOS } \\
\hline \multicolumn{1}{|c|}{ CLIENTE } & $\begin{array}{c}\text { COSTO } \\
\text { PROMEDIO (S/.) }\end{array}$ & $\begin{array}{c}\text { COSTO RELATIVO } \\
(\mathbf{\%})\end{array}$ \\
\hline Costo de granel mermado & 143,450 & 6.38 \\
\hline Costo de oportunidad por dejar de vender & 122,820 & 5.47 \\
\hline Costo de horas extras no planificadas & 68,244 & 3.04 \\
\hline Costo por horas improductivas & 50,820 & 2.26 \\
\hline $\begin{array}{l}\text { COSTO PROMEDIO TOTAL DE } \\
\text { PRODUCCIÓN MENSUAL }\end{array}$ & $\mathbf{2} \mathbf{2 4 6 , 0 6 4}$ & $\mathbf{1 7 . 1 5}$ \\
\hline
\end{tabular}

Fuente: Contabilidad laboratorio cosmético 


\subsection{Vinculación de la causa con la solución}

Figura 26 Vinculación de la causa con la solución

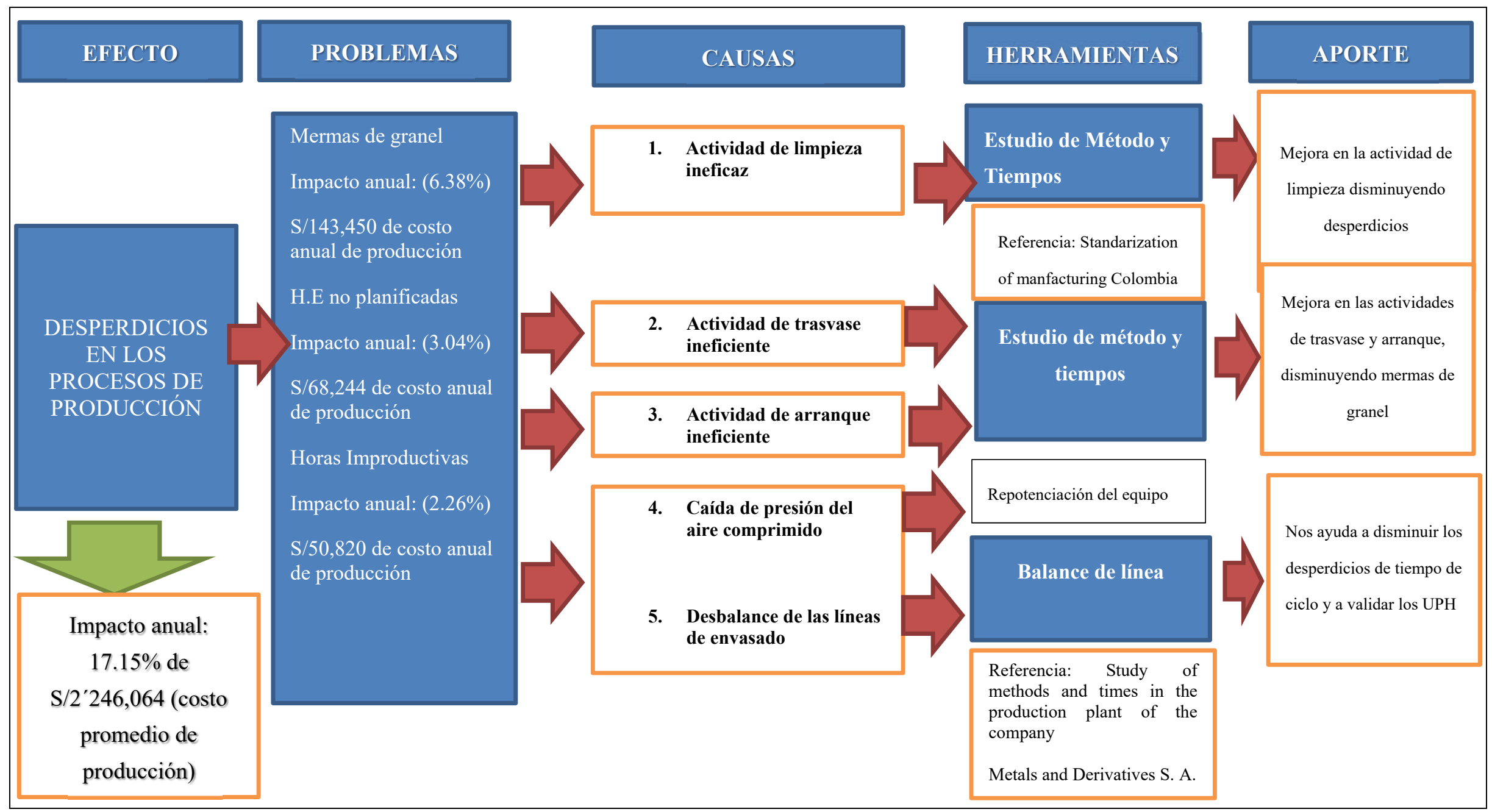

Fuente: Elaboración propia 
De acuerdo a la vinculación de la causa con la solución: la Caída de presión del aire comprimido que afecta al proceso de dosificación requiere una solución de repotenciación del equipo que en este trabajo no será tratado dado que la empresa no está por el momento dispuesto en invertir para mejorar el performance del equipo.

\subsection{Hipótesis}

\subsubsection{Hipótesis general}

El desarrollo de un trabajo de investigación para identificar los desperdicios en la línea de producción y aplicando diferentes herramientas de ingeniería industrial lograremos eliminar las principales causas que generan impactos económicos negativos en el laboratorio cosmético.

\subsubsection{Hipótesis específica}

- Se concluye que el problema encontrado en el proceso de fabricación es la generación de desperdicios a causa de los extensos y complejos sistemas de conductos de la actividad de trasvase y por la ineficiente distribución de planta del área de limpieza donde se sanitiza los equipos. Esto se lograra mitigar con la aplicación del estudio de métodos y tiempos.

- Se determina que los problemas de las actividades de limpieza identificados en los procesos de fabricación y envasado son los sobretiempos y largas distancias de recorrido debido a la mala ubicación del área de limpieza de equipos y la falta de estandarización durante el desarrollo de la actividad. Para disminuir estas mudas se utilizara el estudio de método que permitirá aumentar la eficiencia en el laboratorio cosmético

- Se identifica que la deficiencia por desperdicios en las actividades de arranque durante el proceso de envasado es la inclusión de la pérdida de material (granel) como actividad normal durante la purga, la causa es el ineficiente método empleado actualmente y la mejora empleara el estudio de métodos y tiempos para disminuir estos desperdicios.

- Se estipula que el problema en la estación de envasado y acondicionado es el desperdicio de tiempo (horas extras y horas improductivas) a causa de la mala 
programación, la cual será resuelta utilizando el estudio de tiempos por cronometro validando los UPH actuales y balanceando las líneas.

La presentación del Capítulo II consistió en mostrar a la empresa en todos los aspectos relacionados con el mercado, con las ventas, con los proveedores, su organización interna, y la presentación de los principales problemas que se discutirán en esta investigación, con un análisis dela situación actual, determinado las principales causas reales que deberán ser resueltas usando herramientas de ingeniería industrial, finalmente la vinculación la matriz de consistencia para vincular la causa raíz con las herramientas de solución. 


\section{Capitulo III: Propuesta de Mejora}

En el capítulo anterior se realizó el análisis de causa encontrando las variables que determinan estas y el cual serán los elementos de atención para resolver el(los) problemas presentados, así mismo se presentaron evidencias que demuestran la relación entre variables dependientes e independientes y la presentación de herramientas de la ingeniería industrial que se aplicaran para la resolución de los problemas.

En este capítulo presentaremos la propuesta de mejora a los 4 problemas presentados en el capítulo anterior, se plantea la propuesta de solución de acuerdo a la metodología utilizada en las referencias (Ramirez, J.I. 2017 Optimización de tiempos de procesos en desistabodoras y embotelladora y Negrón, A.M., Fleitas, M.S. 2018. Identificación de costos ocultos a partir de un estudio de organización del trabajo en una empresa del sector farmacéutico en cuba), se propone las mejoras orientadas a disminuir desperdicios de tiempo de trasporte, tiempo de recorrido, recorrido, disminución de merma de granel y balancear las líneas shampoo y cremas validando el estándar de unidades por horas (UPH) en los diferentes productos de las líneas de shampoo y crema 


\subsection{Propuesta de mejora}

Figura 27 Diseño de la propuesta de mejora

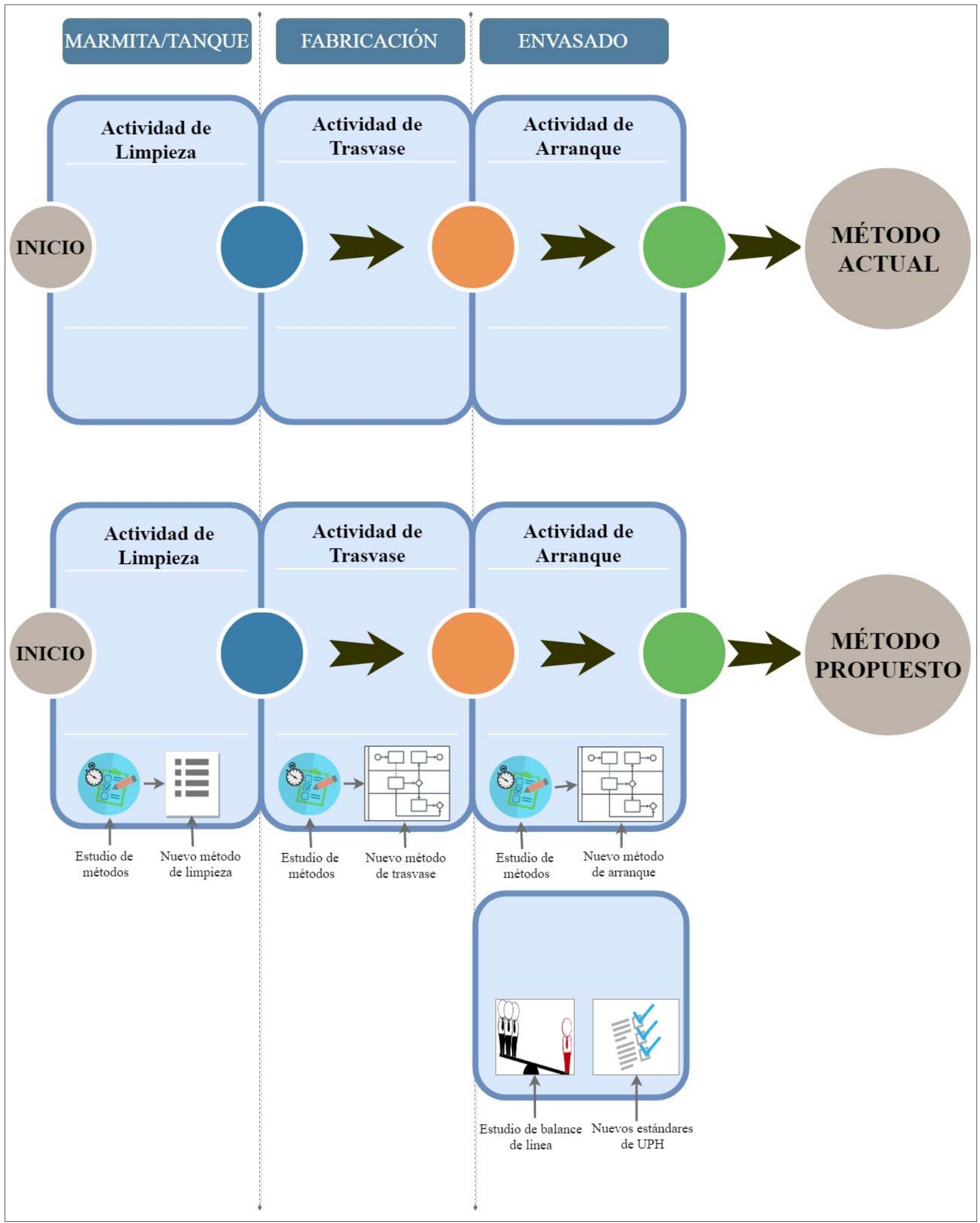

Fuente: Elaboración propia 


\subsubsection{Propuesta en las actividades de limpieza}

Actualmente el proceso de limpieza de los reactores, de los tanques con chaqueta, de la tolva de envasado y de los dosificadores se traslada desde el primer piso hasta el segundo piso, y se inicia utilizando agua tratada hasta arrastrar todo resto de producto que queda en dichos recipientes, luego se agrega solución detergente con la finalidad de arrastrar los elementos grasos, al finalizar este se enjuaga con agua tratada y luego se agrega solución desinfectante de alcohol al 70\%, se pasa aire comprimido para secar cualquier resto de desinfectante y se dejar airear por 45 minutos, Para el caso de la tolva y los dosificadores se purga con producto al empezar la dosificación. Véase el esquema del proceso en la Fig. 28.

Figura 28 Proceso de limpieza actual

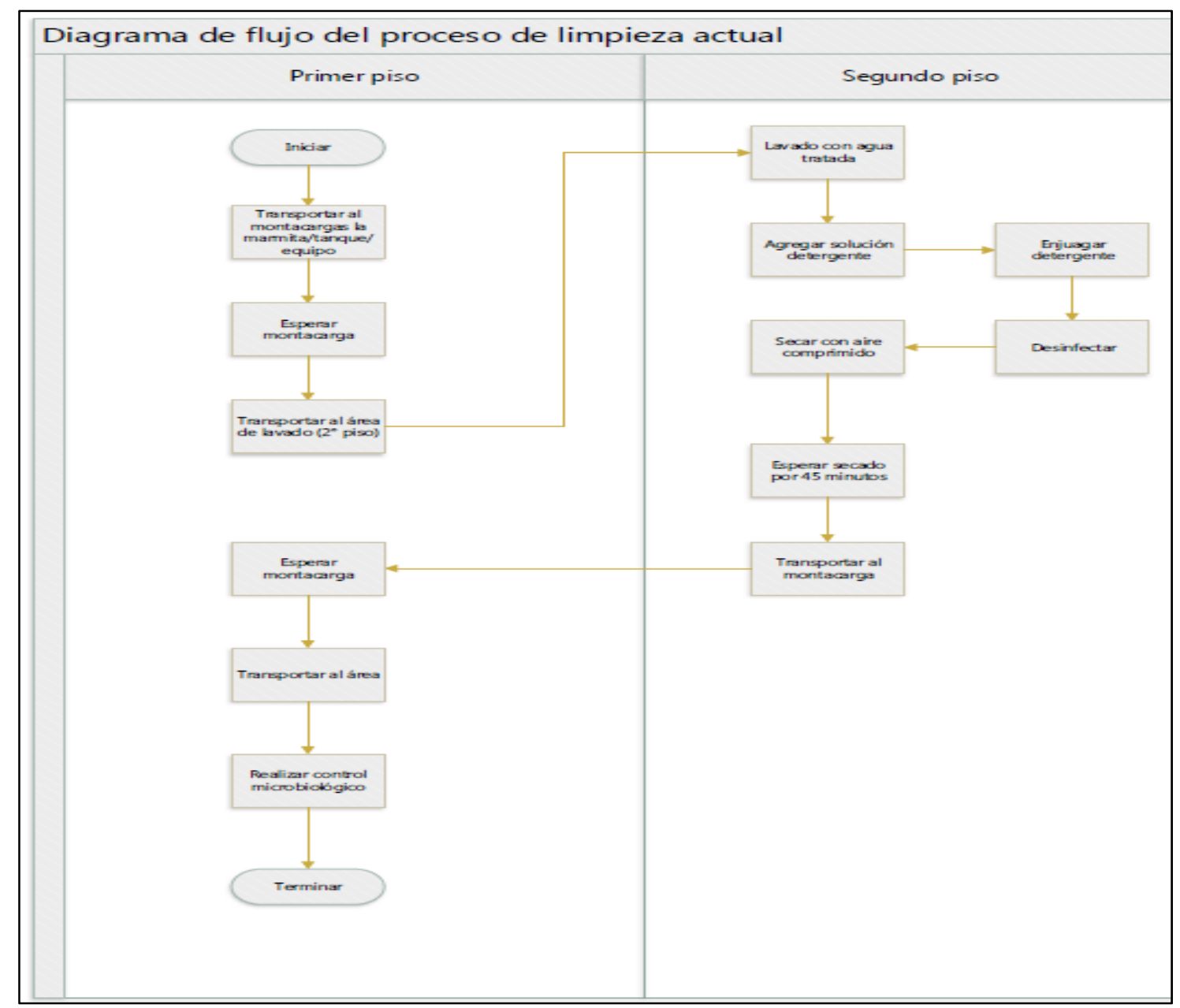

Fuente: Elaboración propia

Se propone disminuir tiempo de recorrido y tiempos de esperas (esto se determina mediante el diagrama de recorrido que permite calcular los metros actuales y mediante el DAP las 
actividades que no generan valor y que se puede eliminar o juntarlas. Se propone habilitar el área de lavado del primer piso que actualmente se usa solo para lavar utensilios. Se propone eliminar la actividad de secar con aire comprimido y reemplazarla utilizando calor a una temperatura de $100^{\circ} \mathrm{C}$, luego de desinfectar, y por último, estas dos actividades en una sola. Esto se puede observar en la Fig. 29.

Figura 29 Proceso de limpieza propuesto

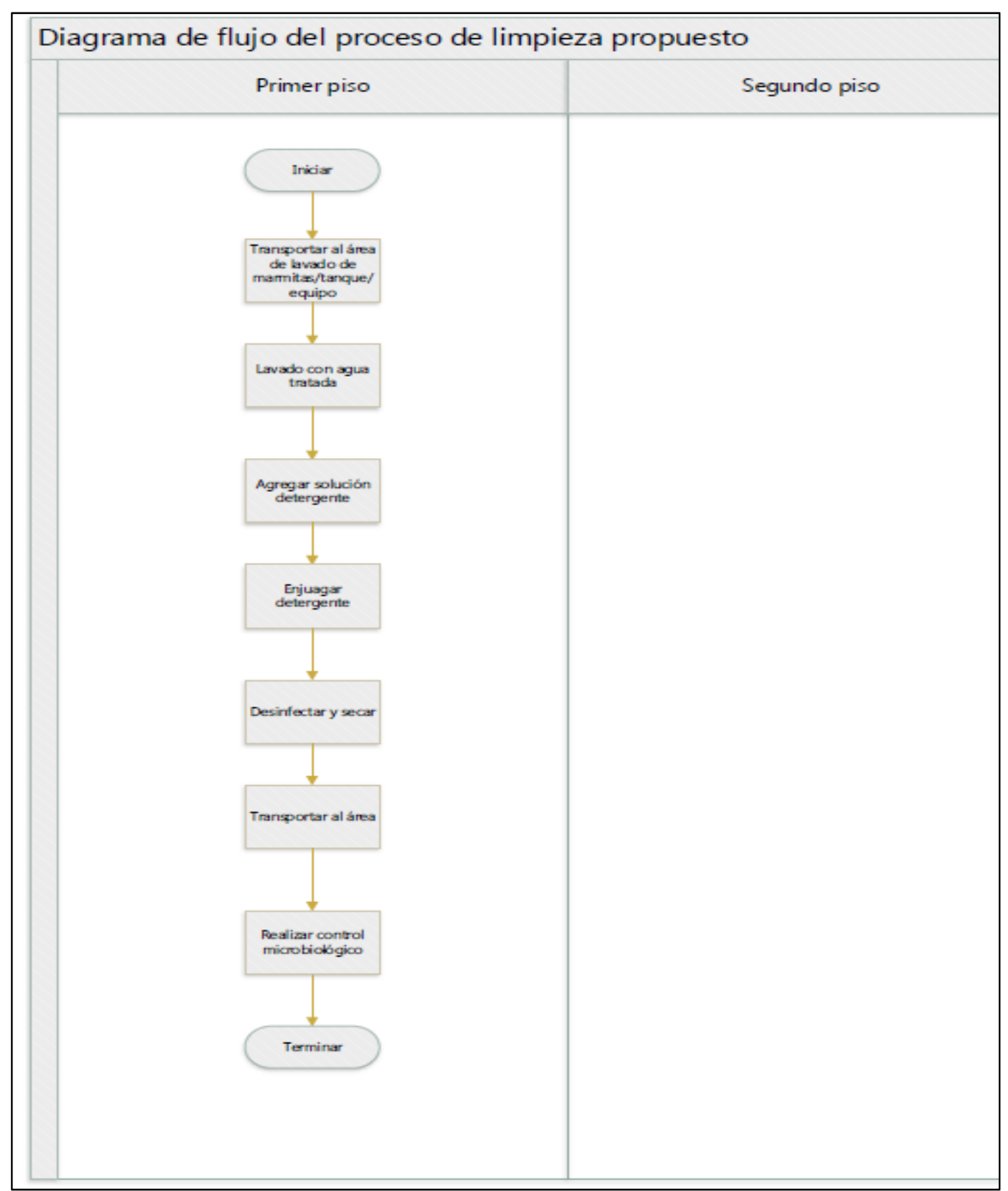

Fuente: Elaboración propia 
A continuación para mayor comprensión de la propuesta se presenta el layout actual de la empresa (Fig. 30) donde se especifica el recorrido de esta actividad de limpieza.

Figura 30 Layout de la empresa con el recorrido actual de la actividad de limpieza

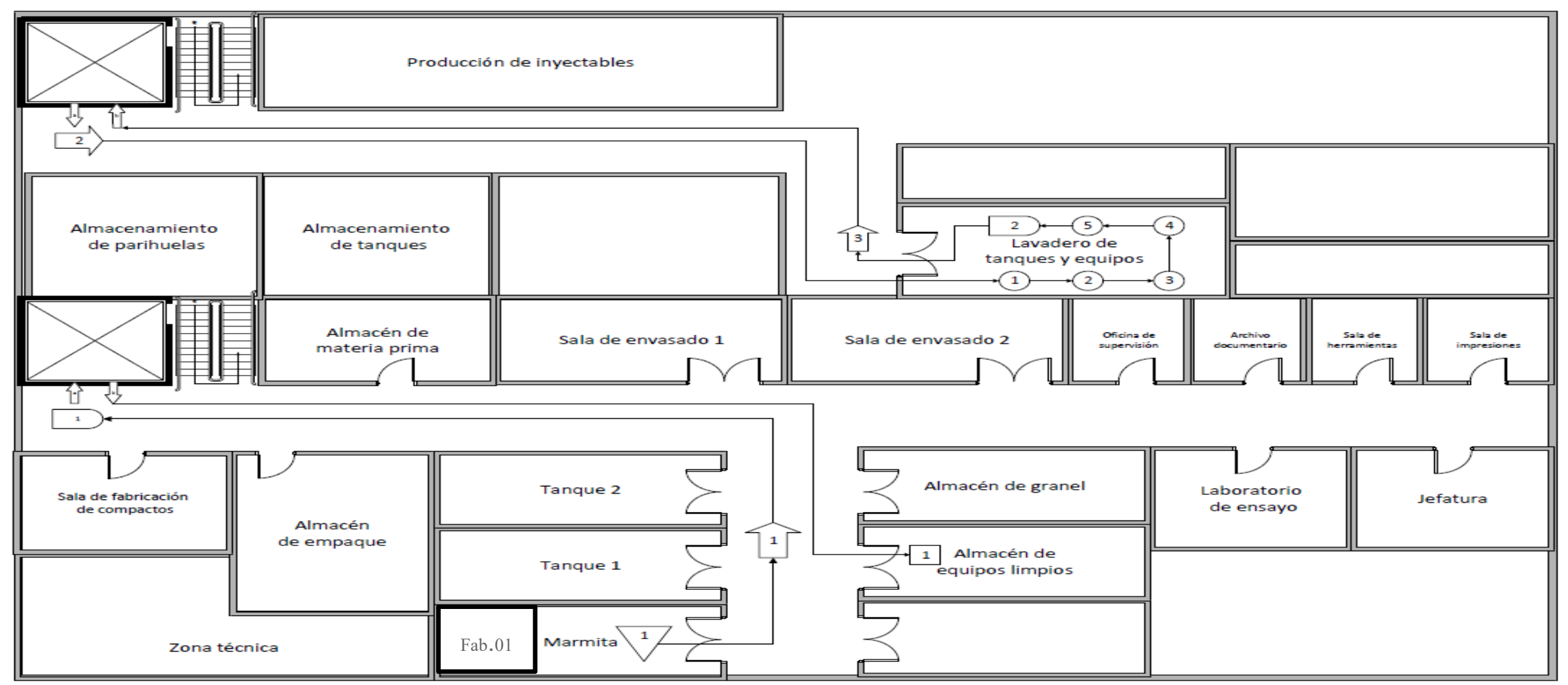

Fuente: Elaboración propia

Se observa que el recorrido del proceso actual, son $98 \mathrm{~m}$ de recorrido considerando el desplazamiento de la limpieza del primer piso al segundo piso y el uso de dos operadores para efectuar dicha actividad. 
Esto según la teoría se puede clasificar como mudas o desperdicios de trasporte, espera, y tiempo; y, a su vez, como oportunidades de mejora.

Figura 31 Diagrama de recorrido de la actividad de limpieza propuesto

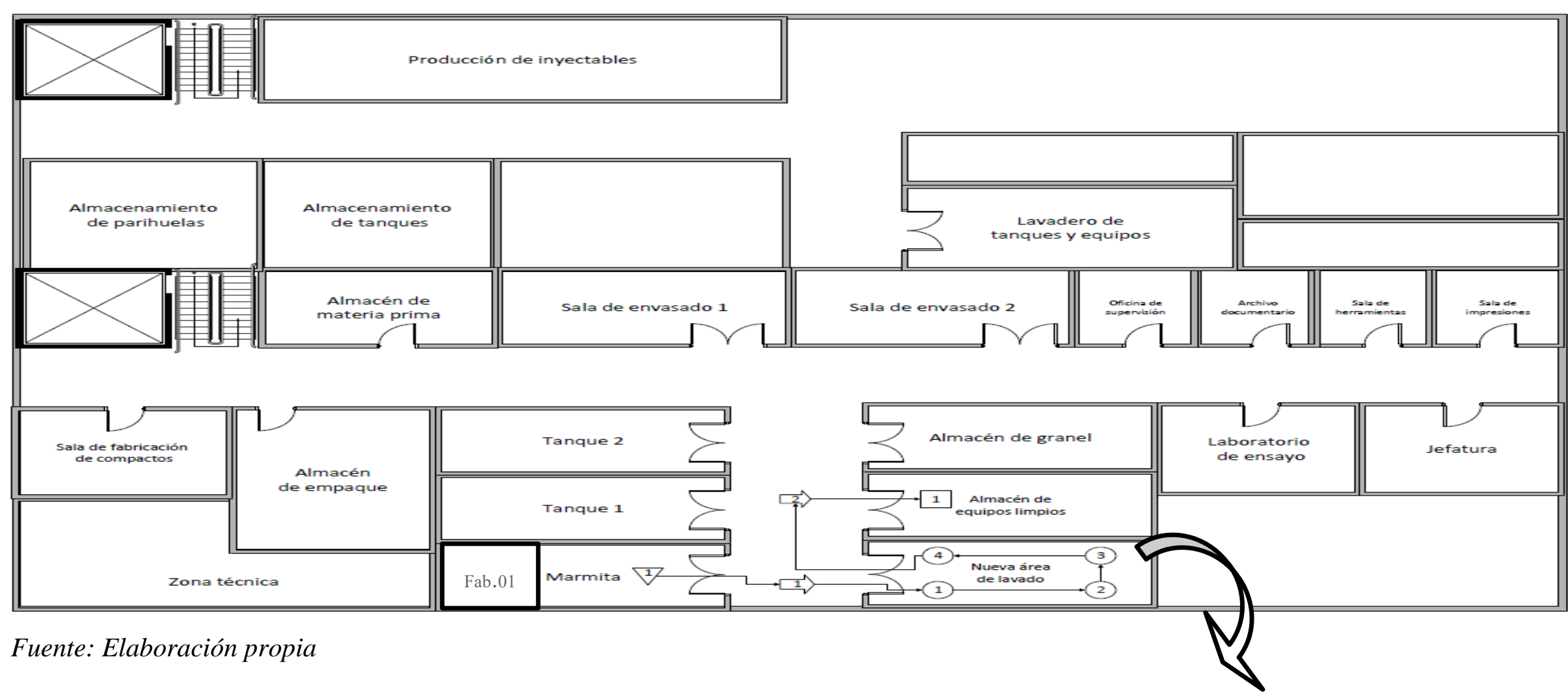

Se propone, mediante el layout de la Fig. 31, disminuir el recorrido en la actividad de limpieza de la marmita y los tanques de fabricación y de almacenamiento de granel, se plantea utilizar el lavadero del primer piso para lo cual se adapta el generador de vapor que se encuentra inoperativo. 
Figura 32.b Ampliación del Diagrama de recorrido de la actividad de limpieza propuesto en el primer piso

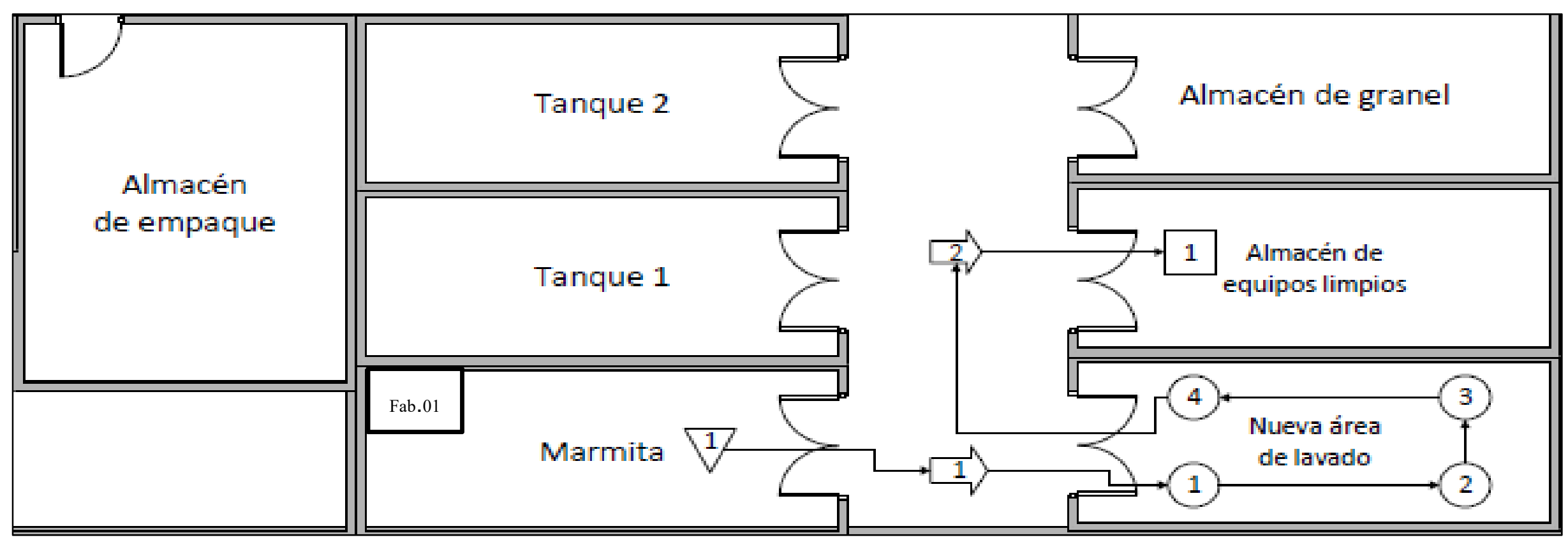

Fuente: Elaboración propia

En la figura 31.b podemos observar con mayor detalles el cambio del recorrido para la limpieza de los tanques y la marmita, el recorrido se inicia desde la sala de fabricación $\mathrm{N}^{\circ} 01 \mathrm{y}$ al frente se encuentra la nueva sala de lavado en el primer piso. 


\subsubsection{Propuesta en la actividades de trasvase en fabricación}

Actualmente el proceso de fabricación se hace utilizando 3 salas de fabricación y se inicia con las actividades de arranque donde se realiza la limpieza del sistema de trasvase que son tubos de acero inoxidable de $10 \mathrm{~cm}$ de diámetro y recorren $9 \mathrm{~m}$. Estos son llevados hasta el segundo piso para su limpieza. La fase acuosa y la fase grasa son trasvasadas a la marmita principal por este canal y se continúa con las demás operaciones unitarias de mezclar, homogenizar, enfriar y descargar.

Figura 33 Proceso de fabricación actual

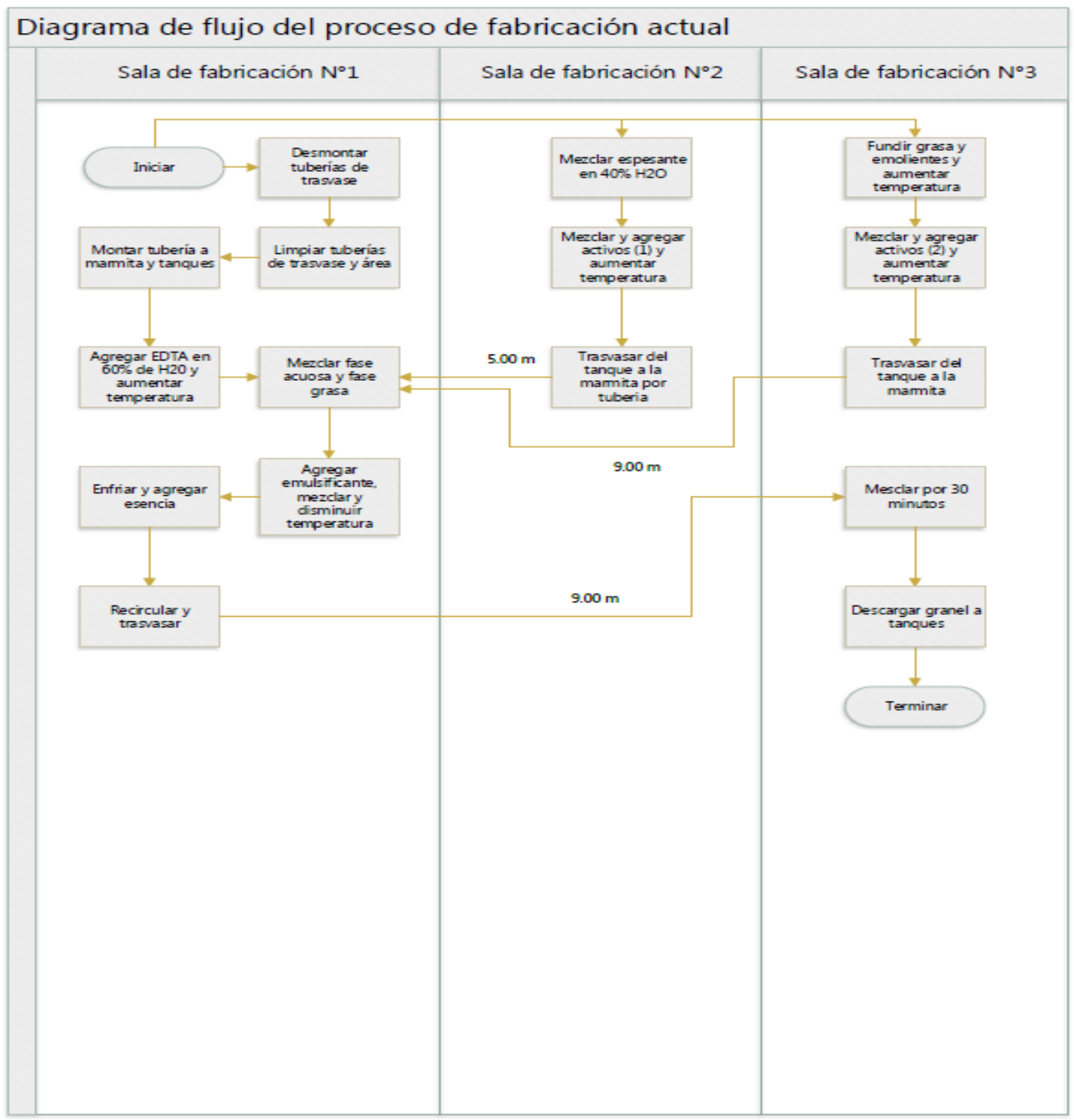

Fuente: Elaboración propia

Se propone disminuir tiempo de recorrido y tiempos de esperas (esto se determina mediante el diagrama de recorrido los metros actuales y mediante el DAP las actividades que no 
generan valor y que se puede eliminar o juntarlas. Se propone realizar toda la fabricación en la sala principal $\mathrm{N}^{\circ} 01$, trasladar los taques 2 y 3 (ponerlos ruedas) e implementar el sistema de trasvase con pequeñas mangueras sanitarias y clanes para juntarlos, esto nos disminuye recorrido y tiempos y merma de granel. Véase la Fig. 33

Figura 34 Proceso de fabricación propuesto

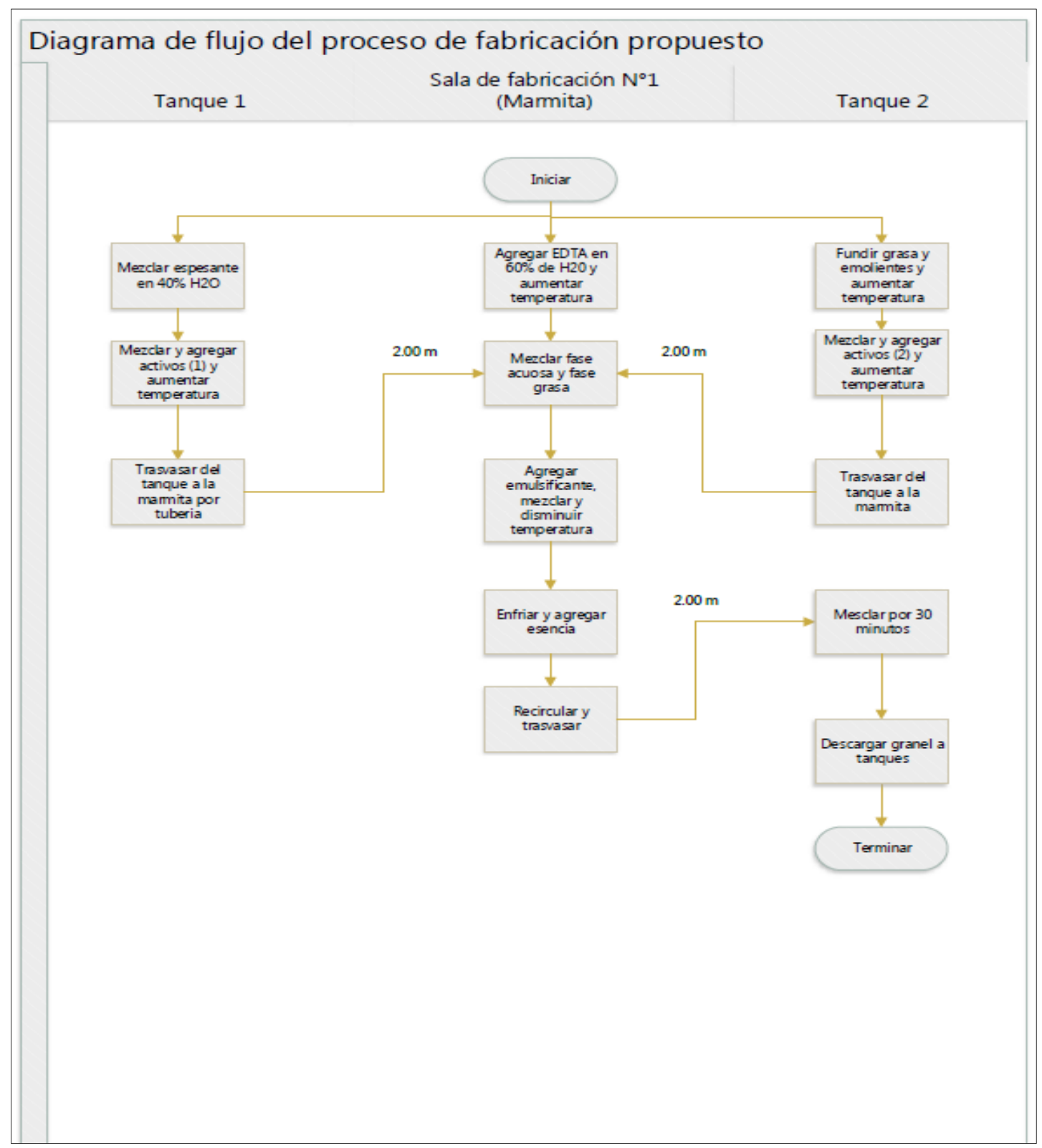

Fuente: Elaboración propia

Se propone disminuir el recorrido en el trasvase y en las actividades de la fase acuosa y la fase grasa, aprovechando que los tanques de fabricación secundarias se pueden mover, con esto se disminuye tiempo de recorrido, tiempo de actividad, merma de granel, debido a que se propone a usar mangueras sanitarias que ya se utilizan en otros procesos para los trasvases. 
Figura 35 Layout de la empresa con el recorrido del proceso de fabricación actual

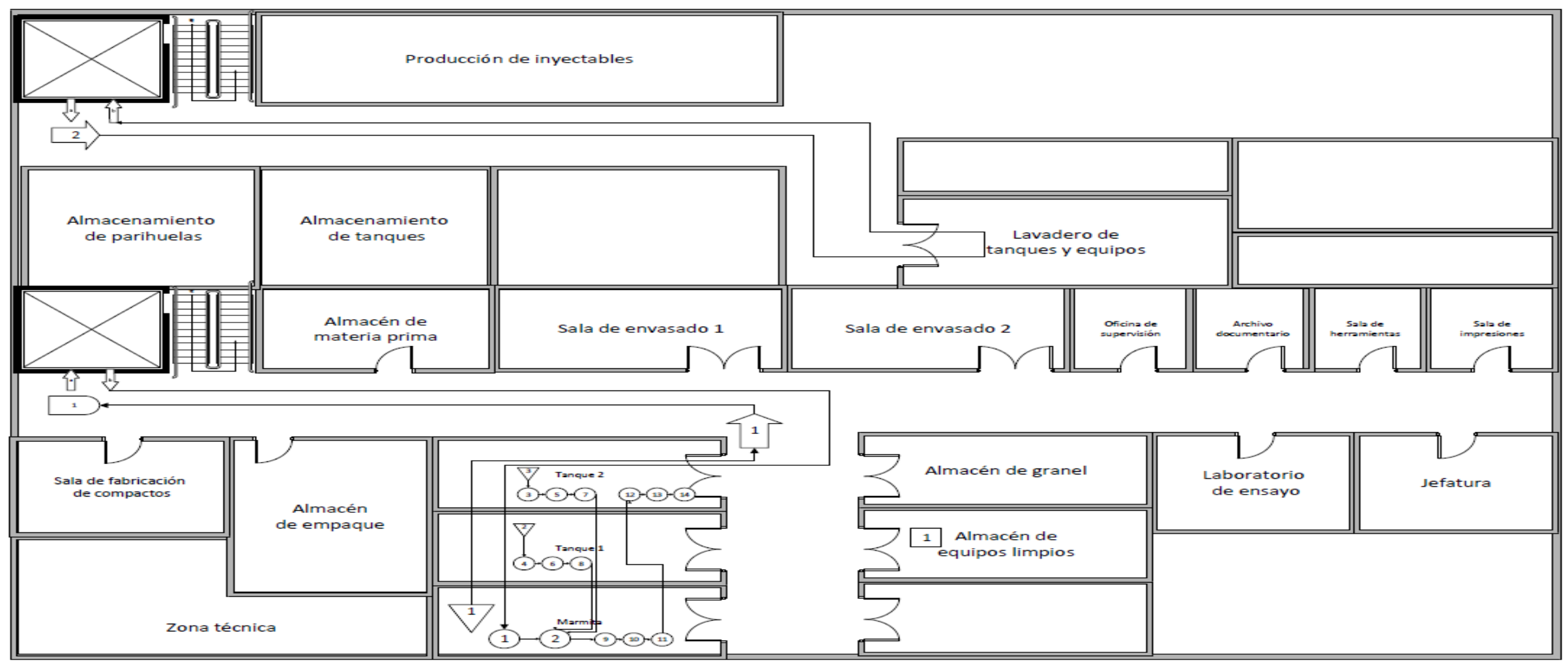

Fuente: Elaboración propia

El recorrido en las actividades de producción implica un recorrido de 98 metros por la actividad de limpieza del sistema de tuberías de trasvase, por otro lado el recorrido de las actividades de trasvase entre tres salas de fabricación ambas son oportunidades de mejora, con la cual se pretende eliminar desperdicios de tiempo y granel. 
Figura 36 Diagrama de recorrido del proceso de fabricación propuesto

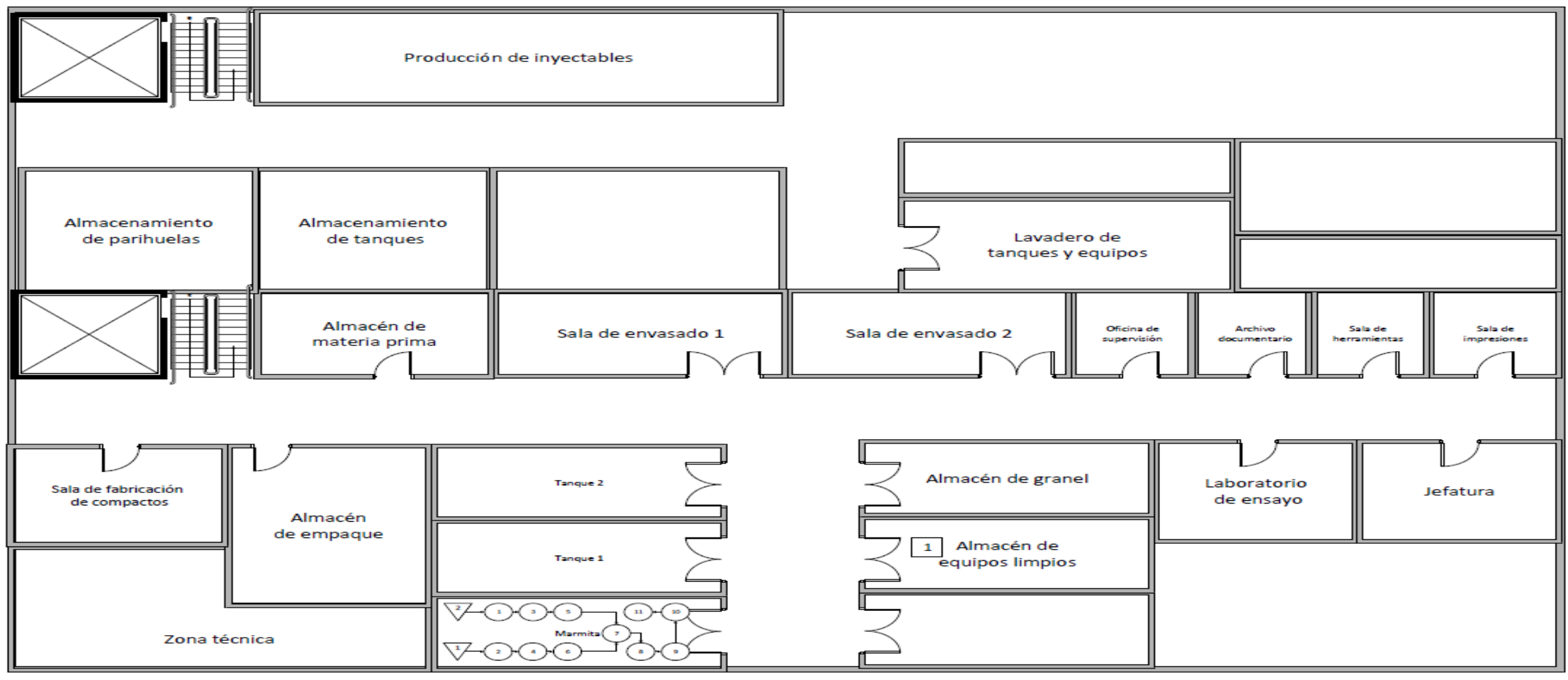

Fuente: Elaboración propia.

El nuevo recorrido en las operaciones de fabricación (Fig. 35) con lo cual se acorta la distancia de los trasvases inicial y el trasvase final de recirculación, esta disminución redunda en una menor merma de granel por que a mayor distancia de recorrido en el sistema de trasvase mayor cantidad de merma. 


\subsubsection{Propuesta en las actividades de arranque en el envasado}

El envasado se inicia con las actividades de arranque, la cual a su vez comienza con la limpieza de la maquina envasadora el cual es traslado desde el primer piso hasta el segundo piso (esta mejora de recorrido ya se ha presentado con los diferentes diagramas de recorrido de las propuestas anteriores), la forma de limpieza actual de la maquina involucra las mismas ineficiencias planteadas en la propuesta de limpieza. Una de las actividades es purgar granel o mermar granel para arrastrar solución desinfectante que pudiera quedar en el sistema. Ver la Fig. 36.

Figura 37 Proceso de envasado actual

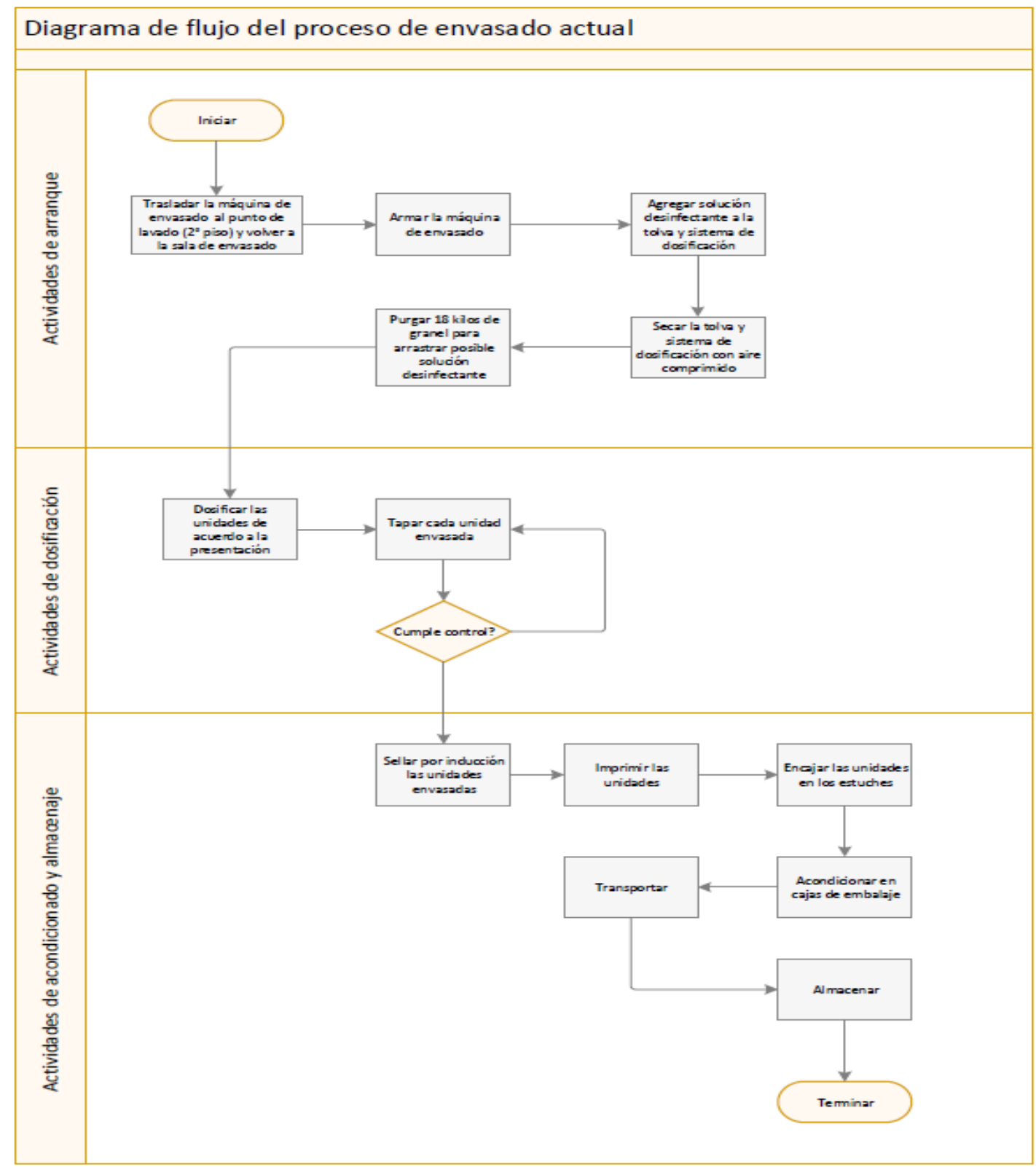

Fuente: Elaboración propia 
Se propone utilizar el nuevo método de limpieza con lo cual se utiliza calor para secar y desinfectar la tolva, con lo cual se hace innecesaria purgar y ahorrar en promedio $17-18 \mathrm{~kg}$ de merma de granel. Ver la Figura 37

Figura 38 Proceso de envasado propuesto

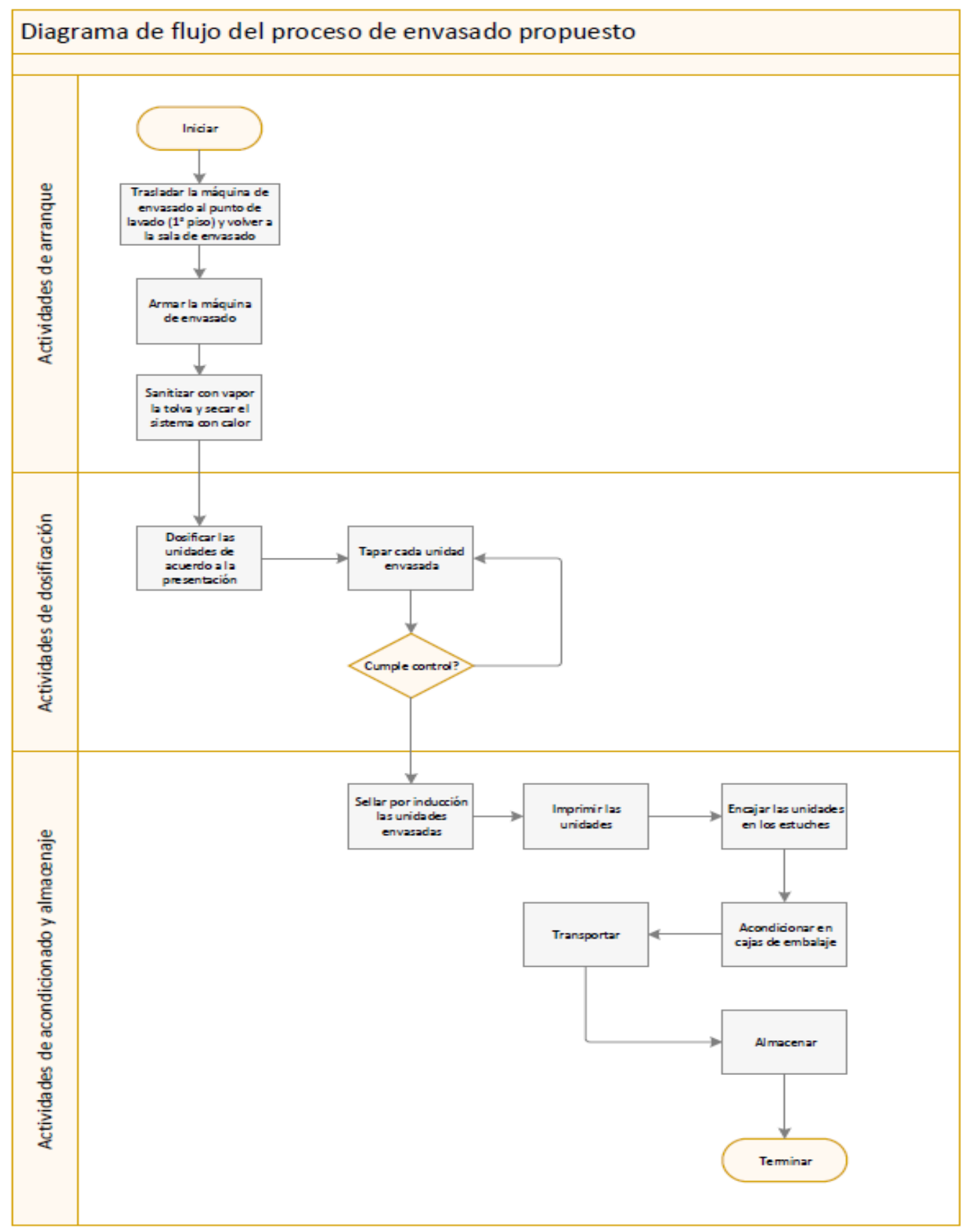

Fuente: Elaboración propia 
Se propone mejorar el recorrido de la actividad de limpieza de la maquina envasadora, unir las actividades de desinfectar y secar y eliminar la actividad de purga, porque se utiliza el sistema de secado de la nueva área de lavado.

\subsubsection{Propuesta de balance de líneas de envasado}

Para el estudio de tiempo se empleó el formato diseñado y adaptado a las actividades del laboratorio cosmético. (Ver anexo)

- Técnica utilizada

La técnica utilizada para el balance de línea será la toma de tiempos con cronómetro

- Población

Para el estudio se tomó en cuenta 15 productos de la línea de shampoo y 15 productos de la línea de cremas y lociones por lo que no hay necesidad determinar la muestra. Se tomaran 10 observaciones de acuerdo a lo que indica García (2014):

- Instrumento para el estudio

Para la toma de datos y análisis utilizaremos el formato de toma de tiempos como hoja de datos.

\subsection{Recursos para el desarrollo de la implementación}

Para el desarrollo de las propuestas se requieren recursos previos para su implementación.

\subsubsection{Capacitaciones}

Tabla 7 Programa de capacitación para la implementación

\begin{tabular}{|c|c|c|c|}
\hline Actividad & Despliegue & Dirigido & $\begin{array}{c}\text { Tiempo de } \\
\text { capacitación }\end{array}$ \\
\hline Capacitación(1) de & Lectura del nuevo & Personal de & \\
las nuevas & procedimiento de & fabricación y & 12 horas \\
actividades de & limpieza de las & Técnicos de & \\
limpieza & máquinas y tanques & envasado & \\
\hline
\end{tabular}




\begin{tabular}{|c|c|c|c|}
\hline $\begin{array}{l}\text { Practica del proceso } \\
\text { de capacitación(1) }\end{array}$ & $\begin{array}{c}\text { Verificar la } \\
\text { aplicación del nuevo } \\
\text { procedimiento }\end{array}$ & $\begin{array}{l}\text { Personal de } \\
\text { fabricación y } \\
\text { Técnicos de } \\
\text { envasado }\end{array}$ & 6 horas \\
\hline $\begin{array}{l}\text { Capacitación }(2) \text { de } \\
\text { las nuevas } \\
\text { actividades de } \\
\text { trasvase }\end{array}$ & $\begin{array}{l}\text { Lectura del nuevo } \\
\text { procedimiento de } \\
\text { trasvase en el } \\
\text { proceso de } \\
\text { fabricación }\end{array}$ & $\begin{array}{l}\text { Personal de } \\
\text { fabricación y } \\
\text { Técnicos de } \\
\text { envasado }\end{array}$ & 12 horas \\
\hline $\begin{array}{l}\text { Practica del proceso } \\
\text { de capacitación(2) }\end{array}$ & $\begin{array}{c}\text { Verificar la } \\
\text { aplicación del nuevo } \\
\text { procedimiento }\end{array}$ & $\begin{array}{l}\text { Personal de } \\
\text { fabricación y } \\
\text { Técnicos de } \\
\text { envasado }\end{array}$ & 6 horas \\
\hline $\begin{array}{c}\text { Capacitación(3) de } \\
\text { las nuevas } \\
\text { actividades de } \\
\text { arranque en el } \\
\text { proceso de envasado }\end{array}$ & $\begin{array}{l}\text { Lectura del nuevo } \\
\text { procedimiento de } \\
\text { limpieza de las } \\
\text { máquinas y tanques }\end{array}$ & $\begin{array}{l}\text { Personal maquinista } \\
\text { y personal de } \\
\text { envasado }\end{array}$ & 12 horas \\
\hline $\begin{array}{l}\text { Practica del proceso } \\
\text { de capacitación(1) }\end{array}$ & $\begin{array}{c}\text { Verificar la } \\
\text { aplicación del nuevo } \\
\text { procedimiento }\end{array}$ & $\begin{array}{l}\text { Personal maquinista } \\
\text { y personal de } \\
\text { envasado }\end{array}$ & 6 horas \\
\hline
\end{tabular}

Fuente: Elaboración propia

\subsubsection{Materiales}

Se requieren los siguientes materiales para la implementación de las mejoras.

Tabla 8 Lista de materiales según problema identificado

\begin{tabular}{|c|c|c|c|}
\hline PROBLEMA 1 & PROBLEMA 2 & PROBLEMA 3 & PROBLEMA 4 \\
\hline $\begin{array}{c}\text { Canaletas y } \\
\text { cables(60mt) }\end{array}$ & $\begin{array}{c}\text { Mangueras sanitarias } \\
\text { flexibles con clanes }\end{array}$ & $\begin{array}{c}\text { Resistencia tipo P } \\
\text { para la tolva de la } \\
\text { chaqueta de } \\
\text { envasado }\end{array}$ & 4 cronómetros \\
\hline $\begin{array}{c}\text { Manguera sanitaria } \\
\text { resistente al calor }\end{array}$ & & & \\
\hline
\end{tabular}




\begin{tabular}{|c|c|l|c|}
\hline & $\begin{array}{c}\text { Instalación de llantas } \\
\text { a los tanques de } \\
\text { fabricación 2 y 3 }\end{array}$ & & $\begin{array}{c}\text { T Tableros para } \\
\text { toma de datos }\end{array}$ \\
\hline $\begin{array}{c}\text { Sistema de válvula de } \\
\text { vapor, termostato, para } \\
\text { el punto de vapor en el } \\
\text { primer piso(nueva área } \\
\text { de lavado) }\end{array}$ & & & \\
\hline $\begin{array}{c}\text { Resistencia tipo J y } \\
\text { pintura epóxica para el } \\
\text { generador de vapor }\end{array}$ & & & \\
\hline
\end{tabular}

Fuente: Elaboración propia 
3.3 Indicadores de medición de la investigación (Ref. Optimización de tiempos de procesos de embolletadora.J.I. Ruiz M. 2017)

Tabla 9 Indicadores de medición de la investigación

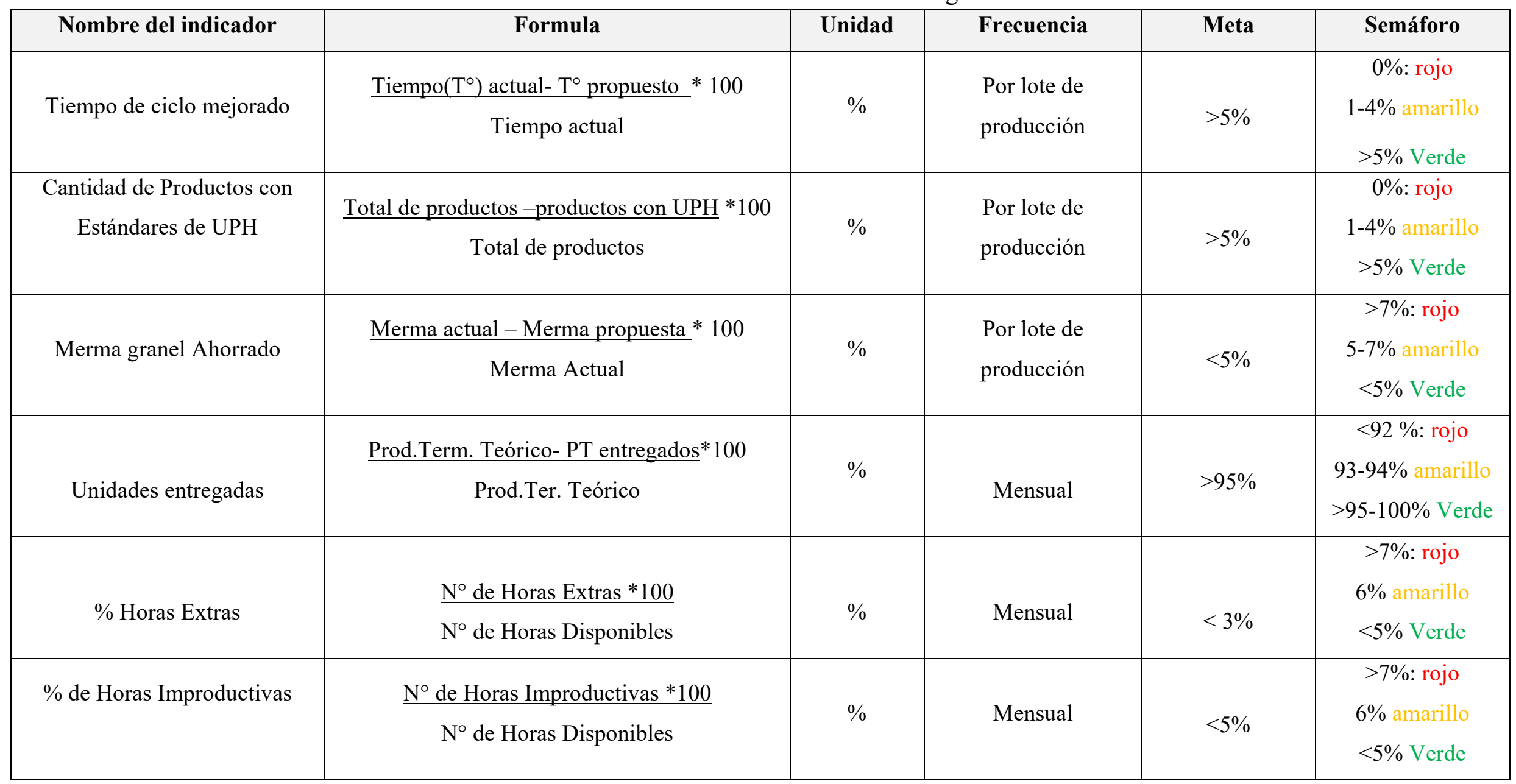

Fuente: Elaboración propia 


\subsection{Cronograma de actividades de la investigación}

Figura 39 Cronograma de actividades de implementación

\begin{tabular}{|c|c|c|c|c|c|c|c|c|c|c|c|c|c|c|c|c|c|c|c|c|c|c|c|c|}
\hline \multirow{2}{*}{ Id. } & \multirow{2}{*}{ Nombre de tarea } & \multirow{2}{*}{ Inicio } & \multirow{2}{*}{ Finalizar } & \multirow{2}{*}{ Duración } & \multicolumn{6}{|c|}{$2 \operatorname{sep} 2018$} & \multicolumn{7}{|c|}{$9 \operatorname{sep} 2018$} & \multicolumn{7}{|c|}{$16 \operatorname{sep} 2018$} \\
\hline & & & & & 3 & 4 & 5 & 6 & 7 & 8 & 9 & 10 & 11 & 12 & 13 & 14 & 15 & 16 & 17 & 18 & 19 & 20 & 21 & 22 \\
\hline 1 & Definición de indicadores de medición & $03 / 09 / 2018$ & $07 / 09 / 2018$ & $5 d$ & & & & & & & & & & & & & & & & & & & & \\
\hline 2 & Problema 1 & $03 / 09 / 2018$ & $21 / 09 / 2018$ & $15 d$ & & & & & & & & & & & & & & & & & & & & 7 \\
\hline 4 & $\begin{array}{l}\text { Observación de actividades de } \\
\text { limpieza actuales (marmitay tanques) }\end{array}$ & $04 / 09 / 2018$ & 05/09/2018 & $2 d$ & 4 & & & & & & & & & & & & & & & & & & & \\
\hline 5 & $\begin{array}{l}\text { Diseño de diagramas de actividades } \\
\text { de limpieza y tanques }\end{array}$ & $06 / 09 / 2018$ & $07 / 09 / 2018$ & $2 d$ & & & & & & & & & & & & & & & & & & & & \\
\hline 6 & $\begin{array}{l}\text { Análisis del método actual de } \\
\text { limpieza }\end{array}$ & $06 / 09 / 2018$ & $07 / 09 / 2018$ & $2 d$ & & & & & & & & & & & & & & & & & & & & \\
\hline 7 & $\begin{array}{l}\text { Propuesta de mejora en actividades } \\
\text { de limpieza y diseño de diagramas }\end{array}$ & $10 / 09 / 2018$ & $10 / 09 / 2018$ & $1 d$ & & & & & & & & & & & & & & & & & & & & \\
\hline 8 & $\begin{array}{l}\text { Compra de material para la aplicación } \\
\text { delas mejoras }\end{array}$ & $11 / 09 / 2018$ & $12 / 09 / 2018$ & $2 d$ & & & & & & & & & & & & & & & & & & & & \\
\hline 9 & $\begin{array}{l}\text { Capacitación de las actividades } \\
\text { mejoradas de limpieza }\end{array}$ & $11 / 09 / 2018$ & $13 / 09 / 2018$ & $3 d$ & & & & & & & & & & & & & & & & & & & & \\
\hline 10 & $\begin{array}{l}\text { Aplicación de la propuesta en los } \\
\text { lotes piloto definidos }\end{array}$ & $14 / 09 / 2018$ & $21 / 09 / 2018$ & $6 d$ & & & & & & & & & & & & & & & & & & & & \\
\hline 11 & $\begin{array}{l}\text { Comparación y medición de } \\
\text { indicadores }\end{array}$ & $18 / 09 / 2018$ & $21 / 09 / 2018$ & $4 d$ & & & & & & & & & & & & & & & & & & & & \\
\hline 12 & Conclusiones y recomendaciones & $19 / 09 / 2018$ & $21 / 09 / 2018$ & $3 d$ & & & & & & & & & & & & & & & & & & & & \\
\hline
\end{tabular}




\begin{tabular}{|c|c|c|c|c|c|c|c|c|c|c|c|c|c|c|c|c|c|}
\hline 13 & Problema 2 & $24 / 09 / 2018$ & $05 / 10 / 2018$ & $10 \mathrm{~d}$ & & & & & & & & & & & & & \\
\hline 14 & Definición de lotes piloto & $24 / 09 / 2018$ & $24 / 09 / 2018$ & $1 d$ & & & & & & & & & & & & & \\
\hline 15 & $\begin{array}{l}\text { Observación de actividades actuales } \\
\text { defabricación }\end{array}$ & $25 / 09 / 2018$ & $25 / 09 / 2018$ & $1 \mathrm{~d}$ & & & & & & & & & & & & & \\
\hline 16 & $\begin{array}{l}\text { Diseño de diagramas de actividades } \\
\text { defabricación }\end{array}$ & $25 / 09 / 2018$ & $26 / 09 / 2018$ & $2 d$ & & & & & & & & & & & & & \\
\hline 17 & $\begin{array}{l}\text { Análisis del método actual de } \\
\text { fabricación }\end{array}$ & $26 / 09 / 2018$ & $27 / 09 / 2018$ & $2 d$ & & & & & & & & & & & & & \\
\hline 18 & $\begin{array}{l}\text { Propuesta de mejora en actividades } \\
\text { defabricación y diseño de diagramas }\end{array}$ & $27 / 09 / 2018$ & 28/09/2018 & $2 d$ & & & & & & & & & & & & & \\
\hline 19 & $\begin{array}{l}\text { Compra de materiales para la } \\
\text { aplicación de las mejoras }\end{array}$ & 28/09/2018 & 28/09/2018 & $1 d$ & & & & & & & & & & & & & \\
\hline 20 & $\begin{array}{l}\text { Capacitación de las actividades } \\
\text { mejoradas defabricación }\end{array}$ & $28 / 09 / 2018$ & 28/09/2018 & $1 d$ & & & & & & & & & & & & & \\
\hline 21 & $\begin{array}{l}\text { Aplicación de la propuesta en los } \\
\text { lotes piloto definidos }\end{array}$ & $28 / 09 / 2018$ & 05/10/2018 & $6 d$ & & & & & & & & & & & & & \\
\hline 22 & $\begin{array}{l}\text { Comparación y medición de } \\
\text { indicadores }\end{array}$ & 03/10/2018 & 05/10/2018 & $3 d$ & & & & & & & & & & & & & \\
\hline 23 & Condusiones y recomendaciones & $04 / 10 / 2018$ & 05/10/2018 & $2 \mathrm{~d}$ & & & & & & & & & & & & & \\
\hline \multirow{2}{*}{ Id. } & \multirow{2}{*}{ Nombre de tarea } & \multirow{2}{*}{ Inicio } & \multirow{2}{*}{ Finalizar } & \multirow{2}{*}{ Duración } & \multicolumn{6}{|l|}{$23 \operatorname{sep} 2018$} & \multicolumn{7}{|c|}{30 sep 2018} \\
\hline & & & & & 24 & 25 & 26 & 27 & 28 & 29 & 30 & 1 & 2 & 3 & 4 & 5 & 6 \\
\hline
\end{tabular}

Fuente: Elaboración propia 


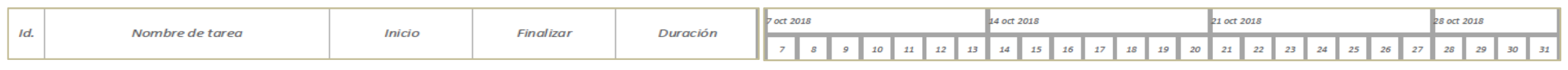

\begin{tabular}{|c|c|c|c|c|}
\hline 24 & Problema 3 & $08 / 10 / 2018$ & $19 / 10 / 2018$ & $10 \mathrm{~d}$ \\
\hline 25 & Definición de lotes piloto & $08 / 10 / 2018$ & $08 / 10 / 2018$ & $1 d$ \\
\hline 26 & $\begin{array}{l}\text { Observación de actividades actuales } \\
\text { de envasado }\end{array}$ & $08 / 10 / 2018$ & $08 / 10 / 2018$ & $1 d$ \\
\hline 27 & $\begin{array}{l}\text { Diseño de diagramas de las } \\
\text { actividades actuales de envasado }\end{array}$ & $09 / 10 / 2018$ & $10 / 10 / 2018$ & $2 \mathrm{~d}$ \\
\hline 28 & $\begin{array}{l}\text { Análisis del método actual de } \\
\text { envasado }\end{array}$ & $10 / 10 / 2018$ & $11 / 10 / 2018$ & $2 d$ \\
\hline 29 & $\begin{array}{l}\text { Propuesta de mejora de actividades de arran que } \\
\text { de envasado y diseño de diæzramas }\end{array}$ & $11 / 10 / 2018$ & $12 / 10 / 2018$ & $2 \mathrm{~d}$ \\
\hline 30 & $\begin{array}{l}\text { Compra de materiales para la } \\
\text { aplicación de las mejoras }\end{array}$ & $12 / 10 / 2018$ & $12 / 10 / 2018$ & $1 d$ \\
\hline 31 & $\begin{array}{l}\text { Capacitación de las actvidades } \\
\text { mejoradas de armanque de envasado }\end{array}$ & $12 / 10 / 2018$ & $12 / 10 / 2018$ & $1 d$ \\
\hline 32 & $\begin{array}{l}\text { Aplicación de la propuesta en los } \\
\text { lotes piloto definidos }\end{array}$ & $15 / 10 / 2018$ & $15 / 10 / 2018$ & $1 d$ \\
\hline 33 & $\begin{array}{l}\text { Comparación y medición de } \\
\text { indicadores }\end{array}$ & $16 / 10 / 2018$ & $18 / 10 / 2018$ & $3 d$ \\
\hline 34 & Condusiones y recomendaciones & $18 / 10 / 2018$ & $19 / 10 / 2018$ & $2 \mathrm{~d}$ \\
\hline 35 & Problema 4 & $22 / 10 / 2018$ & $01 / 11 / 2018$ & 9d \\
\hline 36 & Definición de lotes piloto & $22 / 10 / 2018$ & $22 / 10 / 2018$ & $1 d$ \\
\hline 37 & Toma de tiempos de la línea 'Colonia' & $22 / 10 / 2018$ & $22 / 10 / 2018$ & $1 d$ \\
\hline 38 & $\begin{array}{l}\text { Toma de tiempos de la línea } \\
\text { 'Shampoo' }\end{array}$ & $22 / 10 / 2018$ & $22 / 10 / 2018$ & $1 d$ \\
\hline 39 & Toma de tiempos de la línea 'Cremas' & $22 / 10 / 2018$ & $22 / 10 / 2018$ & $1 \mathrm{~d}$ \\
\hline 40 & Análisis de data & $22 / 10 / 2018$ & $24 / 10 / 2018$ & $3 \mathrm{~d}$ \\
\hline 41 & $\begin{array}{l}\text { Balance de líneas y propuestas de } \\
\text { mejora }\end{array}$ & $24 / 10 / 2018$ & $26 / 10 / 2018$ & $3 d$ \\
\hline 42 & $\begin{array}{l}\text { Comparación y medición de } \\
\text { indicadores }\end{array}$ & $29 / 10 / 2018$ & $31 / 10 / 2018$ & $3 d$ \\
\hline 43 & Condusiones y recomendaciones & $30 / 10 / 2018$ & $01 / 11 / 2018$ & $3 d$ \\
\hline
\end{tabular}

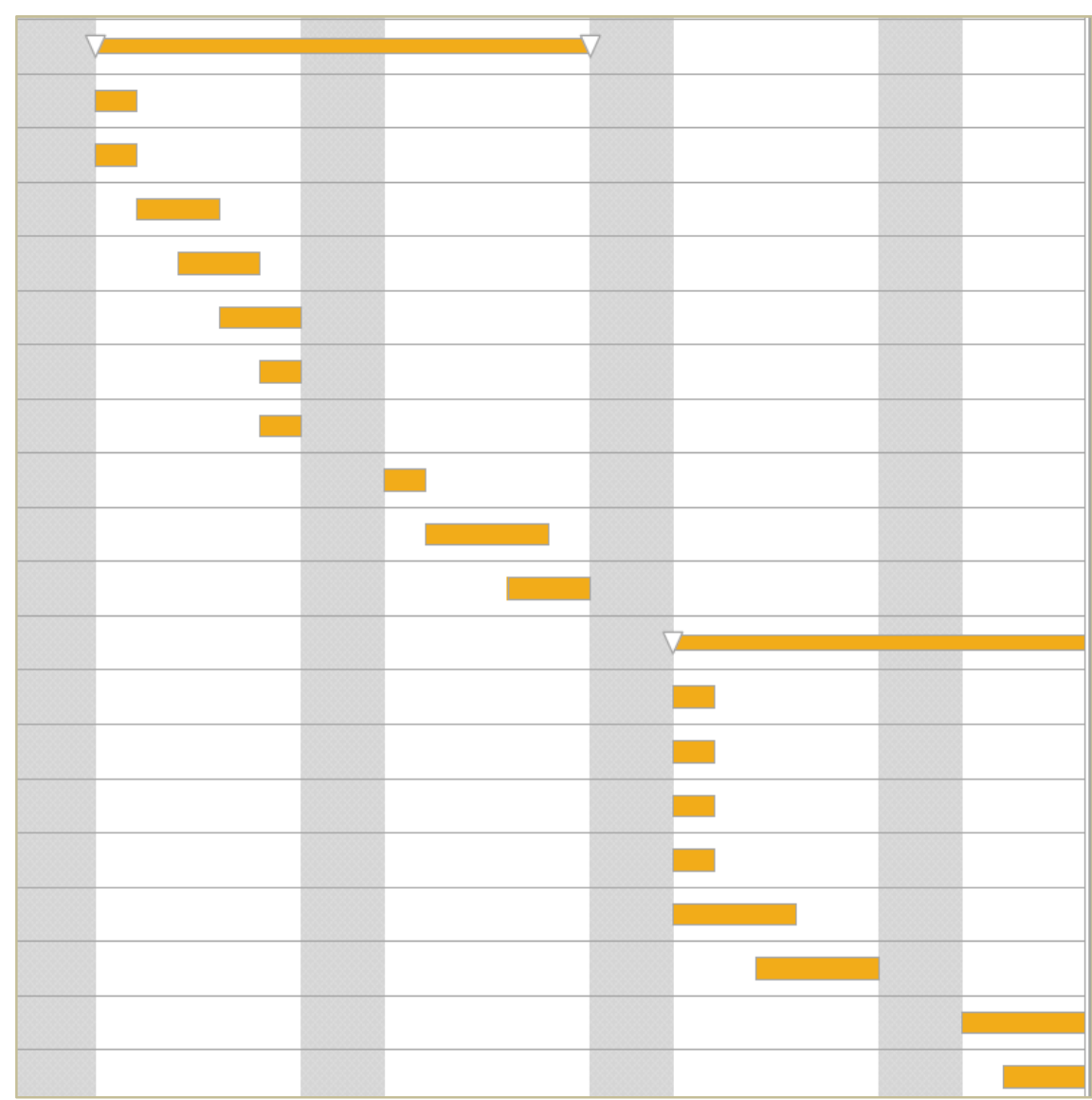

Fuente: Elaboración propia. 
Se termina este capítulo concluyendo la presentación de la propuestas para la disminución de desperdicios como disminución de tiempos de actividades, disminución de tiempos de recorrido, disminución de merma de granel y eliminación de actividades que no generan valor en las actividades de limpieza, en las actividades del trasvase en el proceso de fabricación, y en las actividades del arranque de envasado, el estudio de método nos permitió visualizar las falencia de ineficacia en las actividades mencionadas.

El tiempo ciclo y la validación del estándar real de unidades por hora (UPH real) que redunda en el desbalance de las líneas de producción de Shampoo y Cremas es solucionada en el presente trabajo con el estudio de tiempo por cronometro, el cual se generó la plantilla para la toma de datos y se realizaran sendas observaciones por línea de trabajo de acuerdo a la fórmula de muestreo (Luis Montalvo, 2016).

Se definieron con planeamiento la presentación de los lotes de producción para realizar los pilotos para la aplicación de las propuestas, estos han sido seleccionados de las tres líneas de producción por representar el 75\% de la producción del laboratorio cosmético.

Para la implementación se presentó la lista de recursos y materiales que la empresa tiene que invertir para la ejecución de las mejoras de acuerdo al estudio de recorrido planteado.

Se culmina este capítulo con la presentación del Gantt para la implementación de las propuestas en los lotes pilotes determinados en coordinación con la Jefatura de Producción y el área de planeamiento. 


\section{Capítulo IV: Validación y Resultado}

En el capítulo anterior se presentaron el diseño de la propuesta de mejoras para resolver los problemas planteados en el análisis.

En este capítulo vamos a validar que esa propuesta es consistente y confirma la mejora planteada redundando en una disminución de desperdicios en la línea de producción del laboratorio cosmético.

Esta validación se confirma en la ejecución de lotes pilotos de producción en la planta, en coordinación con el área de planeamiento y con autorización de la alta dirección para poder hacer uso de recursos necesarios para aplicar la propuesta.

La presentación del análisis de los resultados que demuestran las mejoras que manifiestan una disminución de desperdicios (tiempo, horas hombres, mermas de granel)

Finalmente presentaremos la evaluación económica de costo-beneficio por cada mejora presentada y la evaluación de riesgo de la implementación de las mejoras a través de la matriz de leopold.

\subsection{Validación del Piloto}

La validación de la propuesta se ha realizado en lotes pilotos de prueba en cantidades industriales normales de producción en 2 líneas: Shampoo y Cremas-Loción (ver anexo)

\subsubsection{Análisis comparativo de la situación inicial y posterior al piloto}

Se muestra el resumen en la siguiente figura el cual se vincula las causas que generan los efectos mencionados de horas improductivas, incumplimiento de cantidad a entregar a los clientes, merma de granel tanto en fabricación como en envasado, estándares de UPH no validados que afectan a la programación y que contribuyen a generar horas extras no planificadas y horas improductivas, éstos se relacionan con los indicadores obtenidos antes y después del piloto. 
Figura 40 Análisis comparativo de indicadores del proyecto

\begin{tabular}{|c|c|c|c|c|c|c|}
\hline Causa & Efecto & Solución & $\begin{array}{c}\text { Indicador/Etapa } \\
\text { del proyecto }\end{array}$ & $\begin{array}{c}\text { Antes de la } \\
\text { implementación }\end{array}$ & $\begin{array}{c}\text { Después de la } \\
\text { implementación }\end{array}$ & $\%$ de mejora \\
\hline $\begin{array}{l}\text { Actividad de } \\
\text { limpieza } \\
\text { ineficiente }\end{array}$ & $\begin{array}{c}\text { Horas } \\
\text { Improductivas }(\mathrm{t})\end{array}$ & $\begin{array}{l}\text { Nuevo método de } \\
\text { limpieza de } \\
\text { marmitas y } \\
\text { tanques(ver } \\
\text { anexo) }\end{array}$ & $\begin{array}{c}\text { Tiempo de Ciclo } \\
\text { mejorado } \\
\text { Limpieza(t) }\end{array}$ & $2.26 \mathrm{H}$ & $1.81 \mathrm{H}$ & $19.91 \%$ \\
\hline \multirow{2}{*}{$\begin{array}{l}\text { Actividad de } \\
\text { trasvase } \\
\text { ineficiente en } \\
\text { fabricación }\end{array}$} & \multirow[t]{2}{*}{$\begin{array}{l}\text { Incumplimiento } \\
\text { de cantidad } \\
\text { entregada(Unid) }\end{array}$} & \multirow[t]{2}{*}{$\begin{array}{l}\text { Nuevo método de } \\
\text { trasvase(Ver } \\
\text { anexo) }\end{array}$} & $\begin{array}{l}\text { Merma de granel } \\
\text { ahorrado }(\mathrm{Kg})\end{array}$ & $12 \mathrm{Kg}$ & $3 \mathrm{Kg}$ & $75 \%$ \\
\hline & & & $\begin{array}{l}\text { Tiempo de Ciclo } \\
\text { mejorado Fab. }(\mathrm{t})\end{array}$ & $5.69 \mathrm{H}$ & $4.20 \mathrm{H}$ & $26.18 \%$ \\
\hline \multirow{3}{*}{$\begin{array}{l}\text { Actividad de } \\
\text { arranque } \\
\text { ineficiente en } \\
\text { envasado }\end{array}$} & $\begin{array}{l}\text { Mermas de } \\
\text { granel }(\mathrm{Kg})\end{array}$ & \multirow{3}{*}{$\begin{array}{l}\text { Nuevo método de } \\
\text { arranque en el } \\
\text { envasado(ver } \\
\text { anexo) }\end{array}$} & $\begin{array}{l}\text { Merma de granel } \\
\text { ahorrado(Kg) }\end{array}$ & 18 & 0 & $100 \%$ \\
\hline & $\begin{array}{l}\text { Incumplimiento } \\
\text { de cantidad }\end{array}$ & & $\begin{array}{l}\text { Tiempo de Ciclo } \\
\text { mejorado Env.(t) }\end{array}$ & 4.75 & 3.91 & $17.68 \%$ \\
\hline & entregada(Unid) & & $\begin{array}{l}\text { Unidades de } \\
\text { entrega (Und) }\end{array}$ & 20235 & 21145 & $4.49 \%$ \\
\hline \multirow{4}{*}{$\begin{array}{c}\text { Desbalance de las } \\
\text { líneas de } \\
\text { envasado }\end{array}$} & Estándares de & \multirow{4}{*}{$\begin{array}{l}\text { Determinación de } \\
\text { estándares de } \\
\text { UPH(unidades } \\
\text { por Hora) } \\
\text { mediante estudio } \\
\text { de tiempo por } \\
\text { cronómetro y } \\
\text { balance de línea }\end{array}$} & UPH & 2000 & 2226 & $11.3 \%$ \\
\hline & $\begin{array}{l}\text { UPH no validados } \\
\text { que afectan la } \\
\text { programación }\end{array}$ & & $\begin{array}{c}\text { Cantidad de } \\
\text { productos con } \\
\text { estándar de UPH }\end{array}$ & 0 & 20 & $10 \%$ \\
\hline & $\begin{array}{l}\text { Horas Extras no } \\
\text { planificadas }(\mathrm{t})\end{array}$ & & $\begin{array}{c}\text { Hora Extras } \\
\text { ahorradas(H) }\end{array}$ & 478 & 299 & $37.4 \%$ \\
\hline & $\begin{array}{c}\text { Horas } \\
\text { Improductivas }(\mathrm{t})\end{array}$ & & $\begin{array}{c}\text { Horas } \\
\text { improductivas } \\
\text { ahorradas }(\mathrm{H}) \\
\end{array}$ & 428 & 278 & $35.04 \%$ \\
\hline
\end{tabular}

Fuente: Elaboración propia 
Figura 41 Resumen de resultado del comparativo de indicadores

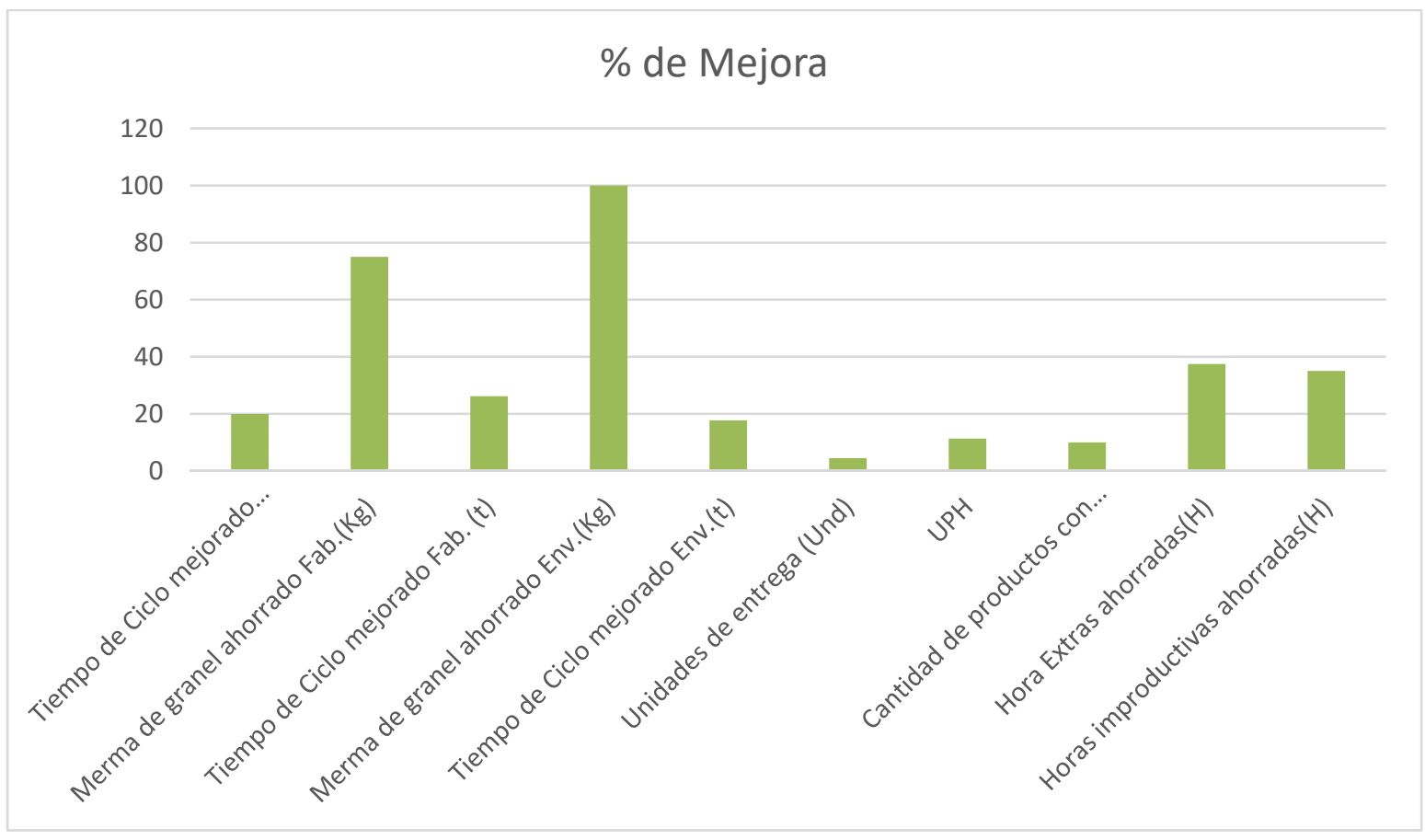

Fuente: Elaboración propia

Previamente se realiza un formato de check list de verificación para la confirmación de los elementos y materiales para la ejecución de las propuestas en los pilotos y se confirma la implementación de estos.

\subsubsection{Implementación de materiales y recursos}

\subsubsection{Para el nuevo método de limpieza en el primer piso}

Tabla 10 Desarrollo de la implementación del método de limpieza en el primer piso propuesto

\begin{tabular}{|c|c|l|}
\hline \multicolumn{1}{|c|}{ Actividad } & Material/Requerimiento & \multicolumn{1}{|c|}{ Logro validado } \\
\hline $\begin{array}{l}\text { Se valida la implementación } \\
\text { de canaleta para acortar } \\
\text { distancia de recorrido para el } \\
\text { nuevo proceso de limpieza } \\
\text { de las marmitas y tanques de } \\
\text { almacenamiento }\end{array}$ & $\begin{array}{l}\text { Por el estudio de recorrido } \\
\text { para el proceso de limpieza } \\
\text { se amplió mediante canaletas } \\
\text { y cables, los puntos para la } \\
\text { obtención del vapor y } \\
\text { energía. }\end{array}$ \\
\hline
\end{tabular}




\begin{tabular}{|c|c|c|}
\hline Actividad & Material/Requerimiento & Logro validado \\
\hline $\begin{array}{l}\text { Adaptación manguera por } \\
\text { disminución de recorrido }\end{array}$ & & $\begin{array}{l}\text { Se compró manguera que } \\
\text { soporta vapor por } \\
\text { disminución de recorrido }\end{array}$ \\
\hline $\begin{array}{l}\text { Instalación de punto de } \\
\text { vapor en sala de lavado del } \\
\text { primer piso }\end{array}$ & & $\begin{array}{l}\text { Se valida la instalación del } \\
\text { punto de vapor para el } \\
\text { proceso de limpieza de } \\
\text { tanques y marmita }\end{array}$ \\
\hline $\begin{array}{l}\text { Compra de resistencia y } \\
\text { pintado del generador de } \\
\text { vapor en desuso }\end{array}$ & & $\begin{array}{l}\text { Se valida el funcionamiento } \\
\text { del generador de vapor que } \\
\text { estaba en desuso en la zona } \\
\text { técnica }\end{array}$ \\
\hline $\begin{array}{l}\text { Capacitación del nuevo } \\
\text { método de limpieza }\end{array}$ & & $\begin{array}{l}\text { Valido capacitación del } \\
\text { nuevo procedimiento a todos } \\
\text { los operadores designados }\end{array}$ \\
\hline $\begin{array}{l}\text { Selección del personal para } \\
\text { el estudio de tiempo de las } \\
\text { actividades de limpieza }\end{array}$ & $\begin{array}{l}\text { Se determina al Sr. Luis Cuadros } \\
\text { como el responsable del análisis de } \\
\text { tiempo }\end{array}$ & $\begin{array}{l}\text { Se pasa al personal a } \\
\text { producción como personal } \\
\text { responsable para la } \\
\text { verificación de tiempo }\end{array}$ \\
\hline
\end{tabular}

Fuente: Elaboración propia 


\subsubsection{Para el nuevo método en las actividades de trasvase}

Tabla 11 Desarrollo de la implementación del método de trasvase propuesto

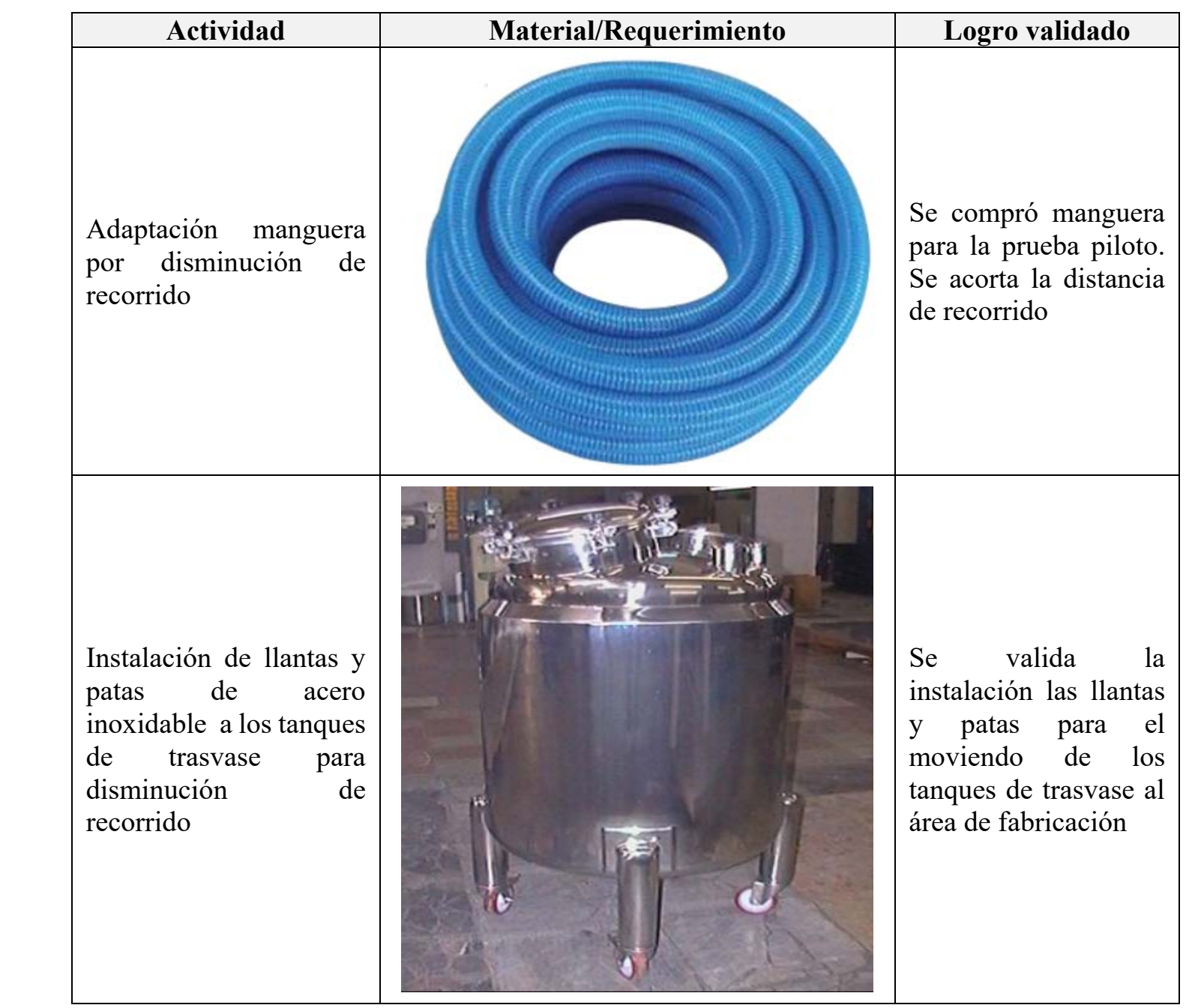

Fuente: Elaboración propia

\subsubsection{Para el nuevo método en las actividades de arranque}

Tabla 12 Desarrollo de la implementación del método de arranque propuesto 


\begin{tabular}{|lll|l|l|}
\hline Actividad & Material/Requerimiento & Logro validado \\
\hline $\begin{array}{l}\text { Compra } \\
\text { reparación de }\end{array}$ & la \\
resistencia & de & la \\
chaqueta & de \\
calentamiento & de \\
las tolvas de & la \\
envasadora &
\end{tabular}

Fuente: Elaboración propia

\subsection{Presentación y análisis de resultados}

\subsubsection{Actividades de limpieza: Se hizo el análisis del DAP}

\subsubsection{Proceso antes de la mejora: (Ver anexo $\mathrm{N}^{\circ} 03$ )}

Actividades para: Ingresar al proceso de fabricación o Envasado

Operadores: 2 
Tabla 13 Resultados del diagrama del proceso de limpieza de marmitas y tanques

\begin{tabular}{|c|c|c|c|c|c|c|c|c|c|}
\hline $\begin{array}{c}\text { PASO } \\
\mathrm{N}^{\circ}\end{array}$ & DETALLE DEL PROCESO & 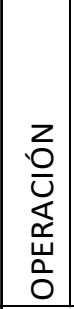 & 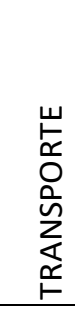 & $\begin{array}{l}z \\
\underline{O} \\
\text { U. } \\
\underline{u} \\
\underline{n} \\
\underline{n}\end{array}$ & 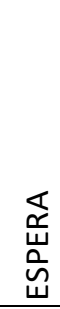 & 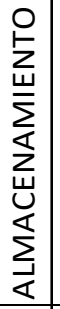 & $\begin{array}{l}\frac{0}{\alpha} \\
\frac{\alpha}{\alpha} \\
\frac{a}{u} \\
0 \\
0\end{array}$ & 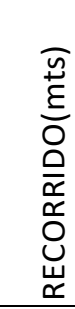 & 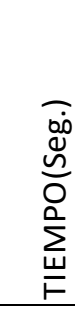 \\
\hline 1 & Trasporte al montacarga & & $\Rightarrow$ & & & & 2 & 14 & 68 \\
\hline 2 & Espera del montacarga & & & & $D$ & & 2 & & 316 \\
\hline 3 & Transportar al area de lavado $2^{\circ}$ piso & & $\Rightarrow$ & & & & 2 & 28 & 72 \\
\hline 4 & Lavado con agua tratada en el segundo piso & O & & & & & 2 & & 2020 \\
\hline 5 & Agregar solución detergente & 0 & & & & & 1 & & 930 \\
\hline 6 & Enjuagar detergente & O & & & & & 1 & & 512 \\
\hline 7 & Desinfectar & $\mathrm{O}$ & & & & & 1 & & 935 \\
\hline 8 & Secar con aire compromido & 0 & & & & & 1 & & 1210 \\
\hline 9 & Esperar airear por 15 minutos & & & & 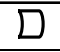 & & 1 & & 902 \\
\hline 10 & Trasporte al montacarga & & $\vec{c}$ & & & & 1 & 28 & 303 \\
\hline 11 & Esperar montacarga & & & & $D$ & & 1 & & 298 \\
\hline 12 & Trasportar al area & & $\Rightarrow$ & & & & 1 & 28 & 286 \\
\hline 13 & control micorobiológico & & & $\square$ & & & 1 & & 300 \\
\hline
\end{tabular}

RESUMEN

\begin{tabular}{|c|c|c|c|c|}
\hline & Cant. & Tiempo(s) & Recorrido(m) & Operario \\
\hline $\mathbf{O}$ & 05 & 5607 & 0 & $2-1$ \\
\hline $\mathbf{D}$ & 04 & 729 & 98 & 2 \\
\hline $\mathbf{D}$ & 03 & 1516 & 0 & 2 \\
\hline$\square$ & 01 & 300 & 0 & 1 \\
\hline Total & & 8152 & 98 & 2 \\
\hline
\end{tabular}

Fuente: Elaboración propia

\subsubsection{Proceso después de la capacitación de la mejora}

Se presenta el DAP propuesto (Ver anexo $\left.\mathrm{N}^{\circ} 04\right)$

Se realizó la capacitación de la mejora y se presentó el nuevo procedimiento de limpieza con código de Aseguramiento: PRO-L01 Versión 02.

Tabla 14 Diagrama del proceso de limpieza de marmitas y tanques propuesto 


\begin{tabular}{|c|c|c|c|c|c|c|c|c|c|}
\hline $\begin{array}{c}\text { PASO } \\
\mathrm{N}^{\circ}\end{array}$ & DETALLE DEL PROCESO & 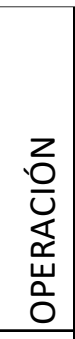 & 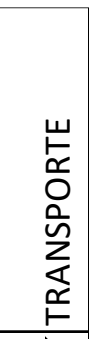 & $\begin{array}{l}z \underline{z} \\
\text { 음 } \\
\underline{u} \\
\underline{\underline{n}} \\
\underline{z}\end{array}$ & 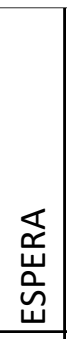 & 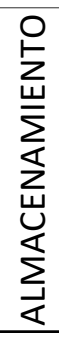 & 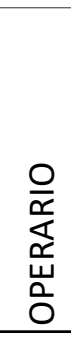 & 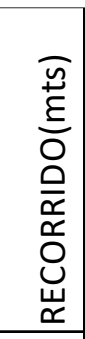 & 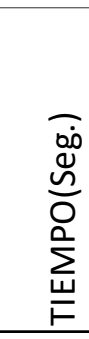 \\
\hline 1 & Trasportar al área nueva de lavado 1 piso & & $\Rightarrow$ & & & & 1 & 8 & 48 \\
\hline 2 & Lavado con agua tratada en el segundo piso & $O$ & & & & & 1 & & 2252 \\
\hline 3 & Agregar solución detergente & 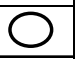 & & & & & 1 & & 982 \\
\hline 4 & Enjuagar detergente & O & & & & & 1 & & 1820 \\
\hline 5 & Desinfectar y secar con calor & $\mathrm{O}$ & & & & & 1 & & 648 \\
\hline 6 & Trasportar al area & & $\Rightarrow$ & & & & 1 & 26 & 480 \\
\hline 7 & control micorobiológico & & & $\square$ & & & 1 & & 300 \\
\hline
\end{tabular}

\section{RESUMEN}

\begin{tabular}{|c|c|c|c|c|}
\hline & Cant. & Tiempo(s) & Recorrido(m) & Operario \\
\hline $\mathbf{O}$ & 04 & 5702 & 0 & 1 \\
\hline$\vec{\square}$ & 02 & 528 & 34 & 1 \\
\hline $\boldsymbol{D}$ & 0 & 0 & 0 & 0 \\
\hline$\square$ & 01 & 300 & 0 & 1 \\
\hline Total & & 6530 & 34 & 1 \\
\hline
\end{tabular}

Fuente: Elaboración propia

Se puede observar de acuerdo a los resultados que hay una disminución de los desperdicios relacionado a la disminución del tiempo total del proceso de limpieza de las marmitas y tanques de 2.26 horas a 1.81 horas, el proceso de limpieza se ha disminuido su recorrido, se ha unificado dos actividades en una sola, se ha dejado de utilizar un operario al poner en uso un área de lavado en el primer piso que no estaba siendo usado eficazmente, y solo se utilizaba para lavar tachos. Esto fue posible habilitando un punto de vapor y reparando el generador de vapor.

\subsubsection{Actividades de trasvase en la fabricación}

\subsubsection{Proceso antes de la mejora: Fabricación, se hizo el análisis DAP (Ver anexo $\left.\mathbf{N}^{\circ} \mathbf{0 5}\right)$}

Actividades para: Ingresar al proceso de fabricación y posterior envasado

Operadores: 2 operadores 
Tabla 15 Diagrama del proceso de fabricación

\begin{tabular}{|c|c|c|c|c|c|c|c|c|c|}
\hline $\begin{array}{c}\text { PASO } \\
\mathrm{N}^{\circ}\end{array}$ & DETALLE DEL PROCESO & 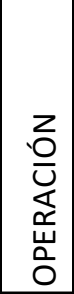 & 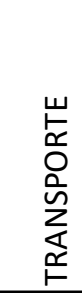 & 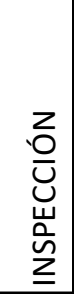 & 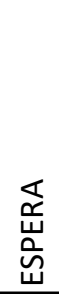 & 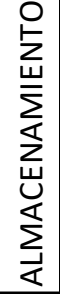 & 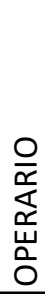 & 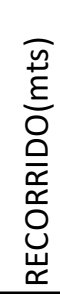 & $\begin{array}{l}\widehat{00} \\
0 \\
0 \\
0 \\
0 \\
\sum \\
\stackrel{0}{0}\end{array}$ \\
\hline 1 & Desmontaje o desacople de tuberias de trasvase & 0 & & & & & 2 & 9 & 1440 \\
\hline 2 & Trasporte de tuberias a lavadero $2^{\circ}$ piso y retorno & & $\Rightarrow$ & & & & 2 & 84 & 480 \\
\hline 3 & Espera en Montacarga de ida y vuela & & & & $D$ & & 2 & 0 & 330 \\
\hline 4 & Limpieza de tuberias de trasvase y areas & $O$ & & & & & 2 & 1 & 3600 \\
\hline 5 & Montaje de tuberias y marmita & 0 & & & & & 1 & 2 & 300 \\
\hline 6 & Mezclar 1 y Agregar EDTA en $60 \%$ de H20 & 0 & & & & & 1 & 1 & 300 \\
\hline 7 & Mezclar 2 espesante en $40 \%$ de $\mathrm{H} 20$ & $\mathrm{O}$ & & & & & 1 & 1 & 600 \\
\hline 8 & Mezclar 3 y agregar Activos 1 , aumentar $\mathrm{T}^{\circ}$ & 0 & & & & & 1 & 1 & 1200 \\
\hline 9 & Trasvasar 1 hasta la marmita & 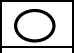 & & & & & 1 & 2 & 720 \\
\hline 10 & Fundir grasa y emolientes y aumentar $\mathrm{T}^{\circ}$ & 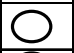 & & & & & 1 & 1 & 780 \\
\hline 11 & Mezclar 4 y agregar activos 2 y aumentar $\mathrm{T}^{\circ}$ & 0 & & & & & 1 & 5 & 1140 \\
\hline 12 & Trasvase 2 hasta la marmita & $\mathrm{O}$ & & & & & 1 & 1 & 600 \\
\hline 13 & Mezclar 5 Fase acuosa y fase grasa & $\mathrm{O}$ & & & & & 1 & 1 & 900 \\
\hline 14 & Emulsificar y mezclar 6/disminuir $\mathrm{T}^{\circ}$ & $\mathrm{O}$ & & & & & 1 & 9 & 1800 \\
\hline 15 & Enfriar y mezclar 7 & O & & & & & 1 & 1 & 900 \\
\hline 16 & Recircular y trasvase 3 & $\mathrm{O}$ & & & & & 1 & 1 & 1800 \\
\hline 17 & Mezcla final & O & & & & & 1 & 1 & 1500 \\
\hline 18 & Descargar & $O$ & & & & & 1 & 1 & 1800 \\
\hline 19 & Control & & & $\square$ & & & 1 & 1 & 300 \\
\hline
\end{tabular}

\section{RESUMEN}

\begin{tabular}{|c|c|c|c|c|}
\hline & Cant. & Tiempo(s) & Recorrido(m) & Operario \\
\hline $\mathbf{O}$ & 16 & 19380 & 38 & $2-1$ \\
\hline$\vec{\square}$ & 01 & 480 & 84 & 2 \\
\hline $\mathbf{D}$ & 01 & 330 & 0 & 2 \\
\hline$\square$ & 01 & 300 & 1 & 1 \\
\hline Total & & 20490 & 123 & 1 \\
\hline
\end{tabular}

Fuente: Elaboración propia

\subsubsection{Proceso después de la capacitación de la mejora}

Se presenta el DAP propuesto (Ver anexo $\mathrm{N}^{\circ} 06$ )

Se realizó la capacitación dela mejora y se presentó el nuevo procedimiento con las actividades propuestas con código de Aseguramiento: FAB-L01 Versión 02. 
Tabla 16 Diagrama del proceso de fabricación

\begin{tabular}{|c|c|c|c|c|c|c|c|c|c|}
\hline $\begin{array}{c}\text { PASO } \\
\mathrm{N}^{\circ}\end{array}$ & DETALLE DEL PROCESO & 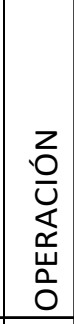 & 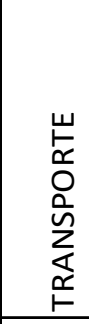 & 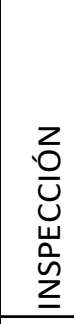 & 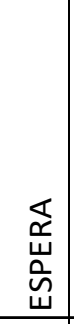 & 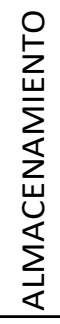 & 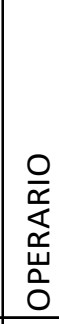 & 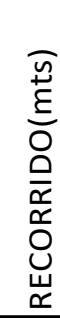 & 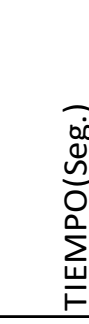 \\
\hline 1 & Mezclar 1 y Agregar EDTA en $60 \%$ de $\mathrm{H} 20$ & 0 & & & & & 1 & 1 & 300 \\
\hline 2 & Mezclar 2 espesante en $40 \%$ de $\mathrm{H} 20$ & $\mathrm{O}$ & & & & & 1 & 1 & 600 \\
\hline 3 & Mezclar 3 y agregar Activos 1 , aumentar $\mathrm{T}^{\circ}$ & 0 & & & & & 1 & 1 & 1260 \\
\hline 4 & Trasvasar 1 hasta la marmita & 0 & & & & & 1 & 1 & 360 \\
\hline 5 & Fundir grasa y emolientes y aumentar $\mathrm{T}^{\circ}$ & O & & & & & 1 & 1 & 780 \\
\hline 6 & Mezclar 4 y agregar activos 2 y aumentar $\mathrm{T}^{\circ}$ & $\mathrm{O}$ & & & & & 1 & 1 & 1140 \\
\hline 7 & Trasvase 2 hasta la marmita & 0 & & & & & 1 & 1 & 330 \\
\hline 8 & Mezclar 5 Fase acuosa y fase grasa & 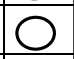 & & & & & 1 & 1 & 900 \\
\hline 9 & Emulsificar y mezclar 6/disminuir $\mathrm{T}^{\circ}$ & 0 & & & & & 1 & 1 & 1800 \\
\hline 10 & Enfriar y mezclar 7 & 0 & & & & & 1 & 1 & 900 \\
\hline 11 & Recircular y trasvase 3 & O & & & & & 1 & 1 & 1200 \\
\hline 12 & Mezcla final & $\mathrm{O}$ & & & & & 1 & 1 & 1500 \\
\hline 13 & Descargar & $\mathrm{O}$ & & & & & 1 & 1 & 1800 \\
\hline 14 & Control & & & $\square$ & & & 1 & 1 & 300 \\
\hline 15 & Transporte de mangueras de trasvase al area de lavado & & $\Rightarrow$ & & & & 1 & 7 & 180 \\
\hline 16 & limpieza de mangueras en nuevo lavadero & $\mathrm{O}$ & & & & & 1 & 0 & 1800 \\
\hline
\end{tabular}

\section{RESUMEN}

\begin{tabular}{|c|c|c|c|c|}
\hline & Cant. & Tiempo(s) & Recorrido(m) & Operario \\
\hline $\mathbf{O}$ & 14 & 14670 & 13 & 1 \\
\hline$\vec{\square}$ & 01 & 180 & 7 & 1 \\
\hline $\mathbf{\square}$ & 01 & 0 & 0 & 1 \\
\hline Total & 01 & 300 & 1 & 1 \\
\hline
\end{tabular}

Fuente: Elaboración propia

Se observa de acuerdo a los resultados que hay una disminución de los desperdicios relacionado a la disminución del en la línea de shampoo y cremas (no se ha considerado para esta propuesta el área de colonia), de 5.60 horas con esta mejora se logra disminuir a un promedio de tiempo de fabricación de 4.00 horas. La eficiencia del proceso de trasvase, se inicia eliminando el sistema de trasvase por tuberías y remplazando a un sistema de 
mangueras, disminuyendo recorrido, con lo cual se disminuye tiempo de fabricación y uso de un operario menos en todo el proceso.

\subsubsection{Actividades de arranque en el envasado}

\subsubsection{Proceso antes de la mejora: Ver DAP (Ver anexo $\left.\mathrm{N}^{\circ} 07\right)$}

Actividades para: Ingresar a la actividad de dosificado y finalmente el acondicionado

Operadores: Varios

Tabla 17 Diagrama del proceso de Envasado-Acondicionado

\begin{tabular}{|c|c|c|c|c|c|c|c|c|c|}
\hline \multicolumn{10}{|c|}{ DIAGRAMA DEL PROCESO DE ENVASADO-ACONDICIONADO } \\
\hline $\begin{array}{c}\text { PASO } \\
\mathrm{N}^{\circ}\end{array}$ & DETALLE DEL PROCESO & 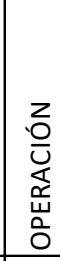 & 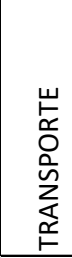 & $\begin{array}{l}z \\
\underline{\underline{O}} \\
\underline{u} \\
\underline{\underline{u}} \\
\underline{n}\end{array}$ & 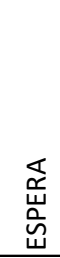 & 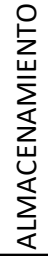 & 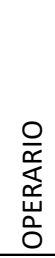 & 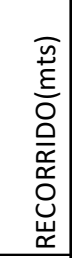 & 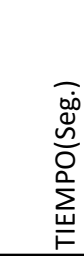 \\
\hline 1 & Limpieza & $\bigcirc$ & $\Rightarrow$ & & $D$ & & 3 & 90 & 4500 \\
\hline & Montaje & 0 & & & & & 1 & 2 & 1800 \\
\hline 2 & Sanitización & O & & & & & 1 & 1 & 900 \\
\hline 3 & secar con aire comprimido la tolva y dosif. & O & & & & & 1 & 1 & 1200 \\
\hline 4 & Purga & O & & & & & 1 & 1 & 600 \\
\hline 5 & Dosificación & $\mathrm{O}$ & & & & & 1 & 1 & 1147 \\
\hline 6 & Tapado & 0 & & & & & 1 & 0 & 1147 \\
\hline 7 & Control & & & $\square$ & & & 1 & 1 & 600 \\
\hline 8 & Sellado & 0 & & & & & 1 & 0 & 1147 \\
\hline 9 & Impresión & 0 & & & & & 1 & 0 & 1147 \\
\hline 10 & Estuchado & 0 & & & & & 4 & 0 & 1147 \\
\hline 11 & Embalado & 0 & & & & & 1 & 0 & 1147 \\
\hline 12 & Transporte & & $\Rightarrow$ & & & & 1 & 5 & 300 \\
\hline 13 & Almacenamiento & & & & & $\nabla$ & 1 & 8 & 300 \\
\hline
\end{tabular}

\section{RESUMEN}

\begin{tabular}{|c|c|c|c|c|}
\hline & Cant. & Tiempo(s) & Recorrido(m) & Operario \\
\hline $\mathbf{O}$ & 11 & 16030 & 96 & 10 \\
\hline $\mathbf{D}$ & 02 & 72 & 5 & 1 \\
\hline $\boldsymbol{\square}$ & 1 & 380 & 0 & 0 \\
\hline$\square$ & 01 & 300 & 1 & 1 \\
\hline $\boldsymbol{\nabla}$ & 01 & 300 & 8 & 1 \\
\hline Total & & 17082 & 110 & 10 \\
\hline
\end{tabular}

Fuente: Elaboración propia 


\subsubsection{Proceso después de la capacitación de la mejora}

Se presenta el DAP propuesto (Ver anexo $\mathrm{N}^{\circ} 08$ )

Tabla 18 Diagrama del proceso de Envasado - Acondicionado propuesto

\begin{tabular}{|c|c|c|c|c|c|c|c|c|c|}
\hline $\begin{array}{c}\text { PASO } \\
\mathrm{N}^{\circ}\end{array}$ & DETALLE DEL PROCESO & 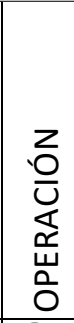 & 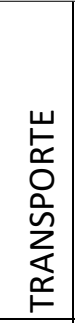 & 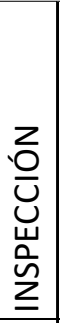 & 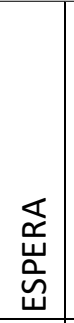 & 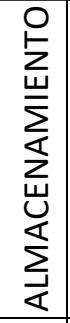 & 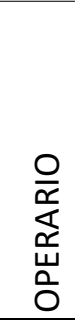 & 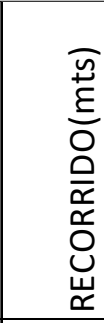 & 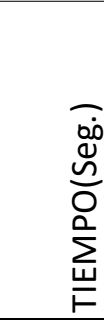 \\
\hline \multirow[t]{2}{*}{1} & Limpieza & 0 & & & & & 2 & 35.72 & 3580 \\
\hline & Montaje & 0 & & & & & 1 & 2 & 1800 \\
\hline 2 & Sanitización y secar & 0 & & & & & 1 & 1 & 600 \\
\hline 3 & Dosificación & 0 & & & & & 1 & 1 & 1147 \\
\hline 4 & Tapado & 0 & & & & & 1 & 1 & 1147 \\
\hline 5 & Control & & & $\square$ & & & 1 & 1 & 600 \\
\hline 6 & Sellado & 0 & & & & & 1 & 1 & 1147 \\
\hline 7 & Impresión & O & & & & & 1 & 0 & 1147 \\
\hline 8 & Estuchado & 0 & & & & & 4 & 0 & 1147 \\
\hline 9 & Embalado & 0 & & & & & 1 & 0 & 1147 \\
\hline 10 & Transporte & & $\Rightarrow$ & & & & 1 & 5 & 300 \\
\hline 11 & Almacenamiento & & & & & $\nabla$ & 1 & 8 & 300 \\
\hline
\end{tabular}

\section{RESUMEN}

\begin{tabular}{|c|c|c|c|c|}
\hline & Cant. & Tiempo(s) & Recorrido(m) & Operario \\
\hline $\mathbf{O}$ & 11 & 12862 & 41.72 & 9 \\
\hline$\vec{D}$ & 01 & 300 & 5 & 1 \\
\hline$\square$ & 0 & 0 & 0 & 0 \\
\hline$\square$ & 01 & 600 & 1 & 1 \\
\hline$\nabla$ & 01 & 300 & 8 & 1 \\
\hline Total & & 14062 & 55.72 & 9 \\
\hline
\end{tabular}

Fuente: Elaboración propia

Se observa de acuerdo a los resultados que hay una disminución de los desperdicios relacionado a la disminución del tiempo total de envasado-acondicionado de 5.70 horas con esta mejora se logra disminuir a un promedio de tiempo de fabricación de 4.00 horas. La eficiencia del proceso en las actividades de arranque se mejora porque hay una disminución de recorrido en la limpieza de la máquina envasadora con la nueva área de 
lavado, la eliminación de la actividad de purga, la unión de dos actividades como son desinfectar y secar en una sola actividad, así como la disminución de un operario.

\subsubsection{Resumen de resultados de la mejora de procesos}

A continuación se presenta los resultados de los diagramas de proceso antes y después de la implementación en los procesos de fabricación y envasado, los cuales se consideran los pilotos del proyecto de investigación.

\subsubsection{Actividades de limpieza}

Figura 42 Resultados de la mejora del tiempo en el proceso de limpieza del área de fabricación y envasado

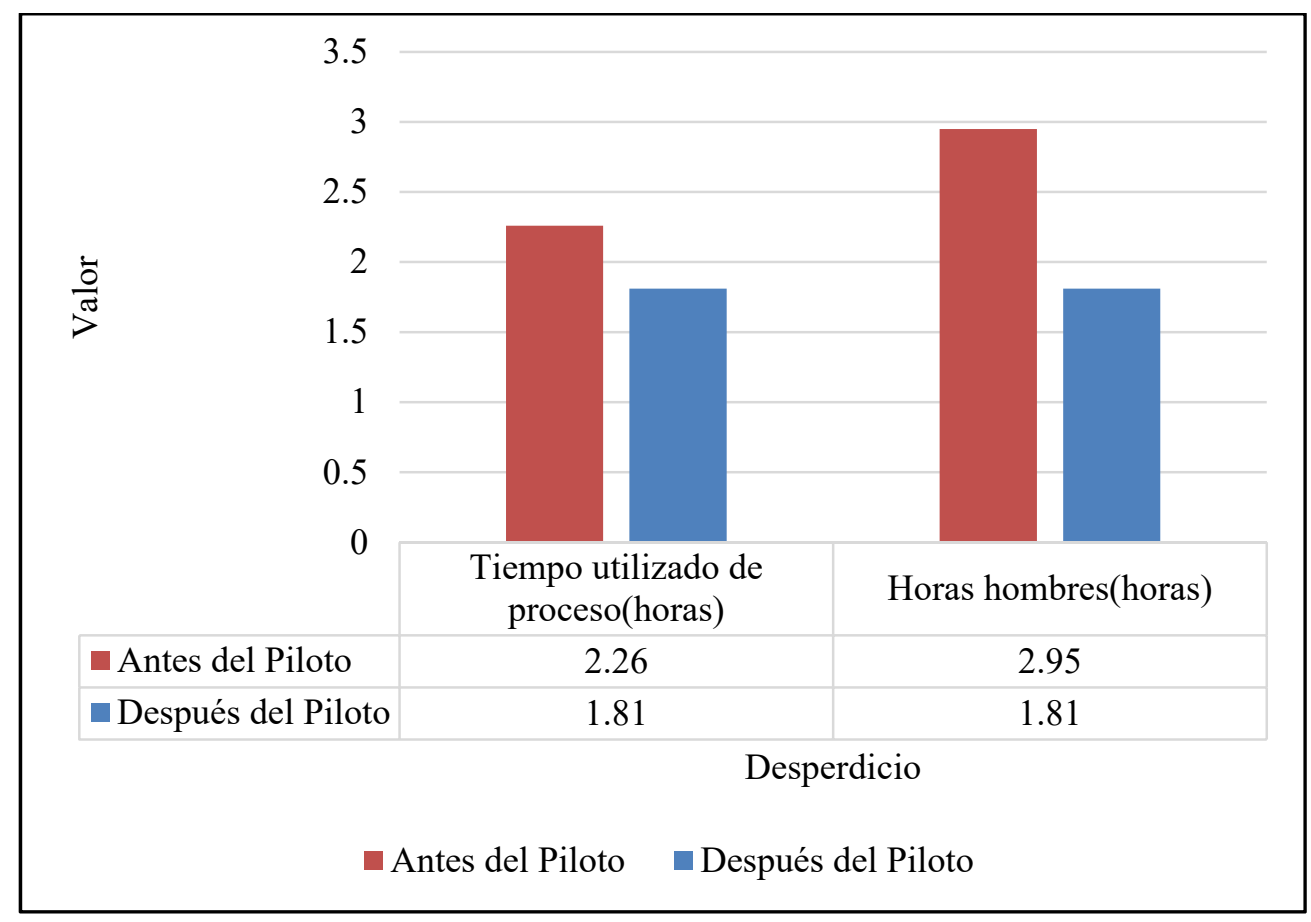

Fuente: Investigación experimental del piloto (Setiembre-Octubre) 
Figura 43 Resultados de la mejora del recorrido en el proceso de limpieza del área de fabricación y envasado

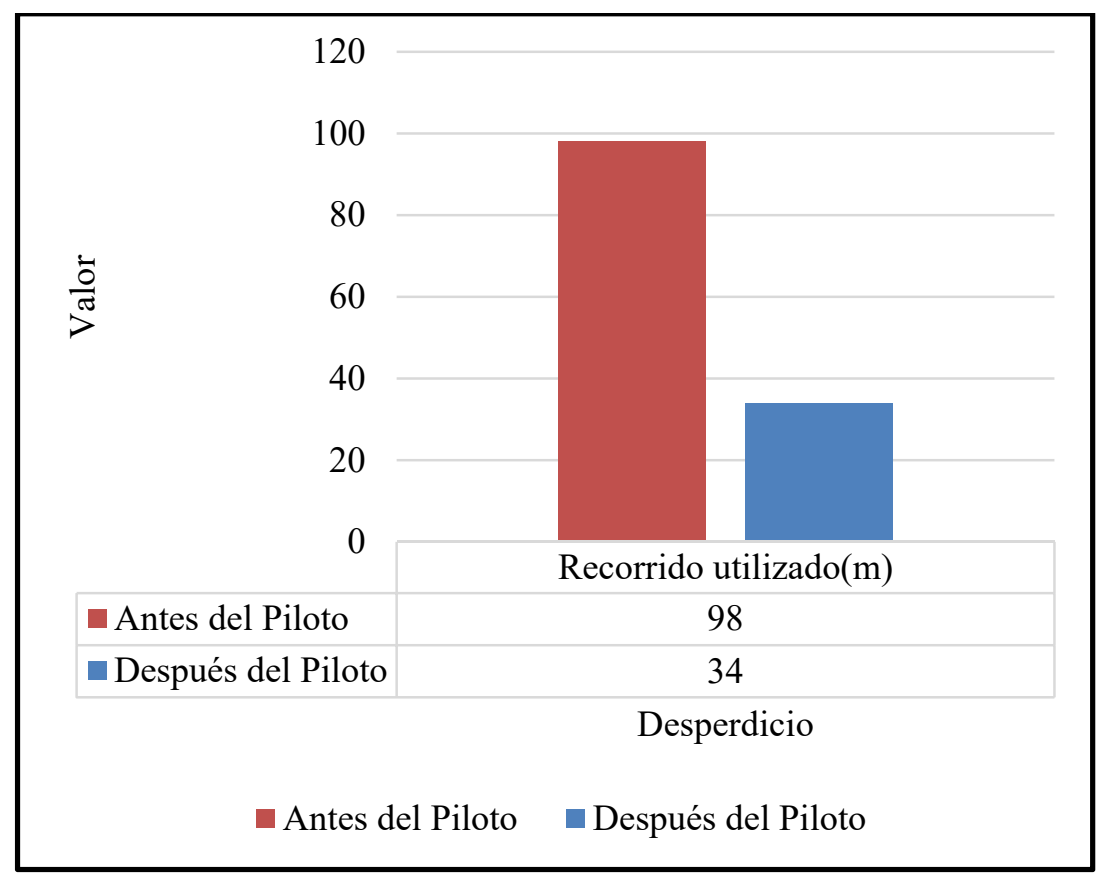

Fuente: Investigación experimental del piloto (Setiembre-Octubre)

Interpretación:

Esta gráfica nos demuestra que fue reducido el tiempo total del proceso de limpieza de marmitas y tanques, como podemos observar antes del piloto todo el proceso demoraba $2.26 \mathrm{H}$, después de la capacitación del nuevo método para aplicar en los pilotos se tiene un promedio de proceso de $1.81 \mathrm{H}$, esto representa una mejora del $20 \%$ en el tiempo total del proceso de limpieza. Esto se ha logrado por que se ha mejorado el recorrido, el cual se ha logrado disminuir $98 \mathrm{~m}$ de recorrido a $34 \mathrm{~m}$, un $65 \%$ de mejora. También se ha logrado disminuir las horas hombres (uso de operario en todo el proceso) de $2.95 \mathrm{H}$ a segundos $1.81 \mathrm{H}$ logrando una mejora de $38.6 \%$.

\subsubsection{Actividades de trasvase en la fabricación}


Figura 44 Resultados de la mejora de tiempos en el proceso de trasvase del área de fabricación

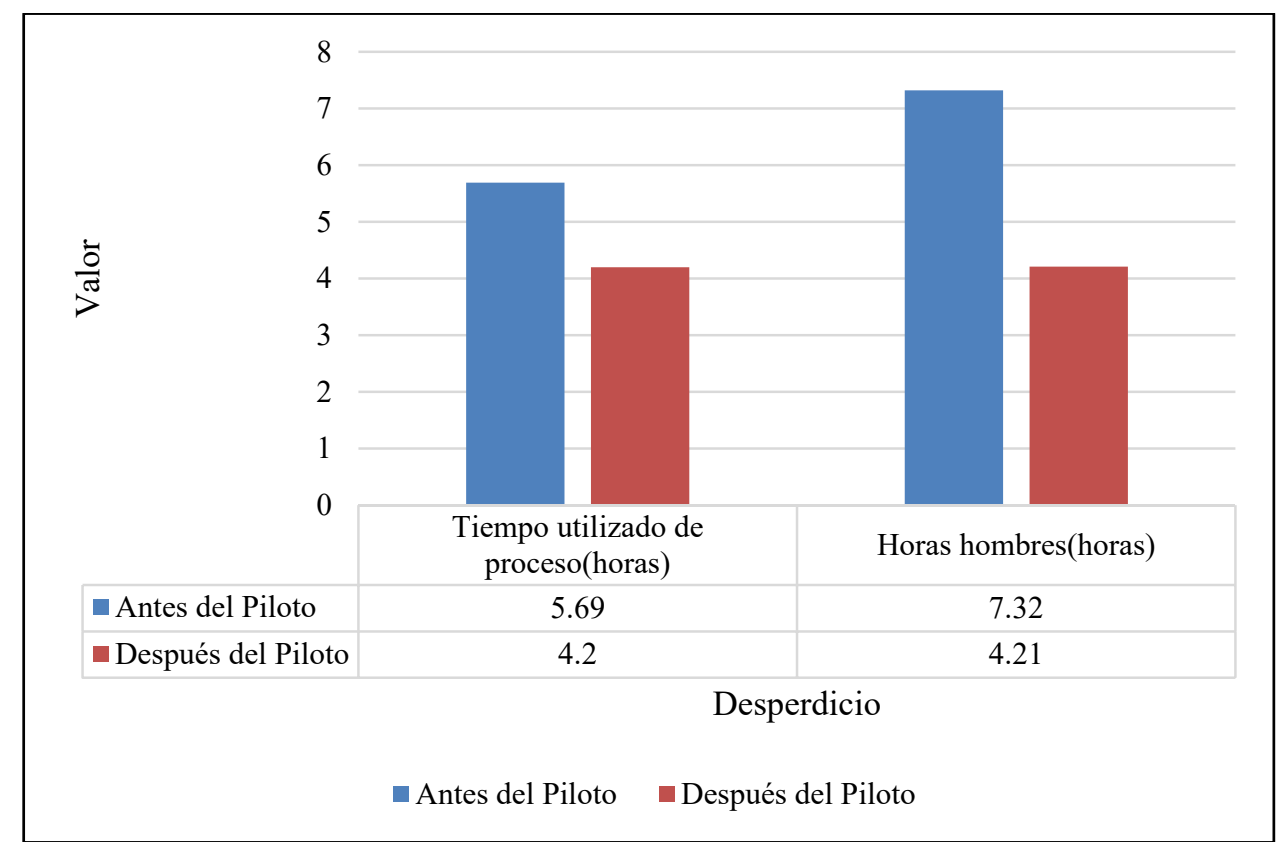

Fuente: Investigación experimental del piloto (Setiembre-Octubre)

Figura 45 Resultados de la mejora del recorrido en el proceso de trasvase del área de fabricación

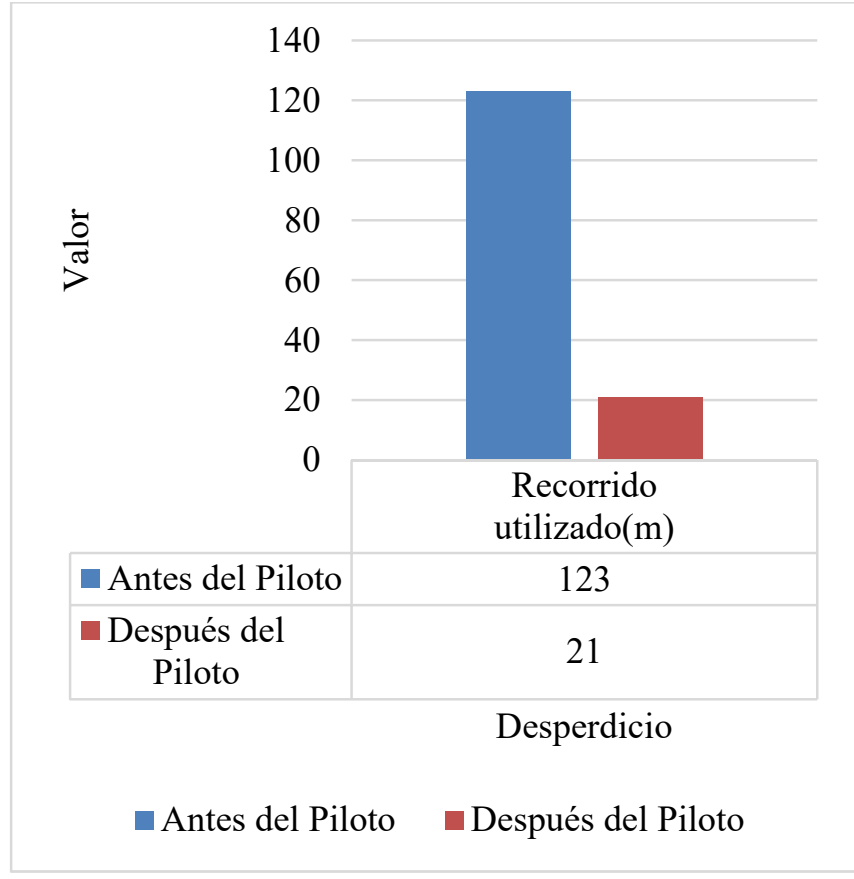

Fuente: Investigación experimental del piloto (Setiembre-Octubre) 


\section{Interpretación:}

Esta gráfica nos demuestra que fue reducido el tiempo total del proceso de fabricación mejorando las actividades de trasvase, como podemos observar antes del piloto todo el proceso demoraba $5.69 \mathrm{H}$, después de la capacitación del nuevo método para aplicar en los pilotos se tiene un promedio de proceso de $4.21 \mathrm{H}$, esto representa una mejora del $26 \%$ en el tiempo total del proceso de fabricación mejorando las actividades de trasvase. Esto se ha logrado por que se ha mejorado el recorrido el cual se ha logrado disminuir de $123 \mathrm{~m}$ de recorrido a $21 \mathrm{~m}$, un $82 \%$ de mejora, además de disminuir las horas hombres (uso de operario en todo el proceso) de $7.31 \mathrm{HH}$ a $4.21 \mathrm{HH}$ logrando una mejora de $42.41 \%$.

La mejora mencionada permitió contribuir a la actividad de trasvase donde se logró en esta fase disminuir la merma de granel en un $75 \%$ de $12 \mathrm{~kg}$ en promedio a $3 \mathrm{~kg}$. Esta contribución se evidencia en la Fig. 45

Figura 46 Resultados de la optimización de granel en la actividad de trasvase

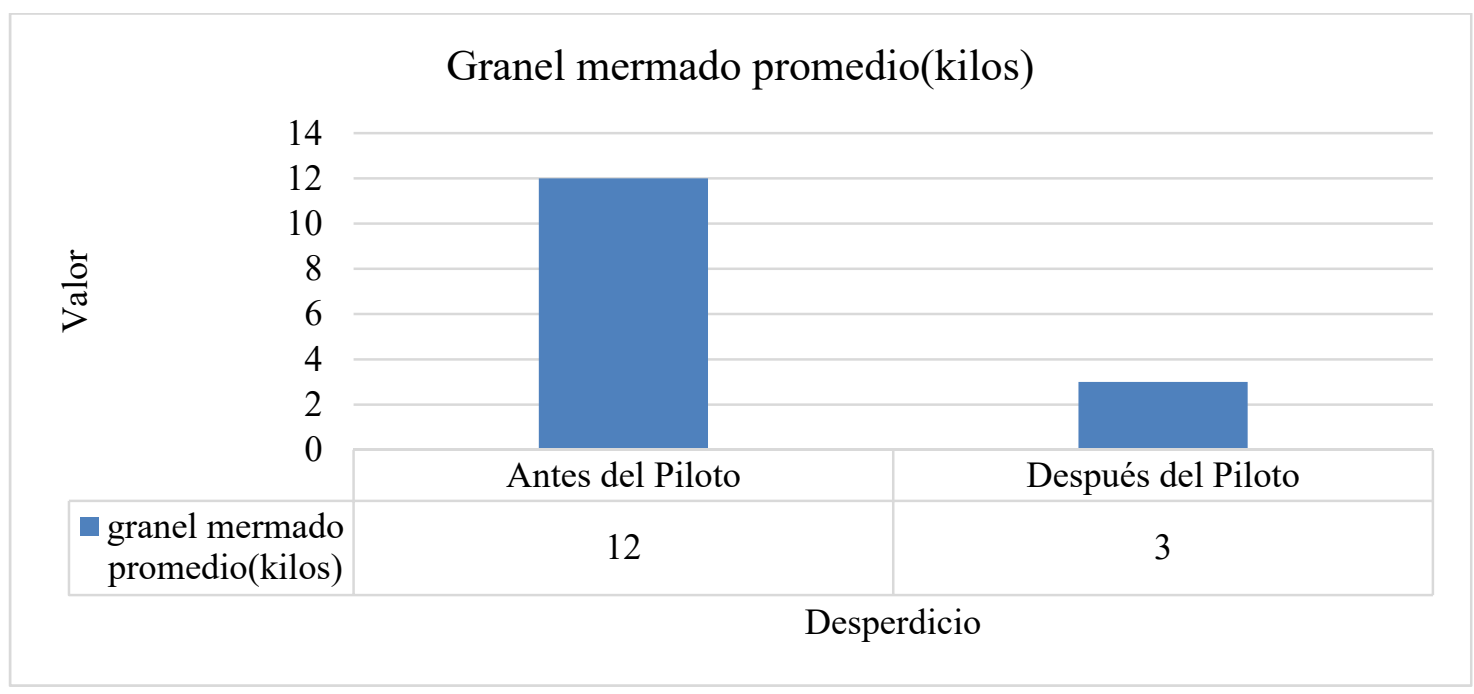

Fuente: Investigación experimental del piloto (Setiembre-Octubre)

\subsubsection{Actividades de arranque en el envasado}


Figura 47 Resultados de la mejora de tiempos en el proceso de arranque en el envasado

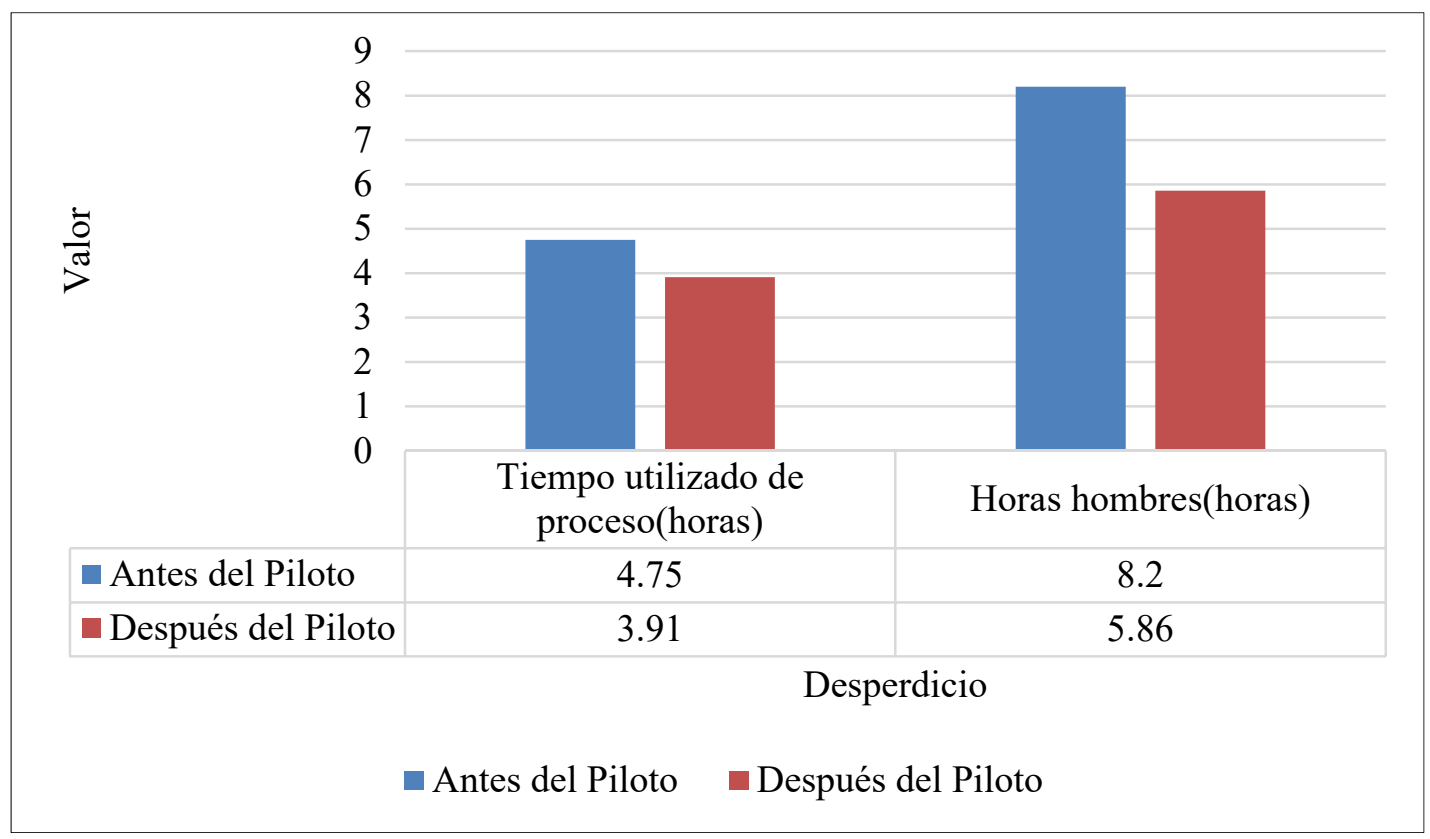

Fuente: Investigación experimental del piloto (Setiembre-Octubre)

Figura 48 Resultados de la mejora de recorridos en el proceso de arranque en el envasado

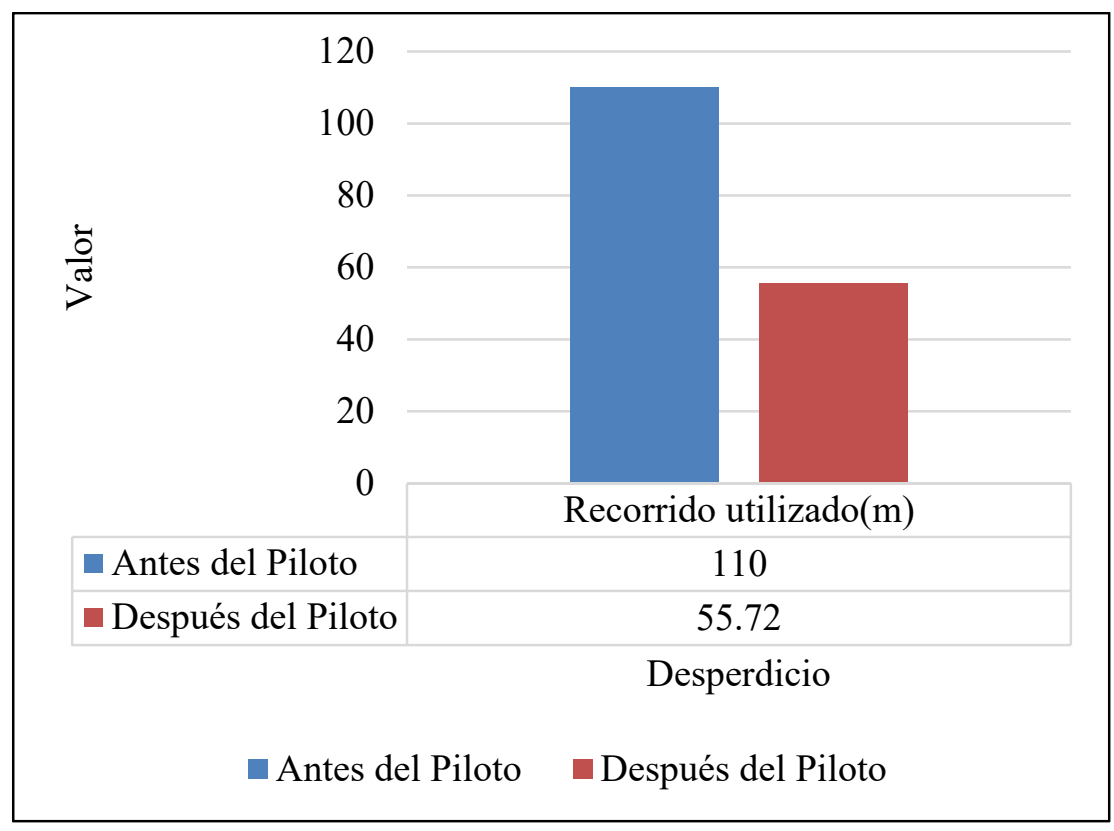

Fuente: Investigación experimental del piloto (Setiembre-Octubre)

La Fig. 47 demuestra que fue reducido el tiempo total del proceso de envasado para esta presentación promedio mejorando las actividades de arranque, como podemos observar antes del piloto todo el proceso demoraba $4.75 \mathrm{H}$, después de la capacitación del nuevo método para aplicar en los pilotos se tiene un promedio de proceso de $3.91 \mathrm{H}$, esto 
representa una mejora del $17.69 \%$ en el tiempo total del proceso de envasado mejorando las actividades de arranque. Asimismo, en la Fig. 47 se observa que se ha logrado mejorar el recorrido el cual se ha logrado disminuir de $110 \mathrm{~m}$ de recorrido a $21 \mathrm{~m}$, un $49.35 \%$ de mejora. Además, se logró disminuir las horas hombres (uso de operario en todo el proceso) de $7.31 \mathrm{HH}$ a $4.21 \mathrm{HH}$ obteniendo una mejora de $28.59 \%$,

Consecuentemente mejorar la actividad de arranque juntando dos actividades y eliminando la actividad de purga ha logrado en esta fase disminuir la merma de granel de $18 \mathrm{~kg}$ por purga. Este se observa en la Fig. 48

Figura 49 Resultados de la optimización de granel en la actividad de purga

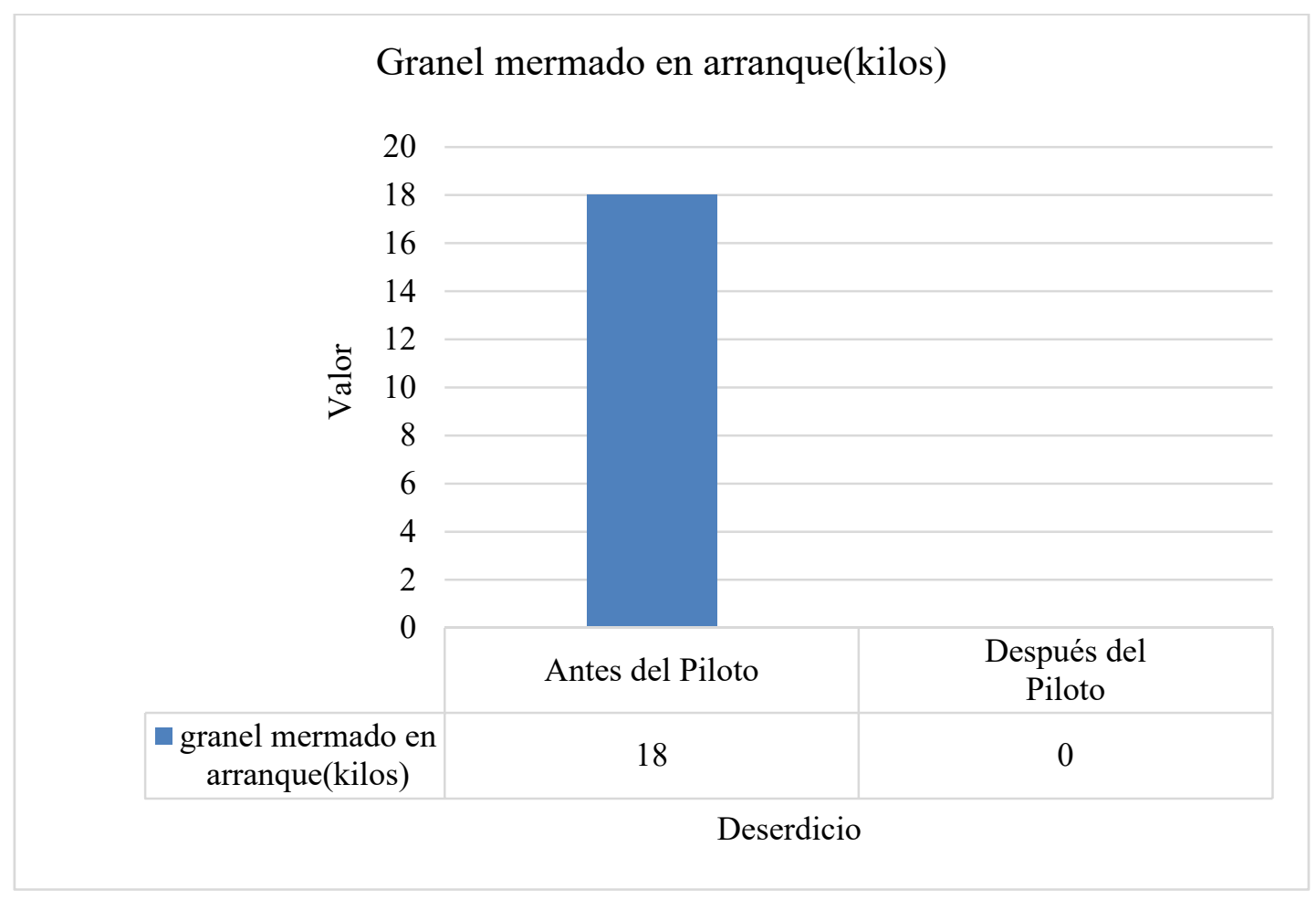

Fuente: Investigación experimental del piloto (Setiembre-Octubre) 


\subsubsection{Resumen de resultados del balance de líneas de envasado y UPH (Ver anexo $\mathrm{N}^{\circ} 02$ )}

Se realizaron el estudio de tiempo por cronometro a lotes industriales cuyos resultados de un lote se presenta en la tabla adjunta y los demás se detallan en los anexos (9-11).

Tabla 19 Ejecución del balance de línea en las líneas de Envasado y UPH utilizando el estudio de tiempos

\begin{tabular}{|c|c|c|c|c|c|c|c|c|c|c|c|c|c|c|c|c|c|c|c|c|c|c|c|c|}
\hline $\begin{array}{l}\text { Código } \\
\text { Código } \\
\text { Código } \\
\text { Código } \\
\text { Linea } \\
\text { Unidades por caj }\end{array}$ & $\begin{array}{l}19162 \\
19713 \\
19711 \\
19158 \\
\end{array}$ & $\begin{array}{l}\text { SHAMPOO AMMENS N } \\
\text { SHAMPOO AMMNES } \\
\text { SHAMPOO AMMENS O } \\
\text { SHAMPOO AMMENS } 0 \\
10 \\
24\end{array}$ & $\begin{array}{l}\text { MANZANLLLAX } \\
\text { MANZ. X X50ML } \\
\text { ORIG X 450ML } \\
\text { ORIGINAL X } 45\end{array}$ & 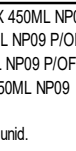 & $\begin{array}{l}\text { P09 } \\
\text { OFERTA } \\
\text { OFERTA } \\
9\end{array}$ & & & & & & & & & ULTIMA AC & ACTUALIZACIÓN & & & 2109/18 & & & & & & \\
\hline & & & & & & & & & VALIDA & ACIÓN & & & & & & & & & & & & & BALAN & \\
\hline $\begin{array}{l}\text { Vo. de de } \\
\text { Operaciöion }\end{array}$ & Procesos & \# operarios observados \# & \#x xoperaciones & $\begin{array}{l}\mathrm{T1} \\
\text { seg. }\end{array}$ & $\begin{array}{l}\text { T2 } \\
\text { seg. }\end{array}$ & $\begin{array}{l}\text { T3 } \\
\text { seg. }\end{array}$ & $\begin{array}{l}\text { T4 } \\
\text { seg. }\end{array}$ & $\begin{array}{l}\text { T5 } \\
\text { seg. }\end{array}$ & $\begin{array}{c}\mathrm{T} 6 \\
\text { seg. }\end{array}$ & $\begin{array}{l}\text { T7 } \\
\text { seg. }\end{array}$ & $\begin{array}{l}\text { T8 } \\
\text { seg. }\end{array}$ & $\begin{array}{l}\text { T9 } \\
\text { seg. }\end{array}$ & \begin{tabular}{l|l} 
T10 \\
seg.
\end{tabular} & TM seg. \# & \# Observaciones TI & $\begin{array}{l}\text { TMSEG X } \\
\text { UND }\end{array}$ & $\mathrm{FV}$ & Tiempo Normal| & TOL 17\% & \begin{tabular}{|c|} 
TS XUNID \\
seg
\end{tabular} & $\begin{array}{c}\text { UpH } \\
\text { Operación }\end{array}$ & UPH processo & \begin{tabular}{|c|} 
N. Personal \\
necesario
\end{tabular} & Redondeo \\
\hline 1 & Abastecer & & & 0.82 & 0.97 & \begin{tabular}{|l|}
0.92 \\
\end{tabular} & 0.99 & 0.96 & 1.55 & 0.97 & 0.84 & 0.99 & 1.05 & 1.01 & & & & & & & & & & \\
\hline 1 & Abastecer & & & \begin{tabular}{l|l}
0.82 \\
\end{tabular} & 0.97 & \begin{tabular}{|l|}
0.92 \\
\end{tabular} & \begin{tabular}{|l|}
0.99 \\
\end{tabular} & 0.96 & & 0.97 & 0.84 & 0.99 & 1.05 & \begin{tabular}{l|l}
0.95 \\
\end{tabular} & 9.00 & 0.946 & & 0.9 & 0.2 & 1.1 & 3254 & 3254 & 0.82 & 1.00 \\
\hline 2 & Envasar & & & 6.84 & 6.82 & 6.80 & 6.20 & 6.84 & 7.00 & $\begin{array}{l}6.83 \\
\end{array}$ & \begin{tabular}{l|l}
6.52 \\
\end{tabular} & 6.25 & 6.46 & 6.66 & & & & & & & & & & \\
\hline 2 & Etviasar' & & & 6.84 & 6.82 & 6.80 & 6.20 & 6.84 & 7.00 & 6.83 & 6.52 & 6.25 & 6.46 & 6.66 & 10.00 & 1.109 & & 1.1 & 0.2 & 1.3 & 2682 & 2682 & 1.00 & 1.00 \\
\hline 3 & Colocar tapa & & & 2.10 & 1.98 & 1.98 & 1.11 & 1.80 & 1.43 & 2.07 & 1.96 & 2.01 & 1.88 & 1.83 & & & & & & & & & & \\
\hline & folicara tapa & & & 2.10 & 1.98 & 1.98 & & 1.80 & & \begin{tabular}{l|l|}
2.07 \\
\end{tabular} & 1.96 & 2.01 & $\begin{array}{l}1.88 \\
\end{array}$ & \begin{tabular}{l|l|}
1.97 \\
\end{tabular} & 8.00 & 0.986 & & 1.0 & 0.2 & 1.2 & 3120 & 3120 & 0.86 & 1.00 \\
\hline 4 & Enroscar & Automatico & & & & & & & & & & & & & & & & & & & & & & \\
\hline 5 & Lotizar & Automatico & & & & & & & & & & & 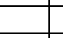 & & & & & & & & & & & \\
\hline 6 & Selladora de induccion & Automatico & & & & & & & & & & & & & & & & & & & & & & \\
\hline 7 & Etiquetar & AUTOMATICO & & & & & & & & & & & & & & & & & & & & & & \\
\hline 8 & Revisar el etiquetado (manual & & & 4.00 & 4.79 & \begin{tabular}{|l|}
3.37 \\
\end{tabular} & 2.95 & 3.25 & 3.52 & 4.16 & 3.42 & 3.29 & 3.68 & 3.64 & & & & & & & & & & \\
\hline 8 & Revsar e e efiquetado (manual) & & & 4.00 & & 3.37 & 2.95 & 3.25 & 3.52 & 4.16 & 3.42 & 3.29 & 3.68 & 3.52 & 9.00 & 3.516 & & 3.5 & 0.6 & 4.1 & 875 & 2626 & 3.06 & 3.00 \\
\hline 9 & & & & 2.92 & 2.53 & 2.38 & 3.26 & 3.26 & 2.88 & 3.58 & 2.50 & 3.20 & 2.96 & 2.95 & & & & & & & & & & \\
\hline 9 & Etiquetar código & & & 2.92 & 2.53 & 2.38 & 3.26 & 3.26 & 2.88 & & 2.50 & 3.20 & 2.96 & 2.88 & 9.00 & 2.877 & & 2.9 & 0.5 & 3.4 & 1070 & 3209 & 2.51 & 3.00 \\
\hline 10 & Apoyo a embalar & & & 37.43 & 43.10 & 34.98 & 36.14 & 38.45 & 34.30 & 53.20 & 53.00 & $56.00 \quad 4$ & 45.20 & 43.18 & & & & & & & & & & \\
\hline & Apoyo a emoalar & & & 37.43 & 43.10 & 34.98 & 36.14 & 38.45 & & & & & 45.20 & 39.22 & 6.00 & 1.634 & & 1.6 & 0.3 & 1.9 & 1883 & 1883 & 1.42 & 1.00 \\
\hline & & & & 5.94 & 4.68 & 6.74 & 5.24 & 6.12 & 7.84 & $\begin{array}{l}6.89 \\
\end{array}$ & 6.75 & 6.98 & 7.12 & 6.43 & & & & & & & & & & \\
\hline 11 & Embalar & 1 & & 5.94 & & 6.74 & \begin{tabular}{|l|} 
\\
\end{tabular} & 6.12 & & 6.89 & 6.75 & 6.98 & $\begin{array}{ll} \\
\end{array}$ & 6.47 & 8.00 & 0.270 & & 0.3 & 0.0 & 0.3 & 11410 & 11410 & 0.24 & 1.00 \\
\hline & Totallseg. & 11 & & & & & & & & & & & & & & & & & & & & & & 111.00 \\
\hline & $\begin{array}{l}\text { Encaragadad de linea } \\
\text { Personal de Apoyyo en el envasado } \\
\text { Total Operarios }\end{array}$ & 13 & & & & & & & & & & & & & & & & & & & & & & \\
\hline & & UPH & TOOLS & & & & & & & & & & & & & & & & & & & & & \\
\hline & & 2000 & & & & UPH REAL & & 2640 & & & & & & & & & & & & & & & & \\
\hline & \begin{tabular}{|l|} 
VALLDACIÓN \\
BALANCE
\end{tabular} & $\begin{array}{ll}2626 \\
2626\end{array}$ & & & & & & & & & & & & & & & & & & & & & & \\
\hline & & & & & & & & & & & & & & & & & & & & & & & & \\
\hline $\begin{array}{l}\text { Observaciones } \\
\text { El| persinond de a } \\
\text { El personal de e. }\end{array}$ & $\begin{array}{l}\text { realiza las funciones de camb } \\
\text { rtiene como funciones, el se }\end{array}$ & h, abastece las & tillas de envases & 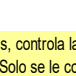 & $\begin{array}{l}\text { la cantidad } \\
\text { :onsidera al }\end{array}$ & $\begin{array}{l}\text { dde granel } \\
\text { al tiempo }\end{array}$ & $\begin{array}{l}\text { len la tolva, } \\
\text { bservado, }\end{array}$ & $\begin{array}{l}\text { a, etc } \\
\text { a la funcio }\end{array}$ & inde sellar & caja. & & & & & & & & & & & & & & \\
\hline
\end{tabular}

Fuente: Investigación experimental del piloto (Setiembre-Octubre) 
Interpretación:

Del estudio de tiempo del producto Shampoo Ammens Manzanilla x $450 \mathrm{~mL}$ evaluado se logra validar que la variación de tiempo empleado para programar actualmente está un $11.3 \%$ por debajo del UPH real, el cual se calculó en el estudio. Además la eficiencia real de la línea está en $88 \%$ frente a $67 \%$ que era considerado en la programación. La productividad de la línea para el shampoo Ammens Manzanilla luego del balance sube a 171 und. /operario frente a 142 und/operario logrando una mejora del 20.4\%.

Tabla 20 Variación porcentual de la programación de UPH

\begin{tabular}{|c|c|c|c|}
\cline { 3 - 3 } \multicolumn{2}{c|}{} & $\begin{array}{c}\text { Programación de } \\
\text { UPH }\end{array}$ & $\begin{array}{c}\text { Diferencia } \\
\text { porcentual }\end{array}$ \\
\hline \multirow{2}{*}{$\begin{array}{c}\text { Producción de } \\
\text { cosméticos }\end{array}$} & Programación actual & 2000 & $11.3 \%$ \\
\cline { 2 - 4 } & Programación real calculada & 2226 & \multicolumn{1}{|c}{} \\
\hline
\end{tabular}

Fuente: Elaboración propia

En cuanto a la línea de shampoo se tiene la validación y el balance de línea de los siguientes productos en la Fig.49 y Fig.50. Cabe resaltar que se utilizaron los ítems de cada producto, para observar la descripción de cada producto ver el anexo 13.

Figura 50 Resultado del estudio de tiempos del producto Shampoo en la línea de envasado

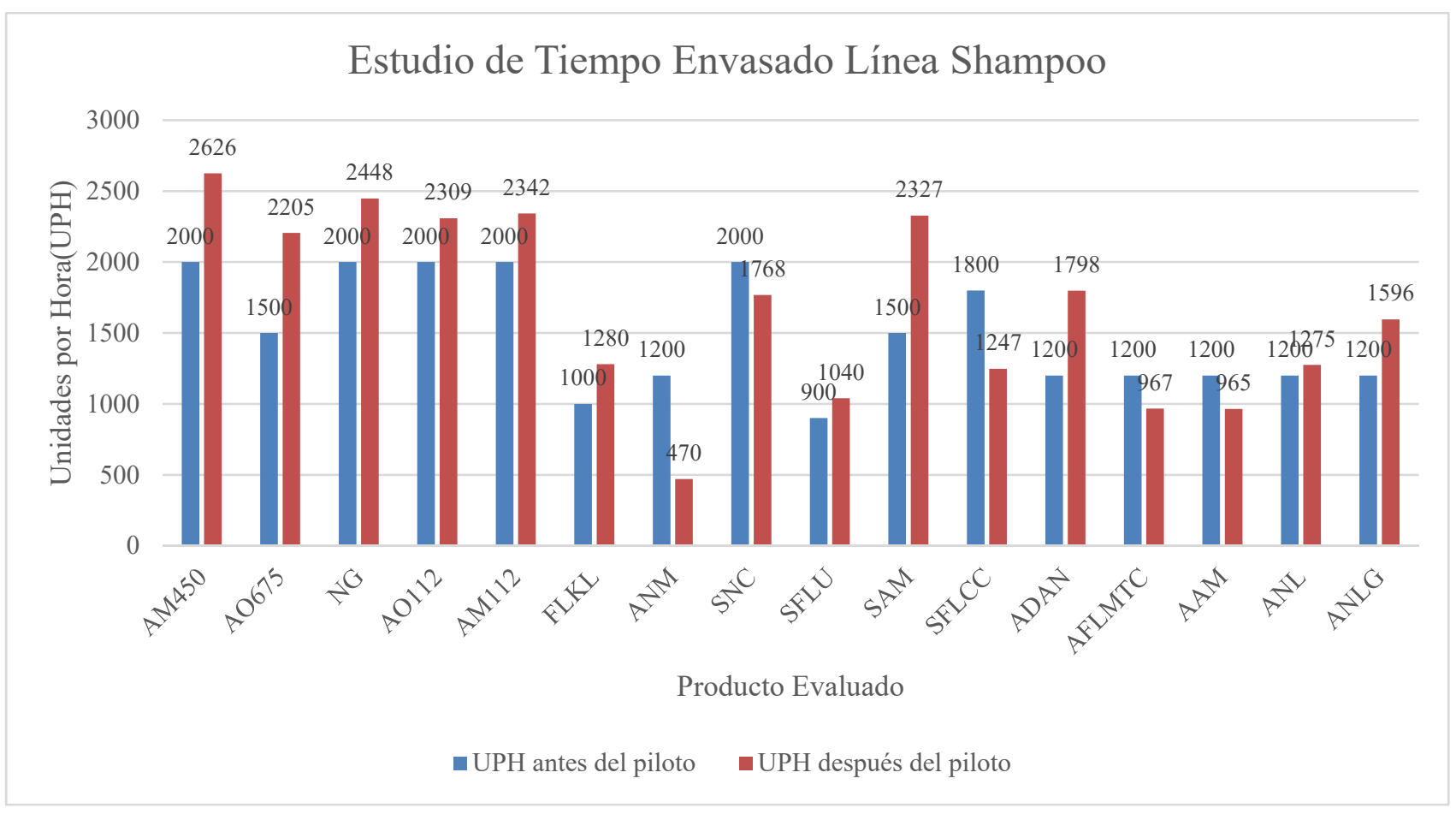

Fuente: Investigación experimental del piloto (Setiembre-Octubre) 
Figura 51 Balance de línea del producto Shampoo en la línea de envasado

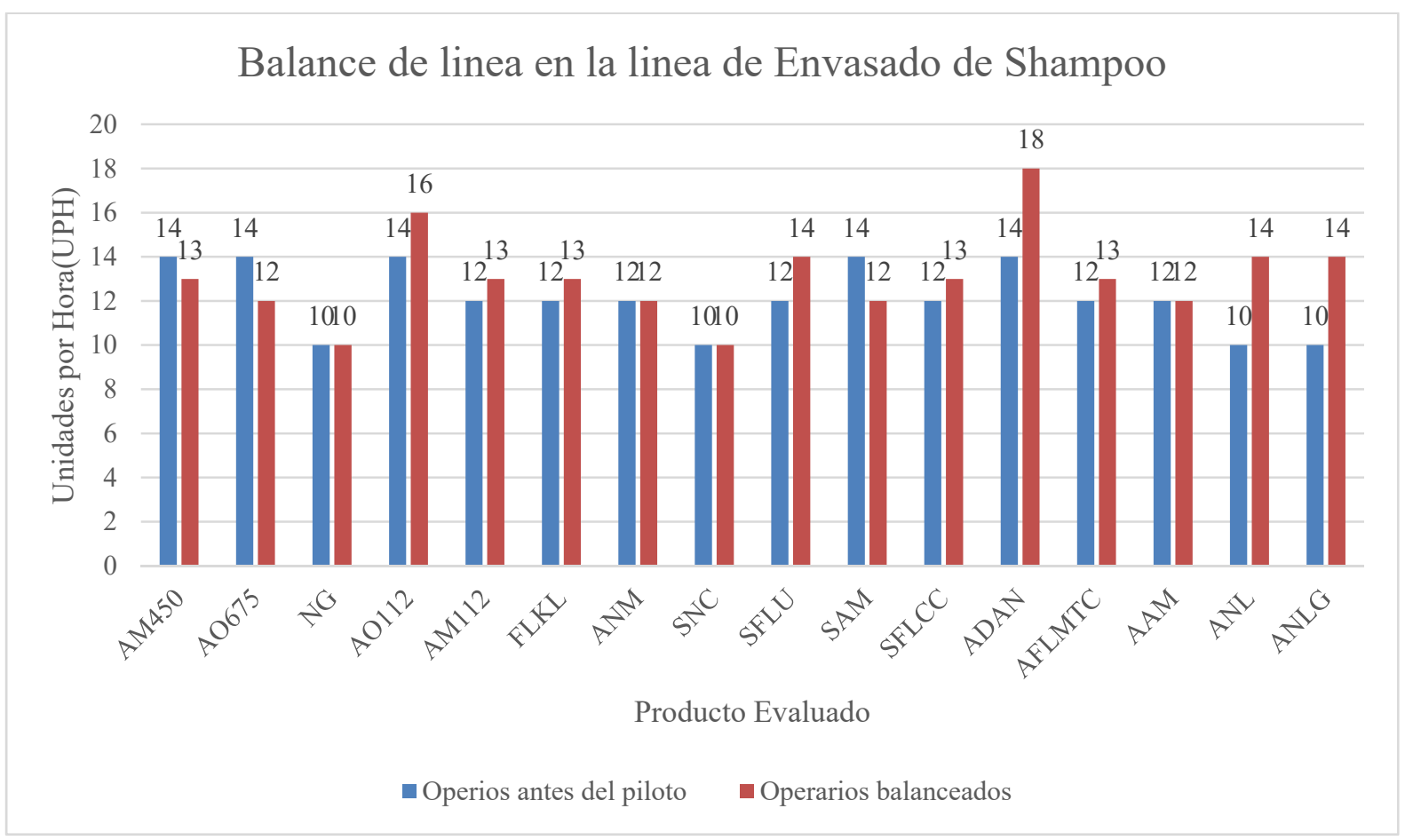

Fuente: Investigación experimental del piloto (Setiembre-Octubre)

Interpretación:

En el estudio de tiempo se valida que el UPH de algunos productos es por debajo de lo que en la práctica resulta por ejemplo de acuerdo a la Fig. 49 y Fig. 50 Se observa que el UPH teórico de Amen Original x 675 (AO675) y que se usa para la programación es 1500 unidades hora, pero en la práctica es 2205 y balanceando la línea se dispondría de 14 personas a 12 personas, Esta variación de UPH entre lo que utiliza planeamiento para la programación constata porque en este producto los operarios terminaban antes de lo programado, no teniendo más trabajo que hacer y disponiéndoles hacer actividades de limpieza que generan horas improductivas.

En otro caso se observa que el UPH está por debajo de lo programado como es el caso del Amen Natural Riso x 200mL que consideraba 1200 unidades por hora pero que luego del estudio se valida que es 470 unidades por hora, esta es la razón que cuando se programa este producto, se tiene que generar horas extras no planificadas para poder culminar con el lote programado. 
De acuerdo a la tabla se puede observar que se mejora el UPH luego de los balanceos, por ejemplo se observa en el anexo 3, en el estudio de tiempo del Ammen Natural C/liso Germen de T x $200 \mathrm{~mL}$, luego de la validación del estudio se confirma que el UPH es 1076 unidades por hora, utilizando 12 personas frente a lo que tenía planeamiento para la programación que es 1200 de UPH con 10 personas, pero haciendo el balanceo de las tareas en esta línea se mejora a un UPH de 1596 balanceando con 14 personas, esta mejora representaría un aumento de UPH del 33\%.

En otros productos se ha confirmado luego de la validación y observando su balance de línea como: Natural Guarana x 1L la cantidad de operarios es la misma 10 operarios antes del estudio y después del estudio, es decir que la línea esta balanceada pero que el UPH validado es mayor que lo que disponía planeamiento para la programación en este caso fue antes del estudio 2000 unidades por hora, frente a 2448 , una mejora del $22.4 \%$ de tiempo disponible para otra programación.

Tabla 22 Resumen de los resultados de la propuesta.

\begin{tabular}{|l|c|c|c|}
\hline \multicolumn{1}{|c|}{ Propuesta } & Actual & Objetivo & Alcanzado \\
\hline $\begin{array}{l}\text { En las actividades } \\
\text { de limpieza }\end{array}$ & & & \\
\hline Tiempo de proceso & $2.95 \mathrm{H}$ & $2.50 \mathrm{H}$ & $1.81 \mathrm{H}$ \\
\hline Horas utilizadas & $2.95 \mathrm{H}$ & $2.50 \mathrm{H}$ & $1.81 \mathrm{H}$ \\
\hline Recorrido & $0.98 \mathrm{mts}$ & $0.50 \mathrm{mts}$ & $0.34 \mathrm{mts}$ \\
\hline $\begin{array}{l}\text { En las actividades } \\
\text { de trasvase-fabric. }\end{array}$ & & & $4.20 \mathrm{H}$ \\
\hline Tiempo de proceso & $5.69 \mathrm{H}$ & $4.50 \mathrm{H}$ & $4.21 \mathrm{H}$ \\
\hline Horas utilizadas & $7.32 \mathrm{H}$ & $5.00 \mathrm{H}$ & $0.21 \mathrm{mts}$ \\
\hline Recorrido & $1.23 \mathrm{mts}$ & $0.65 \mathrm{mts}$ & $3 \mathrm{Kg}$ \\
\hline Granel mermado & $12 \mathrm{Kg}$ & $6 \mathrm{Kg}$ & \\
\hline
\end{tabular}




\begin{tabular}{|l|c|c|c|}
\hline \multicolumn{1}{|c|}{ Propuesta } & Actual & Objetivo & Alcanzado \\
\hline $\begin{array}{l}\text { En las actividades } \\
\text { de arranque-env. }\end{array}$ & & & \\
\hline Tiempo de proceso & $4,75 \mathrm{H}$ & $4.00 \mathrm{H}$ & $3.91 \mathrm{H}$ \\
\hline Horas utilizadas & $8.20 \mathrm{H}$ & $6.00 \mathrm{H}$ & $5.86 \mathrm{H}$ \\
\hline Recorrido & $1.10 \mathrm{mts}$ & $0.60 \mathrm{mts}$ & $55.72 \mathrm{mts}$ \\
\hline Granel mermado & $18 \mathrm{Kg}$ & $0 \mathrm{Kg}$ & $0 \mathrm{Kg}$ \\
\hline $\begin{array}{l}\text { Validación de UPH } \\
\text { y balance de línea }\end{array}$ & & & $88 \%$ \\
\hline Eficiencia & $67 \%$ & $>85 \%$ & $171 \mathrm{unid} / \mathrm{oper}$. \\
\hline Productividad & $142 \mathrm{Unid} / \mathrm{oper}$. & $>160 \mathrm{unid} / \mathrm{oper}$. & 20 \\
\hline Cant. Prod. validado & 0 & $>25$ & $299 \mathrm{horas} / \mathrm{mes}$ \\
\hline Horas Extras & $478 \mathrm{Horas} / \mathrm{mes}$ & $<288 \mathrm{Horas} / \mathrm{mes}$ & \\
\hline $\begin{array}{l}\text { Horas } \\
\text { Improductivas }\end{array}$ & $428 \mathrm{Horas} / \mathrm{mes}$ & $<288 \mathrm{Horas} / \mathrm{mes}$ & $278 \mathrm{horas} / \mathrm{mes}$ \\
\hline
\end{tabular}

Fuente: Elaboración propia.

\subsubsection{Evaluación económica}

Se evalúa el impacto económico de implementar las propuestas de mejora frente a los resultados del piloto desarrollado entre setiembre y octubre. El impacto económico para esta investigación está basado en la metodología costo-beneficio.

Los costos están considerados como los egresos que la empresa ha incurrido para la implementación de las propuestas y los ingresos aquellos beneficios favorables producto de la implementación reflejadas en ahorro de los desperdicios disminuidos.

Se relaciona valores de las matrices de costo con los distintos indicadores obtenidos en el resultado de los pilotos y extrapolamos los datos a un periodo de 12 meses. 
- Costo de la Investigación

Como costo de este trabajo estamos incluyendo los inputs que dentro de lo posible se pueden valorar a precios de mercado o costos espejos del sector cosmético. (Ver anexo 12)

\section{- Costo Beneficio}

El valor real de la ejecución del trabajo de investigación se concreta en la realización de un piloto industrial en la cual se valida las propuestas del diseño, esta relación se da por una diferencia entre los costos incurridos en la implementación y los ahorros que derivados de la mejora al cual le llamaremos beneficios.

Se realiza el flujo de caja proyectado a un horizonte de 12 meses, el resultado del piloto nos permite extrapolar los datos. Se realiza el flujo neto de valores desarrollado en la Tabla 20, para poder determinar el VAN y la Tasa de Recuperación Interna (TIR) resaltado en la Tabla 21. Para la determinación de estos indicadores económicos se considera la tasa de descuento del $30 \%$ que es la rentabilidad de retorno del sector cosmético. 
Tabla 23 Evaluación Económica: Costo-Beneficio y Flujo Neto

\begin{tabular}{|c|c|c|c|c|c|c|c|c|c|c|c|c|c|}
\hline MESES & 0 & 1 & 2 & 3 & 4 & 5 & 6 & 7 & 8 & 9 & 10 & 11 & 12 \\
\hline \multicolumn{14}{|l|}{ INGRESOS } \\
\hline$X$ ahorro de Merma de granel & & 6006 & 6006 & 6006 & 6006 & 6006 & 6006 & 6006 & 6006 & 6006 & 6006 & 6006 & 6006 \\
\hline$x$ ahorros de horas Extras no planific & & 1877 & 1877 & 1877 & 1877 & 1877 & 1877 & 1877 & 1877 & 1877 & 1877 & 1877 & 1877 \\
\hline$x$ ahorro de horas improducitivas & & 1143 & 1143 & 1143 & 1143 & 1143 & 1143 & 1143 & 1143 & 1143 & 1143 & 1143 & 1143 \\
\hline ventas incrental por la mejora & & 4480 & 4480 & 4480 & 4480 & 4480 & 4480 & 4480 & 4480 & 4480 & 4480 & 4480 & 4480 \\
\hline Total Ingresos & 0 & 13,506 & 13,506 & 13,506 & 13,506 & 13,506 & 13,506 & 13,506 & 13,506 & 13,506 & 13,506 & 13,506 & 13,506 \\
\hline & & & & & & & & & & & & & \\
\hline \multicolumn{14}{|l|}{ COSTOS/ITEM } \\
\hline Costo de materiales & 13361 & 0 & 0 & 0 & 0 & 0 & 0 & 0 & 0 & 0 & 0 & 0 & 0 \\
\hline Contratación de Personal OYM & 1800 & 1800 & 1800 & 1800 & 1800 & 1800 & 1800 & 1800 & 1800 & 1800 & 1800 & 1800 & 1800 \\
\hline Horas de Capacitación Mlimp. & 320 & 0 & 0 & 0 & 0 & 0 & 0 & 0 & 0 & 0 & 0 & 0 & 0 \\
\hline Horas de Capacitación Mtras & 200 & 0 & 0 & 0 & 0 & 0 & 0 & 0 & 0 & 0 & 0 & 0 & 0 \\
\hline Horas de Capaticación Marran & 320 & 0 & 0 & 0 & 0 & 0 & 0 & 0 & 0 & 0 & 0 & 0 & 0 \\
\hline Contratar personal de apoyo Inv & 1000 & 1000 & 1000 & 1000 & 1000 & 1000 & 1000 & 1000 & 1000 & 1000 & 1000 & 1000 & 1000 \\
\hline Horas dejadas de producir por Capa & 260 & 0 & 0 & 0 & 0 & 0 & 0 & 0 & 0 & 0 & 0 & 0 & 0 \\
\hline Costo de oportunidad por dejar produc & 4000 & 0 & 0 & 0 & 0 & 0 & 0 & 0 & 0 & 0 & 0 & 0 & 0 \\
\hline Total Costos & 21,261 & 2,800 & 2,800 & 2,800 & 2,800 & 2,800 & 2,800 & 2,800 & 2,800 & 2,800 & 2,800 & 2,800 & 2,800 \\
\hline & & & & & & & & & & & & & \\
\hline \multicolumn{14}{|l|}{ INVERSIONES } \\
\hline Inversión 1 & 0 & 0 & 0 & 0 & 0 & 0 & 0 & 0 & 0 & 0 & 0 & 0 & 0 \\
\hline Total Inversiones & 0 & 0 & 0 & 0 & 0 & 0 & 0 & 0 & 0 & 0 & 0 & 0 & 0 \\
\hline BENEFICIOS & $-21,261$ & 10,706 & 10,706 & 10,706 & 10,706 & 10,706 & 706 & 10,706 & 10,706 & 10,706 & 10,7 & 0,706 & 10,706 \\
\hline
\end{tabular}

\begin{tabular}{|c|c|c|c|c|c|c|c|c|c|c|c|c|c|}
\hline MESES & 0 & 1 & 2 & 3 & 4 & 5 & 6 & 7 & 8 & 9 & 10 & 11 & 12 \\
\hline Ingresos & 0 & 13506 & 13506 & 13506 & 13506 & 13506 & 13506 & 13506 & 13506 & 13506 & 13506 & 13506 & 13506 \\
\hline Costos & 21261 & 2800 & 2800 & 2800 & 2800 & 2800 & 2800 & 2800 & 2800 & 2800 & 2800 & 2800 & 2800 \\
\hline Inversión & 0 & 0 & 0 & 0 & 0 & 0 & 0 & 0 & 0 & 0 & 0 & 0 & 0 \\
\hline Beneficios & -21261 & 10706 & 10706 & 10706 & 10706 & 10706 & 10706 & 10706 & 10706 & 10706 & 10706 & 10706 & 10706 \\
\hline
\end{tabular}

Fuente: Elaboración propia. 
Tabla 24 Evaluación del TIR y VAN para el proyecto de disminución de desperdicios

\begin{tabular}{|c|c|c|c|}
\hline \multicolumn{1}{|c|}{ Cálculo de TIR y VAN Proyecto de Disminución de Desperdicios } \\
Nombre del proyecto a Evaluar \\
Tasa de descuento
\end{tabular}

Fuente: Elaboración propia. 


\subsubsection{Impacto de las partes interesadas}

Para culminar con la validación y propuesta se realizó una matriz para buscar evidenciar el impacto que pudiera generar los riesgos de la implementación de las propuestas con las partes interesadas de la empresa.

Para esto se realizó la adaptación de la matriz de Leopold (Matriz que aporta la ponderación del impacto con los factores que pueden producir los riesgos con las partes de interés), esta ponderación de valores ha sido planteada de acuerdo a consulta con la gerencia y el jefe de planta determinando.

Se definen dos parámetros de medición:

- Magnitud

- Importancia

Dentro de los valores de magnitud: Dentro de los valores de Importancia:

10: Grande 10: Nada de importancia

5: Mediano 1: Alta importancia

1: Pequeño

\begin{tabular}{|l|l|}
\hline Impacto $=$ & $\Sigma$ (Magnitud $\mathrm{x}$ importancia $)$ \\
\hline
\end{tabular}

Evaluación de resultados $=80-100$ (Tomar acciones de inmediatas) rojo

50-80 (Hacer seguimiento y monitoreo continuo) amarillo

0-50 (No genera impacto negativo) verde 
Tabla 25 Matriz de impacto de los interesados

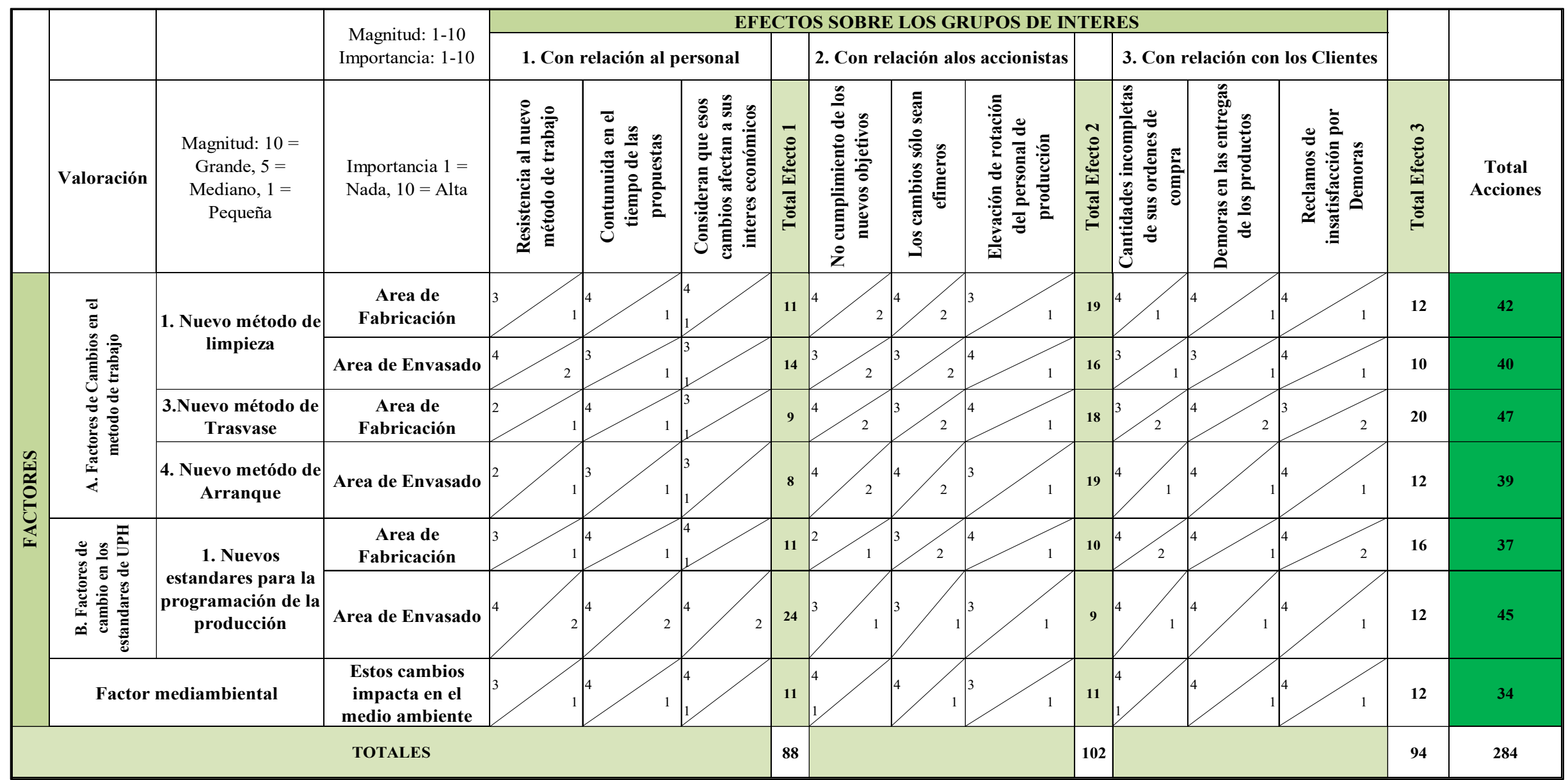

Fuente: Elaboración propia. 
Tabla 25 Matriz de impacto de los interesados

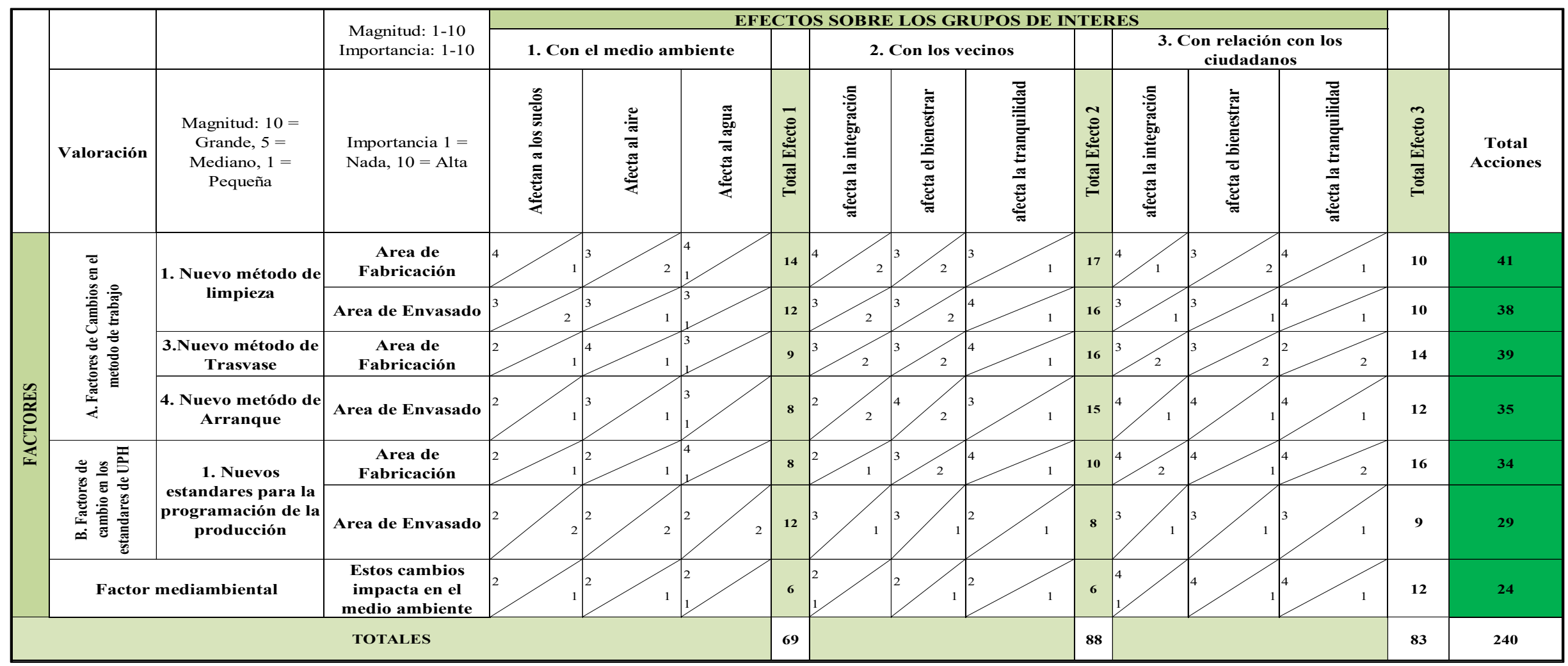

Fuente: Elaboración propia.

La sumatoria de magnitud $\mathrm{x}$ importancia $(3 * 1+4 * 1+4 * 1=11)$ y la suma de totales nos da el valor de 42 el cual según el indicador los factores de cambio no generan impactos negativos importantes en las partes interesadas por tanto se valida su ejecución referente a la evaluación de riesgo 
Interpretación: Se observa en la Tabla 25, la matriz de impacto de los agentes de interés que los factores de cambio planteados en la propuesta de solución para los grupos de interés no generan ningún impacto negativo que lleve a tomar alguna acción de contingencia mediata e inmediata, dado que los resultados del análisis se encuentran dentro de los límites permitidos $(<50)$, así mismo los factores de cambio no afectan al medio ambiente ni tampoco al ciudadano de a pie. 
5 Capítulo V: Conclusiones y Recomendaciones

\section{a. Conclusiones}

- La aplicación de la propuesta planteada en la investigación ha permitido tener resultados de mejoras en todos los indicadores: Una mejora del 50.22\% en la disminución del costo por la pérdida de granel (merma), una mejora del 33\% en la disminución del costo por las horas extras no planificadas, una mejora del $27 \%$ en la disminución del costo por las horas improductivas.

- Se ha incrementado en un $4.5 \%$ las unidades entregadas a los clientes que equivale a un $40 \%$ de mejora por el costo de oportunidad de dejar de entregar unidades de venta a causa de las mermas de granel.

- Se tienen una disminución del 57.94\% del impacto económico generado por los desperdicios enunciados en la presente investigación y una mejora a $7.21 \%$ vs $17.15 \%$ de costo relativo antes de la aplicación del proyecto frente al costo promedio total de producción.

- Se ha logrado validar 20 productos con estándares de UPH (unidades por hora envasadas) validados con lo cual se mejoró en un 10\% del total de productos de la planta Cosmetica, estos indicadores inciden directamente en la planificación de la programación.

- Las situaciones de éxito y los casos de aplicación de investigación revisados en el primer capítulo han permitido direccionar el presente trabajo para la determinación del problema y para la búsqueda de las herramientas que nos permita la propuesta de solución, siempre es importante comparar las situaciones de éxitos con lo que indica la teoría, muchas veces estas no se cumplen con exactitud en los diferentes procesos de manufactura, cada sector de la industria tiene sus particularidades y allí mucho depende del investigador aplicar tal o cual teoría.

- El análisis de la situación actual vista en el capítulo 2 fue muy concienzuda en la presentación de la empresa, se detalló la situación como se presenta antes del estudio 
reflejando claramente los efectos de horas improductivas, horas no planificadas, generación mermas en el proceso de fabricación y de envasado. Este capítulo fue lo más dificultoso y que sirvió para persuadir a los responsable de la empresa de la importancia del estudio y los beneficios que traería disminuir los desperdicios mencionados.

- Con la identificación de los problemas y con los modelos de casos de éxito en otros sectores se vinculó las causas raíces con sus herramientas para dar solución siguiendo un diseño metodológico para la presentación de la propuesta para mejorar la reducción de los desperdicios en producción. El estudio de método y tiempos nos permite plantear una nueva forma para realizar las actividades de limpieza, las actividades de trasvase y las actividades de arranque en el envasado, finalmente el estudio de balance de línea mediante el estudio de tiempos por cronometro nos permitió validar los estándares de UPH que el área de programación de la producción manejaba y que se encontraban desactualizadas muchas veces siendo estas la razón de las horas extras no planificadas y las horas extras improductivas .

- La validación de la propuesta ha sido retada en la aplicación de lotes pilotos desarrollados en las líneas de shampoo y cremas-lociones, la confirmación de las mejoras han sido presentadas en los resultados el cual se evidencia mediante los indicadores un porcentaje de mejora bastante alto en la disminución de las horas extras no planificadas, en las horas improductiva y en la disminución de merma tanto del área de fabricación como del área de envasado.

- En la evaluación económica del estudio se valorizó los costos de los materiales a razón de mercado, éstos se tuvieron que comprar para la implementación de la nueva área de lavado en el primer piso, con lo cual se mejoró tiempos por disminución de recorrido y la compra de mangueras sanitarias para el nuevo método de trasvase en la sala de fabricación $\mathrm{N}^{\circ} 01$ disminuyendo kilogramos de merma por que se disminuye también recorrido de granel en el trasvase. Por otro lado la misma área de lavado que participa en el nuevo método de limpieza contribuye a mejorar de kilogramos de merma por que se elimina la actividad de purga, donde la desinfección se realiza con calor a $100^{\circ} \mathrm{C}$, dejando totalmente seco el sistema quedando innecesario la actividad de purgar, para esto se tuvo 
que comprar algunos repuestos para habilitar en la zona técnica del primer piso el generador de vapor.

- Para culminar la evaluación económica, se presenta el costo de horas de capacitación al personal encargado en los nuevos métodos y la mano de obra para la realización del proyecto, el cual se ve reflejada en la contratación de un profesional Ingeniero industrial junior con un asistente para la creación del área de Organización y Método que hasta antes del proyecto la empresa no disponía. Los estándares de tiempo (UPH) para la programación se encargaba la jefatura de producción sin ninguna medición. Está área a partir de los pilotos se encargaría de hacer la toma de tiempos para las validaciones de líneas y determinación de estándares de tiempo en los diferentes procesos. Con esta información se obtuvo el flujo de caja neto determinando el VAN positivo y el TIR por encima de la tasa de descuento mayor a $30 \%$, que es la tasa natural del sector cosmético.

- Con la confirmación de la viabilidad del proyecto, este trabajo sido aprobado por la empresa para su ejecución, con éste se sienta las bases para continuar con la disminución de los desperdicios generados en las líneas productivas, bajo el esquema de la mejora continua, siempre existirá oportunidades de mejora. 


\section{b. Recomendaciones}

- El estudio en referencia se ha limitado a un piloto de 20 lotes de producción teniendo incidencia en la línea de shampoo y cremas, se recomienda continuar con la propuesta para las líneas del colonias, ampollas y compactos que representan el $25 \%$ de la producción.

- Se recomienda continuar con el estudio de tiempos por cronometro a las demás líneas y productos y poder obtener el 100\% de los estándares de UPH (Unidades por Hora) en las líneas de envasados, esto logrará mejorar al 50\% la planificación de la programación en planta.

- Se recomienda realizar los estudios de tiempos por cronómetros a las estaciones de fabricación del granel, actualmente no se dispone de estándares de UPH de fabricación, frente a los 20 productos ya obtenidos a partir de este estudio (Shampoo y cremas).

- Se recomienda hacer el seguimiento de este estudio a un periodo de 1 año y proponer a la empresa la implementación de otro proyecto para extender el estudio a las líneas de colonia, compactos e inyectables que forman parte dela empresa.

- Con los costos de ahorro por la aplicación de las propuestas en las líneas de shampoo y cremas-lociones se puede plantear un estudio de factibilidad para la implementación de un nuevo equipo compresor con lo cual se puede lograr a disminuir valores de merma de granel cercanos a cero. 


\section{Bibliografía}

- Acero, J.2014. Planeamiento de Productos Nuevos Mediante Programación Lineal MRP: Aplicación a la Industria Cosmética. Madrid: Editorial EAE. Pag. 3-32/45-55

- Analysis of Cosmetic Products, edited by Amparo Salvador, and Alberto Chisvert, Elsevier Science \& Technology, 2015. ProQuest Ebook Central, https://ebookcentral.proquest.com/lib/upc-ebooks/detail.action?docID=291687. Pag.1$25 / 30-40$

- Anaya, J. 2014. Logística integral: La gestión operativa de la empresa. Madrid: ESIC editorial. Pag. 34-45/46-50

- Arévalo, Guevara A; Escobar, Orellana B.; Solórzano, Vides J. (2014) Propuesta de Mejora del Sub-sector cosmético naturales dirigida a la exportación hacia la Unión Europea del enfoque de la cadena de abastecimiento. (Tesis para optar el título de Ingeniería Industrial) El Salvador: Universidad de el Salvador. (http://ri.ues.edu.sv/5823/).

- Cuatrasecas, L. (2015). Gestión competitiva de stocks y procesos de producción. Barcelona: Grupo Planeta. Madrid: Ed. Mac. Laurase. Pag. 15-27/30-45

- Domínguez, De Paz A.; Clará, Díaz R.; Pérez, Medrano E. (2013). Gestión de Mantenimiento productivo total para tallares automotrices del sector público. (Tesis para optar el título de Ingeniero Industrial). El salvador. Universidad de el Salvador.

- Fengzhu LI, Shunan Bao and Sijun LI SAE International Jornal of Materials and Manufacturing Vol. 7, No. 2 (April 2014), pp. 308-312

- Grace, Duffy. Modular Kaizen: Continuous and Breakthrough Improvement, ASQ Quality Press, 2013. ProQuest Ebook Central, https://ebookcentral.proquest.com/lib/upcebooks/detail.action?docID=3002505. 
- Gertsen, Frank, and Jens O. Riis. Continuous Improvement And Innovation, Emerald Publishing 2002. ProQuest Ebook Central, https://ebookcentral.proquest.com/lib/upc-ebooks/detail.action?docID=232271.

- H Saranga and RD Banker The Journal of the Operational Research Society Vol. 61, No. 12 (December 2010), pp. 1777-1788

- ILO. Challenge of Inequality: The Challenge of Inequality, International Labour Office, 2014. ProQuest Ebook Central, https://ebookcentral.proquest.com/lib/upcebooks/detail.action?docID=1936494. Pags. 15-24

- James R. Bradley and Jim Willett Interfaces Vol. 34, No. 6 (Nov. - Dec., 2014), pp.

- 451-459

- Mitra, Amitava. Fundamentals of Quality Control and Improvement, Wiley, 2016. ProQuest Ebook Central, https://ebookcentral.proquest.com/lib/upcebooks/detail.action?docID=4497494.

- Mohamed E. M. El-Sayed SAE International Journal of Materials and Manufacturing

- Vol. 3, No. 1 (2014), pp. 194-201

- Manuel F. Suarez and José Ángel Miguel-Dávila Innovar: Revista de ciencias administrativas y sociales Vol. 21, No. 41 (Julio - septiembre de 2013), pp. 19-37

- Ramachandran, A, Kesavan, R. 2014 Principle in Automotive Industry. National Conference on Contermporary Approaches in Mechanical. India. Anna University

- Sustainability: How the Cosmetics Industry Is Greening Up, edited by Amarjit Sahota, John Wiley \& Sons, Incorporated, 2013. ProQuest Ebook Central, https://ebookcentral.proquest.com/lib/upc-ebooks/detail.action?docID=1574356. Pag. 125

- Sower, Victor. Insightful Quality: Beyond Continuous Improvement, Business Expert Press, 2014. ProQuest Ebook Central, https://ebookcentral.proquest.com/lib/upcebooks/detail.action?docID $=922364$. 
7. Anexos

Anexo 1 Lista de productos más representativos

\begin{tabular}{|c|c|c|c|}
\hline L. Shampoo & L. Lociones & L. Cremas & L. Colonias \\
\hline Babytopic & Multi active body & Sunwork & Col. Ref. Wild Contry \\
\hline Escaltopic & Monligth Land & Ultrashield & Col. Ref. Sweet Honesty \\
\hline Ammen Manz & Monligth Coconut & Ad. Tech Sheen & Col. Ref. Toque de amor \\
\hline Ammen Orig & Care Body & P/cuerpo sensual & Col. Black Suede \\
\hline Natural Guara & Dermatopic S & P/cuerpo vanilla & Col. Musk f/ Men \\
\hline Fiorre-la & Acnetopic Loción & Moonligt Land & Col.Ref. Charisma \\
\hline Natural p/riso & Bodymilk Loción & Reductor Line & Col. Ammen-Ni-O \\
\hline Natural cocoa & Corporal totaly & Wonder Cream & Col. Citrica \\
\hline Fiore-control & Sensual body & Banishing cream & Col. Blossoming Petal \\
\hline Acond. Almo & Atopicare Loción & Milk papá & Col.Body Splash \\
\hline
\end{tabular}

Anexo 2 Estándares de UPH para la programación de la producción

\begin{tabular}{|l|c|c|l|}
\hline \multicolumn{1}{|c|}{ PRODUCTO } & UPH & TOOL & \multicolumn{1}{c|}{ LINEA } \\
\hline COL. REFRESCANTE WILD COUNTRY X 150ML & 2000 & 13 & COLONIA \\
\hline COL. REFRESCANTE SWEET HONESTY X 150ML & 2000 & 12 & COLONIA \\
\hline COL. REFRESCANTE TOQUE DE AMOR X 150ML & 2000 & 12 & COLONIA \\
\hline COL. REFRESCANTE BLACK SUEDE X 150ML & 2000 & 12 & COLONIA \\
\hline COL. REFRESCANTE MUSK F/MEN X 150ML & 2000 & 12 & COLONIA \\
\hline COL. REFRESCANTE SENSUAL MUSK X 150ML & 2000 & 12 & COLONIA \\
\hline COL. REFRESCANTE TOPAZE X 150ML & 2000 & 12 & COLONIA \\
\hline COL. REFRESCANTE CHARISMA X 180 mI & 2000 & 13 & COLONIA \\
\hline COL. AMMENS NIIO X 10OML NPO9 & 1200 & 9 & COLONIA \\
\hline AGUA DE COL. CITRICA X 1 LT NP8 & 540 & 13 & COLONIA \\
\hline COL. SPRAY BLOSSOMING PETALS X 120 ML & 1500 & 12 & COLONIA \\
\hline COL. BODY SPLASH CHERRY BLOSSOM X 250 ML & 1200 & 12 & COLONIA \\
\hline SHAMPOO AMMENS MANZANILLA X 450ML NP09 & 2000 & 14 & SHAMPOO \\
\hline SHAMPOO AMMENS MANZ. X 45OML NP09 & 2000 & 14 & SHAMPOO \\
\hline
\end{tabular}


Anexo 3 Diagrama de Actividades del proceso de limpieza de equipos-maquias y tanques

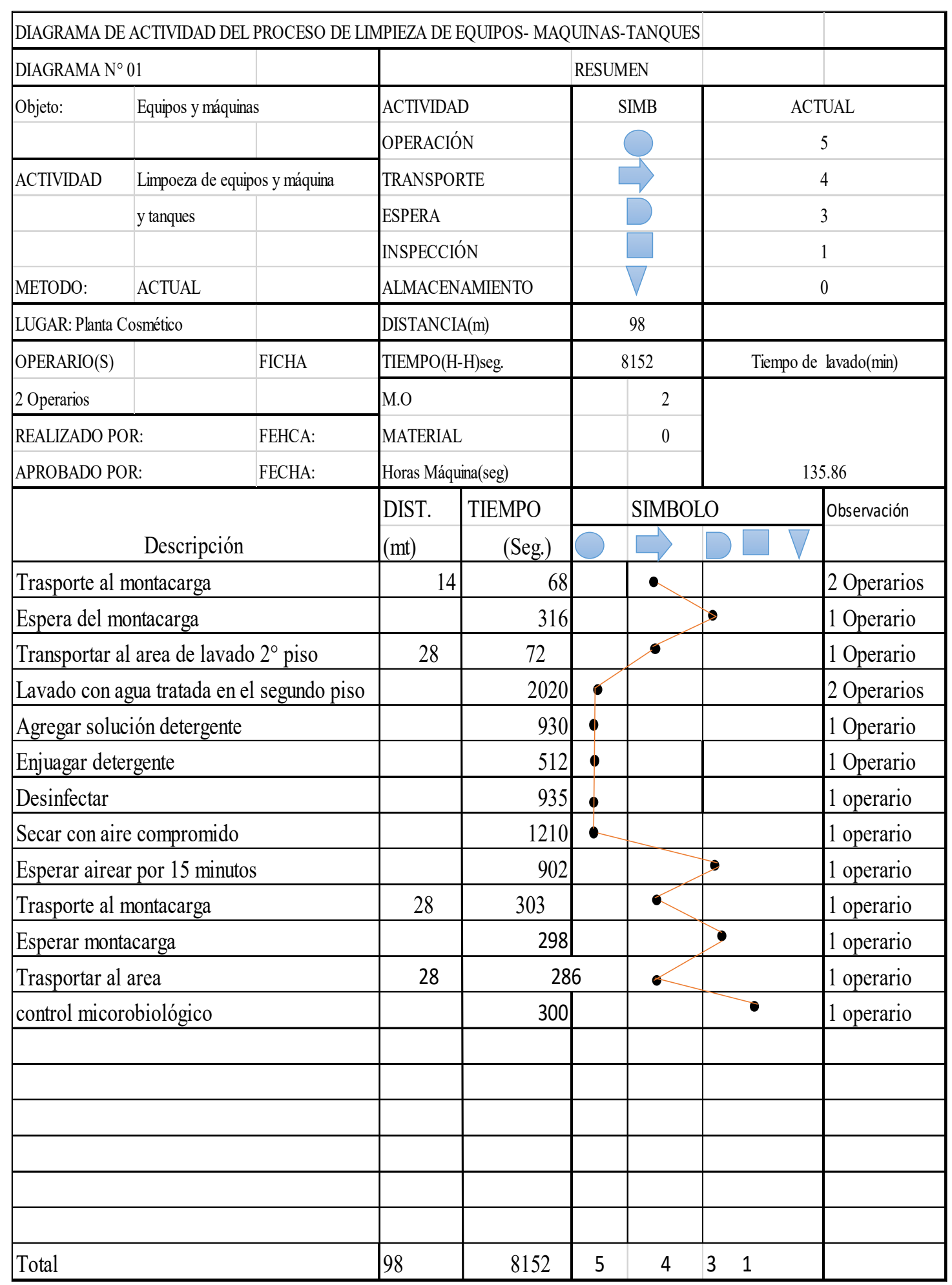


Anexo 4 Diagrama de Actividad del proceso limpieza propuesta

\begin{tabular}{|c|c|c|c|c|c|c|c|c|}
\hline \multicolumn{9}{|c|}{ DIAGRAMA DE ACTIVIDAD DEL PROCESO DE LIMPIEZA DE EQUIPOS- MAQUINAS-TANQUES(PROPUESTO) } \\
\hline \multicolumn{3}{|c|}{ DIAGRAMA N ${ }^{\circ} 02$} & \multicolumn{4}{|c|}{ RESUMEN } & & \\
\hline \multirow[t]{2}{*}{ Objeto: } & \multicolumn{2}{|c|}{ Equipos y máquinas } & \multicolumn{2}{|c|}{ ACTIVIDAD } & \multicolumn{2}{|c|}{ SIMB } & PROPUESTO & AHORRO \\
\hline & & & \multicolumn{2}{|c|}{ OPERACIÓN } & \multicolumn{2}{|c|}{0} & 4 & 1 \\
\hline \multirow[t]{3}{*}{ ACTIVIDAD } & \multicolumn{2}{|c|}{ Limpoeza de equipos y máquina } & \multicolumn{2}{|c|}{ TRANSPORTE } & \multicolumn{2}{|c|}{$\Rightarrow$} & 2 & 2 \\
\hline & y tanques & & \multicolumn{2}{|l|}{ ESPERA } & \multicolumn{2}{|r|}{ D } & 0 & 3 \\
\hline & & & \multicolumn{2}{|c|}{ INSPECCIÓN } & \multirow{2}{*}{\multicolumn{2}{|c|}{ V }} & 1 & 0 \\
\hline METODO: & PROPUESTO & & \multicolumn{2}{|c|}{ ALMACENAMIENTO } & & & & \\
\hline \multicolumn{2}{|c|}{ LUGAR: Planta Cosmético } & & \multicolumn{2}{|c|}{ DISTANCIA(m) } & \multicolumn{2}{|r|}{34} & & \\
\hline OPERARIO(S) & & FICHA & \multicolumn{2}{|c|}{ TIEMPO(H-H)seg. } & \multicolumn{2}{|c|}{6530} & \multicolumn{2}{|c|}{ Tiempo de lavado(min) } \\
\hline 1 Operario & & & \multicolumn{2}{|l|}{ M.O } & \multicolumn{2}{|r|}{1} & & \\
\hline REALIZADO PO & & FEHCA: & MATERIAL & & & & & \\
\hline APROBADO PO & & FECHA: & Horas Máqu & ina(seg) & & & & 8.83 \\
\hline & & & DIST. & TIEMPO & & SIMB & & Observación \\
\hline & Descripción & & (mt) & (Seg.) & 0 & $\Rightarrow$ & $\nabla$ & \\
\hline Transportar a & area de lavado & $1^{\circ}$ piso & 8 & 48 & & - & & 1 Operarios \\
\hline Lavado con a & zua tratada en e & segundo piso & & 2252 & $\sigma$ & & & 1 Operario \\
\hline Agregar soluc & ión detergente & & & 982 & 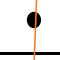 & & & 1 Operario \\
\hline Enjuagar dete & gente & & & 1820 & 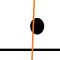 & & & 1 Operarios \\
\hline Desinfectar $\mathrm{y}$ & secar & & & 648 & - & & & 1 Operario \\
\hline Trasportar al & area & & 26 & 480 & & $\cdot$ & & 1 Operario \\
\hline control micor & biológico & & & 300 & & & $\bullet$ & 1 operario \\
\hline & & & & & & & & \\
\hline & & & & & & & & \\
\hline & & & & & & & & \\
\hline & & & & & & & & \\
\hline & & & & & & & & \\
\hline & & & & & & & & \\
\hline & & & & & & & & \\
\hline & & & & & & & & \\
\hline & & & & & & & & \\
\hline & & & & & & & & \\
\hline & & & & & & & & \\
\hline Total & & & 34 & 6530 & 4 & 2 & 01 & \\
\hline
\end{tabular}


Anexo 5 Diagrama de actividades del proceso de fabricación actual

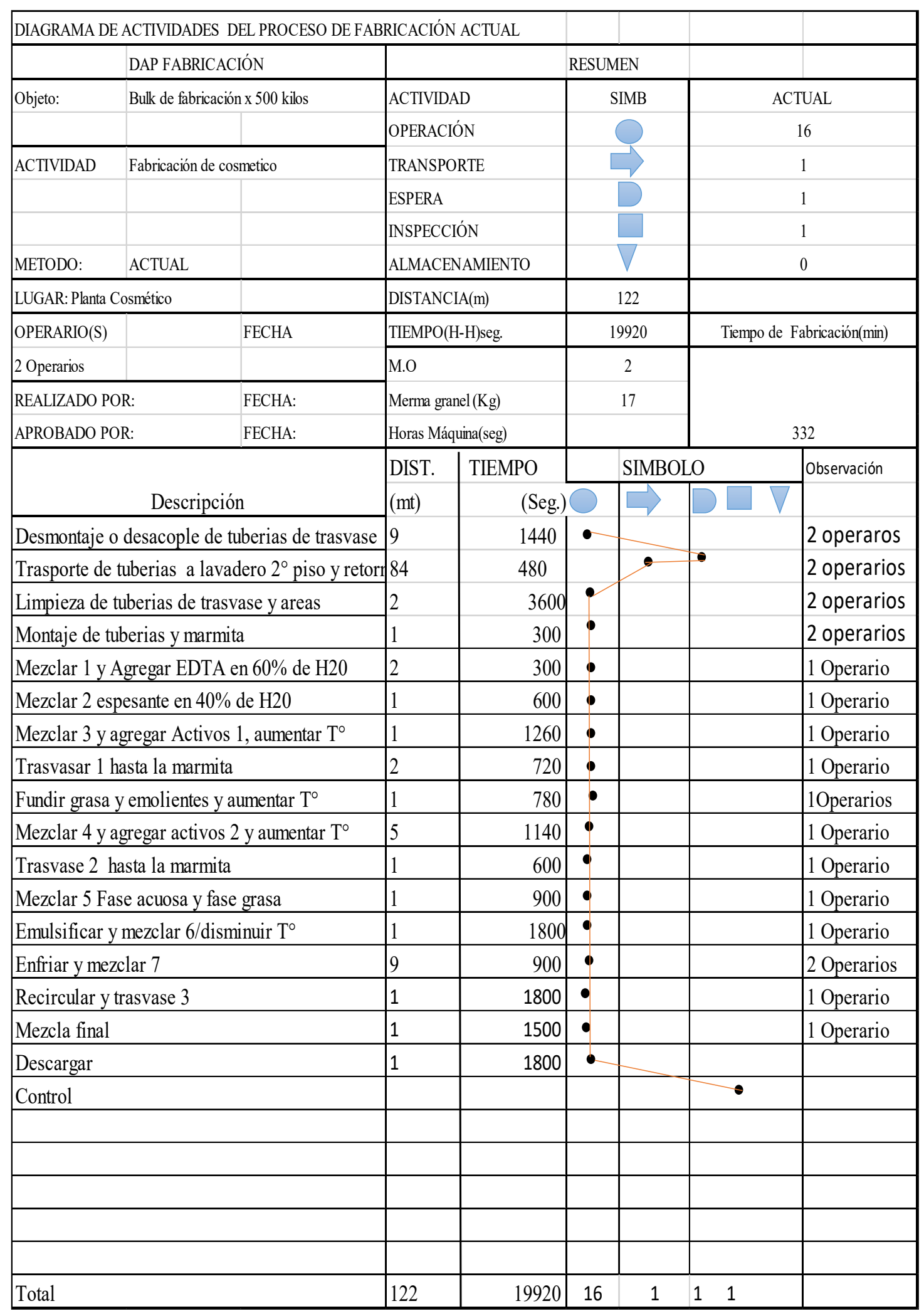


Anexo 6 Diagrama de actividades del proceso de fabricación propuesto

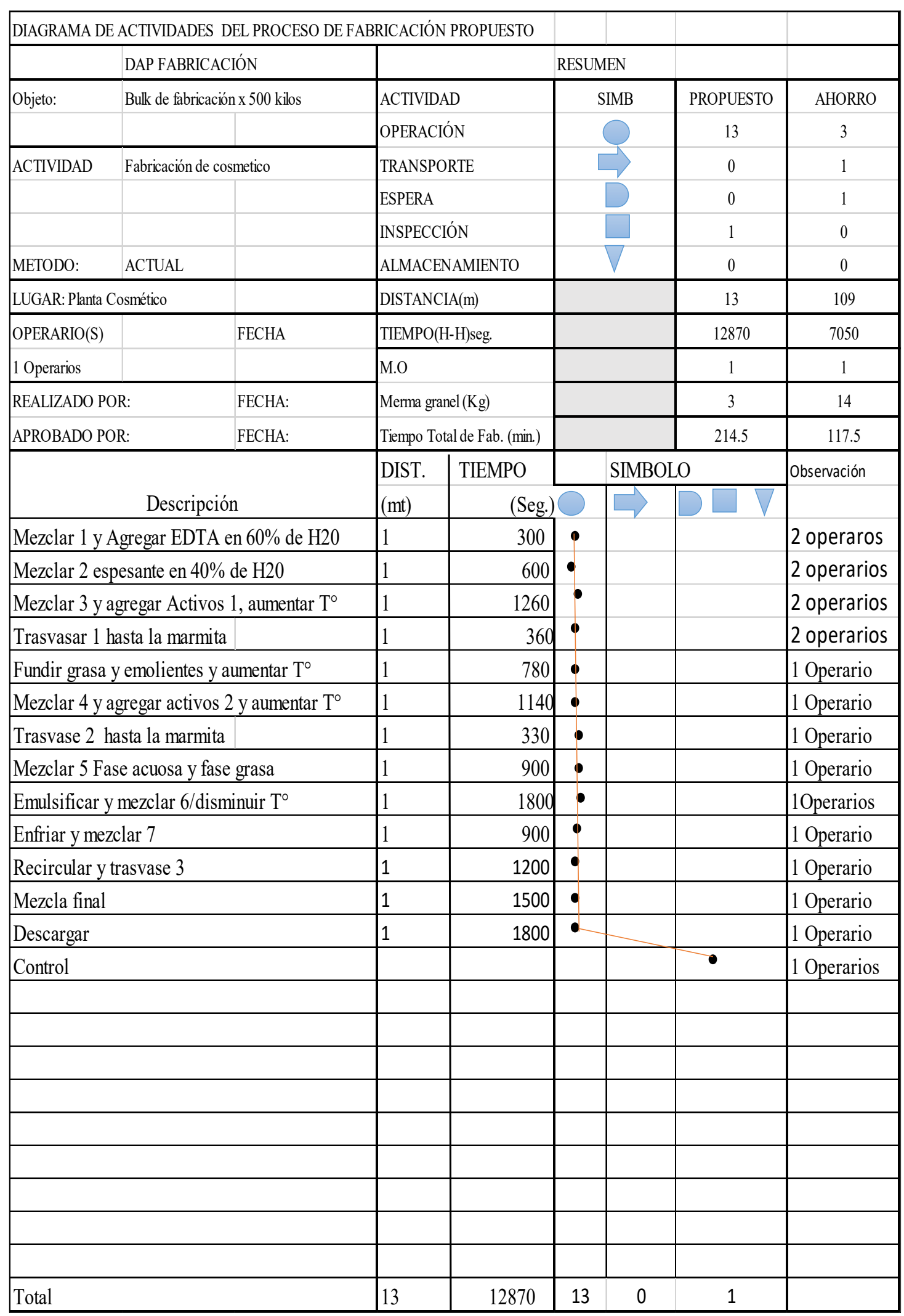


Anexo 7 Diagrama de actividades del proceso de envasado actual

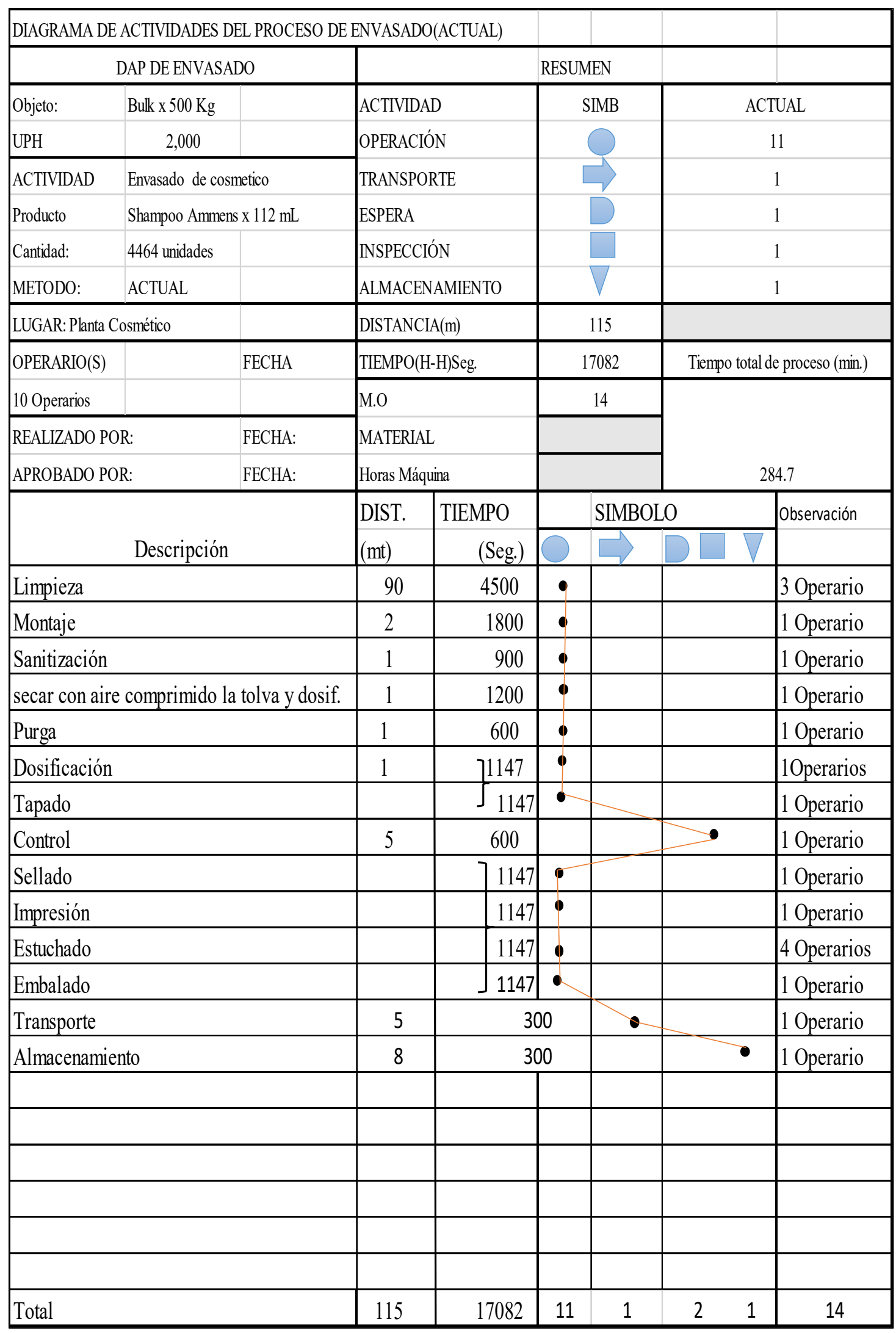


Anexo 8 Diagrama de Actividades del proceso de envasado propuesto

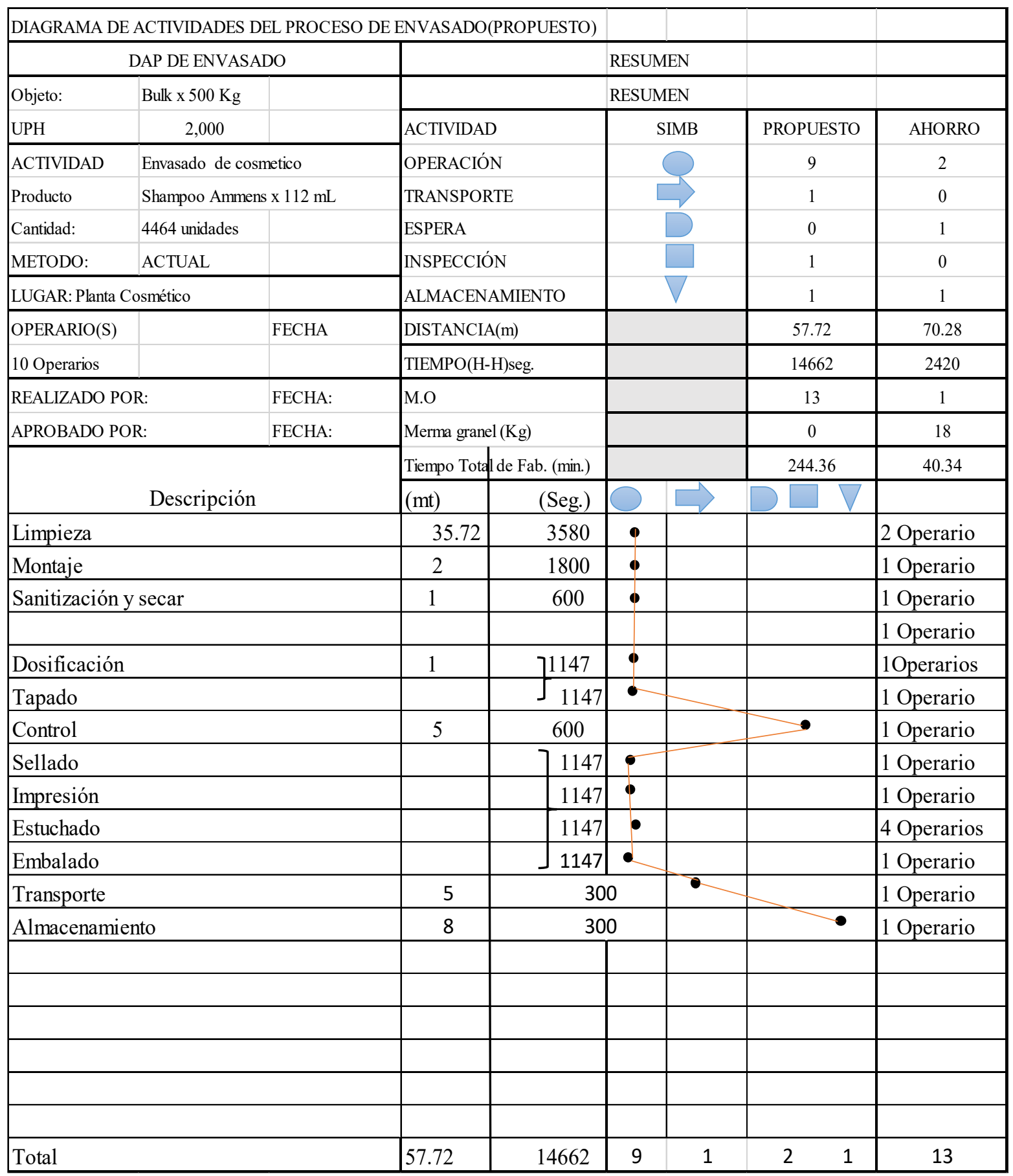


Anexo 9 Estudio de tiempo por cronometro del Shampoo Ammens Original x 675

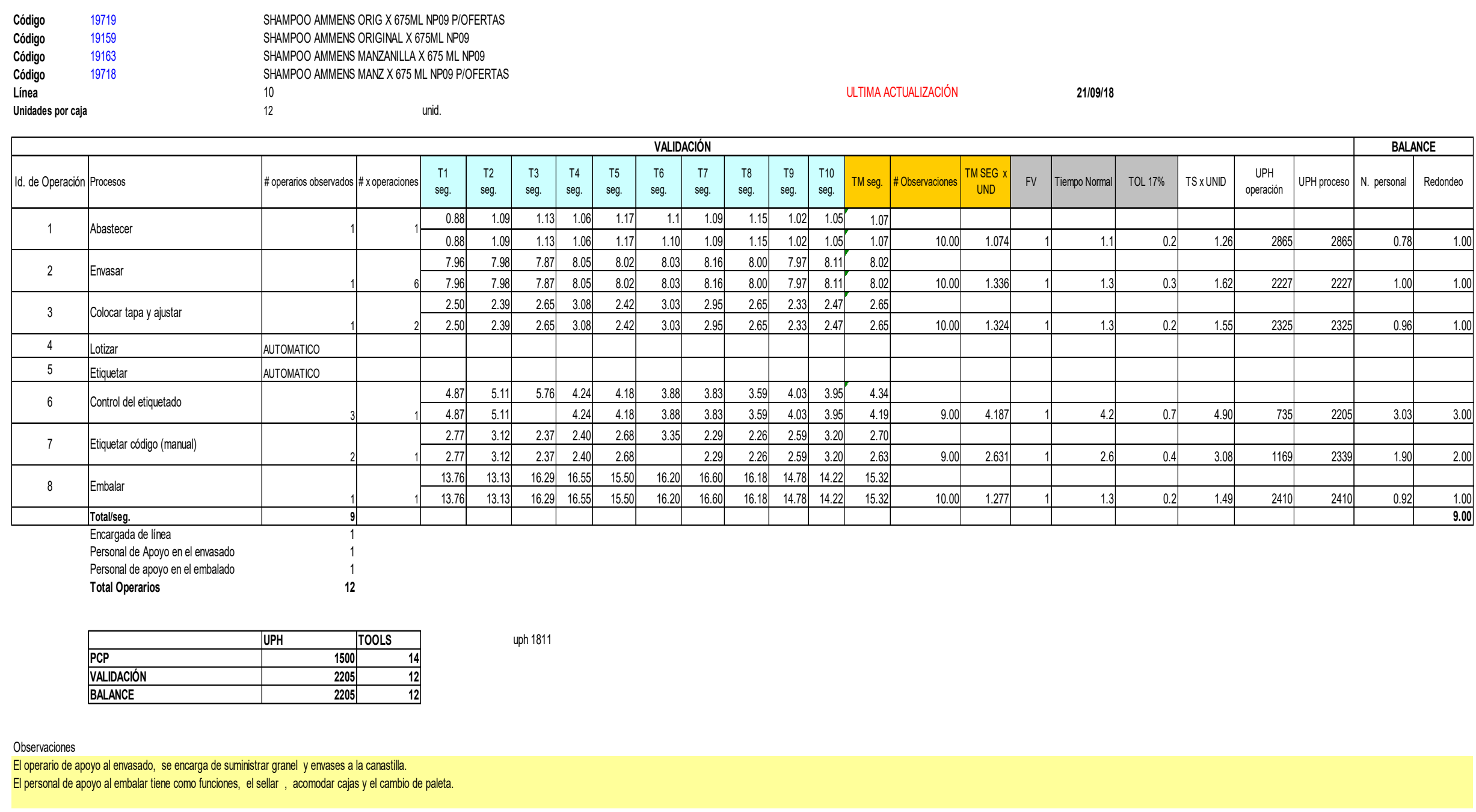


Anexo 10 Estudio de tiempo por cronometro del Sh. Natural Guarana

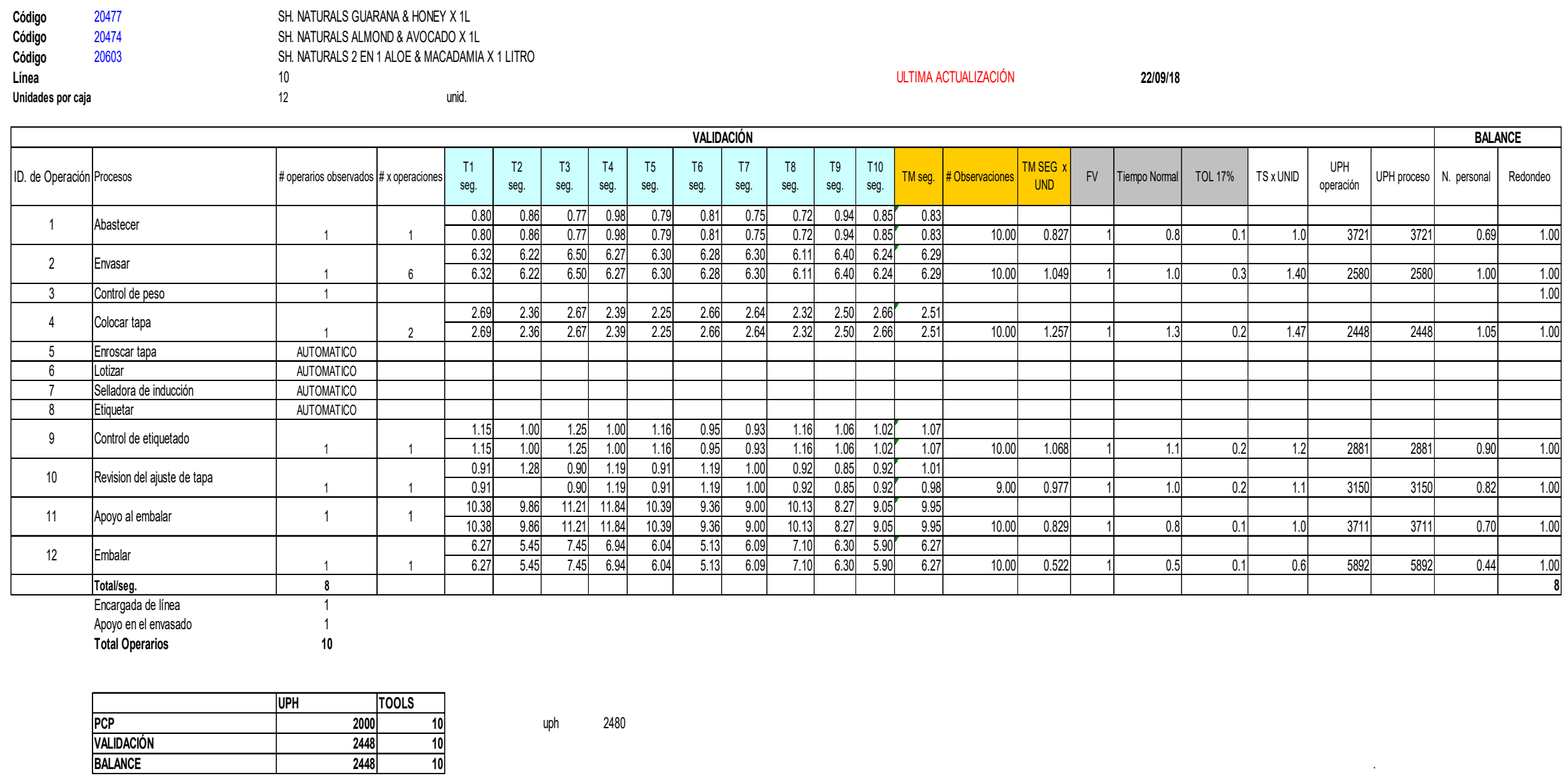

Observaciones

El personal de apoyo realiza las funciones de cambio de bidon, abastece las canastillas de envases, controla la cantidad de granel en la tolva, etc

En la operacion Nro. 11, el operario tiene como función colocar los productos de 12 Und. en caja.

La operacion control de peso, se realiza de forma eventual, designando solo productos que requieran de la operación. Por lo consiguiente, designa una parte de su tiempo a lapoyo en la operación Nro. 4

El personal de embalar tiene como funciones, el sellar , acomodar cajas y el cambio de palta. Solo se le considera al tiempo observado a la funcion de sellar caja. 
Anexo 11 Estudio de tiempo por cronometro del Sh. Ammens Origina x $112 \mathrm{~mL}$

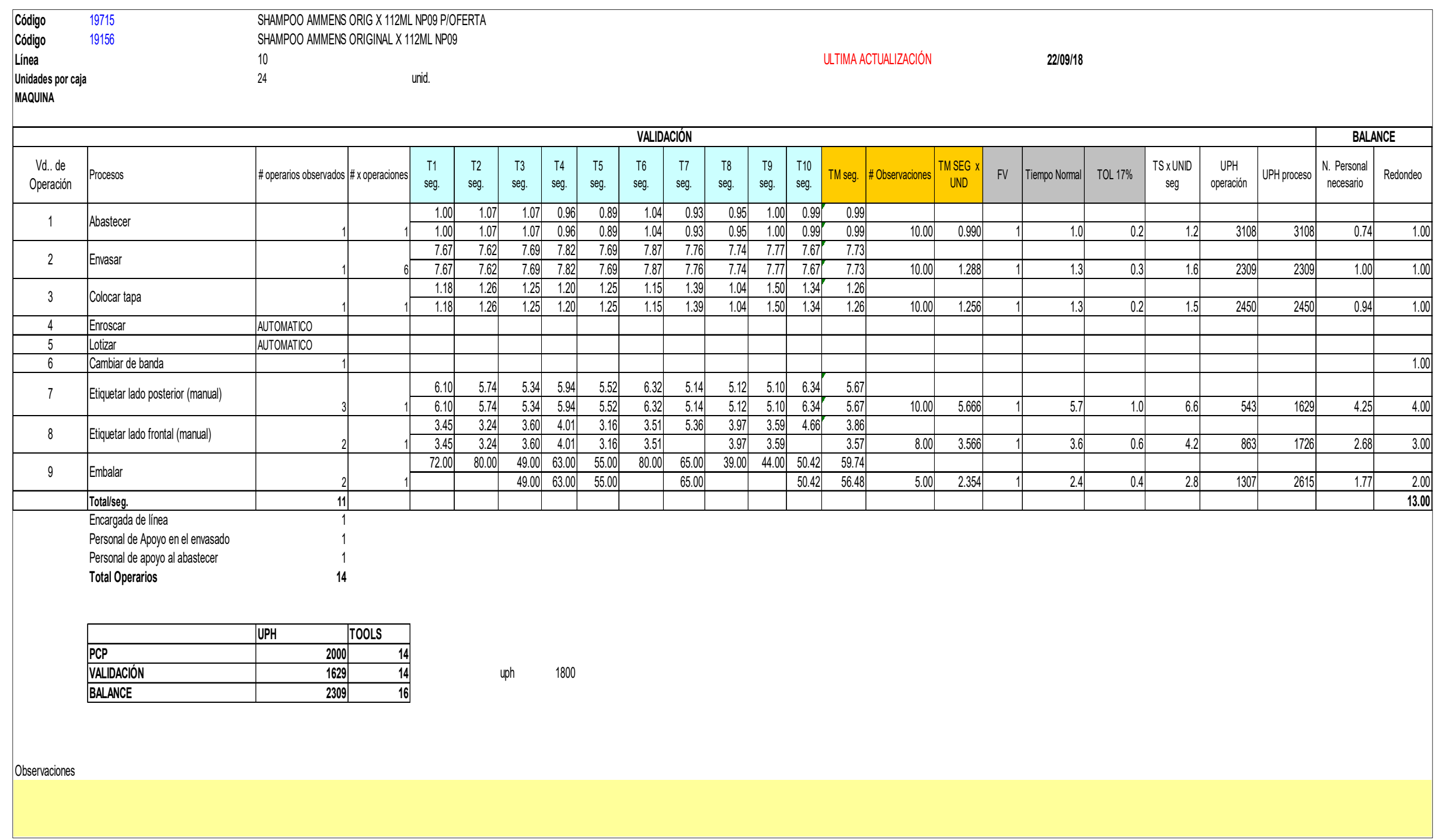


Anexo 12 Costo del proyecto de investigación

\begin{tabular}{|c|c|c|c|}
\hline \multicolumn{4}{|c|}{ Costos del proyecto } \\
\hline Materialels & cantidad & $\begin{array}{c}\text { costo Unitario } \\
\text { (S/.) }\end{array}$ & $\begin{array}{c}\text { costo total } \\
(\mathrm{S} / .)\end{array}$ \\
\hline Canalestas electricas & 50 & 3.26 & 163 \\
\hline cables mellizos 1" & 100 & 2.21 & 221 \\
\hline Marco 1 elemento, color. Niquel negro & 5 & 89.9 & 449.5 \\
\hline Interruptor $10 \mathrm{~A} / 220 \mathrm{~V}$ & 8 & 8.25 & 66 \\
\hline Flecas simpres & 21 & 9.78 & 205.38 \\
\hline Tubo corrugado CR-16 & 12 & 9.25 & 111 \\
\hline Conmutador $10 \mathrm{~A} / 220 \mathrm{~V}$ & 4 & 56.78 & 227.12 \\
\hline Pulsador $10 \mathrm{~A} / 220 \mathrm{~V}$ & 4 & 34.25 & 137 \\
\hline Tapa para toma $2 \mathrm{P}$ & 4 & 17.23 & 68.92 \\
\hline Magnetotérmico LR Gama industrial & 2 & 234.5 & 469 \\
\hline Tapa para toma $2 \mathrm{P}$ & 12 & 5.45 & 65.4 \\
\hline Limitador de subtensión bipolar de cap. St. & 4 & 123.35 & 493.4 \\
\hline Interruptor de control de potencia gama Ind & 2 & 276.5 & 553 \\
\hline Caja icp+ 18 módulos de empotador /con pta blanca & 1 & 354 & 354 \\
\hline Resistencia tipo J & 2 & 188 & 376 \\
\hline Mangueras sanitarias de conexión & 25 & 36 & 900 \\
\hline Manguera de trasvasas poliporpileo & 50 & 34.54 & 1727 \\
\hline Valvulas reductoras de presion de vapor & 2 & 586 & 1172 \\
\hline Separador & 1 & 654 & 654 \\
\hline Valvula de corte de agua & 2 & 145.6 & 291.2 \\
\hline Filtro de vapor & 1 & 128 & 128 \\
\hline Manómetro & 4 & 121.35 & 485.4 \\
\hline Válvulas de interrupción & 4 & 56.45 & 225.8 \\
\hline Purgador de boya & 1 & 567 & 567 \\
\hline Sensor spirati & 1 & 278 & 278 \\
\hline Pintura epoxica & 5 & 89.76 & 448.8 \\
\hline Llantas de Polipropileno 2T cap. & 8 & 186.45 & 1491.6 \\
\hline Cronometros cuenta a cero & 3 & 34.18 & 102.54 \\
\hline Resistencia 3J & 2 & 256.8 & 513.6 \\
\hline Horas máquina de vapor & 8 & 23 & 184 \\
\hline Uso adicional de combustible para vapor & 16 & 14.5 & 232 \\
\hline Total & & & 13361 \\
\hline
\end{tabular}

\begin{tabular}{|l|c|c|c|}
\hline \multicolumn{1}{|c|}{ Recursos Humanos } & $\begin{array}{c}\text { Personal } \\
\text { involucrado }\end{array}$ & Costo & $\begin{array}{c}\text { Costo } \\
\text { Total }\end{array}$ \\
\hline Contratación de personal para OYM & 1 & 1800 & 21600 \\
\hline Horas de capacitación del método de limpieza & 8 & 40 & 320 \\
\hline Horas de capacitación del nuevo método de trasvase & 4 & 50 & 200 \\
\hline Horas de capacitación del nuevo método de arranque & 8 & 40 & 320 \\
\hline Personal de apoyo para el estudio de investigación & 1 & 1000 & 3000 \\
\hline Horas dejadas de producir por capacitación & 20 & 13 & 260 \\
\hline Costo de oportunidad por dejar de producir & 20 & 200 & 4000 \\
\hline \multicolumn{1}{|c|}{ Total } & & & 29700 \\
\hline
\end{tabular}




\begin{tabular}{|c|c|c|c|c|c|}
\hline \multicolumn{4}{|c|}{ Línea Shampoo } & \multicolumn{2}{|c|}{ Balance de Linea } \\
\hline Item & Producto & $\begin{array}{l}\text { UPH antes } \\
\text { del piloto }\end{array}$ & \begin{tabular}{|c|} 
UPH \\
después del \\
piloto
\end{tabular} & $\begin{array}{l}\text { Operios antes } \\
\text { del piloto }\end{array}$ & $\begin{array}{c}\text { Operarios } \\
\text { balanceados }\end{array}$ \\
\hline AM450 & AMMENS MANZANILLA X 450ML & 2000 & 2626 & 14 & 13 \\
\hline A0675 & AMMENS ORIG X 675ML NP09 & 1500 & 2205 & 14 & 12 \\
\hline NG & NATURALS GUARANA X $1 \mathrm{~L}$ & 2000 & 2448 & 10 & 10 \\
\hline $\mathrm{A} 0112$ & AMMENS ORIG X 112ML & 2000 & 2309 & 14 & 16 \\
\hline AM112 & AMMENS MANZANILLA X 112ML & 2000 & 2342 & 12 & 13 \\
\hline FLKL & FIORE-LA KIWI LIMA X $1 \mathrm{~L}$ & 1000 & 1280 & 12 & 13 \\
\hline ANM & AMMENS NAT. C/RIZO MANZ. X 200ML & 1200 & 470 & 12 & 12 \\
\hline SNC & SH. NATURALS COCOA \& X $1 \mathrm{~L}$ & 2000 & 1768 & 10 & 10 \\
\hline SFLU & SHAMPOO FIORE-LA UVA X $1 \mathrm{~L}$ & 900 & 1040 & 12 & 14 \\
\hline SAM & SHAMPOO AMMENS MANZ X 200ML & 1500 & 2327 & 14 & 12 \\
\hline SFLCC & SHAMPOO FIORE-LA CONTROL CAIDA X $1 \mathrm{~L}$ & 1800 & 1247 & 12 & 13 \\
\hline ADAN & ACOND.\& DESENR. AMMENS NAT. & 1200 & 1798 & 14 & 18 \\
\hline AFLMTC & ACOND. FIORE-LA MANZANILLA T/TIPO CAB. X & 1200 & 967 & 12 & 13 \\
\hline AAM & ACOND. AMMENS MANZ. X 200ML & 1200 & 965 & 12 & 12 \\
\hline ANL & AMMENS NAT.C/LISO X 400ML & 1200 & 1275 & 10 & 14 \\
\hline ANLG & AMMENS NATURAL C/LISO GERMEN DE T & 1200 & 1596 & 10 & 14 \\
\hline
\end{tabular}

Anexo 14.: Ponderación de las causas de acuerdo al diagrama de Ishikawa para el diagrama de Pareto

PONDERACIÓN DE LAS CAUSAS DE ACUERDO AL DIAGRAMA DE ISHIKAWA

\begin{tabular}{|l|c|c|}
\hline \multicolumn{1}{|c|}{ Principales Causas } & F.R. & F.A\% \\
\hline Actividad de arranque de envasado ineficiente & 19.7 & 19.7 \\
\hline actividad de trasvase ineficiente & 17.8 & 37.5 \\
\hline Actividad de limpieza ineficaz & & 52.7 \\
\hline & 15.2 & \\
\hline Desbalance de las lineas de envasado & & 66.8 \\
\hline Caida presión de aire comprimido & 14.1 & 79.7 \\
\hline Temperatura alta en los almacenes de empaque & 12.9 & 85.6 \\
\hline Mala calibración de las maquinas & 5.9 & $\mathbf{8 8 . 2}$ \\
\hline & & \\
\hline Los maquinistas no tienen conocimiento basico mtto & 2.6 & 90.3 \\
\hline Falta homologación de proveedores & & 92.2 \\
\hline & 2.1 & \\
\hline Falta de supervisores de producción y mtto & 1.9 & 93.9 \\
\hline Oalta de mtto preventivo & & 97.5 \\
\hline
\end{tabular}


Anexo 15: Data para el análisis de las incidencias de las causas en las ordenes de producción

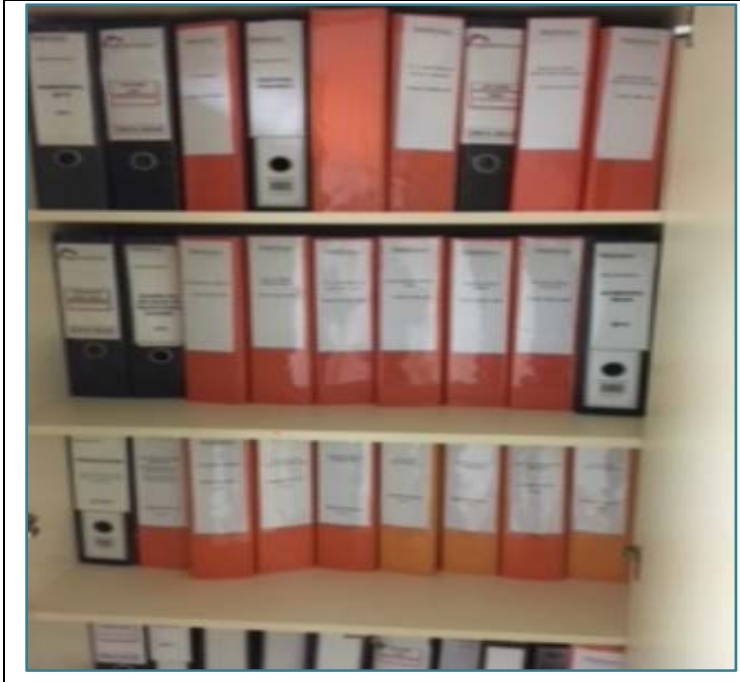

Las ordenes de producción son custodiadas en file por

producto, cada file registra todas las ordenes durante un año y allí se registra operaciones recursos utilizados.
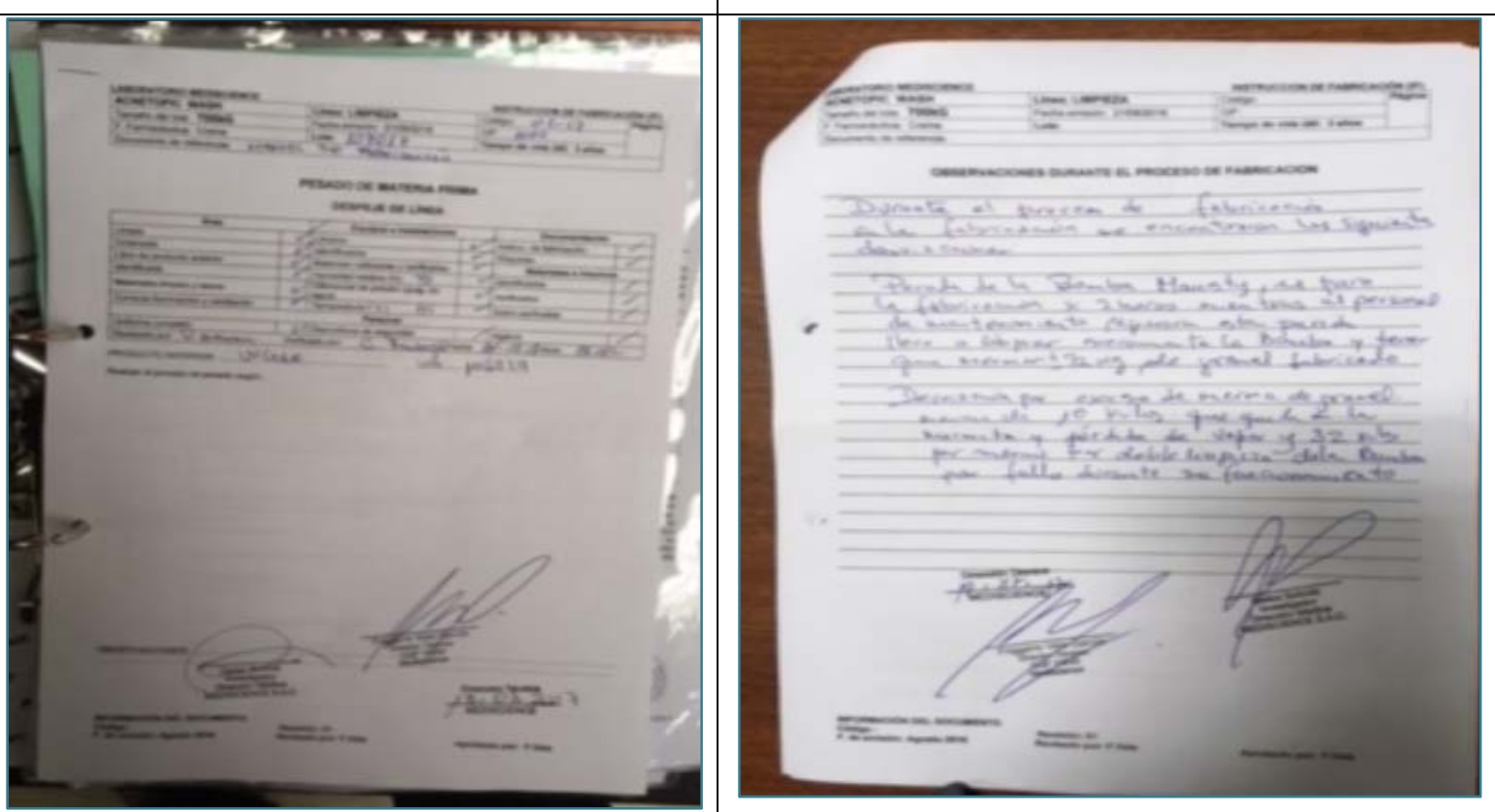

En cada file se encuentran todas las ordenes de producción donde se encuentra toda la información que nos permite trazabilidad de un lote, el manual de fabricación es el documento oficial, firmada y visada.

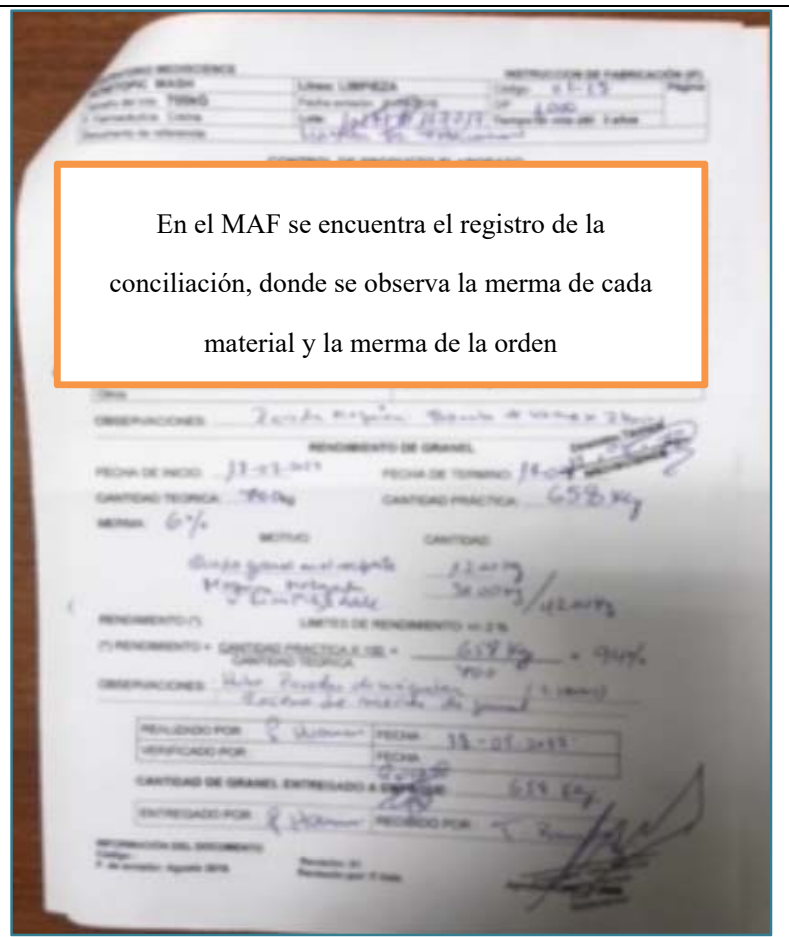

Dentro de los registros de la orden se encuentran los reportes de hora, reportes de parada, de mermas y todas las desviaciones con tiempos y recursos utilizados durante los procesos. Estos registros sirvieron para el análisis de incidencia de las causas 
Anexo 16: costos mensuales por desperdicio de merma por granel

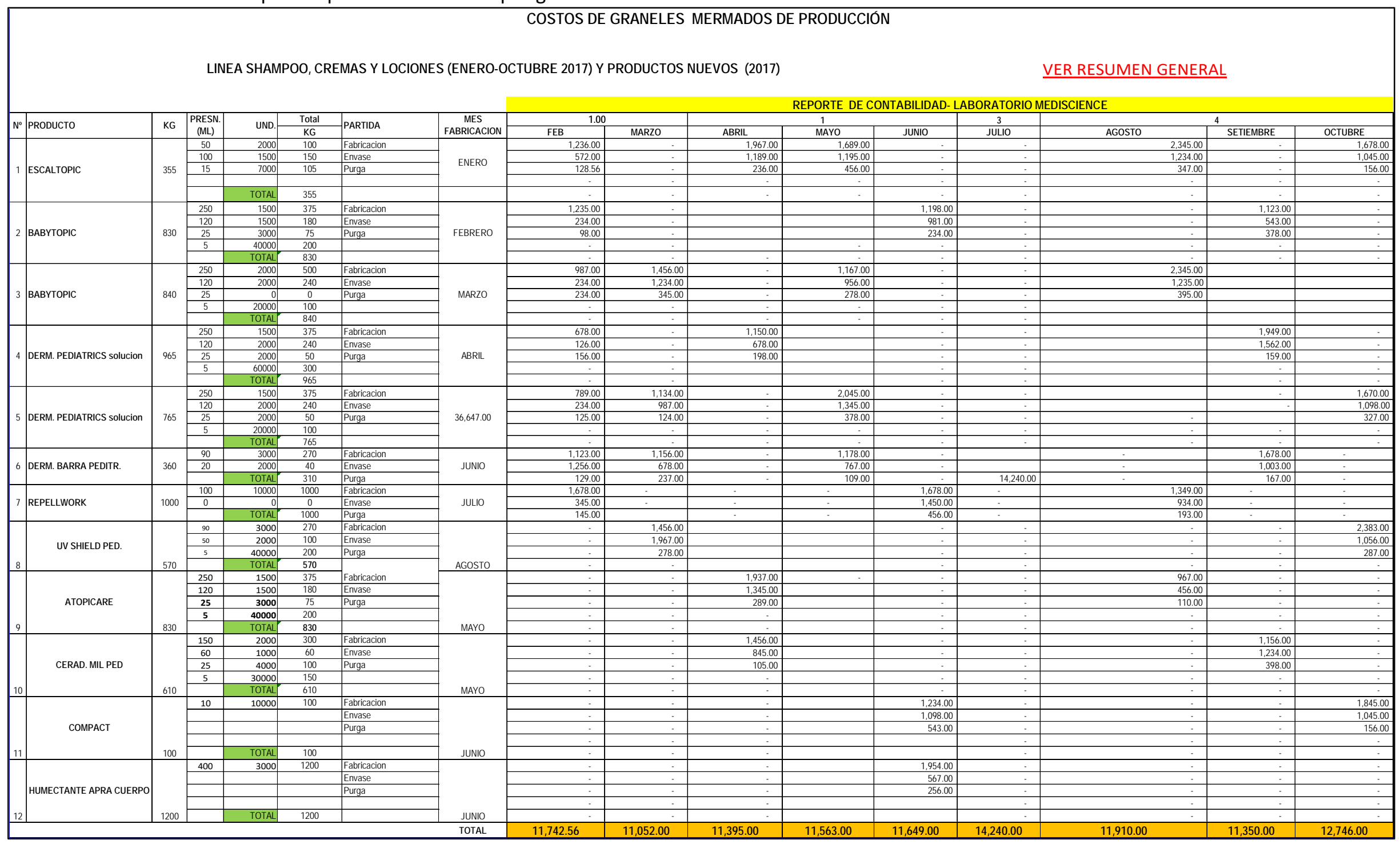

P á g i n a 140 | 141 
Anexo 17: Costos mensuales por desperdicios de horas extras y horas improductivas

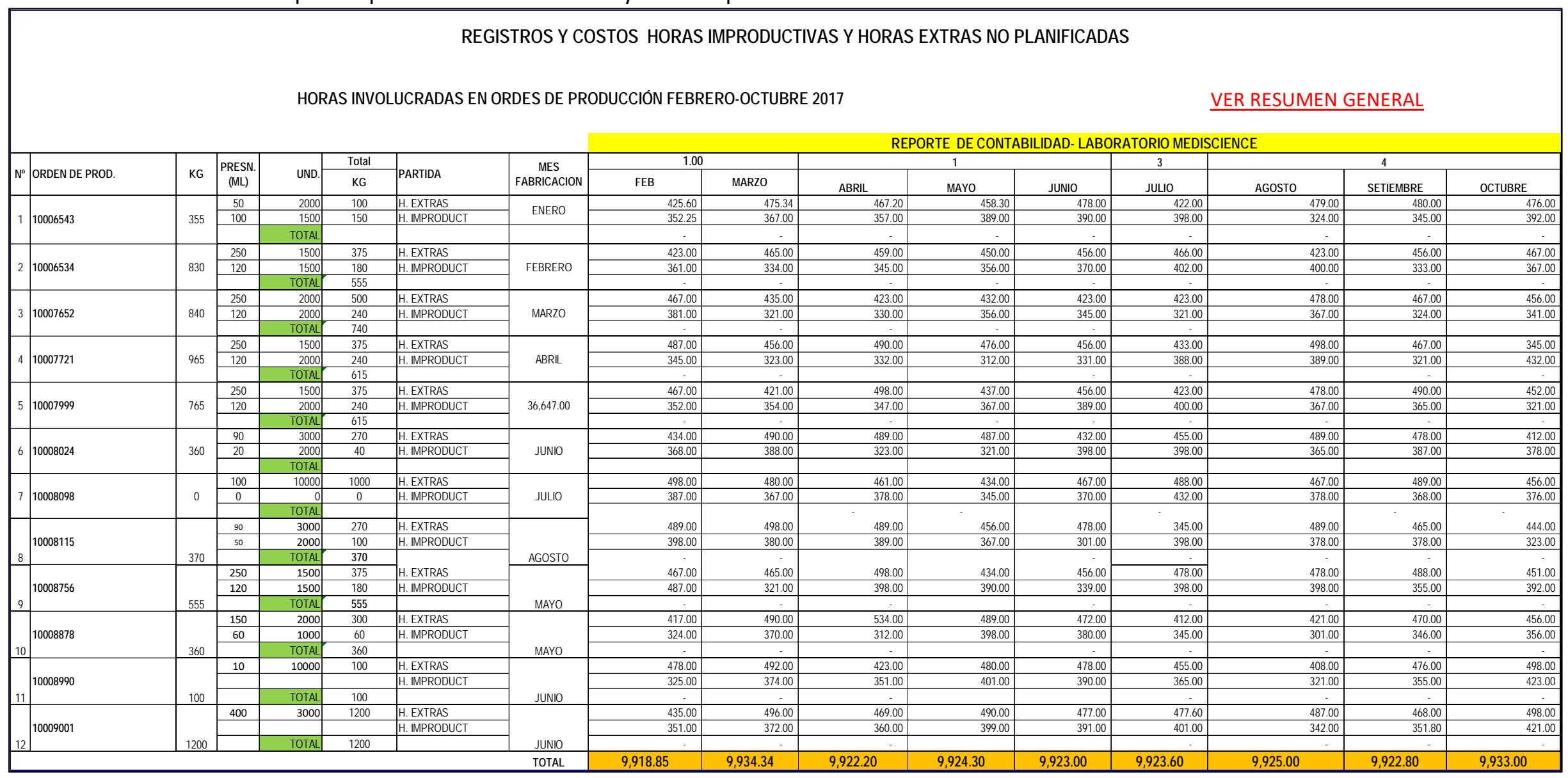

P á g i n a 141 | 141 